\title{
Innovative strategies for intermittent claudication : towards a stepped care approach and new outcome measures
}

Citation for published version (APA):

Fokkenrood, H. J. P. (2015). Innovative strategies for intermittent claudication : towards a stepped care approach and new outcome measures. [Doctoral Thesis, Maastricht University]. Maastricht University. https://doi.org/10.26481/dis.20150611hf

Document status and date:

Published: 01/01/2015

DOI:

10.26481/dis.20150611hf

Document Version:

Publisher's PDF, also known as Version of record

\section{Please check the document version of this publication:}

- A submitted manuscript is the version of the article upon submission and before peer-review. There can be important differences between the submitted version and the official published version of record.

People interested in the research are advised to contact the author for the final version of the publication, or visit the DOI to the publisher's website.

- The final author version and the galley proof are versions of the publication after peer review.

- The final published version features the final layout of the paper including the volume, issue and page numbers.

Link to publication

\footnotetext{
General rights rights.

- You may freely distribute the URL identifying the publication in the public portal. please follow below link for the End User Agreement:

www.umlib.nl/taverne-license

Take down policy

If you believe that this document breaches copyright please contact us at:

repository@maastrichtuniversity.nl

providing details and we will investigate your claim.
}

Copyright and moral rights for the publications made accessible in the public portal are retained by the authors and/or other copyright owners and it is a condition of accessing publications that users recognise and abide by the legal requirements associated with these

- Users may download and print one copy of any publication from the public portal for the purpose of private study or research.

- You may not further distribute the material or use it for any profit-making activity or commercial gain

If the publication is distributed under the terms of Article $25 \mathrm{fa}$ of the Dutch Copyright Act, indicated by the "Taverne" license above, 

Innovative strategies for intermittent claudication

towards a stepped care approach

and new outcome measures 
Innovative strategies for

ClaudicatioNet - Catharina Ziekenhuis - Maxima Medisch Centrum - CZ - Lode / Procare - McRoberts MedCaT - Bolton Medical - The Scientific College Physical Therapy - (WCF) of the Royal Dutch Society for Physical Therapy (KNGF) - ABN Amro - Softmedia

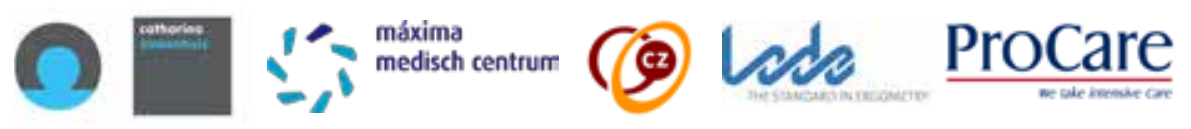

"Financial support by the Dutch Heart Foundation for the publication of this thesis is gratefully acknowledged"

\section{intermittent claudication}

towards a stepped care approach

and new outcome measures

\section{Proefschrift}

ter verkrijging van de graad van doctor aan de Universiteit Maastricht,

op gezag van de Rector Magnificus, Prof. dr. Luc Soete volgens het besluit van het College van Decanen,

in het openbaar te verdedigen

op 11 juni 2015 om 16.00 uur precies

\section{Colofon}

Author:

H.J.P Fokkenrood

Website

www.steppedcare.net

Cover design en lay-out:

Miranda Dood, Mirakels Ontwerp

Gildeprint - The Netherlands

ISBN:

978-94-6108-993-9

\section{(C) H.J.P Fokkenrood, 2015}

All rights reserved. No part of this publication may be reproduced or transmitted

in any form by any means, without permission of the author. door

Hugo Johannes Paulus Fokkenrood

geboren op 19 maart 1986

te Rhenen 


\section{Promotor}

Prof. dr. J.A.W. Teijink

\section{Co-promotor}

Dr. M.R.M. Scheltinga

\section{Beoordelingscommissie}

Prof. dr. M.H. Prins (voorzitter)

Prof. dr. I.C. Heyligers

Prof. dr. H. ten Cate

Prof. dr. C.H.A. Wittens

Dr. P.W.H.E Vriens 


\section{Table of contents}

\section{Chapter 1 General introduction and outline of thesis.}

Adapted from "Vascular Surgery - Principles and Practice", chapter 4, edited by Dai Yamanouchi, ISBN 978-953-51-0828-3, Published: October 31, 2012.

Chapter 2 Supervised exercise therapy versus non-supervised exercise therapy for intermittent claudication.

Cochrane Database Syst Rev. 2013 Aug 23:8.

Chapter 3 Significant savings with a stepped care model for treatment of patients with intermittent claudication.

Eur J Vasc Endovasc Surg. 2014 Oct;48(4):423-9.

Chapter 4 Safety of supervised exercise therapy in patients with intermittent claudication.

J Vasc Surg. 2015 Feb;61(2):512-518.

Chapter 5 Multidisciplinary treatment for peripheral arterial occlusive disease and the role of eHealth and mHealth.

J Multidiscip Healthc. 2012;5:257-63.

Chapter 6 Bicycle testing as an alternative diagnostic tool in patients suspected of intermittent claudication.

Ann Vasc Surg. 2014 Apr;28(3):614-9.

Chapter 7 Agreements and discrepancies between the estimated walking distance, non-graded and graded treadmill testing and outside walking in patients with intermittent claudication Accepted in Ann Vasc Surg.
Physical activity monitoring in patients with periphera arterial disease: validation of an activity monitor

Eur J Vasc Endovasc Surg. 2014 Aug;48(2):194-200.

Chapter 9 Physical activity monitoring in patients with intermitten claudication

Eur J Vasc Endovasc Surg. 2014 Jun;47(6):656-63.

Chapter 10 The effect of supervised exercise therapy on physical activity and ambulatory activities in patients with intermittent claudication.

Eur I Vasc Endovasc Surg. 2015 Feb;49(2):184-91.

Chapter 11 General discussion \& Summary

Chapter 12 Algemene discussie \& Samenvatting

Dankwoord

List of publications

Curriculum vitae 


\title{
Chapter 1
}

\section{General introduction and outline of thesis}

\author{
Adapted from \\ The Role of Supervised Exercise Therapy in \\ Peripheral Arterial Obstructive Disease
}

Fokkenrood HJP

Lauret GJ

Scheltinga MRM

Hendriks HJM

de Bie RA

Teijink JAW

"Vascular Surgery - Principles and Practice", chapter 4, edited by Dai Yamanouchi, ISBN 978-953-51-0828-3,

Published: October 31, 2012 


\section{General Introduction}

"I swear by Apollo, the healer, Asclepius, Hygieia, and Panacea, and I take to witness all the gods, all the goddesses, to keep according to my ability and my judgment, the following Oath and agreement..."

Each medical student likely remembers the very moment he or she took the Hippocratic Oath. By doing so, the world embraced another certified physician. The oath can be broken down into twelve different precepts. One of the most essential ones is the promise of 'abstaining from doing harm'. This portion was later reformulated by the English physician Thomas Sydenham (1624-1689, figure 2) into a popular aphorism 'Primum non nocere' ('First do no harm'). ${ }^{(1)}$ This approach originates from an era when physicians were paternalistic and abstained from shared decision making with their patients. This paradigm derives from an era with very limited alternative treatment options and served well as a touchstone of medical ethical practice. Despite its restrictions, this original thought remains a potent reminder of the fact that each medical and pharmacological decision inherently carries a potential for harm. The implications of this maxim are still up-todate. Improved medical technologies are becoming of more importance in current health care and may offer physicians generous options, possibly without overseeing any future impact. A perfect example of the slippery slope between 'primum non nocere' and the growing set of treatment possibilities is the management of peripheral arterial disease.

\section{Peripheral arterial disease}

Peripheral arterial disease (PAD) commonly results from progressive narrowing or occlusion of arteries feeding or residing in the lower extremities and is mostly due to atherosclerosis ${ }^{(2)}$. The atherosclerotic process of progressive narrowing and hardening of arteries can occur in each human artery. However, it mainly affects coronary, cerebral and peripheral arteries, especially those in the lower extremities ${ }^{(3)}$. The spectral manifestations of PAD range from 'no symptoms' to 'tissue loss that may eventually require amputation of an affected limb.

Total disease prevalence based on objective testing was found to range from 3-10\% in adults, increasing to $15-20 \%$ in persons over 70 years. ${ }^{3}$ PAD increases progressively with age, beginning after the age of 40 . Globally, 202 million people were having PAD in
2010, 70\% in low-income or middle-income countries. ${ }^{4}$ During the preceding decade, the number of individuals with PAD increased by almost $30 \%$ in low-income or middleincome countries, and by $13 \%$ in high income countries. ${ }^{4}$

Intermittent claudication

Up to half of the symptomatic PAD patients will demonstrate typical symptoms of intermittent claudication (IC, which means 'to limp'). ${ }^{(3)}$ IC is defined as muscle discomfort in the lower limb that is reproducibly elicited by exercise and relieved within a 10 minutes rest. ${ }^{(3)}$ Patients with IC have sufficient blood flow at rest and therefore do not experience limb symptoms while standing, when seated or while resting in bed. Conversely, during exercise, obstruction of the arterial supply of the leg muscles limit a required increase in blood flow resulting in a mismatch of oxygen supply and muscle metabolic demand, leading to IC. This mismatch causes cramping or aching pain in the buttock, hip, thigh, calf or in rare occasions the foot, forcing the patient to pause. In rest, the oxygen debt can be redeemed and symptoms are relieved.

Figure 1 Illustration of publication by Larsen and Lassen.

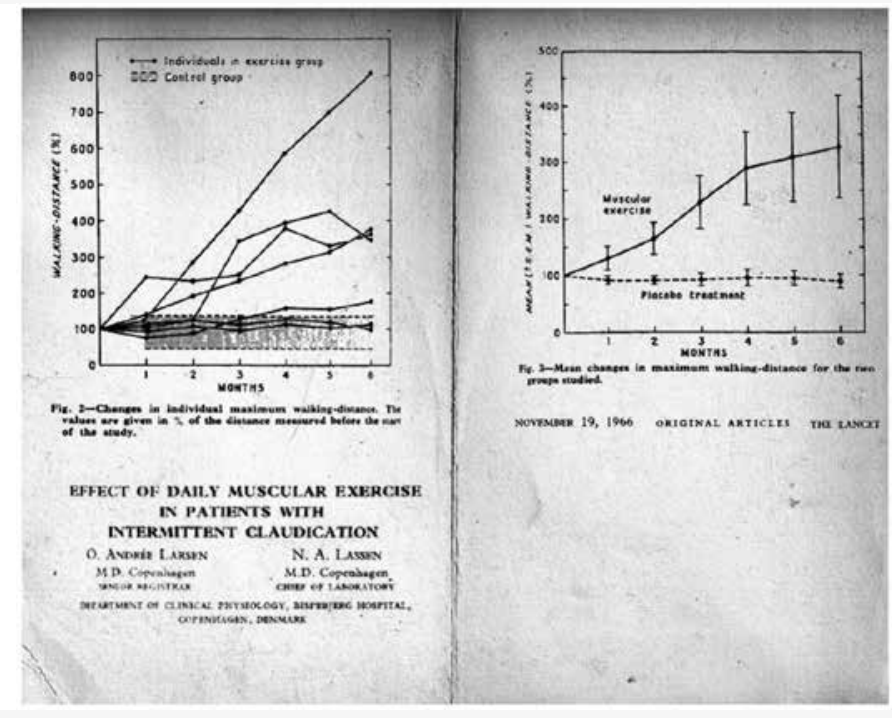

Lancet. 1966 Nov 19;2(7473):1093-6. 
The presence of IC is associated with serious health risks. A 19\% 5-year mortality rate is found of which $70 \%$ is due to cardiovascular causes. Non-fatal cardiovascular events (e.g. myocardial infarction, stroke) in patients with IC are found in $29 \%$ of the population at 5 years of follow-up. ${ }^{(5)}$ An overall strategy is well described in several international guidelines including the American College of Cardiology/American Heart Association (ACC/AHA), Trans-Atlantic Inter-Society Consensus on Management of Peripheral Arterial Disease (TASC II) and the national institute for health and care excellence (NICE) ${ }^{(3,6,7)}$

Treatment of PAD should consist of a multicomponent therapy of cardiovascular risk reduction including lifestyle coaching and symptomatic treatment. The first two components aim to prevent cardio- and neurovascular events (myocardial infarction, stroke) and related morbidity and mortality. The most important modifiable risk factors for atherosclerosis are smoking, hypertension, diabetes mellitus, hyperlipidaemia and obesity. (8) The third component is to improve the overall quality of life (QoL). This regimen is currently mainly focussed on increasing walking capacity that is realized with conservative treatment (daily exercise) or invasive techniques such as vascular surgery or percutaneous transluminal angioplasty (PTA). The latter is a method of mechanically widening of narrowed or obstructed arteries. An empty and collapsed balloon on a guide wire is passed percutaneously into the narrowed artery portion and then inflated to a fixed size. The balloon forces expansion of the atherosclerotic plaque, opening up the artery. The balloon is then deflated and withdrawn, allowing an improved flow. A stent may or may not be inserted to ensure the vessel's patency.

Pharmacological therapy for IC has been subject of numerous studies. However, only beneficial effects of cilostazol and naftidrofuryl were described. ${ }^{(9,10)}$ Interestingly, approval of this type of medicine is limited to a few countries. Other therapies such as Gingko Biloba, vitamin E, chelation therapy, omega- 3 fatty acids and oestrogen therapies were not effective. ${ }^{(3,11)}$ Most pharmacologic treatment regimens for IC typically involve drugs that are used for cardiovascular risk reduction.

\section{Conservative treatment for IC: Exercise therapy}

In 1898 the German neurologist Wilhelm Erb was the first to describe success following exercise therapy in a patient with IC. ${ }^{(12)}$ The first randomized clinical trial (RCT) was performed by Larsen and Lassen in 1966 (figure 1). ${ }^{(13)}$ In this study, 7 patients treated with exercise therapy were compared with a control group of 7 patients who were given a placebo medical treatment using lactose tablets. In contrast to the control patients, the exercise group demonstrated a significant increase in maximum walking time.

Nowadays, exercise therapy for patients with IC is extensively studied. ${ }^{(14-17)}$ Apart from a significantly improved maximum walking distance/time, exercise therapy also reduced levels of hypercholesterolemia, hypertension and diabetes mellitus. ${ }^{(16)}$ Thereby reducing cardiovascular mortality and morbidity as collateral beneficial side effects. ${ }^{(18)}$ The most commonly used exercise therapy prescription consisted of a single oral advice, usually without supervision or follow-up. However, patient adherence to orally administered exercise advices is low. Comorbidity, confusion about (specific) advice, fear, lack of discipline and incomplete supervision are barriers precluding regular walking exercise. ${ }^{19}$ The importance of supervision for IC treatment was gradually recognised over the past decades.

\section{Supervised exercise therapy for IC}

Supervised exercise therapy (SET) entails adequate coaching by a physical therapist or another exercise specialist (e.g. exercise physiologist, exercise therapist, specialised cardiovascular nurse). SET aims to increase maximum walking distance (capacity), physical activity and Health-related Quality of Life (QoL). Effective programs employ treadmill walking of a sufficient intensity causing symptoms, although other modes of exercises were also studied. ${ }^{(20)}$ Exercise sessions are typically conducted three times a week for a period of 3-12 months. ${ }^{(3,7)}$ A 2006 Cochrane review compared SET with non-supervised exercise programmes in patients with IC. ${ }^{14}$ SET showed statistically significant and clinically relevant differences in improvement of maximum walking distance compared to non-supervised exercise therapy regimens, with an overall effect size of 0.58 (95\% confidence interval 0.31 to 0.85 ) at three months. These results translate into an improvement of approximately 150 meters of maximum walking distance in favour of the supervised group.

Another systematic review compared supervised and unsupervised ET with PTA in patients with IC in an effort to obtain the best estimates of their relative effectiveness. ${ }^{2}$ Eleven studies (reporting data on eight RCTs) met inclusion criteria. One trial included patients with isolated aortoiliac artery obstruction ${ }^{(22)}$, three trials studied SET and PTA in femoropopliteal artery obstructions and five trials studied combined lesions. In summary, no obvious preferential strategy could be defined as both SET and PTA showed inconsistent results. Another large multicenter RCT in aortoiliac PAD randomly assigned 
patients to receive optimal medical care (OMC), OMC plus SET, or OMC plus PTA. The authors concluded that SET resulted in superior treadmill walking performance compared to PTA. ${ }^{(23)}$ The most recent guideline therefore advocates a multimodal approach including medication, lifestyle changes and symptomatic treatment, mentioning SET as the primary treatment option independent of the anatomical location of the compromising lesion. ${ }^{(7)}$

Few studies have focussed on the long-term ( $>12$ months) effects of SET. Gardner et al. tried to determine whether improvements in physical function after 6 months of SET were sustained over a subsequent 12 -months in older patients with IC. ${ }^{(24)}$ They concluded that improvements in maximum walking distance and physical activity level, after 6 months of exercise training, were sustained for an additional 12 months period using a less intense exercise maintenance program. Ratliff et al. reported a 3-year follow-up of 212 patients with IC who initially were treated with SET with an exercise programme of two sessions a week for 10 weeks. ${ }^{(25)}$ Their results showed that the maximum walking distance observed at 12 weeks was still present at three years. Based on this limited experience, it appears that SET may have long term benefits for patients with IC.

SET in hospital or community based setting?

An outpatient hospital setting is routinely offered in the majority of studies on SET. This approach may seem appropriate in trials but is associated with several limitations in daily clinical practise. First, the capacity of an exercise therapy program in an outpatient clinic is limited and possibly not sufficient to accommodate all patients with IC. Second, attending a hospital 3 times a week leads to considerable transportation fees and is rather time-consuming. For this reason, implementation of a community-based SET program was instigated in the Netherlands. ${ }^{(26)}$ The first results of a cohort study of patients treated with community-based SET resulted in a statistically significant improvement in maximum walking distance (as determined using a treadmill) after 3 and 6 months. ${ }^{(27)}$ Others suggested initiating exercise programs in a home-based environment, thereby diminishing the amount of labour-intensive supervision. ${ }^{(28,29)}$ Two recent published trials and a meta-analysis revealed promising results regarding the effect of such an approach. ${ }^{(30-33)}$ Although SET may seem superior compared to other conservative treatment regimens with respect to improvement in walking distances, no significant differences between home-based exercise and SET was found at six months of follow up. ${ }^{(31)}$

\section{Cost-effectiveness of SET}

Several cost-effectiveness analyses in the treatment of IC have been performed. ${ }^{(34-39)}$ Non-supervised exercise therapy was compared with supervised programs in both a multi-centered trial and in a Markov model. ${ }^{(34,39)}$ For community-based SET, the incremental cost-effectiveness ratio for cost per QALY was estimated between $£ 1,608$ to $€ 28,693$. Both studies considered SET as cost-effective compared to 'no exercise.' Others compared SET in a randomized cost-effectiveness analysis with endovascular revascularization

(PTA). ${ }^{(35-38)}$ There was no significant difference in effectiveness between endovascular revascularization compared to SET. Any gains following PTA appeared non-significant. Moreover, endovascular revascularization was more costly in relation to the generally accepted threshold of 'willingness-to-pay' ( $£ 11,777$ to $€ 231,800$ per QALY), a result that favors SET. ${ }^{(35,37)}$ Others revealed that QALYs were lost when PTA alone was used as firstline treatment in comparison with SET. ${ }^{(35)}$

Overall, SET seems to be the most cost-effective first-line treatment for IC. ${ }^{(35-38)}$ If SET fails, it may subsequently be combined with endovascular revascularization, a sequence that is probably more cost-effective than PTA alone.

\section{Also 'Primum non nocere' in IC}

The prevalence of IC is growing as a clinical problem due to the increasingly aged population in developed countries. Recently, governments as well as nongovernmental organizations and the private sector were called to assess the social and economic consequences of PAD and to explore the best strategies for optimum treatment and prevention of this disease. $^{(4)}$ Numerous studies and guidelines have issued clear recommendations for IC treatment. Ideally a 'primum non nocere' strategy, existing of an initial treatment with SET should be followed. ${ }^{(7,40)}$ However, SET programs are largely underutilized in daily practice. ${ }^{(41-44)}$ Some blame the lack of a sufficient number of supervised settings as well as the need for patients to travel to a SET facility. ${ }^{(30,36,40,41,45)}$ Another complicating factor is a failing reimbursement policy issue for SET in most of the Western societies including the Netherlands. ${ }^{(30,40,41,44,46)}$ Despite a claimed 100\% Dutch SET availability, reimbursement issues stimulate physicians to direct patients towards a vascular intervention strategy. ${ }^{(44)}$

This reimbursement issue in IC treatment originates from a contradictory policy in the Dutch healthcare system. In the Netherlands, healthcare insurance companies have an obligation to accept everyone for a basic healthcare insurance. The Dutch govern- 


\section{Figure 2 Thomas Sydenham}

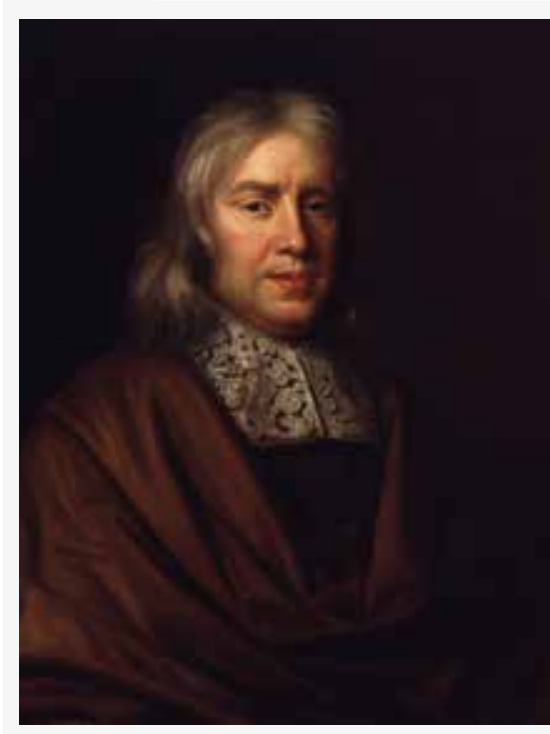

(10 September 1624 - 29 December 1689) ment determines coverage of the standard insurance. In case of patients suffering from IC, the government decided not to cover the first 20 treatment sessions of a SET program. Therefore, these sessions have to be paid by the patient, either directly or through additional insurance. From the $21^{\text {st }}$ session onwards all additional treatment sessions given in one year are covered by the basic health care insurance. Around $30-40 \%$ of the people aged $>50$ years who are insured by $\mathrm{CZ}$ (one of the largest Dutch insurance companies) do not have an additional insurance package that covers $100 \%$ of those first 20 physiotherapy sessions. Therefore, a proven effective, nationwide available SET program with supervision performed by trained physiotherapists, aimed at improving cardiorespiratory health status as well as life style factors and medication compliance is not fully reimbursed in the Netherlands.

On the other hand, a (minimally) invasive intervention, a possibly less effective ${ }^{(23,37,47-49)}$, less durable ${ }^{(50-53)}$, potentially harmful ${ }^{(52,54)}$, and single leg focused treatment option is fully reimbursed from the basic healthcare insurance. Most of these interventions are continuously advertised by marketing campaigns. Novel invasive techniques are thus promoted, frequently without solid level of evidence, by multi-billion dollar companies, whereas SET lacks sponsoring promotional activities. ${ }^{(36,40)}$

Another factor contributing to SET under usage is a knowledge gap of physicians using outdated arguments for not offering SET to IC patients ${ }^{(40,55)}$. As a consequence, exercise regimens often instituted in the form of a basic "go home and walk" advice or the non-"primum non nocere" interventional approach. Patients may also not enthusiastically embrace SET as some are in need, or at least think they are, of a 'quick fix' of their problem. Changed lifestyles such as reducing nicotine use, adopting a healthier diet and increasing exercise habits are not very popular. Current guideline recommendations are clear: "SET is advised as primary treatment option". So the following question arises: "How to optimize the implementation of our current guidelines and research outcomes?" In this thesis, a nationwide innovative strategy (a so-called 'stepped care approach') for the treatment of IC is introduced.

\section{Outline of thesis}

Both the 2007 TransAtlantic Inter-Society Consensus (TASC II) and the 2012 NICE guideline are based on large meta-analyses. Both clearly advise SET as the first line treatment in the symptomatic treatment of patients with IC. ${ }^{(3,7)}$

In chapter two, an update of such an underlying systematic meta-analysis is provided. It focuses on the effectiveness of SET compared to non-supervised exercise as earlier studied by Bendermacher et al. ${ }^{(14)}$ Although it is generally accepted that SET should be part of the initial treatment for each patient with IC, this therapeutic tool is seriously underused in clinical practice. ${ }^{(40,42,43)}$

Since these guidelines recommend SET as primary treatment for $\mathrm{IC}^{(3,7)}$, a calculation of treatment costs in patients with IC was made in chapter three to estimate potential nationwide annual savings if a stepped care model (SCM; primary SET treatment followed by revascularization in case of SET failure) was followed. Data for this study were retrospectively obtained from a database of one of the largest health care providers in the Netherlands (CZ).

Some physicians or physical therapists providing SET fear the onset of cardiovascular events that may possibly occur during exercise. Moreover, (outdated) physical therapists guidelines advocate cardiac screening prior to $\mathrm{SET}^{(56)}$ although evidence to support such a strategy is lacking. In chapter four, a systematic meta-analysis analyzes the safety of SET as reflected by the onset of untoward (cardiovascular) events in patients suffering from IC.

Monitoring of both quality and performance is necessary to study effectiveness of suggested treatment strategies. This is particularly true in case of a nationwide SCM implementation. Structurally obtaining outcome indicators in combination with patient reported outcome measurements (PROMS) could be helpful in facilitating SCM implementation. eHealth and mHealth initiatives may play a major role in both abovementioned goals and are outlined in chapter five in combination with future developments in the organization of a nationwide community based SET network. Innovative technologies may lead to new insights in the conservative treatment of IC. These novel tools can be used to monitor the quality of provided care. 
In the second part of this thesis, the introduction of a possible new clinical outcome parameter is studied. A prospective case-control effort (chapter six) studies whether a bicycle test is a reliable alternative diagnostic tool compared to a standard treadmill test in patients possibly having IC.

A clear call was made for alternative tests to determine walking capacity over a prolonged period of time. ${ }^{(57,58)}$ In chapter seven, the clinical applicability of various types of treadmill protocols is investigated. Moreover, despite the fact that IC patients have an increased risk for cardiovascular or cerebrovascular events ${ }^{(3)}$, current PAD treatment is mainly focussed on the limitation in walking distance. However, an increased walking capacity does not automatically imply a change in a patients' exercise behaviour. From a therapeutic as well as research standpoint, it may be more relevant to determine exercise behaviour or physical activity (PA) as outcome measure for treatment modalities of IC. Therefore, the validity of an activity monitor determining physical activity and ambulatory activities is investigated in a group of IC patients in chapter eight. Subsequently, outcome parameters obtained from this activity monitor are compared to healthy subjects in a prospective case control study in chapter nine. Subsequently the effect of a 3-month SET program on both physical activity and ambulatory activities is investigated in chapter ten.

In chapter eleven, the main findings of this thesis are discussed. Methodological aspects of the different studies, implications for clinical practice, and implications for future research are described. Finally in chapter twelve a valorization document is provided in Dutch.

\section{References}

1. Smith CM. Origin and uses of primum non nocere--above all, do no harm! Journal of clinical pharmacology 2005;45:371-7.

2. Schep G, Bender MH, van de Tempel G, Wijn PF, de Vries WR, Eikelboom BC. Detection and treatment of claudication due to functional iliac obstruction in top endurance athletes: a prospective study. Lancet 2002;359:466-73.

3. Norgren L, Hiatt WR, Dormandy JA, Nehler MR, Harris KA, Fowkes FG. Inter-Society Consensus for the Management of Peripheral Arterial Disease (TASC II). J Vasc Surg 2007;45 Suppl S:S5-67.

4. Fowkes FG, Rudan D, Rudan I, et al. Comparison of global estimates of prevalence and risk factors for peripheral artery disease in 2000 and 2010: a systematic review and analysis. Lancet 2013.

5. Leng GC, Lee AJ, Fowkes FG, et al. Incidence, natural history and cardiovascular events in symptomatic and asymptomatic peripheral arterial disease in the general population. Int J Epidemiol 1996;25:1172-81.

6. Hirsch AT, Haskal ZJ, Hertzer NR, et al. ACC/AHA 2005 Practice Guidelines for the management of patients with peripheral arterial disease (lower extremity, renal, mesenteric, and abdominal aortic): a collaborative report from the American Association for Vascular Surgery/Society for Vascular Surgery, Society for Cardiovascular Angiography and Interventions, Society for Vascular Medicine and Biology, Society of Interventional Radiology, and the ACC/AHA Task Force on Practice Guidelines (Writing Committee to Develop Guidelines for the Management of Patients With Peripheral Arterial Disease): endorsed by the American Association of Cardiovascular and Pulmonary Rehabilitation; National Heart, Lung, and Blood Institute; Society for Vascular Nursing; TransAtlantic Inter-Society Consensus; and Vascular Disease Foundation. Circulation 2006;113:e463-654.

7. Layden J, Michaels J, Bermingham S, Higgins B, Guideline Development G. Diagnosis and management of lower limb peripheral arterial disease: summary of NICE guidance. Bmj 2012;345:e4947.

8. Dormandy J, Heeck L, Vig S. Predictors of early disease in the lower limbs. Semin Vasc Surg 1999;12:109-17.

9. De Backer T, Vander Stichele R, Lehert P, Van Bortel L. Naftidrofuryl for intermittent claudication: meta-analysis based on individual patient data. Bmj 2009;338:b603. 
10. Thompson PD, Zimet R, Forbes WP, Zhang P. Meta-analysis of results from eight randomized, placebo-controlled trials on the effect of cilostazol on patients with intermittent claudication. Am J Cardiol 2002;90:1314-9.

11. Nicolai SP, Kruidenier LM, Bendermacher BL, et al. Ginkgo biloba for intermittent claudication. Cochrane Database Syst Rev 2013;6:CD006888.

12. Erb W. About intermittent walking and nerve disturbances due to vascular disease [Uber das "intermitterende Hinken" und adere nervose Storungen in Folge von Gefasserkrankungen] Deutsch Z Nervenheilk 1898;13:1-76.

13. Larsen OA, Lassen NA. Effect of daily muscular exercise in patients with intermittent claudication. Lancet 1966;2:1093-6.

14. Bendermacher BL, Willigendael EM, Teijink JA, Prins MH. Supervised exercise therapy versus non-supervised exercise therapy for intermittent claudication. Cochrane Database Syst Rev 2006:CD005263.

15. Fakhry F, van de Luijtgaarden KM, Bax L, et al. Supervised walking therapy in patients with intermittent claudication. J Vasc Surg 2012;56:1132-42.

16. Watson L, Ellis B, Leng GC. Exercise for intermittent claudication. Cochrane Database Syst Rev 2008:CD000990.

17. Wind J, Koelemay MJ. Exercise therapy and the additional effect of supervision on exercise therapy in patients with intermittent claudication. Systematic review of randomised controlled trials. Eur J Vasc Endovasc Surg 2007;34:1-9.

18. Heran BS, Chen JM, Ebrahim S, et al. Exercise-based cardiac rehabilitation for coronary heart disease. Cochrane Database Syst Rev 2011:CD001800.

19. Bartelink ML, Stoffers HE, Biesheuvel CJ, Hoes AW. Walking exercise in patients with intermittent claudication. Experience in routine clinical practice. Br J Gen Pract 2004;54:196200.

20. Lauret GJ, Fakhry F, Fokkenrood HJ, Hunink MG, Teijink JA, Spronk S. Modes of exercise training for intermittent claudication. Cochrane Database Syst Rev 2014;7:CD009638.

21. Frans FA, Bipat S, Reekers JA, Legemate DA, Koelemay MJ. Systematic review of exercise training or percutaneous transluminal angioplasty for intermittent claudication. Br J Surg 2012;99:16-28.

22. Greenhalgh RM, Belch JJ, Brown LC, et al. The adjuvant benefit of angioplasty in patients with mild to moderate intermittent claudication (MIMIC) managed by supervised exercise, smoking cessation advice and best medical therapy: results from two randomised trials for stenotic femoropopliteal and aortoiliac arterial disease. Eur J Vasc Endovasc Surg 2008; $36: 680-8$
23. Murphy TP, Cutlip DE, Regensteiner JG, et al. Supervised exercise versus primary stenting for claudication resulting from aortoiliac peripheral artery disease: six-month outcomes from the claudication: exercise versus endoluminal revascularization (CLEVER) study. Circulation 2012;125:130-9.

24. Gardner AW, Katzel LI, Sorkin JD, Goldberg AP. Effects of long-term exercise rehabilitation on claudication distances in patients with peripheral arterial disease: a randomized controlled trial. J Cardiopulm Rehabil 2002;22:192-8.

25. Ratliff DA, Puttick M, Libertiny G, Hicks RC, Earby LE, Richards T. Supervised exercise training for intermittent claudication: lasting benefit at three years. Eur J Vasc Endovas Surg 2007;34:322-6.

26. Willigendael EM, Bendermacher BL, van der Berg C, et al. The development and implementation of a regional network of physiotherapists for exercise therapy in patients with peripheral arterial disease, a preliminary report. BMC Health Serv Res 2005;5:49.

27. Bendermacher BL, Willigendael EM, Nicolai SP, et al. Supervised exercise therapy for intermittent claudication in a community-based setting is as effective as clinic-based. $J$ Vasc Surg 2007;45:1192-6.

28. Collins TC, Lunos S, Carlson T, et al. Effects of a home-based walking intervention on mobility and quality of life in people with diabetes and peripheral arterial disease: a randomized controlled trial. Diabetes care 2011;34:2174-9.

29. Regensteiner JG, Meyer TJ, Krupski WC, Cranford LS, Hiatt WR. Hospital vs home-based exercise rehabilitation for patients with peripheral arterial occlusive disease. Angiology 1997;48:291-300.

30. Gardner AW, Parker DE, Montgomery PS, Scott KJ, Blevins SM. Efficacy of quantified home-based exercise and supervised exercise in patients with intermittent claudication: a randomized controlled trial. Circulation 2011;123:491-8.

31. Gommans LN, Saarloos R, Scheltinga MR, et al. Editor's Choice - The Effect of Supervision on Walking Distance in Patients with Intermittent Claudication: A Meta-analysis. Eur J Vasc Endovasc Surg 2014;48:169-84.

32. McDermott MM, Liu K, Guralnik JM, et al. Home-based walking exercise intervention in peripheral artery disease: a randomized clinical trial. Jama 2013;310:57-65.

33. Rejeski WJ, Spring B, Domanchuk K, et al. A group-mediated, home-based physical activity intervention for patients with peripheral artery disease: effects on social and psychological function. Journal of translational medicine 2014;12:29.

34. Bermingham SL, Sparrow K, Mullis R, et al. The Cost-effectiveness of Supervised Exercise for the Treatment of Intermittent Claudication. Eur J Vasc Endovasc Surg 2013;46:707-14. 
35. Mazari FA, Khan JA, Carradice D, et al. Economic analysis of a randomized trial of percutaneous angioplasty, supervised exercise or combined treatment for intermittent claudication due to femoropopliteal arterial disease. Br J Surg 2013;100:1172-9.

36. O'Brien-Irr MS, Harris LM, Dosluoglu HH, Dryjski ML. Endovascular intervention for treatment of claudication: is it cost-effective? Annals of vascular surgery 2010;24:833-40.

37. Spronk S, Bosch JL, den Hoed PT, Veen HF, Pattynama PM, Hunink MG. Cost-effectiveness of endovascular revascularization compared to supervised hospital-based exercise training in patients with intermittent claudication: a randomized controlled trial. J Vasc Surg 2008;48:1472-80.

38. Treesak C, Kasemsup V, Treat-Jacobson D, Nyman JA, Hirsch AT. Cost-effectiveness of exercise training to improve claudication symptoms in patients with peripheral arterial disease. Vasc Med 2004;9:279-85.

39. van Asselt AD, Nicolai SP, Joore MA, Prins MH, Teijink JA. Cost-effectiveness of exercise therapy in patients with intermittent claudication: supervised exercise therapy versus a 'go home and walk' advice. Eur J Vasc Endovasc Surg 2011;41:97-103.

40. Popplewell MA, Bradbury AW. Why Do Health Systems Not Fund Supervised Exercise Programmes for Intermittent Claudication? Eur J Vasc Endovasc Surg 2014.

41. Mays RJ, Regensteiner JG. Exercise therapy for claudication: latest advances. Current treatment options in cardiovascular medicine 2013;15:188-99.

42. Makris GC, Lattimer CR, Lavida A, Geroulakos G. Availability of supervised exercise programs and the role of structured home-based exercise in peripheral arterial disease. Eur J Vasc Endovasc Surg 2012;44:569-75; discussion 76.

43. Shalhoub J, Hamish M, Davies AH. Supervised exercise for intermittent claudication - an under-utilised tool. Annals of the Royal College of Surgeons of England 2009;91:473-6.

44. Fokkenrood HJ, Lauret GJ, Scheltinga MR, Spreeuwenberg C, de Bie RA, Teijink JA. Multidisciplinary treatment for peripheral arterial occlusive disease and the role of eHealth and mHealth. Journal of multidisciplinary healthcare 2012;5:257-63.

45. Lauret GJ, Gijsbers HJ, Hendriks EJ, Bartelink ML, de Bie RA, Teijink JA. The ClaudicatioNet concept: design of a national integrated care network providing active and healthy aging for patients with intermittent claudication. Vasc Health Risk Manag 2012;8:495-503.

46. Saxton JM, Zwierska I, Blagojevic M, Choksy SA, Nawaz S, Pockley AG. Upper- versus lower-limb aerobic exercise training on health-related quality of life in patients with symptomatic peripheral arterial disease. J Vasc Surg 2011;53:1265-73.
47. Creasy TS, McMillan PJ, Fletcher EW, Collin J, Morris PJ. Is percutaneous transluminal angioplasty better than exercise for claudication? Preliminary results from a prospective randomised trial. European journal of vascular surgery 1990;4:135-40.

48. Spronk S, Bosch JL, den Hoed PT, Veen HF, Pattynama PM, Hunink MG. Intermittent claudication: clinical effectiveness of endovascular revascularization versus supervised hospital-based exercise training--randomized controlled trial. Radiology 2009;250:586-95.

49. Ahimastos AA, Pappas EP, Buttner PG, Walker PJ, Kingwell BA, Golledge J. A meta-analysis of the outcome of endovascular and noninvasive therapies in the treatment of intermittent claudication. J Vasc Surg 2011;54:1511-21.

50. Fakhry F, Rouwet EV, den Hoed PT, Hunink MG, Spronk S. Long-term clinical effectiveness of supervised exercise therapy versus endovascular revascularization for intermittent claudication from a randomized clinical trial. Br J Surg 2013;100:1164-71.

51. Geraghty PJ, Mewissen MW, Jaff MR, Ansel GM, Investigators V. Three-year results of the VIBRANT trial of VIABAHN endoprosthesis vs bare nitinol stent implantation for complex superficial femoral artery occlusive disease. J Vasc Surg 2013.

52. Jongkind V, Akkersdijk GJ, Yeung KK, Wisselink W. A systematic review of endovascular treatment of extensive aortoiliac occlusive disease. J Vasc Surg 2010;52:1376-83.

53. Lensvelt MM, Reijnen MM, Wallis De Vries BM, Zeebregts CJ. Treatment strategies for extensive chronic SFA occlusions: indications and results. The Journal of cardiovascular surgery 2012;53:161-70.

54. Stewart KJ, Hiatt WR, Regensteiner JG, Hirsch AT. Exercise training for claudication. N Engl J Med 2002;347:1941-51.

55. Lauret GJ, van Dalen HC, Hendriks HJ, et al. When is supervised exercise therapy considered useful in peripheral arterial occlusive disease? A nationwide survey among vascular surgeons. Eur J Vasc Endovasc Surg 2012;43:308-12.

56. Jongert M, Hendriks H, van Hoek J, Kaasboer Kogelman K, Robeer G, Simens B. KNGF richtlijn claudicatio intermittens. Nederlands Tijdschrift voor Fysiotherapie 2003:3-50.

57. Frans FA, Zagers MB, Jens S, Bipat S, Reekers JA, Koelemay MJ. The relationship of walking distances estimated by the patient, on the corridor and on a treadmill, and the Walking Impairment Questionnaire in intermittent claudication. J Vasc Surg 2013;57:720-7 e1.

58. Nicolai SP, Viechtbauer W, Kruidenier LM, Candel MJ, Prins MH, Teijink JA. Reliability of treadmill testing in peripheral arterial disease: a meta-regression analysis. J Vasc Surg 2009;50:322-9. 


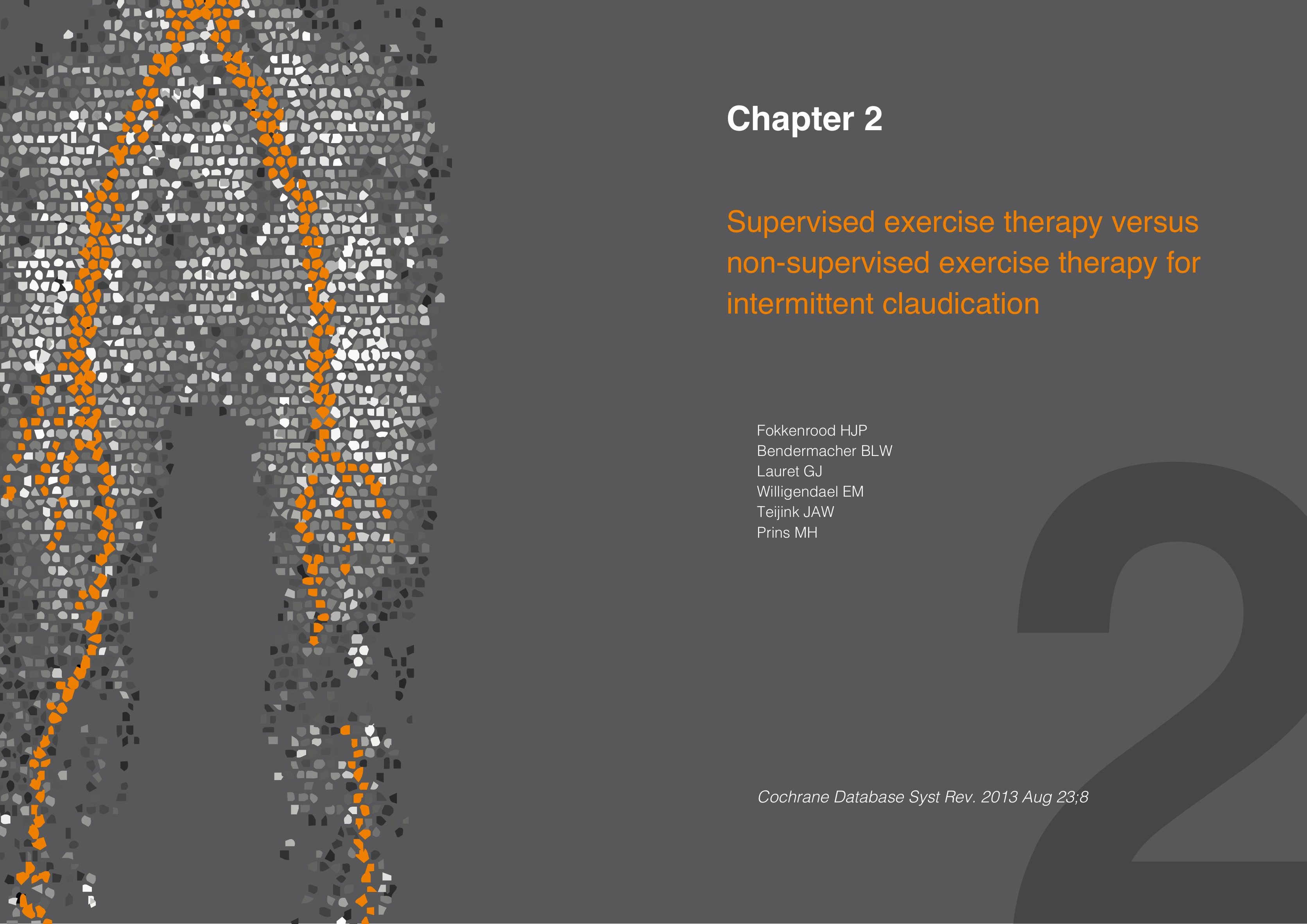




\section{Abstract}

Background

Although supervised exercise therapy is considered to be of significant benefit for people with leg pain (peripheral arterial disease (PAD)), implementing supervised exercise programs (SETs) in daily practice has limitations. This is an update of a review first published in 2006.

Objectives

The main objective of this review was to provide an accurate overview of studies evaluating the effects of supervised versus non-supervised exercise therapy on maximal walking time or distance on a treadmill for people with intermittent claudication.

Search methods

For this update, the Cochrane Peripheral Vascular Diseases Group Trials Search Co-ordinator searched the Specialised Register (last searched September 2012) and CENTRAL (2012, Issue 9). In addition, we handsearched the reference lists of relevant articles for additional trials. No restriction was applied to language of publication.

\section{Selection criteria}

Randomized clinical trials comparing supervised exercise programs with non-supervised exercise programs (defined as walking advice or a structural home-based exercise program) for people with intermittent claudication. Studies with control groups, which did not receive exercise or walking advice or received usual care (maintained normal physical activity), were excluded.

\section{Data collection and analysis}

Two review authors (HJPF and BLWB) independently selected trials and extracted data. Three review authors (HJPF, BLWB, and GJL) assessed trial quality, and this was confirmed by two other review authors (MHP and JAWT). For all continuous outcomes, we extracted the number of participants, the mean differences, and the standard deviation. The 36-Item Short Form Health Survey (SF-36) outcomes were extracted to assess quality of life. Effect sizes were calculated as the difference in treatment normalized with the standard deviation (standardized mean difference) using a fixed-effect model.

\section{Main results}

A total of 14 studies involving a total of 1002 male and female participants with PAD were included in this review. Follow-up ranged from six weeks to 12 months. In general, supervised exercise regimens consisted of three exercise sessions per week All trials used a treadmill walking test as one of the outcome measures. The overall quality of the included trials was moderate to good, although some trials were small with respect to the number of participants, ranging from 20 to 304 .

Supervised exercise therapy (SET) showed statistically significant improvement in maximal treadmill walking distance compared with non-supervised exercise therapy regimens, with an overall effect size of 0.69 (95\% confidence interval (CI) 0.51 to 0.86$)$ and 0.48 (95\% CI 0.32 to 0.64$)$ at three and six months, respectively. This translates to an increase in walking distance of approximately 180 meters that favored the supervised group. SET was still beneficial for maximal and pain-free walking distances at 12 months, but it did not have a significant effect on quality of life parameters.

\section{Authors' conclusions}

SET has statistically significant benefit on treadmill walking distance (maximal and pain-free) compared with non-supervised regimens. However, the clinical relevance of this has not been demonstrated definitively; additional studies are required that focus on quality of life or other disease-specific functional outcomes, such as walking behavior, patient satisfaction, costs, and long-term follow-up. Professionals in the vascular field should make SET available for all patients with intermittent claudication. 


\section{Plain language summary}

Some people experience a type of leg pain in the calf of one or both legs that occurs during walking and is relieved only by rest. This is called intermittent claudication (IC), and it is the main symptom of peripheral arterial disease (PAD). PAD is characterized by reduced flow of blood in the leg due to hardening of the arteries, or blood vessels. Exercise is considered to provide significant benefit for people with this type of leg pain. People need to walk at least three times a week by themselves, or they can participate in a formal, supervised exercise program that involves walking on a treadmill. This review found that people in a supervised program improved their walking ability to a greater extent than those following an unsupervised walking program. After three months, people who followed the supervised treadmill program could walk 180 meters farther than those who did unsupervised exercise. Before participating in the program, they had walked around 300 meters, with a pain-free distance of 200 meters, so this improvement is likely to help with independence. These conclusions are drawn from the findings of 14 trials in which participants with PAD had been assigned to either supervised or unsupervised exercise. Altogether, 1002 participants with a mean age of 67 years were included. The overall quality of the included trials was moderate to good, although each had enrolled only a small number of participants. The trials lasted from six weeks to twelve months. Keeping to an exercise program is important because it leads to decreased leg pain and the likelihood of improving general physical condition, but it is not yet clear if it also improves quality of life.

\section{Background}

Description of the condition

Intermittent claudication (IC) is a symptom of peripheral arterial disease (PAD) and is defined as leg pain in the muscles of the lower extremities that occurs with exercise and is relieved by rest. PAD increases progressively with age, in particular after the age of 40 . The relationship between PAD prevalence and age was illustrated by data from the 19992000 National Health and Nutrition Examination Survey (NHANES), an ongoing crosssectional survey of the civilian, non-institutionalized population of the United States. The prevalence of $\mathrm{PAD}$, defined as an ankle-brachial index (ABI; the ratio of blood pressure in the lower legs to blood pressure in the arms) $<0.90$ in either leg, was $0.9 \%$ between the ages of 40 and $49,2.5 \%$ between the ages of 50 and $59,4.7 \%$ between the ages of 60 and 69 , and $14.5 \%$ in those 70 years of age and older (Selvin 2004). These numbers indicate that PAD affects more than 5 million adults in the United States. International guidelines reveal 27 million affected individuals in North America and Europe (Norgren 2007).

Description of the intervention

The primary and most effective treatment for people with IC is exercise therapy (Stewart 2002), which was first suggested by Erb (Erb 1898). In 1966 the first randomized controlled trial (RCT) of exercise therapy in participants with PAD demonstrated an obvious improvement in treadmill walking ability (Larsen 1966). In a Cochrane systematic review of randomized clinical trials, Leng et al (Leng 2000) and later the updated version by Watson et al (Watson 2008) described an overall improvement in maximal walking time: mean difference (MD) 5.12 minutes (95\% confidence interval (CI) 4.51 to 5.72 ) with an overall improvement in walking ability of approximately $50 \%$ to $200 \%$ associated with exercise therapy compared with no exercise therapy. However, the exercise programs included in this meta-analysis vary widely, ranging from physician recommended unsupervised walking in the community to a formal supervised exercise program involving walking on a treadmill.

How the intervention might work

Exercise training provides significant symptomatic benefit for patients with claudication; however, the exact mechanisms for this improvement remain unclear (Beckitt 2012). The mechanisms of response to exercise training have been reviewed previously and include improvement in walking efficiency, induction of vascular angiogenesis, inflammatory activation, increased exercise pain tolerance, endothelial and mitochondrial dysfunction, and metabolic adaptations within skeletal muscle (Gustafsson 2001; Hamburg 2011; Nor gren 2007; Stewart 2008; Zwierska 2005). Further benefits of exercise therapy are seen in the reduction of cardiovascular risk factors such as hypercholesterolemia, hypertension, and diabetes mellitus. Exercise is therefore implemented in secondary prevention therapies in patients with coronary artery disease (Smith 2011). Given its clear benefits, the importance of exercise therapy is highlighted in contemporary international guidelines (Hirsch 2006; Norgren 2007). In daily practice, lack of specific individual guidance and the absence of uniform supervision appear to be important barriers to the initiation and continuation of exercise therapy (Bartelink 2004). 
Why it is important to do this review

Before the release of the original version of this review in 2006, the prescription of exercise therapy consisted mostly of "go home and walk" advice by the general practitioner, sometimes accompanied by a brochure. After this review was published, more studies compared supervised exercise therapy with non-supervised exercise therapy. Although supervised exercise therapy proved effective in the treatment of PAD by increasing maximal or pain-free walking time or distance, exercise programs are not designed to change day-to-day walking behavior (Crowther 2008; McDermott 2009). Moreover, limitations continue to hinder implementation of supervised exercise programs in daily practice. Some describe the lack of a supervised setting to which patients can be referred to or a lack of knowledge among referring healthcare professionals; in other studies participants are not willing to persist with an exercise program to maintain the benefit (Fokkenrood 2012; Lauret 2012a; Makris 2012; Norgren 2007; Stewart 2008). Therefore debate continues about whether exercise should be offered under supervision. With disregard for all financial and organizational aspects, we believe it is important to provide an accurate systematic review of the effects of supervised exercise therapy in relation to non-supervised exercise on walking distance and quality of life.

\section{Objectives}

The main objective of this review was to provide an accurate overview of studies evaluating the effects of supervised versus non-supervised exercise therapy on maximal walking time or distance on a treadmill for people with intermittent claudication.

\section{Methods}

\section{Criteria for considering studies for this review}

Types of studies

Parallel-group RCTs comparing supervised exercise programs with non-supervised exercise programs, in participants with PAD, were included. Trials were included irrespective of whether an intention-to-treat analysis was carried out.
Types of participants

Adults (18 years and older) with intermittent claudication (Fontaine II/Rutherford 1 to 3) (Fontaine 1954; Rutherford 1997) due to atherosclerotic disease, diagnosed by questionnaire or clinically, who were considered for conservative treatment, were included. Studies of participants with asymptomatic lower limb atherosclerosis identified by testing were excluded.

\section{Types of interventions}

Supervised exercise programs

A supervised exercise program needed to consist of more than six consecutive weeks of training, with more than $50 \%$ of the exercise time spent on walking or training the lower limbs. Inclusion of trials was not limited by frequency or intensity of the exercise program.

Non-supervised exercise programs

Non-supervised exercise programs were defined as those in which control group members were advised to walk (with or without a predefined exercise scheme or logbook) or were treated according to a structural home-based exercise program (walk advice with regular contact and exercise support from medically trained personnel). Studies with control groups, which did not receive exercise or walking advice or which received usual care (maintained normal physical activity), were excluded.

\section{Types of outcome measures}

Primary outcomes

The primary outcome measure was the effect on maximal treadmill walking distance or time. Outcomes had to be available at baseline.

Secondary outcomes

The following secondary outcome measures were also considered:

- Pain-free treadmill walking distance, or time;

- Mortality;

- Adherence to exercise program; and

- Quality of life. 
Search methods for identification of studies

No restriction on language of publication was applied.

\section{Electronic searches}

For this update, the Cochrane Peripheral Vascular Diseases Group Trials Search Coordinator (TSC) searched the Specialized Register (last searched September 2012) and the Cochrane Central Register of Controlled Trials (CENTRAL) 2012, Issue 9, part of The Cochrane Library (www.thecochranelibrary.com). See Appendix 1 for details of the search strategy used to search CENTRAL.

The Specialized Register is maintained by the TSC and is constructed from weekly electronic searches of MEDLINE, EMBASE, CINAHL, and AMED, and through hand searching of relevant journals. The full list of the databases, journals, and conference proceedings which have been searched, as well as the search strategies used, are described in the Specialized Register section of the Cochrane Peripheral Vascular Diseases Group module in The Cochrane Library (www.thecochranelibrary.com),

\section{Searching other resources}

A hand search of references lists of relevant studies was carried out.

\section{Data collection and analysis}

$$
\text { Selection of studies }
$$

Two review authors (HJPF and BLWB) independently selected trials for this review, whereas two other review authors (JAWT and MHP) confirmed the suitability of selected trials for inclusion in the review. Disagreements regarding inclusion/exclusion of selected trials were resolved by discussion.

Data extraction and management

Two review authors (HJPF and BLWB) independently extracted data using a standard data collection form. Data were entered into Review Manager (RevMan 2011). When necessary, additional information was sought for included trials. For all continuous outcomes (ie, walking distance or walking time, adherence to exercise program, quality of life), we extracted the number of participants and the mean difference between treatment groups per follow up period with accompanying standard deviation for each treatment group, if available. We also recorded other details of the included trials, for example, the study set- ting, the statistical power, and the number of dropouts in each group. We contacted authors for missing information regarding their methods.

Trials that compared three or more different therapy programs - supervised and nonsupervised therapy programs - with other kinds of programs, were included. From these trials, only participants treated by supervised or non-supervised exercise therapy were taken into account.

\section{Assessment of risk of bias in included studies}

Three review authors (HJPF, BLWB, and GJL) assessed and one review author (MHP) confirmed the methodological quality of the trials, primarily for adequacy of allocation concealment and follow-up. In trials that compared exercise programs with walking distance as the primary outcome, blinding of staff and participants is not possible and was therefore not considered.

We graded study quality in a table of risk of bias on the basis of a checklist of design components. This checklist comprised random sequence generation, allocation concealment, incomplete outcome data, and selective reporting. We achieved consensus by informal discussion. We summarized the adequacy of each category as "low", "unclear", or "high" risk according to the criteria provided in the Cochrane Handbook for Systematic Reviews of Interventions (Higgins 2011).

\section{Measures of treatment effect}

We standardized reported data on walking time and distance to effect sizes to enable the calculation of an overall standardized mean difference (SMD). If standard errors (SEs) had been reported (and authors did not reply to our request to send unpublished data) we converted these to standard deviations. We used a fixed-effect model to obtain summary statistics for all types of outcome measures. When significant heterogeneity was found $(\mathrm{P}<0.05)$, we calculated overall efficacy using random-effects models.

Unit of analysis issues

Only RCTs with follow-up of at least six weeks' duration were included in this review.

\section{Dealing with missing data}

We contacted the study authors to request any missing information. For each trial, we extracted the number of participants originally allocated to each treatment arm from the data, and we performed an intention-to-treat analysis. 
Assessment of heterogeneity

We used both a $\mathrm{Chi}^{2}$ test and an $\mathrm{I}^{2}$ statistic to test for heterogeneity between trial results. We used the tests of heterogeneity at a significance level of alpha $=0.05$ to examine whether observed variation in study results was compatible with the variation expected by chance alone. When possible, we pooled trial results by meta-analysis.

\section{Assessment of reporting biases}

We contacted authors to request missing data. To prevent language bias, we did not impose a language restriction. Funnel plots were used to identify potential publication bias.

\section{Data synthesis}

If data were available, we performed statistical analyses using the Review Manager software (RevMan 2011). We standardized reported data on walking time and distance to effect sizes to enable the calculation of an overall standardized mean difference. For this purpose, the difference in outcomes of each study was expressed in the standard deviation (SD) observed in the study (Altman 1991). For articles with non-parametric data, SDs were calculated by dividing the SD by 1.35, according to Chapter 7.7.3.5 of the Cochrane Handbook for Systematic Reviews of Interventions (Higgins 2011). We calculated the standardized mean difference (SMD) using a fixed-effect model, as the results were presented on different scales (distance or time).

Subgroup analysis and investigation of heterogeneity

Potential heterogeneity in non-supervised exercise programs might exist as the result of differences in intervention components (ranging from structural "go home and walk" advice to a formal home-based exercise program). We performed a subgroup analysis by dividing non-supervised exercise programs into studies that treated participants with "go home and walk" advice and trials that used a home-based exercise program. Home-based exercise was defined as walking advice supplemented with some form of observation method (eg, exercise logs, telephone support, educational videos, step monitors) used by medically trained personnel. In studies that compared both non-supervised types with a supervised exercise program, the "shared" supervised group was split into two groups and included in two comparisons according to Chapter 16.5 of the Cochrane Handbook for Systematic Reviews of Interventions (Higgins 2011).
Sensitivity analysis

Individual study effects on the results were examined by removing each study one at a time to examine whether removing a particular study changed the results significantly. Studies with apparent risk of bias were excluded.

\section{Results}

\section{Description of studies}

See Characteristics of included studies; Characteristics of excluded studies; and Characteristics of ongoing studies (in the online version of this Cochrane review).

\section{Results of the search}

For this update, a total of 240 potentially new studies were identified by the Cochrane Peripheral Vascular Diseases Group, and the hand search yielded four potential studies for inclusion. After title and abstract evaluation, 48 articles on supervised exercise therapy in participants with PAD remained for full-text analysis. The eight included and 19 excluded (27 in total) clinical trials identified in the initial review of 2006 were re-evaluated.

\section{Selection process}

One review author (HJPF) obtained full-text copies of the 75 articles (48 new articles and 27 originally documented in the 2006 review) for further assessment. We (HJPF, BLWB, JAWT, MHP) excluded 53 articles of 53 studies (Characteristics of excluded studies) and included 20 articles based on 14 studies (Characteristics of included studies). In addition, we found one ongoing trial (two articles) with potentially usable outcome variables (Frans 2012).

\section{Unpublished data}

To avoid publication bias, we contacted six authors of included studies to obtain unpublished data for the assessment of secondary outcome variables. From four authors, we received additional data (Collins 2011; Nicolai 2010; Sanderson 2006; Treat-Jacobson 2009). We were unable to obtain appropriate or adequate data for two studies (Cheetham 2004; Gardner 2011) 
Included studies

For this update, nine additional studies were included (Collins 2011; Gardner 2011; Gardner 2012; Hodges 2008; Nicolai 2010; Parr 2009; Sanderson 2006; Stewart 2008; Treat-Jacobson 2009), making a total of 14 included studies. Three of the eight studies (Degischer 2002; Nielsen 1975; Nielsen 1977) that were included in the previous version of this review were excluded in this update for the reasons given in Characteristics of excluded studies. The 14 included trials involved a total of 1002 participants; 589 received supervised exercise therapy (SET), and 413 received non-supervised exercise therapy. The trials were conducted in the United States (7), the UK (4), Australia (1), the Netherlands (1), and South Africa (1). Nine of the trials were relatively recent (2006 to 2012). Five trials were conducted from 1997 to 2005 and were reported in the original review.

Some of the included trials were small; seven included fewer than 30 participants (Hodges 2008; Kakkos 2005; Parr 2009; Regensteiner 1997; Sanderson 2006; Savage 2001; Treat-Jacobson 2009), and four others included fewer than 80 participants (Cheetham 2004; Gardner 2011; Patterson 1997; Stewart 2008). Three trials included more than 140 participants (Collins 2011; Gardner 2012; Nicolai 2010); the largest trial, which was conducted in the Netherlands, consisted of 304 participants and was the only multicenterbased study (Nicolai 2010).

In three studies (Parr 2009; Sanderson 2006; Treat-Jacobson 2009), three different modes of exercise regimens were investigated. For this review, we used data from the supervised walk- ing groups and the regular non-supervised groups only. One trial was designed to investigate the effects of home-based exercise, but participants were treated with a supervised session once a week (Collins 2011). Therefore this study was included in the supervised group. Another trial (Gardner 2011) investigated the effects of supervised exercise in a three-armed randomized study. In this trial, a control group with "go home and walk" advice was compared with a group given home-based or supervisedbased exercise against a background of standard medical care. We (HJPF, BLWB, JAWT, MHP) decided to use the results of the non-supervised exercise groups ("go home and walk" advice and home- based exercise) separately in the subgroup analysis. The results of the supervised group therefore were equally split and were used as comparator.
Inclusion criteria

In six of the trials, in order to be eligible for inclusion, participants with intermittent claudication had to be stable for several months (Cheetham 2004; Kakkos 2005; Patterson 1997; Regensteiner 1997; Sanderson 2006; Stewart 2008). This criterion was not mentioned in the other trials. In all trials, both males and females were included (Characteristics of included studies), except for one trial, which included only male participants (Regensteiner 1997).

The mean age of participants in the SET and control groups was 65.3 years (range 57 to 69 ) and 66.3 (range 61 to 70 ), respectively. In the four trials that used age restrictions, participants had to be older than 18 years of age (Treat-Jacobson 2009), older than 40 years of age (Collins 2011), older than 50 years of age (Savage 2001), or between 50 and 75 years of age (Patterson 1997). A diagnosis of PAD was an essential inclusion criterion in all trials. In one trial (Savage 2001), the diagnosis of intermittent claudication was based on a clinical history. In two other trials (Kakkos 2005; Parr 2009), participants were in cluded when intermittent claudication was clinically determined and a peripheral arterial lesion was found on ultrasound or angiography, or both. The remaining trials (Cheetham 2004; Collins 2011; Gardner 2011; Gardner 2012; Hodges 2008; Nicolai 2010; Patterson 1997; Regensteiner 1997; Sanderson 2006; Stewart 2008; Treat-Jacobson 2009) used a low ankle-brachial index (ABI) or a drop in ankle pressure after exercise to determine the clinical diagnosis of PAD. Collins et al included participants with PAD and diabetes mellitus type 1 or 2 (medication use, diet control, or hyperglycemia) (Collins 2011).

\section{Exclusion criteria}

The exclusion criteria used by the included trials were variable. In general, ischemic rest pain, comorbid illness with limitations in an exercise therapy program, and recent vascular surgery or percutaneous transluminal angioplasty (PTA) were mentioned. In one study, smoking habits (Savage 2001), and, in another, the presence of diabetes mellitus (Regensteiner 1997) were exclusion criteria. Kakkos 2005 and Nicolai 2010 excluded participants with a maximal claudication distance greater than 300 or with a maximal claudication distance less than 50 meters and greater 500 meters, respectively. Two trials excluded cases in which the results of the treadmill test differed by more than $25 \%$ in terms of absolute claudication distance derived from three screening tests (Kakkos 2005 Treat-Jacobson 2009). Collins excluded participants without a phone (Collins 2011), and 
Sanderson 2006 did not include participants who lived farther than $50 \mathrm{~km}$ from the research center. Gardner et al excluded participants who used cilostazol or pentoxifylline or both (Gardner 2011; Gardner 2012).

Supervised exercise regimens

In general, the supervised exercise programs consisted of three exercise sessions a week for durations of six weeks (Parr 2009; Sanderson 2006), three months (Gardner 2011; Hodges 2008; Patterson 1997; Regensteiner 1997; Treat-Jacobson 2009), six months (Gardner 2012; Kakkos 2005), and 12 months (Nicolai 2010). However, in three trials (Cheetham 2004; Collins 2011; Stewart 2008), the supervised program was given as a weekly session during six months, a weekly session with phone call support during three months, and biweekly supervised therapy during three months, respectively. Generally, a training session involved walking on a treadmill with varying intensity until moderate or intense pain occurred; this was followed by a short period of rest. Three studies (Cheetham 2004; Parr 2009; Patterson 1997) described an alternative training regimen with walking training as the dominant exercise but with additional exercises for lower limb strengthening. In one trial, treadmill exercises were not performed and exercises were described as based on training of the lower extremity, but unfortunately this was not specified further (Stewart 2008). In all trials, the duration of each supervised exercise session varied between 30 and 70 minutes, except in Patterson 1997, in which a session lasted 20 to 40 minutes. Four trials with an initial supervised period of three months and an additional three months' unsupervised follow-up were included (Patterson 1997; Savage 2001; Stewart 2008; Treat-Jacobson 2009). Cheetham and Kakkos treated participants with six months of SET with an additional six months' unsupervised follow-up (Cheetham 2004; Kakkos 2005). The remaining trials did not have a follow-up period without supervised therapy. In two trials (Patterson 1997; Savage 2001), participants were additionally educated weekly or monthly about PAD, and Treat-Jacobson 2009 described all non-supervised exercises in reports.

\section{Non-supervised exercise regimens}

In ten trials, participants in the non-supervised exercise therapy groups were advised to walk (Cheetham 2004; Collins 2011 Gardner 2011; Gardner 2012; Hodges 2008; Kakkos 2005; Nicolai 2010; Parr 2009; Sanderson 2006; Stewart 2008). This walking advice was given once and predominantly consisted of walking at least three times weekly with walking intensity ranging between tolerance and intense pain. Besides receiving this advice, participants in four trials were treated with standard medical therapy (Cheetham 2004; Hodges 2008; Nicolai 2010; Sanderson 2006). Nicolai et al provided an additional brochure as well (Nicolai 2010). In five other trials, participants in the control group were treated with a home-based exercise program (Gardner 2011; Patterson 1997; Regensteiner 1997; Savage 2001; Treat-Jacobson 2009).

\section{Outcome measurements}

All trials used a treadmill walking test to measure the pain-free treadmill walking distance or time and the maximal treadmill walking distance or time. The treadmill tests used varied between trials and are reported in the table of Characteristics of included studies. Three trials used a fixed protocol (Cheetham 2004; Kakkos 2005; Stewart 2008), and the other eleven used a graded protocol. Seven of these studies (Collins 2011; Gardner 2011; Gardner 2012; Hodges 2008; Nicolai 2010; Parr 2009; Savage 2001) used the Gardner Skinner protocol (Gardner 1991). Data on the maximal treadmill walking distance of Cheetham (Cheetham 2004) were calculated on the basis of the P value, and it was assumed that the standard deviations of both groups were equal. Data from Patter son (Patterson 1997) were extracted from the accompanying figures. Seven trials (Cheetham 2004; Gardner 2011; Gardner 2012; Kakkos 2005; Parr 2009; Stewart 2008; TreatJacobson 2009) measured adherence to the exercise program by registering absence in the supervised groups. In the non-supervised groups, attendance was noted in three trials on the basis of self-reported logbooks (Cheetham 2004; Gardner 2011; Treat-Jacobson 2009). Participant-reported outcomes were taken into account in nine trials (Cheetham 2004; Collins 2011; Gardner 2011; Gardner 2012; Kakkos 2005; Nicolai 2010; Patterson 1997; Regensteiner 1997; Savage 2001). The Medical Outcomes Study (MOS) Short Form (SF)-36 was used in seven trials (Cheetham 2004; Collins 2011; Gardner 2011; Kakkos 2005; Nicolai 2010; Patterson 1997; Savage 2001); the MOS SF-20 was used in the trial of Regensteiner (Regensteiner 1997). Additionally, the Walking Impairment Questionnaire (WIQ) was used in four trials (Gardner 2011; Gardner 2012; Kakkos 2005; Nicolai 2010), the Intermittent Claudication Questionnaire (ICQ) in one trial (Kakkos 2005), the Geriatric Depression Scale (GDS) in one trial (Collins 2011), and the Charing Cross Claudication Questionnaire (CCCQ) in one trial (Cheetham 2004). 


\section{Excluded studies}

For this update, 34 additional studies were excluded (Ciuffetti 1994; Collins 2005; Crowther 2008; Dahllöf 1976; Degischer 2002; Fakhry 2011; Fowler 2002; Gardner 2005; Greenhalgh2008; Grizzo 2011; Hobbs 2007; Krause 1974; Kruidenier 2011; Leicht 2011; Leon 2005; Manfredini 2008; McDermott 2009; Menêses 2011; Mika 2005; Mika 2006; Mika 2011; Murphy 2012; Nielsen 1975; Nielsen 1977; Ritti-Dias 2010; Saxton 2011; Schlager 2011; Schlager 2012; Spronk 2009; Tebbutt 2011; Tew 2009; Walker 2000; Wood 2006; Zwierska 2005). A summary of the excluded studies can be found in the table entitled Characteristics of excluded studies. Overall, 53 studies were excluded. Thirty-two studies compared SET with a non-exercising group or a group that maintained usual care with or without usual medical care. Seven trials (Ciuffetti 1994; Gardner 2005; Grizzo 2011; Krause 1974; Lepantalo 1991; Menêses 2011; Ritti-Dias 2010) compared SET with another kind of supervised therapy, and six studies compared SET with an invasive procedure (Gelin 2001; Kruidenier 2011; Murphy 2012; Spronk 2009; Taft 2001; Taft 2004). Four trials (Fowler 2002; Leon 2005; Manfredini 2008; Tebbutt 2011) compared home-based exercise therapy with walk advice. In another study (Tisi 1997), participants were treated with a 4-week SET program. Five trials (Degischer 2002; Fakhry 2011; Nielsen 1975; Nielsen 1977; Wind 2007) were excluded because they used a non-randomized study design. Three of these had been classified as included studies in the original review (Degischer 2002; Nielsen 1975; Nielsen 1977). However, because a greater number of eligible studies were available, we decided to include RCT designs only in the current update.

Ongoing studies

One trial (Frans 2012) was a description of a study protocol.

Risk of bias in included studies

See Figure 1; Figure 2.
Figure 1 Risk of bias graph: review authors' judgements about each risk of bias item presented as percentages across all included studies.

Random sequence generation (selection bias)

Allocation concealment (selection bias)

Blinding of participants and personnel (performance bias)

Blinding of outcome assessment (detection bias)

Incomplete outcome data (attrition bias)

Selective reporting (reporting bias)

$$
\text { Other bias }
$$$$
\text { bias }
$$

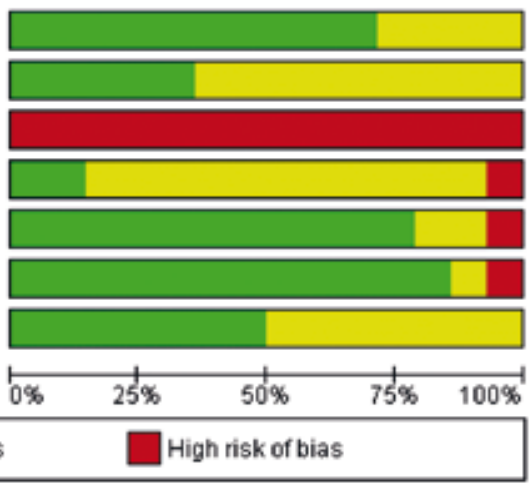

Low risk of bias $\square$ Unclear risk of bias

\section{Allocation}

Sequence generation

Four studies did not detail the process of sequence generation (Patterson 1997; Regensteiner 1997; Savage 2001; Treat-Jacobson 2009). All others (Cheetham 2004; Collins 2011; Gardner 2011; Gardner 2012; Hodges 2008; Kakkos 2005; Nicolai 2010; Parr 2009; Sanderson 2006; Stewart 2008) described an adequate sequence generation.

Concealment of allocation

Five studies described adequate concealment of allocation, using sealed opaque envelopes or a computer program with or without block randomization (Gardner 2011; Gardner 2012; Nicolai 2010; Sanderson 2006; Stewart 2008). Allocation concealment was not detailed in the remaining nine studies (Cheetham 2004; Collins 2011; Hodges 2008; Kakkos 2005; Parr 2009; Patterson 1997; Regensteiner 1997; Savage 2001; Treat-Jacobson 2009).

Blinding

In trials that compared exercise programs with walking distance as the primary outcome, blinding of staff and participants is not possible and therefore was not considered. Two trials were judged to have a low risk of detection bias because a blinded analysis of the outcomes was performed (Cheetham 2004; Nicolai 2010). 
Figure 2 Risk of bias summary: review authors' judgements about each risk of bias item for each included study.

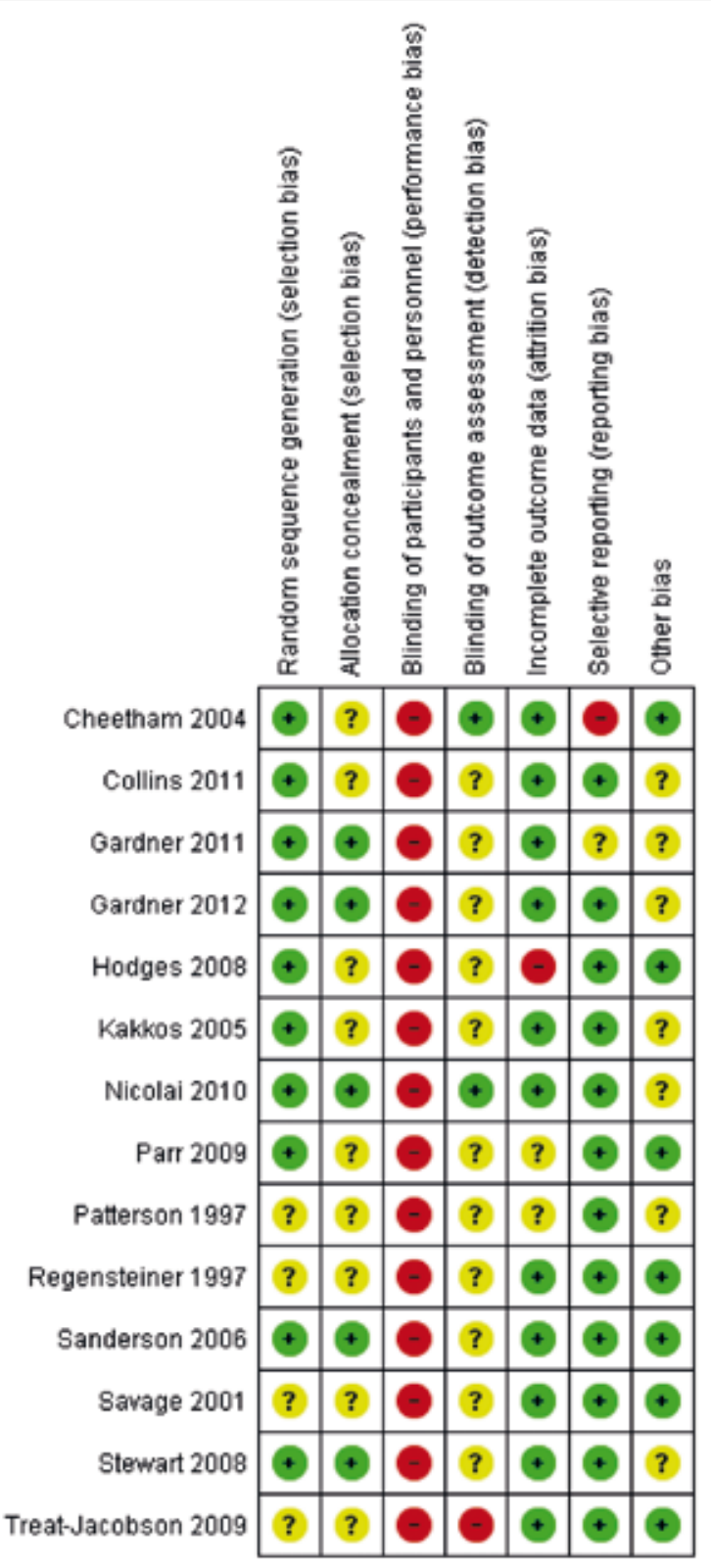

Incomplete outcome data

All included studies reported results of predefined primary outcome variables. Nicolai et al reported additional outcome variables, which were not published (Nicolai 2010). However, through contact with the author, these unpublished data were obtained. Five trials reported an intention-to-treat analysis (Collins 2011; Gardner 2011; Gardner 2012; Kakkos 2005; Nicolai 2010), and six other trials reported no dropouts or had minimal loss to follow-up and therefore did not perform an intention-to-treat analysis (Cheetham 2004; Regensteiner 1997; Sanderson 2006; Savage 2001; Stewart 2008; Treat-Jacobson 2009). Overall, 159 participants were lost to follow-up (15.9\%). Two trials were unclear in their attrition bias description (Parr 2009; Patterson 1997), and Hodges et al reported no details on attrition (Hodges 2008).

Selective reporting

Reporting bias was difficult to determine. No study protocols of trials were obtained. All included studies reported commonly used primary outcome parameters, so a low reporting bias was assumed for these outcomes. In one trial, we assessed a high risk of reporting bias (Cheetham 2004). In this study, quality of life was measured with Medical Outcomes Study Short Form 36; however, we could not obtain usable data from the figures. In another trial, reporting bias was just as unclear because quality of life was reported in a "Physical function score" only (Gardner 2011). Only one author replied with unpublished SF-36 data (Nicolai 2010)

Other potential sources of bias

To detect publication bias, we analyzed the two best represented outcome variables (maximal walking distance at three and six months) with the use of funnel plots (Figure 3; Figure 4). No asymmetrical plots were observed, leading to the conclusion that publication bias was minimal. Seven trials were judged to have an unclear risk of potential bias. The work of Collins 2011 was funded by the American Diabetes Association; however no potential conflicts of interest relevant to this article were reported. Two studies by Gardner et al (Gardner 2011; Gardner 2012) could be influenced by participation bias. Participants in these trials were volunteers; therefore, they may represent those more in terested in exercise. Four other trials reported data in interquartile range (IQR) format, which had to be recalculated; this could have led to potential bias (Kakkos 2005; Nicola 2010; Patterson 1997; Stewart 2008). All other trials were judged to have low risk (Chee- 
tham 2004; Hodges 2008; Parr 2009; Regensteiner 1997; Sanderson 2006; Savage 2001; Treat-Jacobson 2009).

Figure 3 Funnel plot of comparison: Maximal treadmill walking distance after 3 months.

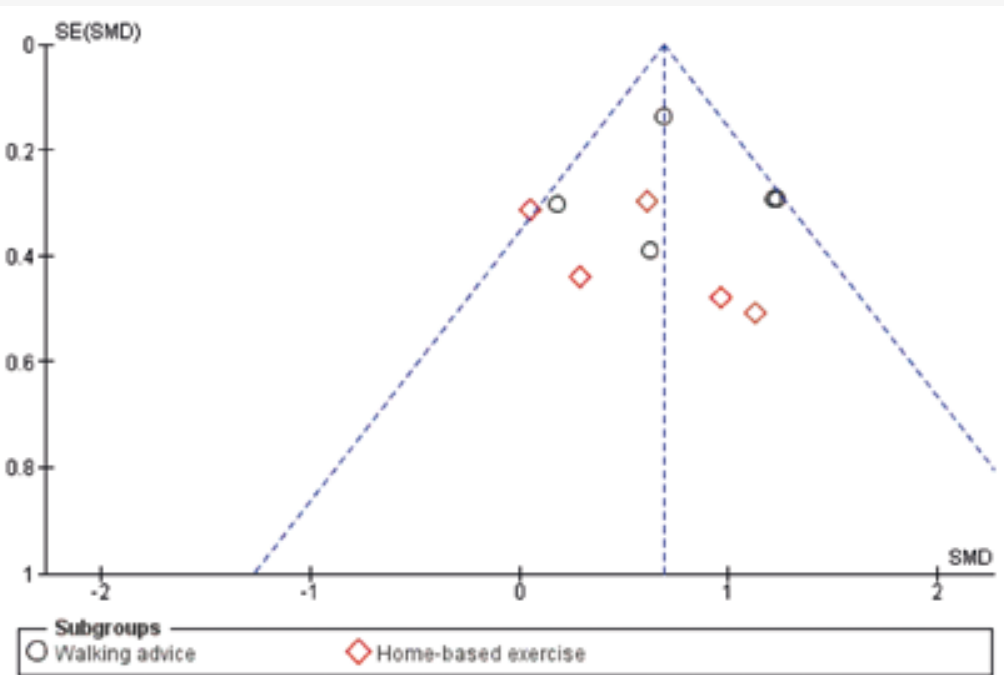

Figure 4 Funnel plot of comparison: Maximal treadmill walking distance after 6 months.

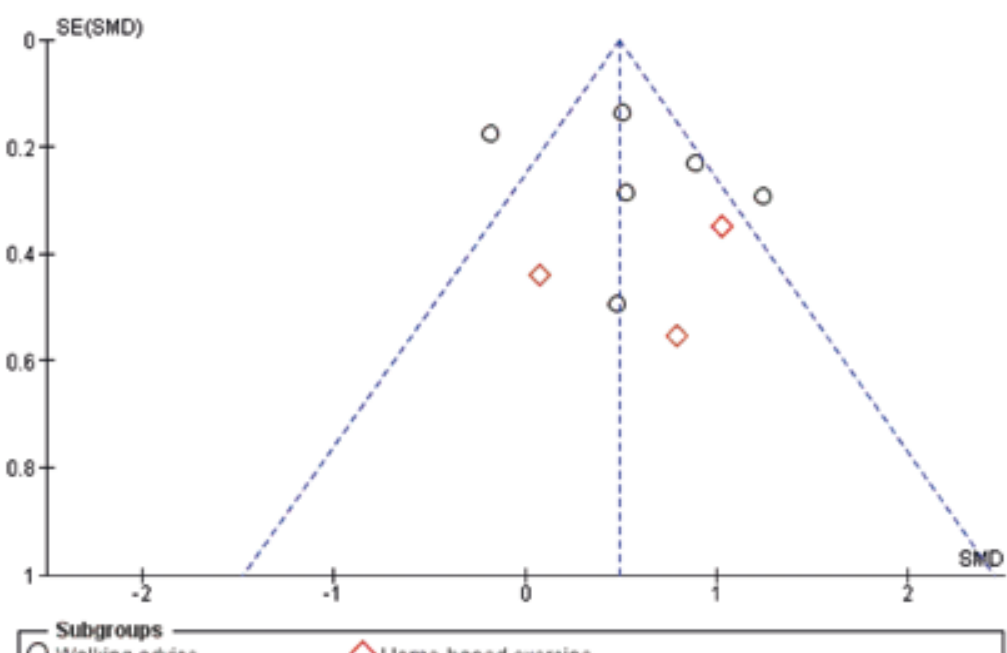

O Walking advice

Home-based exercise

\section{Effects of interventions}

Primary outcome

Maximal treadmill walking distance or time

Data on maximal treadmill walking distance after six weeks of exercise therapy were available in five trials (Gardner 2012; Hodges 2008; Kakkos 2005; Parr 2009; Sanderson 2006) with a total sample size of 234 participants. This outcome was repeated after three months in nine trials ( $n=592)$ (Cheetham 2004; Gardner 2011; Hodges 2008; Nicolai 2010; Patterson 1997; Regensteiner 1997; Savage 2001; Stewart 2008; Treat-Jacobson 2009), after six months ( $\mathrm{n}=686)$ in nine trials (Cheetham 2004; Collins 2011; Gardner 2012; Kakkos 2005; Nicolai 2010; Patterson 1997; Savage 2001; Stewart 2008; Treat-Jacobson 2009), after nine months $(\mathrm{n}=308)$ in two trials (Cheetham 2004; Nicolai 2010), and after 12 months $(\mathrm{n}=321)$ in three trials (Cheetham 2004; Kakkos 2005; Nicolai 2010). We calculated the effect estimates after standardization of mean differences. At six weeks, the maximal treadmill walking distance was increased with an overall effect size (ES) of 0.52 (95\% confidence interval (CI) 0.24 to 0.81 ) when the fixed-effect model was used in favor of the SET group. At three months, the overall effect size increased to 0.69 (95\% CI 0.51 to 0.86 ). This translates to a difference in favor of the supervised group of approximately $180 \mathrm{~m}$ in increased walking distance, corresponding with an approximately $35 \%$ to $40 \%$ difference in increase between the groups. At six months, this effect was maintained with an overall effect size of 0.48 (95\% CI 0.32 to 0.64 ). In two trials in which the outcomes were repeated, the effect was present at nine months (ES 0.60, 95\% CI 0.36 to 0.85) (Cheetham 2004; Nicolai 2010) and 12 months after exercise therapy (ES 0.61, 95\% CI 0.37 to 0.84 ) (three trials: Cheetham 2004; Kakkos 2005; Nicolai 2010). We performed a subgroup analysis at three months and six months of follow-up by splitting the non-supervised group into a walking advice group and a home-based exercise group. At three months, the difference favored the supervised group, with an ES of 0.76 (95\% CI 0.56 to 0.96 ) and 0.50 (95\% CI 0.17 to 0.83 ) for the walking advice group and the home-based group, respectively. No significant difference was found between the two subgroups $(P=0.19)$. At six months, the supervised exercise group was still in favor compared with both non-supervised groups. In addition, we found no significant differences between the two subgroups $(\mathrm{P}=0.78)$. At six weeks, non-significant heterogeneity was noted with an $\mathrm{I}^{2}$ of $27 \%(\mathrm{P}=0.24)$. At three months, moderate heterogeneity was observed $\left(\mathrm{I}^{2}=43 \% ; \mathrm{P}=0.07\right)$. Use of the random- 
effects model for the results after three months resulted in a similar overall effect size of 0.69 (95\% CI 0.43 to 0.94 ), indicating that this heterogeneity is of non-importance. At six months, significant heterogeneity was seen $\left(\mathrm{I}^{2}=71 \% ; \mathrm{P}=0.0006\right)$. With a randomeffects model, the effect size was increased from 0.48 to 0.58 ( $95 \%$ CI 0.24 to 0.91 ). This heterogeneity is likely due to the negative trial of Collins (Collins 2011). When a sensitivity analysis was performed by excluding this trial, a non-important heterogeneity was achieved $\left(\mathrm{I}^{2}=25 \% ; \mathrm{P}=0.23\right)$. At other time points, moderate heterogeneity was noted at nine months $\left(\mathrm{I}^{2}=82 \% ; \mathrm{P}=0.02\right)$ and at 12 months $\left(\mathrm{I}^{2}=64 \% ; \mathrm{P}=0.06\right)$.

Figure 5 Comparison: Maximal treadmill walking distance after 3 months.

\begin{tabular}{|c|c|c|c|c|c|c|c|}
\hline Study or subgroup & $\begin{array}{r}\text { SET } \\
\mathrm{N} \\
\end{array}$ & Mean(5D) & $\begin{array}{r}\text { Non-SET } \\
\mathrm{N} \\
\end{array}$ & $\operatorname{Mean}(5 D)$ & 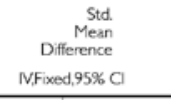 & Weight & 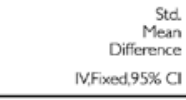 \\
\hline $\begin{array}{l}\text { I Walling advice } \\
\text { Chectham } 2004\end{array}$ & 28 & $1.3(0.48)$ & 28 & $0.71(0.48)$ & $\rightarrow$ & $9.1 \%$ & $1.21[0.64,1.79]$ \\
\hline Gartiner 2011 & 17 & $1.06(0.55)$ & 30 & $0.97(0.47)$ & - & $8.4 \%$ & $0.18[-0.42 .0 .77]$ \\
\hline Hodges 2008 & 14 & $1.21(0.6)$ & 14 & $0.79(0.7)$ & •- & $5.1 \%$ & $0.63[-0.14,1.39]$ \\
\hline Neolai 2010 & 169 & $1.15(0.74)$ & 83 & $0.69(0.47)$ & $=$ & $41.0 \%$ & $0.69[0.420 .966]$ \\
\hline Stewart 2008 & 28 & $1.41(0.88)$ & 28 & $0.59(0.3)$ & $\rightarrow$ & $9.0 \%$ & $1.23[0.66,1.80]$ \\
\hline 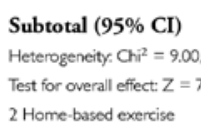 & $\begin{array}{l}256 \\
d f=4(P) \\
34(P<\end{array}$ & $=0.06) ; P^{R}=56 \%$ & 183 & & - & $72.7 \%$ & $0.76[0.56,0.96]$ \\
\hline Garcher 2011 & 16 & $1.02(0.53)$ & 29 & $0.99(0.7)$ & - & $8.0 \%$ & $0.05[-0.56,0.66]$ \\
\hline Patterson 1997 & 25 & $1.17(0.47)$ & 23 & $0.87(0.5)$ & $\cdot$ & $8.9 \%$ & $0.61[0.03,1.19]$ \\
\hline Regensteiner 1997 & 10 & $1.25(0.52)$ & 10 & $0.75(0.48)$ & & $3.4 \%$ & $0.96[0.021 .89]$ \\
\hline Swage 2001 & 11 & $1.06(0.48)$ & 10 & $0.93(0.37)$ & - & $4.0 \%$ & $0.29[-0.57 .1 .15]$ \\
\hline TreattJacobson 2009 & 11 & $1.25(0.61)$ & 8 & $0.65(0.31)$ & 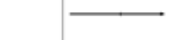 & $3.0 \%$ & $1.13[0.13 .212]$ \\
\hline 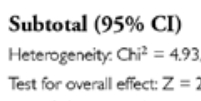 & $\begin{array}{c}73 \\
d f=4(d) \\
95(p=\end{array}$ & $=0.29: R=19 \%$ & 80 & & - & $27.3 \%$ & $0.50[0.17,0.83]$ \\
\hline 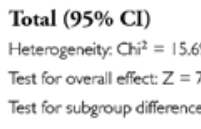 & $\begin{array}{l}329 \\
9 . \mathrm{df}=9 \\
180 \mathrm{CP}< \\
\mathrm{Ch}^{2}=\end{array}$ & 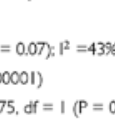 & 263 & & - & $100.0 \%$ & $0.69[0.51,0.86]$ \\
\hline
\end{tabular}

Secondary outcomes

Pain-free treadmill walking distance or time

Data on pain-free treadmill walking distance after six weeks were available in four trials (Gardner 2012; Kakkos 2005; Parr 2009; Sanderson 2006) with a total sample size of 171. This outcome was repeated after three months in seven trials $(n=479)$ (Gardner 2011; Nicolai 2010; Patterson 1997; Regensteiner 1997; Savage 2001; Stewart 2008; Treat-Jacobson 2009), at six months in eight trials $(\mathrm{n}=630)$ (Collins 2011; Gardner 2011 Kakkos 2005;Nicolai 2010; Patterson 1997; Savage 2001; Stewart 2008; Treat- Jacobson 2009), and at 12 months after exercise therapy in two trials (Kakkos 2005; Nicolai 2010) $(n=266)$. We calculated the effect estimates after standardization of the mean differences. At six weeks, the pain-free treadmill walking distance was increased, with an overall effect size of 0.51 ( $95 \%$ CI 0.18 to 0.84 ), when the fixed-effect model was used in favor of the SET group. At three months, the overall effect size increased to 0.70 (95\% CI 0.52 to 0.89 ). This translates to a difference in favor of the supervised group of approximately $150 \mathrm{~m}$ in increased pain-free walking distance. At six months and twelve months, this effect was maintained, with an overall effect size of 0.52 (95\% CI 0.35 to 0.69 ) and 0.50 (95\% CI 0.24 to 0.76 ), respectively.We again performed a subgroup analysis in the non-supervised group at three months and six months of follow-up. At three months, the difference favored the supervised group, with an ES of 0.72 (95\% CI 0.49 to 0.94 ) and 0.65 (95\% CI 0.29 to 1.01) for the walking advice group and the home-based group, respectively. No significant differences were found between the two subgroups $(\mathrm{P}=0.76)$. At six months of follow-up, the SET group was still in favor, with an ES of 0.45 (95\% CI 0.27 to 0.63 ) and 1.04 (95\% CI 0.54 to 1.53 ) compared with the walk advice group and the home-based exercise group, respectively. However, a significant difference $(\mathrm{P}=0.03)$ between the non-supervised subgroups was found in favor of the home-based group. No statistical heterogeneity was observed at six weeks $\left(\mathrm{I}^{2}=0 \% ; \mathrm{P}=0.45\right)$, at three months $\left(\mathrm{I}^{2}\right.$ $=0 \% ; \mathrm{P}=0.56)$, and at 12 months $\left(\mathrm{I}^{2}=0 \% ; \mathrm{P}=0.54\right)$. However, at six months, substantial heterogeneity was reported $\left(\mathrm{I}^{2}=64 \% ; \mathrm{P}=0.007\right)$. After a sensitivity analysis that excluded the negative trial of Collins (Collins 2011), we found an unimportant heterogeneity $\left(\mathrm{I}^{2}=\right.$ $16 \% ; \mathrm{P}=0.30$ ). 
Mortality

In five of the fourteen trials (Cheetham 2004; Kakkos 2005; Nicolai 2010; Patterson 1997; Stewart 2008), a total of thirteen participants died during the course of the study. In the trial of Patterson 1997, nothing is mentioned about the cause of death of the two participants who died during follow-up (both from the supervised group). Cheetham 2004 registered two deaths (one from each group), neither of which could be attributed to a vascular event. Kakkos (Kakkos 2005) described one death. This person died as the result of acute leg ischemia after undergoing an operation for bladder cancer. Nicolai et al mentioned three deceased people in the control group (coronary heart disease $(n=2)$, renal cell carcinoma $(\mathrm{n}=1)$ ) and four deaths in the supervised group (complication lower extremity bypass surgery $(n=1)$, lung carcinoma $(n=1)$, ruptured abdominal aortic aneurysm $(\mathrm{n}=1)$, pancreatic cancer $(\mathrm{n}=1)$ ) (Nicolai 2010). One death occurred in the control group of Stewart (Stewart 2008). No deaths were reported in the remaining trials.

Adherence to exercise program

Five trials (Cheetham 2004; Gardner 2011; Gardner 2012; Parr 2009; Stewart 2008) studied adherence to exercise training. Cheetham 2004 simply asked participants whether they walked "less than three times", "three times", or "more than three times" a week. Twice as many participants in the SET group as in the non-supervised group claimed to be walking more than three times a week. Gardner 2011 provided participants with a step activity monitor, and they were instructed to wear it for each exercise session. Additionally, participants received an exercise logbook in which they were to record their walking sessions. Adherence to home-based exercise and supervised exercise was similar ( $82.5 \%$ vs $84.8 \%$ completion of exercise sessions, respectively). Unfortunately, no adherence data were available from the group that re-ceived walking advice at baseline only. The adherence ratio from the exercise group in Gardner 2012 did not differ greatly ( $74 \%$ completion) from that obtained in their earlier research, although a progressive decline in attendance was evident from the first two months to the final stage at six months (from $86 \%$ to $63 \%$ ). Kakkos 2005, Parr 2009, and Stewart 2008 noted the attendance of the supervised group only (mean attendance: $60 \%, 80 \%$, and $89 \%$, respectively). Treat-Jacobson 2009 revealed an adherence of $100 \%$ in $61 \%$ of participants in the SET group, and $97 \%$ of participants completed at least $75 \%$ of the prescribed training. Conversely, $75 \%$ of control group participants reported participation in outside exercise at least three times a week.
Patient-reported outcomes (quality of life)

In this update, we calculated the effect estimates after standardization of mean differences in SF-36 outcomes after three and six months. The SF-36 was used in seven trials after three months (Cheetham 2004; Collins 2011; Gardner 2011; Kakkos 2005; Nicolai 2010; Patterson 1997; Savage 2001), and the MOS SF-20 in the trial of Regensteiner (Regensteiner 1997). However, Collins 2011 and Cheetham 2004 published SF-36 results as a change from baseline, but they were not usable. We contacted the study authors but were not able to obtain raw or unpublished data. Results of the physical function role were presented in five trials (Gardner 2011; Nicolai 2010; Patterson 1997; Regensteiner 1997; Savage 2001); both social function and the emotional role were noted in four trials (Nicolai 2010; Patterson 1997; Regensteiner 1997; Savage 2001); and the remaining roles were mentioned in three trials (Nicolai 2010; Patterson 1997; Savage 2001). The role "general health" showed significant improvement with supervised exercise (ES $0.30,95 \%$ CI 0.05 to 0.55 ) only. The other roles showed a positive trend toward the intervention; however, these changes are not statistically significant. A sub analysis of non-supervised exercise programs could not be made because of the small number of studies. SF-36 outcomes at six months were obtained in four trials (Kakkos 2005; Nicolai 2010; Patterson 1997; Savage 2001). Again, almost all roles showed a positive trend toward supervised exercise, except for the role of "pain", which revealed a significant positive change (ES $0.25,95 \%$ CI 0.00 to 0.49 ). SF36 outcomes at other time periods were not used because they could be obtained only from unpublished data of Nicolai 2010 and summary data of Kakkos 2005. No statistical heterogeneity was noted in all quality of life analyses, except for the vitality role, at three months' follow-up ( $\mathrm{I}^{2}=79 \%$; $\left.\mathrm{P}=0.008\right)$. Use of random-effects models resulted in a somewhat increased overall effect size from 0.05 to 0.30 (95\% CI -0.43 to 1.03), indicating that no important heterogeneity was present. Using the CCCQ, Cheetham 2004 reported a statistically significant difference between the two groups $(\mathrm{P}<0.05)$ after nine months of exercise in favor of the SET group. Intragroup analyses of the WIQ and the ICQ showed less improvement or even reduction in the non-supervised group compared with an increase in score in the supervised group (Kakkos 2005; Regensteiner 1997). However, these changes were not compared between groups (Kakkos 2005; Regensteiner 1997). 


\section{Discussion}

\section{Summary of main results}

Primary outcome

We included data from 14 randomized trials enrolling a total of 1002 participants. Statistically significant and clinically relevant differences in improvement in walking distance were consistently demonstrated in favor of SET compared with non-supervised exercise therapy regimens during the first year of treatment. A subanalysis was performed to investigate the influence of two types of non-supervised exercise regimens. No significant differences were found between "go home and walk" advice and a more structural homebased exercise program. Despite the variability of prescribed exercise training and treadmill walking tests used to measure the outcome, heterogeneity was present only for the results of the maximal treadmill walking distance after six months. This is likely a result of the negative trial of Collins (Collins 2011). Indeed removing this trial from the analysis resulted in the absence of statistical heterogeneity. In addition to chance alone, several factors could contribute to the observed heterogeneity. First, the supervised exercise regimen used by Collins was described as home-based exercise and consisted of once-a-week supervised training only, thereby reducing the intensity of supervision compared with the other trials, which trained three times a week or biweekly (Stewart 2008). Furthermore, in the trial of Collins (Collins 2011), all participants had diabetes mellitus. Reported data on walking time and distance were standardized to allow calculation of the difference in increase between the two treatment groups. When the standardized data were translated back to walking distances, summary estimates of maximal treadmill walking distance showed a difference in increase of approximately $180 \mathrm{~m}$ in favor of the SET regimens over non-supervised therapy for three months. This difference was maintained at six, nine, and twelve months.

Secondary outcomes

In line with maximal walking distance, pain-free walking distance was more increased by supervised exercise than non-supervised exercise during the first year of treatment, with a maximal effect size of 0.76 (95\% CI 0.57 to 0.95$)$ at three months. This effect was maintained at six and twelve months. A significant difference was found in the sub analysis between "go home and walk" advice and a more structured home-based exercise program, probably as a result of the SET negative trial of Collins (Collins 2011). Furthermore, significant heterogeneity was found at six months. A sensitivity analysis excluding the trial of Collins (Collins 2011) resulted in non-important heterogeneity and no significant difference between the two non-supervised exercise types. No obvious results in mortality registration were obtained. Thirteen of the 1002 participants died, but none of these deaths were related to exercise therapy. Participant-related outcomes (SF-36) were not significantly different between the two exercise regimens. This could be explained by an underpowered analysis. We obtained complete SF-36 data from three studies $(n=245)$ at three months of follow-up (Nicolai 2010; Patterson 1997; Savage 2001) and from four trials at six months of follow-up $(n=258)$ (Kakkos 2005; Nicolai 2010; Parr 2009; Savage 2001). Five other studies did record SF-36 outcomes; however, we were not able to obtain the raw data. This could have led to a potential publication bias.

\section{Overall completeness and applicability of evidence}

Participants

Both inclusion and exclusion criteria were variable across studies, but they did not differ very widely from daily practice. Regensteiner 1997 included solely male participants, and Collins 2011 included participants with diabetes mellitus only.

Interventions

Most included studies were performed in hospital settings all over the world. One trial provided supervised exercise in part at the hospital and in part at home (Collins 2011). Another used community-based supervised exercise (Nicolai 2010). Kruidenier concluded that community-based SET appeared to be as effective as hospital-based SET, so it seems unlikely that these potential factors of heterogeneity limit the applicability of the results (Kruidenier 2009). In three trials, training sessions were complemented by strength training (Cheetham 2004; Parr 2009; Patterson 1997), and one trial was based on exercise therapy of the lower extremity without treadmill walking (Stewart 2008). There were no indications that these supervised sessions were less stringent than in the other studies. The effectiveness of different modes of exercise will be compared in another Cochrane review (Lauret 2012b). Six trials had a follow-up period without supervision. After a sensitivity analysis was performed by removing four trials with a non-supervised follow-up period ( $\mathrm{n}=350$; Patterson 1997; Savage 2001; Stewart 2008; Treat-Jacobson 2009), effect 
size at six months did decrease slightly from 0.48 (95\% CI 0.32 to 0.64 ) to 0.45 ( $95 \%$ CI 0.27 to 0.63 ). This suggests that exercise therapy with a period of supervision could have a prolonged effect on increasing walking distance and could be as effective as that described in trials with a full follow-up trajectory.

\section{Comparator}

This review compared supervised with non-supervised exercise therapy. We found that non-supervised regimens showed a lot of heterogeneity from simple walking advice at the start of treatment to a structured home-based exercise program with some form of remote "supervision". Therefore, we performed a sub analysis within the non-supervised exercise group, which was divided into a "go home and walk" advice group and a homebased exercise group. In one three-armed trial (Gardner 2011), the results of the control group and those of the home-based treated exercise group were compared with results of the supervised group by splitting the supervised group into two groups.

Outcomes

All trials used treadmill exercise to investigate the effectiveness of supervision. Only three trials used a fixed protocol. Furthermore, we used standardized mean differences to reduce potential heterogeneity caused by differences in treadmill testing. To reduce heterogeneity in secondary outcomes, we used SF-36 values only for participant-reported outcomes.

$$
\text { Applicability }
$$

To determine the clinical relevance of the ability to walk $180 \mathrm{~m}$ farther, one should realize that a mean maximal walking distance at baseline is approximately $300 \mathrm{~m}$ with an even shorter pain-free walking distance of approximately $200 \mathrm{~m}$. Regular exercise, such as walking, has been shown to significantly reduce cardiovascular events (Izquierdo 2000; Wannamathee 2001). Because claudicants have high cardiovascular morbidity and mortality (30\% mortality at five years) (Aquino 2001; Dormandy 1999; Hooi 2002), a habit of regular walking with increased exercise capacity could be of considerable importance. Results of our review reveal increased ability to perform on a treadmill. However, such an increase might not have any influence on walking behavior in daily life because some studies have found that supervised exercise does not affect day-to-day walking behavior (Crowther 2008; McDermott 2009).
Quality of the evidence

Unfortunately, the raw data from one study (Cheetham 2004) were not directly available and had to be derived by working backward from the reported $\mathrm{P}$ values. We assumed that the standard deviations of both groups were equal. Compared with other trials that reported equal standard deviations, this seemed reasonable. The data of Patterson (Patterson 1997) were extracted from the accompanying figures. Previously included non randomized studies were excluded (Degischer 2002; Nielsen 1975; Nielsen 1977). Other detailed information of quality is presented in the Assessment of risk of bias in included studies. We noted two important limitations in the quality of the evidence. The nature of the interventions made participant blinding effectively impossible. In addition, participation bias may have influenced the results, in that enrollment in a study motivated participants to walk (Collins 2011).

Potential biases in the review process

Unfortunately, heterogeneity was noted in the non-supervised comparator group. We tried to minimize this by introducing a subgroup analysis. Furthermore, because of differences in inclusion and exclusion criteria, such as age or gender restrictions or the presence of diabetes mellitus and smoking behavior, generalization of the results of this meta-analysis could be a topic of discussion. Not all outcome data were available for inclusion. This potentially introduced bias into our review and may reflect publication bias. Therefore, we conducted a formal analysis of publication bias by using a funnel plot. It is suggested from this analysis that publication bias is not a matter of importance (Figure 3; Figure 4).

Agreements and disagreements with other studies or reviews

Several other systematic reviews have been performed that are in line with our findings. Watson et al suggested that exercise therapy should play an important part in the care of selected patients with intermittent claudication, to improve walking times and distances. Effects were demonstrated after three months of supervised exercise, although some programs lasted longer than one year (Watson 2008). Wind et al concluded that SET increases pain-free and absolute walking distances in participants with intermittent claudication as well (Wind 2007). A recent review of Fakhry et al. compared supervised exercise with no interventional observation. The authors concluded that supervised exercise yielded significant clinical benefit (Fakhry 2012). 
Several plausible mechanisms might explain the beneficial results of SET over nonsupervised regimens. A first explanation could be the fact that the exercise regimen of the SET group mainly consisted of treadmill walking, which involves a higher workload than level ground walking at "normal" speed as used by the non-supervised group (Degischer 2002). It is very difficult to measure the intensity of training, but it is generally assumed that home training cannot be considered to be performed with the same energy as training under supervision (Nielsen 1975). Second, a higher workload will lead to a larger positive effect of the general physical condition of the patient, possibly as the result of increased cardiovascular stress, providing a better stimulus for exercise-induced adaptations (Hamburg 2011). Furthermore, a supervised program could offer additional encouragement and motivation to patients resulting in a higher adherence rate, which can be explained in part by the Hawthorne effect as mentioned by Wind et al (Wind 2007). The Hawthorne effect describes the effect that the awareness of being under observation can alter the way a patient behaves or can positively influence the outcome. Nevertheless, when adherence is taken into account, and on the basis of the contrasting results between two trials (Cheetham 2004; Gardner 2011), nothing can be suggested about the influence of a supervised exercise regimen on adherence. However, adherence in a supervised exercise setting is effortlessly measurable during the session in contrast to adherence during home-based intervals or in home-based settings.

\section{Authors' conclusions}

\section{Implications for practice}

Supervised exercise therapy provides statistically significant benefits for treadmill walking distance when compared with non-supervised regimens. The clinical relevance of this difference requires additional studies with a focus on quality of life or other diseasespecific functional outcomes, such as walking behavior, patient satisfaction, and costs. The results of this review are consistent with those of previously performed studies and meta-analyses. All indicate that SET is an effective treatment that should be available as part of the care of patients with intermittent claudication. However, the availability of SET in clinical practice is far from optimal (Lauret 2012a; Makris 2012; Nicolai 2010; Shalhoub 2009). Professionals in the vascular field are obliged to take action to make supervised exercise therapy that is community or hospital based available for all patients with intermittent claudication.
Implications for research

Research to optimize exercise program components (eg, duration, exercise intensity, different modes of exercise, endurance training vs interval training, implementation of lifestyle interventions) is needed. Future research should include people who have a more severe stage of PAD and other comorbidities, as this is more representative of the PAD population.

Most of the included studies in this review have focused on treadmill hospital-based exercise, although the effectiveness of community-based exercise programs is an interesting consideration for future research (Kruidenier 2009), particularly because some form of conservative treatment should be initiated before an invasive revascularization is performed (Hirsch 2006; Norgren 2007). Others have shown that access to a conservative supervised exercise program is low across Europe (UK: 36.4\%; Germany: 46.7\%; Greece: 10\%) (Makris 2012). Research is needed to investigate the effects of community-based exercise programs on walking behavior, physical activity, and costs, and their long-term effects on morbidity, cardiovascular risk factors, and mortality (eg, the ClaudicatioNet concept, which was launched in The Netherlands; 100\% SET access; Makris 2012). The concept aims to implement nationwide coverage of regional networks that provide quality care according to contemporary guidelines for patients with PAD (Fokkenrood 2012; Lauret 2012a).

\section{Acknowledgements}

We acknowledge the help and infrastructure rovided by the Department of Vascular Surgery of the Catharina Hospital, in particular, Nicole Verhofstad, PhD, Pieter Broos, MD, and Saskia Houterman, epidemiologist. We acknowledge the help provided by $\mathrm{Dr}$ Marlene Stewart, Managing Editor, and Dr Karen Welch, Trials Search Co-ordinator, of the Cochrane Peripheral Vascular Diseases Group, and their support in updating this review. 


\section{References}

References to studies included in this review

- Cheetham DR, Burgess L, Ellis M, Williams A, Greenhalgh RM, Davies AH. Does supervised exercise offer adjuvant benefit over exercise advice alone for the treatment of intermittent claudication? A randomised trial. European Journal of Vascular and Endovascular Surgery 2004;27(1): 17-23.

- Collins TC, Lunos S, Carlson T, Henderson K, Lightbourne M, Nelson B, et al.Effects of a home-based walking intervention on mobility and quality of life in people with diabetes and peripheral arterial disease: a randomized controlled trial. Diabetes Care 2011;34(10):2174-9.

- Gardner AW, Parker DE, Montgomery PS, Scott KJ, Blevins SM. Efficacy of quantified home-based exercise and supervised exercise in patients with intermittent claudication: a randomized controlled trial. Circulation 2011;123(5):491-8.

- Gardner AW, Montgomery PS, Parker DE. Optimal exercise program length for patients with claudication. Journal of Vascular Surgery 2012;55(5):1346-54.

- Hodges LD, Sandercock GR, Das SK, Brodie DA. Randomized controlled trial of supervised exercise to evaluate changes in cardiac function in patients with peripheral atherosclerotic disease. Clinical Physiology Functional Imaging 2008;28(1):32-7.

- Kakkos SK, Geroulakos G, Nicolaides AN. Improvement of the walking ability in intermittent claudication due to superficial femoral artery occlusion with supervised exercise and pneumatic foot and calf compression: a randomised controlled trial. European Journal of Vascular and Endovascular Surgery 2005;30(2):164-75.

- Nicolai SP, Hendriks EJ, Prins MH, Teijink JA. Optimizing supervised exercise therapy for patients with intermittent claudication. Journal of Vascular Surgery 2010;52(5): 1226-33.

- Nicolai SPA, Prins MH, Teijink JAW. Supervised exercise therapy is more effective than walking advice in patients with intermittent claudication; a randomized multicenter study. [Dutch]. Nederlands Tijdschrift voor Geneeskunde 2011;155(2):55-62.

- Nicolaï SP, Teijink JA, Prins MH, Exercise Therapy in Peripheral Arterial Disease Study Group. Multicenter randomized clinical trial of supervised exercise therapy with or without feedback versus walking advice for intermittent claudication. Journal of Vascular Surgery 2010;52(2): 348-55.

- Teijink JAW, Prins MH. (Cost) Effectiveness study of exercise therapy in patients with peripheral arterial disease. http://clinicaltrials.gov/ct/show/NCT00279994?order=1 2006.
- van Asselt AD, Nicolai SP, Joore MA, Prins MH, Teijink JA, Exercise Therapy in Peripheral Arterial Disease Study Group. Cost-effectiveness of exercise therapy in patients with intermittent claudication: supervised exercise therapy versus a 'go home and walk' advice. European Journal of Vascular and Endovascular Surgery 2011;41(1):97-103.

- Parr BM, Noakes TD, Derman EW. Peripheral arterial disease and intermittent claudication: efficacy of short-term upper body strength training, dynamic exercise training, and advice to exercise at home. South African Medical Journal 2009;99(11):800-4.

- $\quad *$ Patterson RB, Pinto B, Marcus B, Colucci A, Braun T, Roberts M. Value of a supervised exercise program for the therapy of arterial claudication. Journal of Vascular Surgery 1997;25(2):312-9.

- Pinto BM, Marcus BH, Patterson RB, Roberts M, Colucci A, Braun C. On-site versus home exercise programs: psychological benefits for individuals with arterial claudication. Journal of Aging and Physical Activity 1997;5: 311.

- Regensteiner JG, Meyer TJ, Krupski WC, Cranford LS, Hiatt WR. Hospitals vs homebased exercise rehabilitation for patients with peripheral arterial occlusive disease. Angio$\log$ 1997;48(4):291-300.

- Sanderson B, Askew C, Stewart I, Walker P, Gibbs H, Green S. Short-term effects of cycle and treadmill training on exercise tolerance in peripheral arterial disease. Journal of Vascular Surgery 2006;44(1):119-27.

- Savage P, Ricci MA, Lynn M, Gardner A, Knight S, Brochu M, et al.Effects of home versus supervised exercise for patients with intermittent claudication. Journal of Cardiopulmonary Rehabilitation 2001;21(3):152-7.

- Stewart AH, Smith FC, Baird RN, Lamont PM. Local versus systemic mechanisms underlying supervised exercise training for intermittent claudication. Vascular and Endovascular Surgery 2008;42(4):314-20.

- Bronas UG, Treat-Jacobson D, Leon AS. Comparison of the effect of upper body-ergometry aerobic training vs treadmill training on central cardiorespiratory improvement and walking distance in patients with claudication. Journal of Vascular Surgery 2011;53(6):1557-64.

- $\quad{ }^{\star}$ Treat-Jacobson D, Bronas UG, Leon AS. Efficacy of arm- ergometry versus treadmill exercise training to improve walking distance in patients with claudication. Vascular Medicine 2009;14(3):203-13. 


\section{References to studies excluded from this review}

- Arosio E, Cuzzolin L, De Marchi S, Minuz P, Degan M, Crivellente F, et al.Increased endogenous nitric oxide production induced by physical exercise in peripheral arterial occlusive disease patients. Life Sciences 1999;65(26): 2815-22.

- Arosio E, Minuz P, Prior M, Zuliani V, Gaino S, De Marchi S, et al.Vascular adhesion molecule-1 and markers of platelet function before and after a treatment with iloprost or a supervised physical exercise program in patients with peripheral arterial disease. Life Sciences 2001;69(4):421-33.

- Ciuffetti G, Paltriccia R, Lombardini R, Lupattelli G, Pasqualini L, Mannarino E. Treating peripheral arterial occlusive disease: pentoxifylline vs exercise. International Angiology 1994;13(1):33-9.

- Collins EG, Edwin Langbein W, Orebaugh C, Bammert C, Hanson K, Reda D, et al.PoleStriding exercise and vitamin $\mathrm{E}$ for management of peripheral vascular disease. Medicine and Science in Sports and Exercise 2003;35(3):384-93.

- Collins EG, Langbein WE, Orebaugh C, Bammert C, Hanson K, Reda D, et al.Cardiovascular training effect associated with polestriding exercise in patients with peripheral arterial disease. Journal of Cardiovascular Nursing 2005;20(3):177-85.

- Crowther RG, Spinks WL, Leicht AS, Sangla K, Quigley F, Golledge J. Effects of a longterm exercise program on lower limb mobility, physiological responses, walking performance, and physical activity levels in patients with peripheral arterial disease. Journal of Vascular Surgery 2008;47(2):303-9.

- Dahllö AG, Holm J, Scherstén T, Sivertsson R. Peripheral arterial insufficiency; effect of physical training on walking tolerance, calf blood flow, and blood flow resistance. Scandinavian Journal of Rehabilitation Medicine 1976;8(1): 19-26.

- Degischer S, Labs KH, Hochstrasser J, Aschwanden M, Tschoepl M, Jaeger KA. Physical training for intermittent claudication: a comparison of structured rehabilitation versus home-based training. Vascular Medicine 2002;7(2): 109-15.

- Fakhry F, Spronk S, de Ridder M, den Hoed PT, Hunink MG. Long-term effects of structured home-based exercise program on functional capacity and quality of life in patients with intermittent claudication. Archives of Physical Medicine Rehabilitation 2011;92(7):1066-73.

- Fowler B, Jamrozik K, Norman P, Allen Y, Wilkinson E. Improving maximum walking distance in early peripheral arterial disease: randomised controlled trial. Australian Journal of Physiotherapy 2002;48(4):269-75.
- Gardner AW, Katzel LI, Sorkin JD, Bradham DD, Hochberg MC, Flinn WR, et al.Exercise rehabilitation improves functional outcomes and peripheral circulation in patients with intermittent claudication: a randomized controlled trial. Journal of the American Geriatric Society 2001;49(6):755-62.

- Gardner AW, Katzel LI, Sorkin JD, Goldberg AP. Effects of long-term exercise rehabilitation on claudication distances in patients with peripheral arterial disease: a randomized controlled trial. Journal of Cardiopulmonary Rehabilitation 2002;22(3):192-8.

- Gardner AW, Montgomery PS, Flinn WR, Katzel LI. The effect of exercise intensity on the response to exercise rehabilitation in patients with intermittent claudication. Journal of Vascular Surgery 2005;42(4):702-9.

- Gelin J, Jivegard L, Taft C, Karlsson J, Sullivan M, Dahllöf A-G, et al.Treatment efficacy of intermittent claudication by surgical intervention, supervised physical exercise training compared to no treatment in unselected randomised patients I: one year results of functional and physiological improvements. European Journal of Vascular and Endovascular Surgery 2001;22(2):107-13.

- Gibellini R, Fanello M, Bardile AF, Salerno M, Aloi T, Gibellini R, et al.Exercise training in intermittent claudication. International Angiology 2000;19(1):8-13.

- Greenhalgh RM, Belch JJ, Brown LC, Gaines PA, Gao L, Reise JA, et al.Mimic Trial Participants. The adjuvant benefit of angioplasty in patients with mild to moderate,intermittent claudication (MIMIC) managed by supervised exercise, smoking cessation advice and best medical therapy: results from two randomised trials for stenotic femoropopliteal and aortoiliac arterial disease. European Journal Vascular and Endovascular Surgery 2008;36(6): $680-8$.

- Grizzo Cucato G, de Moraes Forjaz CL, Kanegusuku H, da Rocha Chehuen M, Riani Costa LA, Wolosker N, et al.Effects of walking and strength training on resting and exercise cardiovascular responses in patients with intermittent claudication. Vasa 2011;40(5):390-7.

- Hiatt WR, Regensteiner JG, Hargarten ME, Wolfel EE, Brass EP. Benefit of exercise conditioning for patients with peripheral arterial disease. Circulation 1990;81(2):602-9.

- Hiatt WR, Wolfel EE, Meier RH, Regensteiner JG. Superiority of treadmill walking exercise versus strength training for patients with peripheral arterial disease. Implications for the mechanism of the training response. Circulation 1994;90(4):1866-74.

- Hobbs SD, Marshall T, Fegan C, Adam DJ, Bradbury AW. The effect of supervised exercise and cilostazol on coagulation and fibrinolysis in intermittent claudication: a randomized controlled trial. Journal of Vascular Surgery 2007;45(1):65-70. 
- Jansen T, Weiss T, Amendt K, Hsu E, Hubsch-Muller C, Diehm C. Effect of a 2-year ambulatory vascular sports program on walking distance in claudication patients--a controlled study [German]. Vasa Supplementum 1991;33: 175.

- Krause D. Results of physical therapy of peripheral arterial circulatory disorders(III) [Ergebnisse bei der physikalischen therapie peripherer arterieller durchblutungsstorungen (III)]. Munchener Medizinische Wochenschrift 1974;116(8): 385-8.

- Kruidenier LM, Nicolaï SP, Rouwet EV, Peters RJ, Prins MH, Teijink JA. Additional supervised exercise therapy after a percutaneous vascular intervention for peripheral arterial disease: a randomized clinical trial. Journal of Vascular and Interventional Radiology 2011;22(7):961-8.

- Langbein WE, Collins EG, Orebaugh C, Maloney C, Williams KJ, Littooy FN, et al.Increasing exercise tolerance of persons limited by claudication pain using polestriding. Journal of Vascular Surgery 2002;35(5):887-93.

- Larsen OA, Lassen NA. Effect of daily muscular exercise in patients with intermittent claudication. Lancet 1966;2 (7473):1093-6.

- Leicht AS, Crowther RG, Golledge J. Influence of peripheral arterial disease and supervised walking on heart rate variability. Journal of Vascular Surgery 2011;54(5):1352-9.

- Leon AS. Does long-term aerobic exercise slow progression of atherosclerosis?. Clinical Journal of Sport Medicine 2005; 15(4):285-6.

- Lepantalo M, Kalajo K, Lilius G. Does drug treatment have a placebo effect on programmed training in intermittent claudication? A randomized clinical trial. Clinical Rehabilitation 1991;5(1):65-9.

- Manfredini F, Malagoni AM, Mascoli F, Mandini S, Taddia MC, Basaglia N, et al.Training rather than walking: the test in-train out program for home-based rehabilitation in peripheral arteriopathy. Circulation Journal 2008;72(6): 946-52.

- McDermott MM, Tiukinhoy S, Greenland P, Liu K, Pearce WH, Guralnik JM, et al.A pilot exercise intervention to improve lower extremity functioning in peripheral arterial disease unaccompanied by intermittent claudication. Journal of Cardiopulmonary Rehabilitation 2004;24(3): 187-96.

- McDermott MM, Ades P, Guralnik JM, Dyer A, Ferrucci L, Liu K, et al.Treadmill exercise and resistance training in patients with peripheral arterial disease with and without intermittent claudication: a randomized controlled trial. JAMA 2009;301(2):165-74.

- Menêses AL, de Lima GH, Forjaz CL, Lima AH, Silva GQ, Cucato GG, et al.Impact of a supervised strength training or walking training over a subsequent unsupervised the- rapy period on walking capacity in patients with claudication. Journal of Vascular Nursing 2011;29(2):81-6.

- Mika P, Spodaryk K, Cencora A. Effects of treadmill training on walking distance and lower limb blood flow in patients with intermittent claudication. Medical Rehabilitation 2005;9(1):3-9.

- Mika P, Spodaryk K, Cencora A, Mika A. Red blood cell deformability in patients with claudication after pain-free treadmill training. Clinical Journal of Sport Medicine 2006 Jul;16(4):335-40.

- Mika P, Wilk B, Mika A, Marchewka A, Nizankowski R. The effect of pain-free treadmill training on fibrinogen, haematocrit, and lipid profile in patients with claudication. European Journal of Cardiovascular Prevention and Rehabilitation 2011;18(5):754-60.

- Murphy TP, Cutlip DE, Regensteiner JG, Mohler ER, Cohen DJ, Reynolds MR, et al.CLEVER Study Investigators. Supervised exercise versus primary stenting for claudication resulting from aortoiliac peripheral artery disease. Six-month outcomes from the claudication: exercise versus endoluminal revascularization (CLEVER) study. Circulation 2012;125(1):130-9.

- Nawaz S, Walker RD, Wilkinson CH, Saxton JM, Pockley AG, Wood RF. The inflammatory response to upper and lower limb exercise and the effects of exercise training in patients with claudication. Journal of Vascular Surgery 2001; 33(2):392-9.

- Nielsen SL, Gyntelberg F, Larsen B, Lassen NA. Hospital versus home training, a clinica trial. Aktuelle Probleme in der Angiologie 1975;30:121-6

- Nielsen SL, Larsen B, Prahl M, Jensen CT, Jensen BE, Wenkens V. Hospital training compared with home training in patients with intermittent claudication. Ugeskrift for laeger 1977;139(46):2733-6.

- Ritti-Dias RM, Wolosker N, de Moraes Forjaz CL, Carvalho CR, Cucato GG, Leão PP, et al.Strength training increases walking tolerance in intermittent claudication patients: randomized trial. Journal of Vascular Surgery 2010;51(1): 89-95.

- Saxton JM, Zwierska I, Blagojevic M, Choksy SA, Nawaz S, Pockley AG. Upper- versus lower-limb aerobic exercise training on health-related quality of life in patients with symptomatic peripheral arterial disease. Journal of Vascular Surgery 2011;53(5):1265-73.

- Schlager O, Giurgea A, Schuhfried O, Seidinger D, Hammer A, Gröger M, et al.Exercise training increases endothelial progenitor cells and decreases asymmetric dimethylarginine in peripheral arterial disease: a randomized controlled trial. Atherosclerosis 2011;217(1):240-8. 
- Schlager O, Hammer A, Giurgea A, Schuhfried O, Fialka- Moser V, Gschwandtner M, et al.Impact of exercise training on inflammation and platelet activation in patients with intermittent claudication. Swiss Medical Weekly 2012;14: 142.

- Spronk S, Bosch JL, den Hoed PT, Veen HF, Pattynama PM, Hunink MG. Intermittent claudication: clinical effectiveness of endovascular revascularization versus supervised hospital-based exercise training--randomized controlled trial. Radiology 2009;250(2):586-95.

- Taft C, Karlsson J, Gelin J, Jivegard L, Sandström R, Arfvidsson B, et al.Treatment efficacy of intermittent claudication by invasive therapy, supervised physical exercise training compared to no treatment in unselected randomised patients. II. One year results of health-related quality of life. European Journal of Vascular and Endovascular Surgery 2001;22(2):114-23.

- Taft C, Sullivan M, Lundholm K, Karlsson J, Gelin J, Jivegard L. Predictors of treatment outcome in intermittent claudication. European Journal of Vascular and Endovascular Surgery 2004;27(1):24-32.

- Tebbutt N, Robinson L, Todhunter J, Jonker L. A plantar flexion device exercise programme for patients with peripheral arterial disease: a randomised prospective feasibility study. Physiotherapy 2011;97(3):244-9.

- Tew G, Nawaz S, Zwierska I, Saxton JM. Limb-specific and cross-transfer effects of armcrank exercise training in patients with symptomatic peripheral arterial disease. Clinical Science 2009;117(12):405-13.

- Tisi PV, Hulse M, Chulakadabba A, Gosling P, Shearman CP. Exercise training for intermittent claudication: does it adversely affect biochemical markers of the exercise-induced inflammatory response?. European Journal of Vascular and Endovascular Surgery 1997;14(5):344-50.

- Tsai JC, Chan P, Wang CH, Jeng C, Hsieh MH, Kao PF, et al.The effects of exercise training on walking function and perception of health status in elderly patients with peripheral arterial occlusive disease. Journal of Internal Medicine 2002;252(5):448-55.

- Walker RD, Nawaz S, Wilkinson CH, Saxton JM, Pockley AG, Wood RF. Influence of upper- and lower-limb exercise training on cardiovascular function and walking distances in patients with intermittent claudication. Journal of Vascular Surgery 2000;31(4):662-9.

- Wood RE, Sanderson BE, Askew CD, Walker PJ, Green S, Stewart IB. Effect of training on the response of plasma vascular endothelial growth factor to exercise in patients with peripheral arterial disease. Clinical Science 2006;111 (6):401-9.

- Zwierska I, Walker RD, Choksy SA, Male JS, Pockley AG, Saxton JM. Upper- vs lower-limb aerobic exercise rehabilitation in patients with symptomatic peripheral arterial disease: a randomized controlled trial. Journal of Vascular Surgery 2005;42(6):1122-30.

\section{References to ongoing studies}

- Anon. SUPERvised exercise therapy or immediate PTA for intermittent claudication in patients with an iliac artery obstruction: a randomized controlled trial. SUPER study, 2011. http://clinicaltrials.gov/show/NCT01385774.

- $\quad{ }^{*}$ Frans FA, Bipat S, Reekers JA, Legemate DA, Koelemay MJW, on behalf of the SUPER Study Collaborators. SUPERvised exercise therapy or immediate PTA for intermitten claudication in patients with an iliac artery obstruction - A multicentre randomised controlled trial; Super study design and rationale. European Journal of Vascular and Endovascular Surgery 2012;43(4):466-71.

\section{Additional references}

- Altman DG. Clinical trials. Practical statistics for medical research. London: Chapman \& Hall, 1991:440-76.

- Aquino R, Johnnides C, Makaroun M, Whittle JC, Muluk VS, Kelley ME, et al.Natural history of claudication: long- term serial follow-up study of 1244 claudicants. Journal of Vascular Surgery 2001;34(6):962-70

- Bartelink ML, Stoffers HE, Biesheuvel CJ, Hoes AW. Walking exercise in patients with intermittent claudication. Experience in routine clinical practice. British Journal of General Practice 2004;54(500):196-200.

- Beckitt TA, Day J, Morgan M, Lamont PM. Calf muscle oxygen saturation and the effects of supervised exercise training for intermittent claudication. Journal of Vascular Surgery 2012;56(2):470-5

- Dormandy J, Heeck L, Vig S. The natural risk of claudication: risk of life and limb. Seminars in Vascular Surgery 1999;12(2):123-37.

- $\quad$ Erb W. About intermittent walking and nerve disturbances due to vascular disease [Über das "intermitterende Hinken" und adere nervöse Storungen in Folge von Gefässerkran kungen]. Deutsch Z Nervenheilk 1898;13: 1-76.

- Fakhry F, van de Luijtgaarden KM, Bax L, den Hoed PT, Hunink MG, Rouwet EV, et al.Supervised walking therapy in patients with intermittent claudication. Journal of Vascular Surgery 2012;56(4):1132-42.

- Fokkenrood HJ, Lauret GJ, Scheltinga MR, Spreeuwenberg C, de Bie RA, Teijink JA. Multidisciplinary treatment for peripheral arterial occlusive disease and the role of eHealth and mHealth. Journal of Multidisciplinary Healthcare 2012; 5:257-63. 
- Fontaine R, Kim M, Kieny R. Surgical treatment of peripheral circulation disorders [Die chirurgische Behandlung der peripheren Durchblutungsstorungen]. Helvetica Chirurgica Acta 1954;21(5/6):499-533.

- Gardner AW, Skinner JS, Cantwell BW, Smith LK. Progressive vs single-stage treadmill tests for evaluation of claudication. Medicine and Science in Sports and Exercise 1991;23(4):402-8.

- Gustafsson T, Kraus WE. Exercise-induced angiogenesis- related growth and transcription factors in skeletal muscle, and their modification in muscle pathology. Frontiers in Bioscience 2001;1(6):D75-89.

- Hamburg NM, Balady GJ. Exercise rehabilitation in peripheral artery disease: functional impact and mechanisms of benefits. Circulation 2011;123(1):87-97.

- Higgins JPT, Green S (editors). Cochrane Handbook for Systematic Reviews of Interventions Version 5.1.0 [updated March 2011]. The Cochrane Collaboration, 2011. www.cochrane-handbook.org.

- Hirsch AT, Haskal ZJ, Hertzer NR, Bakal CW, Creager MA, Halperin JL, et al.ACC/AHA 2005 Practice Guidelines for the management of patients with peripheral arterial disease (lower extremity, renal, mesenteric, and abdominal aortic): a collaborative report from the American Association for Vascular Surgery/Society for Vascular Surgery, Society for Cardiovascular Angiography and Interventions, Society for Vascular Medicine and Biology, Society of Interventional Radiology, and the ACC/AHA Task Force on Practice Guidelines (Writing committee to develop guidelines for the management of patients with peripheral arterial disease): endorsed by the American Association of Cardiovascular and Pulmonary Rehabilitation; National Heart, Lung, and Blood Institute; Society for Vascular Nursing; TransAtlantic Inter-Society Consensus; and Vascular Disease Foundation. Circulation 2006;113(11):e463-654.

- Hooi JD, Stoffers HE, Kester AD, Knottnerus JA. Peripheral arterial occlusive disease: prognostic value of signs, symptoms, and the ankle-brachial pressure index. Medical Decision Making 2002;22(2):99-107.

- Izquierdo-Porrera AM, Gardner AW, Powell CC, Katzel LI. Effects of exercise rehabilitation on cardiovascular risk factors in older patients with peripheral arterial occlusive disease. Journal of Vascular Surgery 2000;31(4):670-7.

- Kruidenier LM, Nicolai SP, Hendriks EJ, Bollen EC, Prins MH, Teijink JA. Supervised exercise therapy for intermittent claudication in daily practice. Journal of Vascular Surgery 2009;49(2):363-70
- Lauret GJ, Gijsbers HJH, Hendriks EJM, Bartelink ML, de Bie RA, Teijink JAW. The ClaudicatioNet concept: design of a national integrated care network providing active and healthy aging for patients with intermittent claudication. Vascular Health and Risk Management 2012;8:495-503.

- Lauret GJ, Fakhry F, Fokkenrood HJP, Hunink MG, Teijink JAW, Spronk S. Modes of exercise training for intermittent claudication. Cochrane Database of Systematic Reviews 2012, Issue 2. [DOI: 10.1002/14651858.CD009638]

- Leng GC, Fowler B, Ernst E. Exercise for intermittent claudication. Cochrane Database of Systematic Reviews 2000, Issue 2. [DOI: 10.1002/14651858.CD000990]

- Makris GC, Lattimer CR, Lavida A, Geroulakos G. Availability of supervised exercise programs and the role of structured home-based exercise in peripheral arterial disease. European Journal of Vascular and Endovascular Surgery 2012; 44(6):569-75.

- Norgren L, Hiatt WR, Dormandy JA, Nehler MR, Harris KA, Fowkes FG, TASC II Working Group. Inter-Society Consensus for the Management of Peripheral Arterial Disease (TASC II). Journal of Vascular Surgery 2007;45 (Suppl S):5-67.

- The Nordic Cochrane Centre, The Cochrane Collaboration. Review Manager (RevMan) 5.1. Copenhagen: The Nordic Cochrane Centre, The Cochrane Collaboration, 2011

- Rutherford RB, Baker JD, Ernst C, Johnston KW, Porter JM, Ahn S, et al.Recommended standards for reports dealing with lower extremity ischemia:revised version Journal of Vascular Surgery 1997;26(3):517-38.

- Selvin E, Erlinger TP. Prevalence of and risk factors for peripheral arterial disease in the United States: results from the National Health and Nutrition Examination Survey, 19992000. Circulation 2004;110(6):738-43.

- Shalhoub J, Hamish M, Davies AH. Supervised exercise for intermittent claudication - an under-utilised tool. Annals of the Royal College of Surgeons of England 2009;91(6):473-6.

- Smith SC Jr, Benjamin EJ, Bonow RO, Braun LT, Creager MA, Franklin BA, et al.Endorsed by the World Heart Federation and the Preventive Cardiovascular Nurses Association. AHA/ACCF Secondary prevention and risk reduction therapy for patients with coronary and other atherosclerotic vascular disease: 2011 update: a guideline from the American Heart Association and American College of Cardiology Foundation. Circulation 2011;124(22): 2458-73.

- Stewart KJ, Hiatt WR, Regensteiner JG, Hirsch AT. Exercise training for claudication. New England Journal of Medicine 2002;347(24):1941-51.

- Wannamathee SG, Shaper AG. Physical activity in the prevention of cardiovascular disease: an epidemiological perspective. Sports Medicine 2001;31(2):101-14. 
- Watson L, Ellis B, Leng GC. Exercise for intermittent claudication. Cochrane Database of Systematic Reviews 2008, Issue 4. [DOI: 10.1002/14651858.CD000990.pub2]

- Wind J, Koelemay MJ. Exercise therapy and the additional effect of supervision on exercise therapy in patients with intermittent claudication. Systematic review of randomised controlled trials. European Journal of Vascular and Endovascular Surgery 2007;34(1):1-9.

References to other published versions of this review

- Bendermacher BLW, Willigendael EM, Teijink JAW, Prins MH. Supervised exercise therapy versus non-supervised exercise therapy for intermittent claudication. (Review). $\mathrm{Co}$ chrane Database of Systematic Reviews 2006, Issue 2. [DOI: 10.1002/14651858.CD005263. pub2]

*Indicates the major publication for the study

\section{Figures}

For additional figures, analyses and tables we would like to refer to the online document 


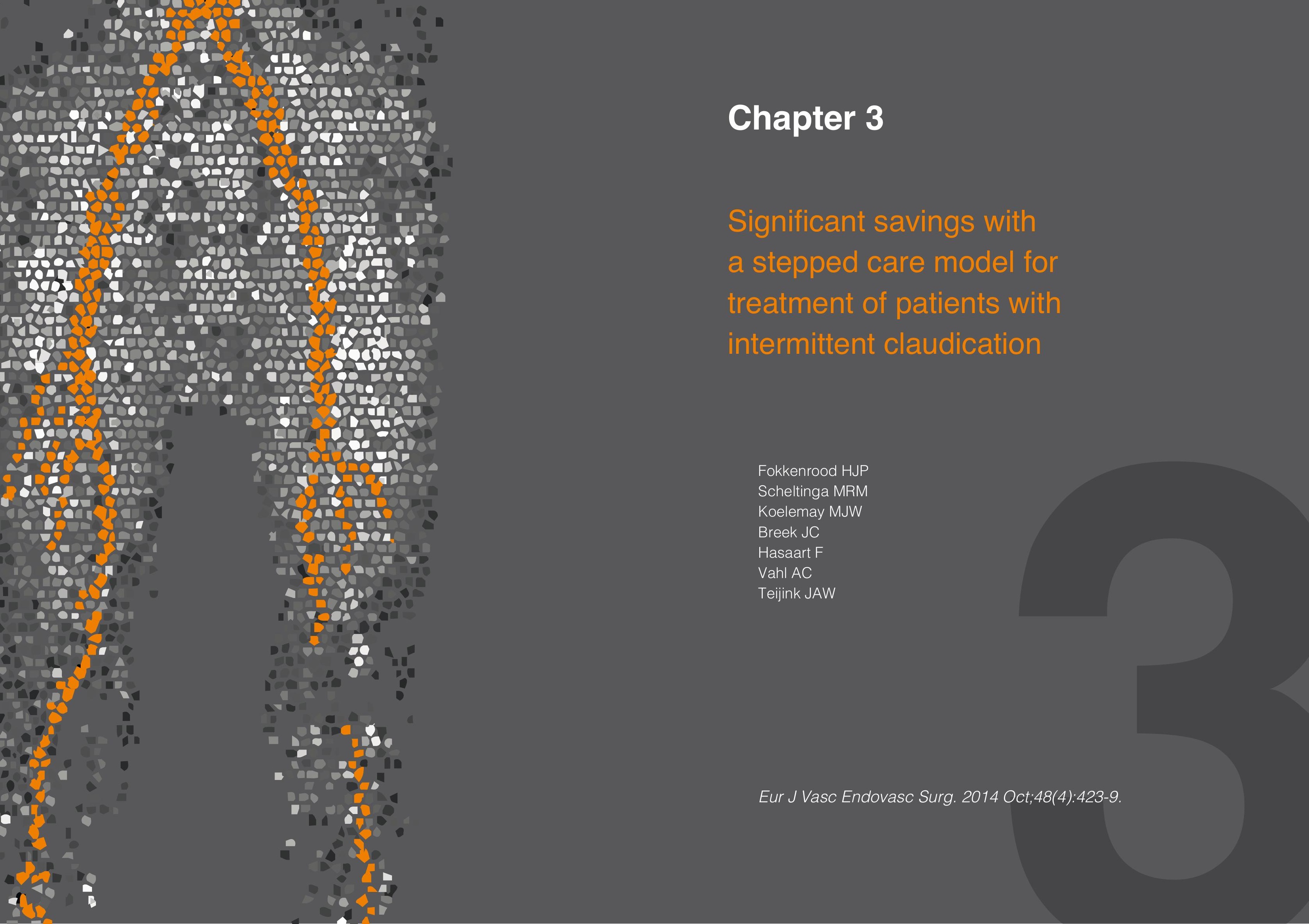




\section{Abstract}

International guidelines recommend supervised exercise therapy (SET) as primary treatment for intermittent claudication (IC). The aim of this study was to calculate treatment costs in patients with IC and to estimate nationwide annual savings if a stepped care model (SCM, primary SET treatment followed by revascularization in case of SET failure) would have been followed.

Invoice data of all patients with IC in 2009 were obtained from a Dutch health insurance company (3.4 million members). Patients were divided into three groups based on initial treatment as followed after diagnosis ( $t 0)$. The SET group received SET initiated at any time between 12 months before and up to 3 months after t0. The intervention group (INT) underwent endovascular or open revascularization between $t 0$ and $t+3$ months. The third group (REST) received neither SET nor an intervention. All peripheral arterial occlusive disease (PAOD) related invoices were recorded during 2 years and average costs per patient were calculated. Savings following use of a SCM were calculated for 3 scenarios.

Data on 4954 patients were analysed. Initial treatment was SET ( $\mathrm{n}=701,14.1 \%)$, INT $(n=1363,27.5 \%)$ or REST ( $n=2890,58.3 \%)$. Within two years from $\mathrm{t} 0$, invasive revascularization in the SET group was performed in 45 patients (6.4\%). Additional interventions (primary at other location and/or re-interventions) were performed in 480 INT patients (35.2\%). Some 431 REST patients received additional SET ( $\mathrm{n}=299$, $10.3 \%)$ or an intervention ( $\mathrm{n}=132,4.5 \%)$. Mean total IC related costs per patient were $€ 2191$, $€ 9851$ and $€ 824$ for SET, INT and REST, respectively. Based on a hypothetical worst, moderate, and best case scenario, some $3.8,20.6$ or 33.0 million euros would have been saved per annum if SCM was implemented in the Dutch health care system.

Implementation of a SCM treatment for patients with IC may lead to significant savings of health care resources.

\section{Introduction}

Recently governments, nongovernmental organizations, and the private sector were called to assess the social and economic consequences of peripheral arterial disease (PAD) and to explore the best strategies for optimum treatment and prevention of this disease ${ }^{(1)}$. Although treatment strategies for PAD are well described in international guidelines ${ }^{(2-4)}$ and advocate a multimodal approach, including medication, lifestyle changes and symptomatic treatment, mentioning supervised exercise therapy (SET) as the primary treat ment option ${ }^{(3)}$, the actual availability of these SET programs worldwide is limited (5-9). In contrast, The Netherlands have a high availability of SET programs (10). However, a proven effective SET program (performed by physiotherapists trained at improving cardiorespiratory health status as well as life style factors and medication compliance) is in many cases not fully reimbursed.

This reimbursement issue originates from a contradictory policy in the Dutch healthcare system. In the Netherlands, healthcare insurance companies have an obligation to accept everyone for a basic healthcare insurance. The Dutch government determines coverage of the standard insurance. In case of patients suffering from intermittent claudication (IC) the government decided not to cover the first 20 treatment sessions of a SET program, which have to be paid by the patient (either directly or through additional insurance). From the $21^{\text {st }}$ session onwards all additional treatment sessions given in one year are covered by the basic health care insurance. Medication (prescribed by a physician) and invasive vascular interventions are both included in the standard package and fully reimbursed. As a consequence SET is largely underutilized. Patients may receive a proven insufficient and less cost-effective "go home and walk" advice ${ }^{(11-14)}$ or a vascular intervention as an alternative first-line treatment strategy ${ }^{(5)}$, which are contradictory to contemporary guidelines.

The advocated treatment strategy in above-mentioned guidelines, could be incorporated into a so-called "stepped care" model $(\mathrm{SCM})^{(5,15,16)}$. This theoretical approach strives to initially refer all IC patients to a SET program and restrict revascularization for only those, who are not responding to SET. Several cost-effectiveness analyses have been performed supporting such a SET first treatment strategy $y^{(13,16-20)}$. However no study was performed to investigate the overall economic consequences of a SCM implementation

saving of health care resources. 
nationwide. We decided to perform a cost-analysis in case of SCM implementation in the Dutch healthcare system. Costs of IC treatment were calculated and compared to estimated costs associated with three hypothetical scenarios of nationwide SCM implementation

\section{Methods}

Inclusion and exclusion

The 2009 database of CZ, a large Dutch healthcare insurance company ( $n=3.419 .604$ insured persons, approximately $21 \%$ of the Dutch population) was retrospectively analysed. Insured patients that had received an invoice related to the diagnosis "PAD Fontaine 2" corresponding to IC complaints as diagnosed by a vascular surgeon, were eligible for inclusion. Only patients that had been insured for at least two consecutive years at CZ were eligible, excluding crossover patients from other insurance companies (possibly harbouring an unknown 2-year history of PAD). In order to restrict the study to newly diagnosed IC patients, all patients that underwent vascular interventions in 2007 or 2008

Figure 1 Flow-chart of study population and classification of subgroups

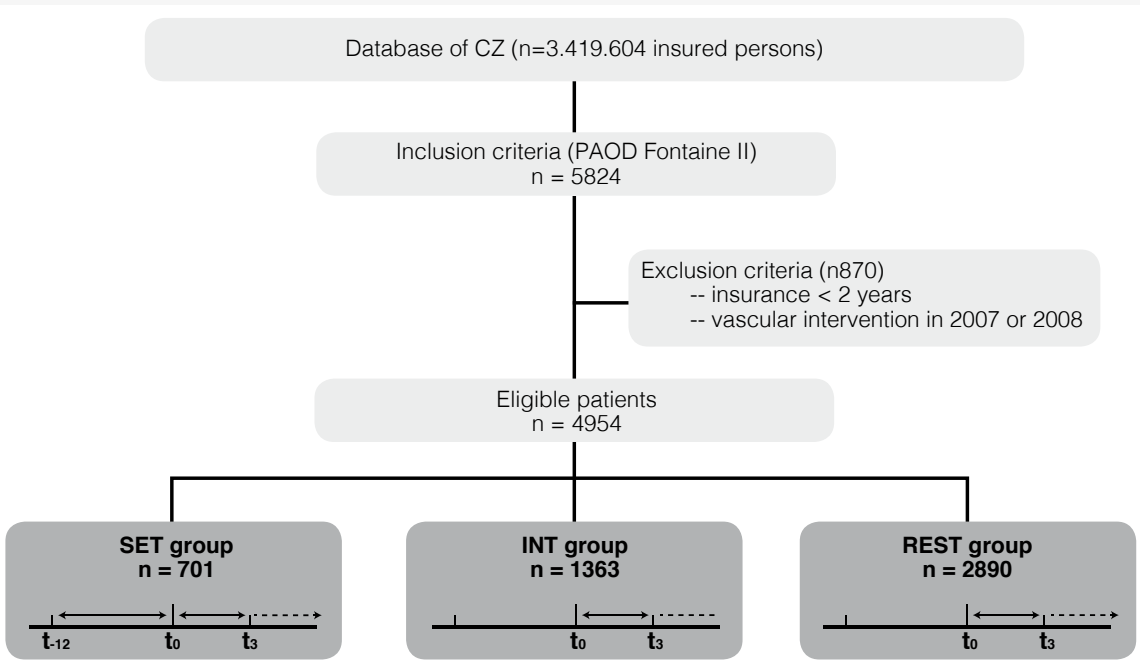

Notes: PAOD: peripheral arterial occlusive disease

straight line: primary treatment; dashed line: secondary treatment were also excluded (figure 1). Data on comorbidity (diabetes mellitus, COPD, hypercholesterolemia and heart failure) were collected on the basis of prescribed medication.

\section{Definition of IC subgroups}

Patients meeting inclusion criteria were subdivided into three groups based on their primary treatment as initiated by a vascular surgeon within three months after diagnosis $\left(\mathrm{t}_{0}<\right.$ $\mathrm{t}_{3 \text { months }}$ ) (figure 1).

- SET group: community-based SET started in the period between 12 months prior to diagnosis up to 3 months after the diagnosis of IC by a vascular surgeon (graph 1). SET prior to diagnosis was possible in case of referral by a patient's general practitioner (GP) who already initiated SET.

- INT group: Any form of revascularization received within 3 months after the diagnosis of IC by a vascular surgeon.

- $\quad$ REST group: Neither SET nor INT group inclusion criteria were met (graph 1). It was assumed that these patients received a "go home and walk" advice or had no IC at all (this contradictory 'no IC in an IC population' phenomenon is explained later on in the sensitivity-analysis paragraph).

Graph 1 Referral of SET in the SET and REST group 12 months prior and after diagnosis $\left(\mathrm{t}_{0}\right)$

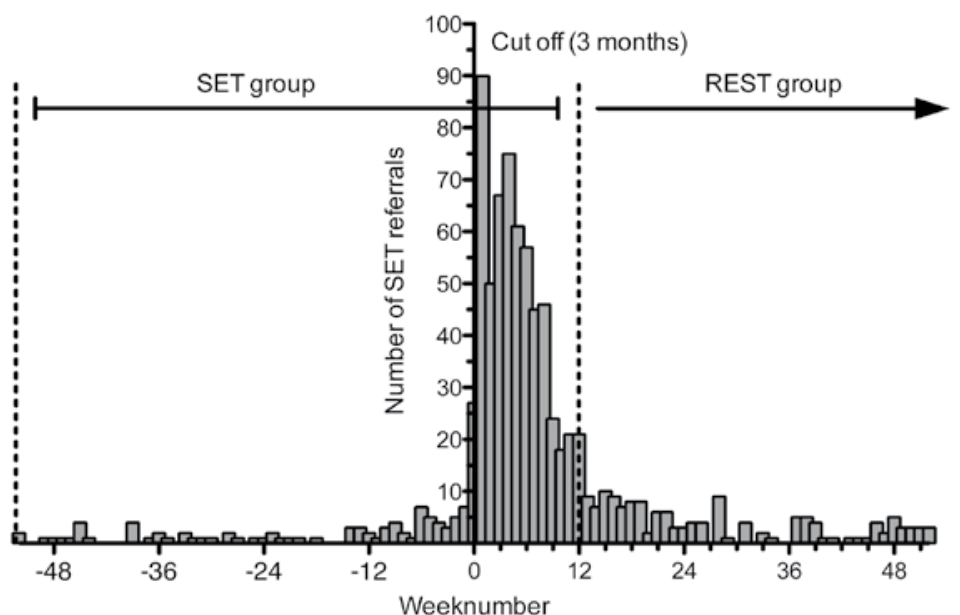


Secondary treatment was defined as a second intervention (primary at other location and/or re-interventions or SET) that was performed following primary treatment. This population included patients with either failure of primary treatment (re-intervention), treatment of the contralateral leg as well as treatment delay (treatment $>t_{3 \text { months }}$ ). Differentiation between these groups was not possible due to the nature of the database. It was assumed that all patients received best medical treatment (BMT) prescribed at the discretion of the physician.

\section{Costs of PAD treatment}

A Fontaine classification by a vascular surgeon is always required for billing purposes in the Dutch healthcare system. All claudication related invoices (by physician and physiotherapists) for primary as well as secondary treatment within two years of follow-up after $t_{0}$ were screened. The majority of interventions in 2009 were performed by radiologists, based on a vascular surgeons indication. Total costs generated in the SET, INT and REST groups were calculated by adding all intervention costs for the group the patient was initially allocated to. Discrimination between a secondary ipsilateral intervention and a primary contralateral intervention was not possible due to the nature of the database, aimed at costs registration. Mean total costs (MTC) per patient per group were calculated. Expenditures for medication use were not incorporated into the calculations.

Sensitivity-analysis of the REST group

Patients in the REST group were supposed to have received a walking advice. When a patient is referred to a vascular surgeon for IC by a GP, a "PAD Fontaine 2" (synonymous to IC) invoice is registered. However, if IC is subsequently ruled out, the invoice is often not corrected into the proper invoice "ruling out IC". In a prospective analysis of 100 consecutive patients we found that $30 \%$ of the GP referrals with presumed IC in fact received an alternative, non-IC diagnosis ${ }^{(21)}$. This phenomenon is not financially driven since reimbursement of a "rule out" invoice appears $€ 1.43$ higher. This incorrect registration may have contaminated the composition of the REST group and it was decided to exclude the REST group from the SCM cost-analysis. However, a cost-analysis of the REST group was performed in an additional sensitivity analysis (SA), assuming 30\% non-IC patients.

Cost-analysis of a nationwide adherence to a SCM The costs of a SCM were estimated for patients in the SET and INT group. Successful treatment guided by a SCM depends on two critical success factors:
1. the surgeons' compliance (willingness) to refer each IC patient to SET. Despite the fact that, according to contemporary international guidelines, all patients with IC initially should be referred for $\mathrm{SET}^{(2-4)}$, this ratio was hypothetically set to $80 \%$ (best), $50 \%$ (moderate) and $30 \%$ (worst) based on reimbursement issues, appreciation of SET by vascular surgeons and preference (although evidence to do so is lacking) for a revascularization in certain cases.

2. the patient's motivation to participate in a SET program, which largely depends on reimbursement issues (level of compensation by the insurance company) as well as a thorough understanding of the benefits of a SET program in comparison to an invasive intervention. The latter is also strongly associated with the surgeon's knowledge regarding SET and the willingness to refer. To allow for a variation in patients' willingness, this ratio was arbitrarily set at $80 \%$ in case of full reimbursement for all IC patients and optimal provision of information. On the other end, $25 \%$ was chosen for the current levels of reimbursement and information provision. These ratios were also suggested by the results of a questionnaire completed by a cohort of Dutch vascular surgeons ${ }^{(9)}$.

Combining doctor and patient factors in a comparative model resulted in six hypothetical scenarios (80\%-80\%; 80\%-25\%; 50\%-80\%; 50\%-25\%; 30\%-80\% and 30\%-25\%). As both factors are interrelated (physicians will limit SET referrals if patients drop out due to reimbursement issues; conversely, physicians may not refer to SET due to presumed preference for an intervention), only the three most likely scenarios were considered: best (80\%-80\%), moderate (50\%-80\%) and worst case (30\%-25\%). In addition, extrapolation for the Dutch population was performed by multiplying total savings on the total group by a factor 4.94 ( $21 \%$ of the Dutch population is insured by CZ).

Data analysis

The insurance database was analyzed with SAS (SAS Institute Inc, New York, USA). Differences between categorical variables were analyzed with a chi-square test. Statistical analyses were performed using SPSS 20 software (SPSS Inc, Chicago, USA). A two-sided $\mathrm{p}<.05$ was considered statistically significant. Calculations of costs were calculated with Excel 2011 (Microsoft Office, Redmond, USA). Graphs were created with Graphpad Prism 5 (GraphPad Software Inc, La Jolla, USA). 


\section{Results}

Adherence to a SCM

A total of 5824 patients with "PAD Fontaine 2" (IC) were identified of which 871 patients were excluded for reasons listed in figure 1, leaving 4954 IC patients for analysis. Fourteen percent received SET, whereas $28 \%$ was primarily treated with an invasive intervention (INT). The remaining $58 \%(\mathrm{n}=2890)$ did not receive any of these two treatment regimens within three months after diagnosis (REST). Patient characteristics of the three groups are shown in table 1. Significant differences between groups were found with respect to age, gender and congestive heart failure. Patients in the INT group were younger, more often male and had less often congestive heart failure.

Primary and secondary treatments are depicted in table 2 and 3. A total of 45 SET patients $(6.4 \%)$ were secondarily treated with an endovascular $(n=43)$ or open surgical $(\mathrm{n}=2)$ procedure (table 2). A total of 1055 endovascular (aortoiliac lesions: 696; femoro-popliteal lesions: 340 ) and 308 open surgical procedures were initially performed in 1363 INT subjects (table 2). In 480 of these patients (35.2\%), an additional revascularization procedure (endovascular: $n=464$; open: $n=16$ ) was performed within 2 years. In the REST group, 299 patients (10.3\%) were additionally treated with SET and 132 patients (144 interventions, 4.6\%) with an endovascular revascularization.

\section{Costs of IC treatment}

A wide range of costs was found regarding the physician based invoices. Bills ranged from a minimum of $€ 99$ and $€ 2,515$ to a maximum of $€ 14,428$ and $€ 50,173$ for the SET and INT group, respectively. Total costs ranged from a single visit at the patient outdoor clinic (€99) to a bilateral open surgical revascularization. Mean costs of SET declarations ranged from $€ 28$ to $€ 7,187$ in the SET group to a maximum of $€ 12,886$ in the REST group as related to the number of SET sessions (1 to 470 sessions; table 3). The MTC per patient in the SET group $(€ 2,191)$ was almost five times lower compared a patient in the INT group $(€ 9,851$; table 4$)$

Cost-analysis of a hypothetical nationwide adherence to a SCM The effects on cost-savings of a SCM with and without sensitivity analysis (SA) are shown in table 5. In the 2009 situation ( $14 \%$ SCM), the costs were 17.3 million euros. In the hypothetical best-case scenario ( $80 \%-80 \%), 1573$ of the 2064 eligible patients would receive
SET and 491 a vascular intervention as initial treatment. Nationwide implementation of such an $80 \%-80 \%$ scenario SCM would result in a 33.0 million euros annual savings for the Dutch population (table 5). Implementation of the worst-case scenario (30\%-25\%) would still reduce the yearly costs of IC treatment with 3.9 million euros (table 5). In the sensitivity-analysis (SA), 2023 of 2890 patients remained in the REST group (30\% nonPAD exclusion) leaving 4087 eligible IC patients for analysis. In the best-case scenario, 2868 of these patients would receive SET, 491 a vascular intervention and 728 a walking advice. Savings would still be reduced from 33.0 to 24.2 million with an $80 \%-80 \%$ SCM implementation after SA (table 5).

Table 1 Patient characteristics

\begin{tabular}{l|cccc} 
& \multicolumn{4}{|c}{ Group } \\
\cline { 2 - 5 } & SET & INT & REST & $\mathbf{p}$ \\
\hline Number of patients $(\mathrm{n}-\%)$ & $701(14 \%)$ & $1363(27 \%)$ & $2890(58 \%)$ \\
Age (years) & 69 & 65 & 68 & $\mathrm{p}<0.001$ \\
Gender (\% male) & $57.3 \%$ & $64.8 \%$ & $58.9 \%$ & $\mathrm{p}<0.001$ \\
Diabetes II (\%) & $6.9 \%$ & $7.0 \%$ & $8.2 \%$ & $\mathrm{p}=0.24$ \\
CARA (\%) & $8.1 \%$ & $10.7 \%$ & $10.1 \%$ & $\mathrm{p}=0.17$ \\
Hypercholesterolemia (\%) & $30.5 \%$ & $29.3 \%$ & $27.4 \%$ & $\mathrm{p}=0.16$ \\
Congestive heart failure (\%) & $9.6 \%$ & $8.7 \%$ & $12.0 \%$ & $\mathrm{p}<0.01$
\end{tabular}


Table 2 Revascularizations per group per anatomical section

\begin{tabular}{l|l|c|ccc}
\multicolumn{2}{l|}{} & $\begin{array}{l}\text { Primary } \\
\text { treatment }\end{array}$ & \multicolumn{3}{|c}{ Secondary treatment } \\
\cline { 2 - 6 } & INT - group & SET - group & INT - group & REST - group \\
\hline \multicolumn{2}{l|}{$\begin{array}{l}\text { Patients with intervention ( } \mathrm{n}-\%) \\
\text { Interventions per section }\end{array}$} & $1363(100 \%)$ & $45(6.4 \%)$ & $480(35.2 \%)$ & $132(4.6 \%)$ \\
\hline $\begin{array}{l}\text { Invoices of Radiology } \\
\text { dept. }\end{array}$ & $\begin{array}{l}\text { Bypass } \\
\text { revascularization } \\
\text { Ao-II, } \\
\text { (one sided) }\end{array}$ & 8 & 2 & 8 & 2 \\
$\begin{array}{l}\text { Ao-II, } \\
\text { (both sides) }\end{array}$ & 219 & 5 & 94 & 19 \\
$\begin{array}{l}\text { FemPop } \\
\text { (one sided) }\end{array}$ & 313 & 17 & 147 & 47 \\
$\begin{array}{l}\text { FemPop } \\
\text { (both sides) } \\
\text { Crural } \\
\text { (one sided) }\end{array}$ & 27 & 1 & 14 & 6 \\
\hline Invoice of Surgery dept. & $\begin{array}{l}\text { Endovascular } \\
\text { Open }\end{array}$ & 9 & 0 & 8 & 1 \\
\hline $\begin{array}{l}\text { Open } \\
\text { (both sides) }\end{array}$ & 12 & 19 & 0 & 0 & 0 \\
\hline
\end{tabular}

Note: * Unspecified due to suboptimal registration. Ao-II: aorto-liac, FemPop: femoral-popliteal

\begin{tabular}{|c|c|c|c|c|c|}
\hline \multirow[t]{3}{*}{ Table 3} & ins per group & \multirow{3}{*}{$\begin{array}{c}\text { Primary treatment } \\
\text { SET - group }\end{array}$} & & & \\
\hline & & & \multicolumn{3}{|c|}{ Secondary treatment } \\
\hline & & & SET - group & INT - group & REST - group \\
\hline Patients with SET & $(n-\%)$ & $701(100 \%)$ & NR & $141(10.3 \%)$ & $299(10.3 \%)$ \\
\hline Number of SET sessions & $\begin{array}{l}(\text { mean } \pm S D) \\
(\min -\max )\end{array}$ & $\begin{array}{l}48( \pm 42) \\
(1-271)\end{array}$ & NR & $\begin{array}{l}38( \pm 35) \\
(1-176)\end{array}$ & $\begin{array}{l}42( \pm 47) \\
(1-470)\end{array}$ \\
\hline
\end{tabular}

Note: $\quad{ }^{*} \mathrm{NR}=$ not relevant
Table 4 Mean total costs per patient per group during two years of follow up

\begin{tabular}{l|ccc} 
& \multicolumn{3}{|c}{ Group } \\
\cline { 2 - 4 } & $\begin{array}{c}\text { SET } \\
\text { mean } \\
(\mathbf{m i n}-\mathbf{m a x})\end{array}$ & $\begin{array}{c}\text { INT } \\
\text { mean } \\
(\mathbf{m i n}-\text { max })\end{array}$ & $\begin{array}{c}\text { REST } \\
\text { mean } \\
(\mathbf{m i n}-\text { max })\end{array}$ \\
\hline Physician based invoices $(€)$ & 890 & 9,745 & 705 \\
Physiotherapist based invoices $(€)$ & $(99-14,428)$ & $(2,515-50,173)$ & $(99-17,935)$ \\
& $(28-7,187)$ & $(28-4,914)$ & $(28-12,886)$ \\
\hline Mean Total Costs (MTC) & $€ \mathbf{2 , 1 9 1}$ & $€ \mathbf{9 , 8 5 1}$ & $\mathbf{8} \mathbf{8 2 4}$
\end{tabular}

Table 5 Implementation of a stepped care model

\begin{tabular}{|c|c|c|c|c|c|c|c|c|c|c|}
\hline \multirow[t]{3}{*}{ Scenario } & \multicolumn{2}{|c|}{ Groups } & \multirow[t]{3}{*}{ Costs } & \multicolumn{7}{|c|}{ Savings } \\
\hline & \multirow{2}{*}{\multicolumn{2}{|c|}{$\begin{array}{cc}\text { SET } & \text { INT } \\
\text { (n) } & (\mathbf{n})\end{array}$}} & & \multicolumn{2}{|c|}{ Cost-analysis } & \multicolumn{2}{|c|}{ Group } & \multicolumn{3}{|c|}{ Sensitivity analysis } \\
\hline & & & & INT to SET* & $\begin{array}{c}\text { Dutch } \\
\text { population }\end{array}$ & $\begin{array}{l}\text { SET } \\
\text { (n) }\end{array}$ & $\begin{array}{c}\text { REST } \\
\text { (n) }\end{array}$ & $\begin{array}{c}\text { REST } \\
\text { to } S^{*} T^{*}\end{array}$ & $\begin{array}{c}\text { (INT to SET) } \\
+ \\
\text { (REST to SET)* }\end{array}$ & $\begin{array}{c}\text { Dutch } \\
\text { population }\end{array}$ \\
\hline $\begin{array}{l}\text { Current } \\
(14 \%-\mathrm{NR} \%)\end{array}$ & 701 & 1363 & $€ 14.953 .716$ & NR & NR & 701 & 2023 & NR & NR & NR \\
\hline $\begin{array}{l}\text { Best case } \\
(80 \%-80 \%)\end{array}$ & 1573 & 491 & $€ 8.276 .594$ & $€ 6,677,121$ & $€ 32.992 .834$ & 1996 & 728 & $-€ 1,770,685$ & $€ 4,906,436$ & $€ 24,237,794$ \\
\hline $\begin{array}{l}\text { Moderate } \\
\text { case } \\
(50 \%-80 \%)\end{array}$ & 1246 & 818 & $€ 10.780 .515$ & $€ 4,173,201$ & $€ 20.620 .521$ & 1510 & 1214 & $-€ 1,106,678$ & $€ 3,066,523$ & $€ 15,148,624$ \\
\hline $\begin{array}{l}\text { Worst case } \\
(30 \%-25 \%)\end{array}$ & 803 & 1261 & $€ 14.171 .240$ & $€ 782,475$ & $€ 3.866 .348$ & 853 & 1871 & - $€ 207,502$ & $€ 574,973$ & $€ 2,840,367$ \\
\hline
\end{tabular}

Notes: NR . not relevant.

$$
\text { Based on CZ population. }
$$

\section{Discussion}

Three international guidelines recommend SET as a first line treatment for patients with IC ${ }^{(2-4)}$, supported by cost-effectiveness analyses ${ }^{(13,16-20)}$. Unfortunately, the availability of SET programs in Europe is low ${ }^{(10,22)}$. Some consider the substantial investments to obtain nationwide implementation of SET programs as a problem ${ }^{(13)}$. Our findings implicate that the initial investments to increase SET availability in other countries may be beneficial when guidelines and therefore the SCM are followed. Despite that the Dutch have a 
well-organised community based SET network should not be an excuse for other European countries but a motivation to implement such a network. Furthermore SCM implementation effects and thus cost-savings may even be larger since most foreign health care systems have low penetration of (community-based) SET programs and thus a potential lower threshold for invasive vascular interventions. Moreover the calculated savings of a SCM approach in this study are in euros, while a reduction of morbidity and mortality ratios might account as well.

Makris et al. claimed a $100 \%$ SET availability in the Netherlands in $2012^{(10)}$. The present study demonstrated that a mere $14 \%$ of the IC patients were actually referred to SET in 2009. The discrepancy between a relatively low percentage of SET referrals and high availability of SET programs might be explained by the combination of conflicting reimbursement issues, increased patients' and physicians' enthusiasm for interventional procedures ${ }^{(16)}$, and a lack of appreciation of $\mathrm{SET}^{(9)}$. The latter might be caused by ambiguities in contemporary guidelines, which may be responsible for a too liberal use of invasive procedures in patients with IC due to aortoiliac lesions as stated in the TASC ${ }^{(4)}$. In contrast the NICE guideline suggest to initiate this type of lesion with $\mathrm{SET}^{(3)}$. Several large trials show inconclusive results concerning treatment of aortoiliac lesions ${ }^{(23-26)}$. In the present study, $28 \%$ of the patients received a primary revascularization, of which $51 \%$ concerned aortoiliac lesions. More than half (58\%) of the included patients were even assumed to have received a walking advice. The present study therefore clearly demonstrates that the TASC II / NICE guidelines (restricting interventions to patients not responding to SET) are largely neglected in Dutch practices. A nationwide implementation of a SCM might tackle these issues, whereas expected cost-savings as presented in this study may facilitate current conflicting issues in reimbursement.

Moreover, a SCM may have substantial influence on IC patients' individual treatment strategy. It is known that patients suffering from IC, regardless of the severity of the walking restriction, have a range of other limitations ${ }^{(27)}$. Initiating treatment with SET may provide awareness of important functional restrictions in daily life other than caused by IC (e.g. COPD, congestive heart failure, osteoarthritis, spinal stenosis, equilibrium disorders). So following a SCM, may prevent potentially futile vascular interventions in multimorbid patients who are limited by more than just IC. Furthermore, once (successful) invasive treatment has been performed, recurrent ipsilateral or new- ly developed contralateral obstructions are likely again treated by invasive means too, contributing to a high re-interventions ratio (35\%) in the INT group. Surprisingly, this was also found by others ${ }^{(16)}$ and is in line with reported patency rates of endovascular revascularizations ${ }^{(28,29)}$. Additionally, initiating a SET first policy might not meet the contemporary articulate and demanding patient, focused on a quick fix of the problem. Our findings suggest that a SCM, with a three-month trial period preceding invasive treatment, in which patients not responding to SET are eligible for invasive treatment might decrease the number of interventions.

Our study has limitations inherent to its retrospective character. Some might argue that selection bias may have influenced the results, since patients with more severe IC complaints or with a specific atherosclerotic lesion may preferentially have been treated by invasive means. However, all included patients had IC classified as Fontaine II and according to contemporary guidelines should have received SET as a primary treatment ${ }^{(2-4)}$. In addition, we applied a correcting factor, in our (best-case scenario) calculations referral rate was set at an $80 \%$ ratio (instead of the guidelines' $100 \%$ ), permitting the remaining $20 \%$ to be treated based on personal preference of the patient or of the vascular surgeon

Furthermore our study showed differences in patient characteristics between groups (age, gender and CHF). Unfortunately we were not able to adjust our analyses for these covariates due to privacy limitations of the insurance company database. Our findings reveal that young males were treated more frequently with revascularization compared to older patients or females. This phenomenon might reflect assumptions and indirect evidence suggesting that invasive treatment should be preferred in a working age population as recovery is deemed faster. The same might be the case in the assumption that since en dovascular treatment for aortoiliac lesions is more durable compared to femoropopliteal lesions, this warrants an intervention in aortoiliac lesions ${ }^{(28)}$. However, as far as we know, no evidence substantiates such an invasive first line treatment for certain IC subgroups.

A formal cost-effectiveness study could not be performed since the insurance company's database lacks data on treatment effect or outcome. Furthermore, costs related to an intervention of the ipsi- or contralateral leg could not be identified which may have biased total costs of the INT group. However, this limitation is relative as walking exercise pertains to both legs. 


\section{Future perspectives}

Reimbursement issues in the Dutch health care system remain an issue. Optimization of a SCM depends on political decision-making and awareness of health care insurers concerning the functional and financial advantages of SET. The impact of a SCM implementation on the Dutch as well as European society should be subject to future research.

\section{Conclusion}

In addition to the solid evidence supporting SET as first line treatment for patients with IC, introduction of and adherence to a SCM may lead to significant savings of health care resources associated with the treatment of patients with intermittent claudication.

\section{Acknowledgements}

We would like to thank Monique Kant-Cox, project manager at CZ and Dennis van der Rijt, senior consultant of Opera Consultancy \& Implementation. The authors report no conflicts of interest in this work.

\section{References}

1. Fowkes FGR, Rudan D, Rudan I, Aboyans V, Denenberg JO, McDermott MM, et al. Comparison of global estimates of prevalence and risk factors for peripheral artery disease in 2000 and 2010: a systematic review and analysis. The Lancet. 2013. Epub August 1.

2. Hirsch AT, Haskal ZJ, Hertzer NR, Bakal CW, Creager MA, Halperin JL, et al. ACC/AHA 2005 Practice Guidelines for the management of patients with peripheral arterial disease. Circulation. 2006 Mar 21;113(11):e463-654. PubMed PMID: 16549646. Epub 2006/03/22. eng.

3. Layden J, Michaels J, Bermingham S, Higgins B, Guideline Development G. Diagnosis and management of lower limb peripheral arterial disease: summary of NICE guidance. Bmj. 2012;345:e4947. PubMed PMID: 22875949.

4. Norgren L, Hiatt WR, Dormandy JA, Nehler MR, Harris KA, Fowkes FG. Inter-Society Consensus for the Management of Peripheral Arterial Disease (TASC II). J Vasc Surg. 2007 Jan;45 Suppl S:S5-67. PubMed PMID: 17223489. Epub 2007/01/16. eng.

5. Fokkenrood HJ, Lauret GJ, Scheltinga MR, Spreeuwenberg C, de Bie RA, Teijink JA. Multidisciplinary treatment for peripheral arterial occlusive disease and the role of eHealth and mHealth. Journal of multidisciplinary healthcare. 2012;5:257-63. PubMed PMID: 23093906. Pubmed Central PMCID: 3476374. Epub 2012/10/25. eng.

6. Mays RJ, Regensteiner JG. Exercise therapy for claudication: latest advances. Current treatment options in cardiovascular medicine. 2013 Apr;15(2):188-99. PubMed PMID: 23436041. Pubmed Central PMCID: 3627476. Epub 2013/02/26. eng.

7. Gardner AW, Parker DE, Montgomery PS, Scott KJ, Blevins SM. Efficacy of quantified home-based exercise and supervised exercise in patients with intermittent claudication a randomized controlled trial. Circulation. 2011 Feb 8;123(5):491-8. PubMed PMID 21262997. Pubmed Central PMCID: 3154843. Epub 2011/01/26. eng.

8. Saxton JM, Zwierska I, Blagojevic M, Choksy SA, Nawaz S, Pockley AG. Upper- versus lower-limb aerobic exercise training on health-related quality of life in patients with symptomatic peripheral arterial disease. J Vasc Surg. 2011 May;53(5):1265-73. PubMed PMID 21215558.

9. Lauret GJ, van Dalen HC, Hendriks HJ, van Sterkenburg SM, Koelemay MJ, Zeebregts $\mathrm{CJ}$, et al. When is supervised exercise therapy considered useful in peripheral arterial occlusive disease? A nationwide survey among vascular surgeons. Eur J Vasc Endovasc Surg. 2012 Mar;43(3):308-12. PubMed PMID: 22240337. Epub 2012/01/14. eng. 
10. Makris GC, Lattimer CR, Lavida A, Geroulakos G. Availability of supervised exercise programs and the role of structured home-based exercise in peripheral arterial disease. Eur J Vasc Endovasc Surg. 2012 Dec;44(6):569-75; discussion 76. PubMed PMID: 23034408. Epub 2012/10/05. eng.

11. Fokkenrood HJ,Bendermacher BL,LauretGJ, WilligendaelEM,PrinsMH,TeijinkJA.Supervised exercise therapy versus non-supervised exercise therapy for intermittent claudication. Cochrane Database Syst Rev. 2013 Aug 23;8:CD005263. PubMed PMID: 23970372.

12. Nicolai SP, Teijink JA, Prins MH. Multicenter randomized clinical trial of supervised exercise therapy with or without feedback versus walking advice for intermittent claudication. J Vasc Surg. 2010 Aug;52(2):348-55. PubMed PMID: 20478681. Epub 2010/05/19. eng

13. Bermingham SL, Sparrow K, Mullis R, Fox M, Shearman C, Bradbury A, et al. The Costeffectiveness of Supervised Exercise for the Treatment of Intermittent Claudication. Eur J Vasc Endovasc Surg. 2013 Dec;46(6):707-14. PubMed PMID: 24103792.

14. Spronk S, Bosch JL, den Hoed PT, Veen HF, Pattynama PM, Hunink MG. Intermittent claudication: clinical effectiveness of endovascular revascularization versus supervised hospital-based exercise training--randomized controlled trial. Radiology. 2009 Feb;250(2):586-95. PubMed PMID: 19188327.

15. Lauret GJ, Gijsbers HJ, Hendriks EJ, Bartelink ML, de Bie RA, Teijink JA. The ClaudicatioNet concept: design of a national integrated care network providing active and healthy aging for patients with intermittent claudication. Vasc Health Risk Manag. 2012;8:495-503. PubMed PMID: 22942648. Pubmed Central PMCID: 3428244. Epub 2012/09/04. eng.

16. O’Brien-Irr MS, Harris LM, Dosluoglu HH, Dryjski ML. Endovascular intervention for treatment of claudication: is it cost-effective? Annals of vascular surgery. 2010 Aug;24(6):833-40. PubMed PMID: 20638623. Epub 2010/07/20. eng.

17. Mazari FA, Khan JA, Carradice D, Samuel N, Gohil R, McCollum PT, et al. Economic analysis of a randomized trial of percutaneous angioplasty, supervised exercise or combined treatment for intermittent claudication due to femoropopliteal arterial disease. Br J Surg. 2013 Aug;100(9):1172-9. PubMed PMID: 23842831.

18. Spronk S, Bosch JL, den Hoed PT, Veen HF, Pattynama PM, Hunink MG. Cost-effectiveness of endovascular revascularization compared to supervised hospital-based exercise training in patients with intermittent claudication: a randomized controlled trial. J Vasc Surg. 2008 Dec;48(6):1472-80. PubMed PMID: 18771879. Epub 2008/09/06. eng.

19. Treesak C, Kasemsup V, Treat-Jacobson D, Nyman JA, Hirsch AT. Cost-effectiveness of exercise training to improve claudication symptoms in patients with peripheral arterial disease. Vasc Med. 2004 Nov;9(4):279-85. PubMed PMID: 15678620. Epub 2005/02/01. eng.
20. van Asselt AD, Nicolai SP, Joore MA, Prins MH, Teijink JA. Cost-effectiveness of exercise therapy in patients with intermittent claudication: supervised exercise therapy versus a 'go home and walk' advice. Eur J Vasc Endovasc Surg. 2011 Jan;41(1):97-103. PubMed PMID 21159527. Epub 2010/12/17. eng.

21. results not published.

22. Shalhoub J, Hamish M, Davies AH. Supervised exercise for intermittent claudication - an under-utilised tool. Annals of the Royal College of Surgeons of England. 2009 Sep;91(6):4736. PubMed PMID: 19558766. Pubmed Central PMCID: 2966198. Epub 2009/06/30. eng.

23. Murphy TP, Cutlip DE, Regensteiner JG, Mohler ER, Cohen DJ, Reynolds MR, et al. Supervised exercise versus primary stenting for claudication resulting from aortoiliac peripheral artery disease: six-month outcomes from the claudication: exercise versus endoluminal revascularization (CLEVER) study. Circulation. 2012 Jan 3;125(1):130-9. PubMed PMID: 22090168. Epub 2011/11/18. eng.

24. Mazari FA, Khan JA, Carradice D, Samuel N, Abdul Rahman MN, Gulati S, et al. Randomized clinical trial of percutaneous transluminal angioplasty, supervised exercise an combined treatment for intermittent claudication due to femoropopliteal arterial disease Br J Surg. 2012 Jan;99(1):39-48. PubMed PMID: 22021102.

25. Fakhry F, Rouwet EV, den Hoed PT, Hunink MG, Spronk S. Long-term clinical effectiveness of supervised exercise therapy versus endovascular revascularization for intermitten claudication from a randomized clinical trial. Br J Surg. 2013 Aug;100(9):1164-71. PubMed PMID: 23842830

26. Frans FA, Bipat S, Reekers JA, Legemate DA, Koelemay MJ. Systematic review of exercise training or percutaneous transluminal angioplasty for intermittent claudication. Br J Surg. 2012 Jan;99(1):16-28. PubMed PMID: 21928409. Epub 2011/09/20. eng.

27. Breek JC, Hamming JF, De Vries J, van Berge Henegouwen DP, van Heck GL. The impact of walking impairment, cardiovascular risk factors, and comorbidity on quality of life in patients with intermittent claudication. J Vasc Surg. 2002 Jul;36(1):94-9. PubMed PMID: 12096264.

28. Jongkind V, Akkersdijk GJ, Yeung KK, Wisselink W. A systematic review of endovascular treatment of extensive aortoiliac occlusive disease. J Vasc Surg. 2010 Nov;52(5):1376-83. PubMed PMID: 20598474.

29. Lensvelt MM, Reijnen MM, Wallis De Vries BM, Zeebregts CJ. Treatment strategies for extensive chronic SFA occlusions: indications and results. The Journal of cardiovascular surgery. 2012 Feb;53(1 Suppl 1):161-70. PubMed PMID: 22433735. 


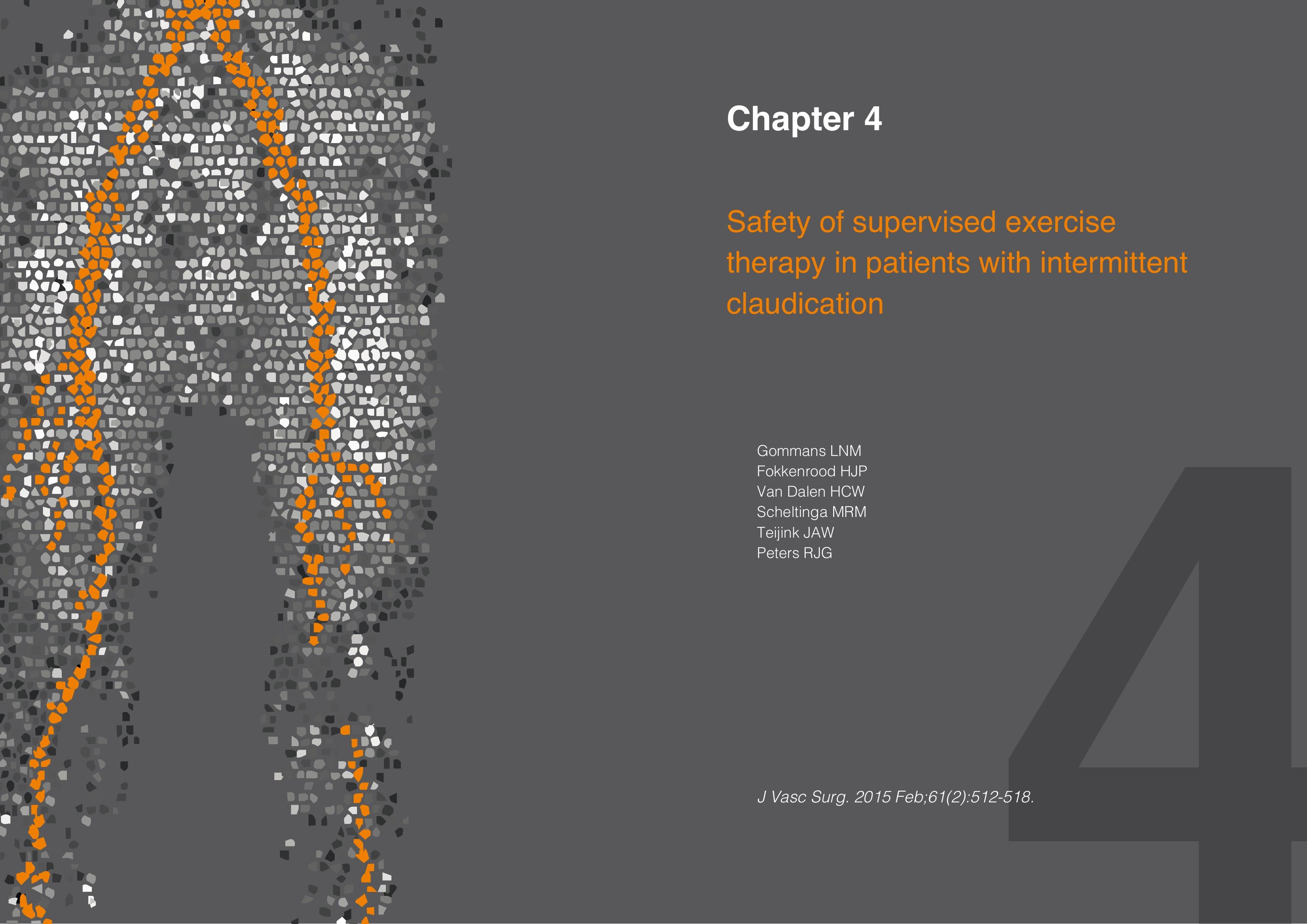




\section{Abstract}

Background

Supervised exercise therapy (SET) is recommended as the primary treatment for patients with intermittent claudication (IC). However, there is concern regarding the safety of performing SET because IC patients are at risk for untoward cardiovascular events. The Dutch physical therapy guideline advocates cardiac exercise testing before SET, if indicated. Perceived uncertainties concerning safety may contribute to the underuse of SET in daily practice. The objective of this review was to analyse the safety of supervised exercise training in patients with IC.

Methods:

Two authors independently studied clinical trials investigating SET. Data were obtained from MEDLINE, EMBASE, and The Cochrane Central Register of Controlled Trials. Complication rates were calculated and expressed as number of events per number of patient-hours. The usefulness of cardiac screening before SET was evaluated in a sub analysis.

Results:

Our search strategy revealed 2703 abstracts. We selected 121 articles, of which 74 met the inclusion criteria. Studies represent 82,725 hours of training in 2876 IC patients. Eight adverse events were reported, six of cardiac and two of noncardiac origin, resulting in an all-cause complication rate of one event per 10,340 patienthours.

\section{Conclusions:}

SET can safely be prescribed in patients with IC because an exceedingly low allcause complication rate was found. Routine cardiac screening before commencing SET is not required. Our results may diminish perceived uncertainties regarding safety and will possibly increase the use of SET in daily practice.

\section{Introduction}

Some $50 \%$ to $80 \%$ of patients with peripheral arterial disease (PAD) are symptomatic with intermittent claudication (IC). ${ }^{(1)}$ IC is defined as muscle discomfort in the lower limb(s) elicited by exercise that resolves after a short period of rest. ${ }^{(1)}$ IC is associated with significant disability, reduced quality of life, ${ }^{(2,3)}$ and an increased risk of death. (4) A recent study found a significant difference in survival when patients with and without PAD were compared; for instance, the all-cause and cardiovascular mortality rates were $24 \%$ and $7.7 \%$ in patients with $\mathrm{PAD}$ vs $9.5 \%$ and $2.4 \%$ in patients without PAD, respectively. ${ }^{(5)}$ The unfavourable prognosis associated with PAD is dominated by the concomitant presence of cerebral and coronary artery disease (CAD) due to generally accepted risk factors (smoking, hypertension, diabetes mellitus, hyperlipidaemia). ${ }^{(6-8)}$ The estimated overall prevalence of atherosclerotic CAD in PAD is $72 \%$, with an obstructive nature in $61 \%$ to $98 \%$ in certain subgroups. ${ }^{(9,10)}$ The Quebec Cardiovascular Study reported that the risk of fatal and nonfatal cardiovascular events in men with IC was twice as high compared with men without known cardiovascular disease. ${ }^{(11)}$ International guidelines state that treatment of IC should consist of a multimodal approach that includes cardiovascular risk reduction combined with symptomatic treatment. ${ }^{(1,7)}$ First-choice symptomatic treatment, demonstrated by Level I evidence, is daily-supervised exercise therapy (SET). ${ }^{(12-17)}$ Apart from symptomatic improvement, a 12-week SET program also reduced overall cardiovascular mortality by $52 \%$ and morbidity by $30 \%{ }^{(18)}$ Although it is generally accepted that SET should be part of the initial treatment for each patient with IC, this therapeutic tool is seriously underused in clinical practice. ${ }^{(19-21)}$ A study among surgeons in the United Kingdom revealed that only $24 \%$ of IC patients had access to SET. ${ }^{(21)}$ Moreover, a large variation was found in the proportion of eligible patients referred to such an exercise program. Lack of knowledge on referral criteria was also observed in a recent nationwide survey among Dutch vascular surgeons. Approximately $70 \%$ of the interviewed surgeons were convinced that coexisting cardiopulmonary comorbidity or aortoiliac stenosis or occlusion, or both, were relative contraindications for participation in a SET program. ${ }^{(20)}$ These doubts are strengthened by a worry among physical therapists providing SET because they fear the onset of cardiovascular events that may possibly occur during exercise. Moreover, physical therapy guide- lines advocate cardiac screening before SET, ${ }^{(22)}$ although evidence to support such a strategy is 
currently lacking. SET is often described as well tolerated, and two studies re- ported cardiovascular complications were rare. ${ }^{(23,24)}$ The aim of the present study was to analyze the safety of SET in patients with IC in terms of onset of untoward (cardiovascular) events.

\section{Figure Flow chart of study selection}

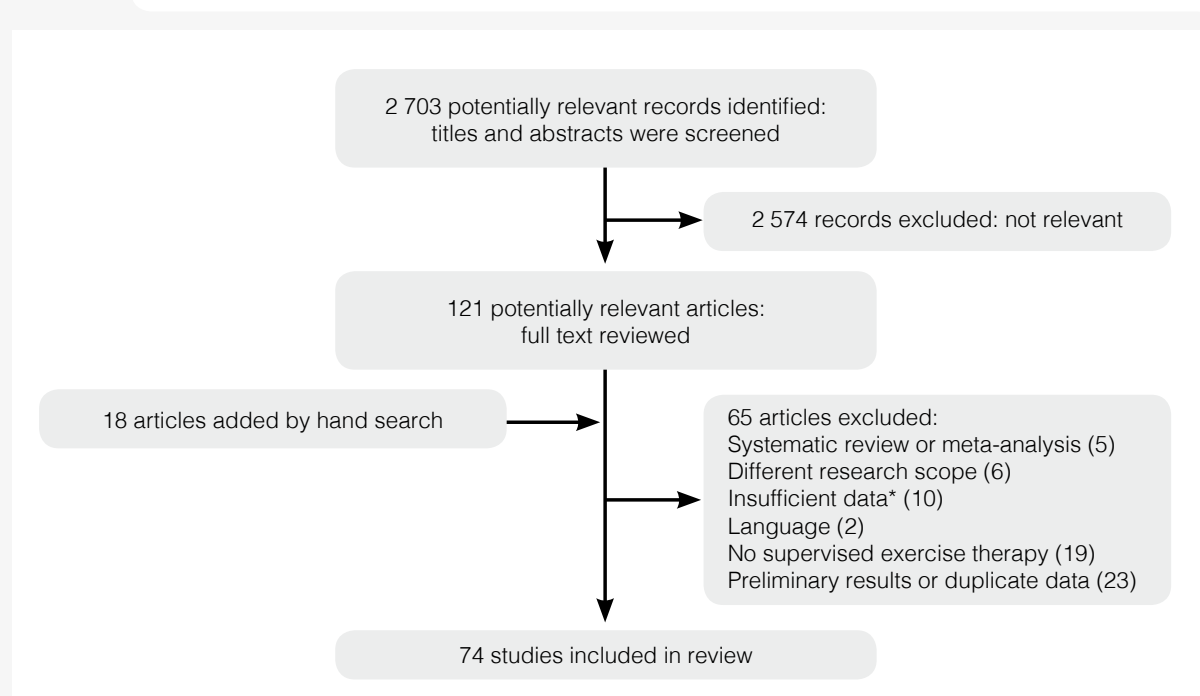

Notes: *Defined as missing data on complications during supervised exercise training SET) incomplete data on reasons for dropout,

or nonresponse on e-mail request as a final attempt to obtain information.

\section{Methods}

\section{Participants}

We included studies that investigated the role of SET in patients diagnosed with IC (Fontaine II/ Rutherford 1-3).

\section{Types of studies}

Eligible studies examined SET alone or in a comparison model with other treatments such as endovascular treatment, vasoactive medication, or non- SET. Randomized and nonrandomized studies were included. Although treadmill walking is conside- red an important component of a SET program, uncertainty remains regarding the most effective content of such a program. ${ }^{(25)}$ All types of SET programs were therefore included (eg, pole-striding and strength training). The search was limited to studies in humans and articles written in Dutch, German, or English. No limitation to date of publication was considered.

\section{Search strategy}

We performed a search in MEDLINE (1966 to June 2013) using the following Medical Subject Heading terms: "peripheral arterial diseases," "peripheral vascular diseases," "intermittent claudication," "peripheral arter ${ }^{\star}$ occlus $^{*}$," "claudica ${ }^{*}$," "isch ${ }^{\star}$ limb $^{*}$," "exercise," "exercise therapy," "exercise movement techniques," "walk*," "runni*," "exerc*," "train*," and "treadmill." Additional articles were found by matching a previous search of Cochrane Central Register of Controlled Trials (1966 to September 2012) and EMBASE (1974 to June 2013) and removing duplicates. We also searched bibliographies of included articles. After screening titles and abstracts, two reviewers (L.G., H.F.) independently selected articles, based on a full-text evaluation. Disagreement between reviewers was discussed and resolved by consensus.

Data extraction and management

Two authors (L.G., H.F.) used a standardized data extraction form to extract the following data: details of the study population, country, research setting, number of participants, number of dropouts/lost to follow-up, reasons for dropout, age, gender, inclusion and exclusion criteria, description of the supervised exercise protocol, frequency, duration, content, all types of reported complications related to SET, and the use of cardiopulmonary exercise testing (CPET). To exclude the potential influence of medication, only results obtained from participants in the placebo control group of randomized controlled trials were included. If studies did not explicitly report possible occurrence of adverse events, we used information on the number of dropouts and reasons for dropout. Studies that contained dropouts due to medical causes were excluded. An E-mail was sent to authors who reported unclear data regarding SETrelated complications or reasons for dropout to obtain details on the occurrence of untoward events. Studies of authors who did not respond to this e-mail were also excluded. 
Statistical analysis and data synthesis

Data were analyzed using SPSS 18.0 software (SPSS Inc, Chicago, Ill). The total number of patient-hours was calculated as the number of patients multiplied by the number of training sessions corrected for the mean duration of each session. When information on the exact duration of training sessions was lacking, an approximation of 30 minutes was assumed. Adverse events were character- ized as cardiac or noncardiac. The role of cardiac screening was studied by performing a sub analysis. We calculated separated event rates based on the use of CPET before SET.

\section{Results}

\section{Study selection}

We identified 2703 records resulting in the study of 121 relevant articles. Overall, 74 studies (Supplementary Appendix, online only) with a total of 2876 IC patients met inclusion criteria (Fig). Patients represented 82,725 patient-hours of SET.

\section{Study characteristics}

Most of the SET studies were performed in Western Europe and North America. Mean patient age ranged from 54 to 76 years, and more men than women participated (Table I). Frequently reported patient exclusion criteria were IC presenting with pain at rest, critical ischemia, exercise capacity limited by symp- toms of angina, congestive heart failure, chronic obstructive pulmonary disease, arthritis, and poorly controlled hypertension. Exercise programs consisted of treadmill training $(n=49)$, mixed exercise therapy $(n=8)$, circuit training $(n=11)$, strength training $(n=2)$, arm ergometry $(n=2)$, or pole-striding $(n=2)$. Duration of the exercise programs ranged from 2 weeks to 12 months. Training frequencies varied from one to seven times a week, and 30 to 120 minutes per day (Table II).

\section{Main outcome measurement}

Potential adverse events were explicitly reported in 35 of the 74 studies. Another 32 studies reported no dropouts or dropouts without medical cause. The remaining seven studies were included after positive e-mail conformation. Eight adverse described during $>80,000$ patient-hours of SET, resulting in an all-cause complication rate of one event in 10,340 patient-hours. Therefore, the risk of complications during SET is considered exceedingly low. Focusing on the two major cardiac complications, an even lower event rate of one event in 41,362 patient-hours was calculated. These results are in line with a prospective registry on complications during exercise for cardiac rehabilitation reporting an almost similar rate of one event per 49,565 patient-hours. ${ }^{(26)}$ Moreover, these rates may even be considered relatively high because events that were reported in studies from $>30$ years ago were also included. Medical treatment has greatly improved the overall prognosis, potentially resulting in even lower current event rates. CPET has been used for $>60$ years for risk stratification in patients with heart diseases, ${ }^{(27)}$ but this technique is no longer recommended as a screening tool for myocardial ischemia in people without known CAD, as suggested by a recent guideline of The National Institute for Health and Clinical Excellence. ${ }^{(28)}$ Prediction of a future severe cardiac event during exercise is very difficult, if not impossible. ${ }^{(26)}$ In the present review, 28 studies (32\% of total patient-hours) included cardiac screening, but because an equal number of adverse events (n $1 / 44)$ was found in studies with or without cardiac screening, the results may indicate that cardiac screening in IC patients is indeed not useful. However, by the observational and retrospective design of our study, firm conclusions cannot be drawn. Yet, given the very low complication rate, cardiac screening as a tool for a safe execution of SET seems clinically irrelevant.

There is also a downside using CPET as a screening technique. As all screening tests do, CPET also inherently carries a risk of false-positive testing ${ }^{(29)}$; for instance, a $15 \%$ events of cardiac $(n=6)$ and noncardiac $(n=2)$ origin were reported (Table III). One fatal adverse event was reported. The total all-cause event rate was one event per 10,340 patient-hours. Total cardiac and noncardiac event rates were one per 13,788 and one per 41,363 patient- hours, respectively (Table IV). Sub analysis on cardiac screening. Of 28 studies (26,790 patient-hours of SET [32\%]) that included cardiac screening before SET was initiated, 23 used electro- cardiography registration. Four of the eight adverse events were reported in these 28 studies. The remaining four, including a fatal myocardial infarction, were found in the 46 remaining studies that did not included cardiac screening $(55,935$ patient-hours of SET [68\%]). Six studies reported results of 1703 CPETs before SET inclusion. Abnormal CPET findings resulted in 59 patients (3.5\%) being excluded from SET participation. 
1 Demographic characteristics $(N=2876)$

\section{Characteristics}

Age, years

Mean (range) or No.

$64(54-76)$

Europe

North America

South America

Oceania

Africa

Note: $\quad a=$ Number of studies performed in listed continents

Table 2 Characteristics of included studies

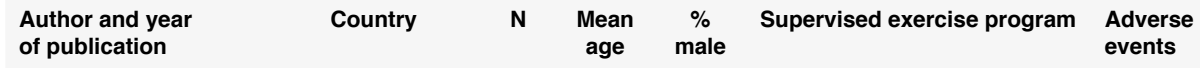

\begin{tabular}{|c|c|c|c|c|c|c|c|c|c|}
\hline & & & & & & $\begin{array}{l}\begin{array}{l}\text { Dura- } \\
\text { tion } \\
\text { (weeks) }\end{array} \\
\end{array}$ & $\begin{array}{l}\begin{array}{l}\text { Frequen- } \\
\text { cy" } \\
\text { (per week) }\end{array} \\
\end{array}$ & $\begin{array}{l}\begin{array}{l}\text { Content } \\
\text { (main } \\
\text { component) }\end{array} \\
\end{array}$ & \\
\hline Andreozzi & 2008 & Italy & 74 & 65 & 91 & 6 & 3 & Treadmill & None \\
\hline Andreozzi & 2007 & Italy & 22 & 67 & 100 & 6 & 3 & Treadmill & None \\
\hline Arosio & 2001 & Italy & 12 & 65 & NR & 2 & 7 & Treadmill & None \\
\hline Badger & 2007 & Ireland & 8 & 70 & NR & 6 & 2 & Treadmill & None \\
\hline Beckitt & 2012 & UK & 27 & 68 & 98 & 12 & 2 & $\begin{array}{l}\text { Circuit } \\
\text { training }\end{array}$ & None \\
\hline Beckitt & 2012 & UK & 42 & 66 & 69 & 12 & 2 & $\begin{array}{l}\text { Circuit } \\
\text { training }\end{array}$ & None \\
\hline Bendermacher & 2007 & Netherlands & 93 & 64 & 63 & 24 & 2,5 & Treadmill & None \\
\hline Cachovan & 1994 & Germany & 21 & 62 & NR & 4 & 5 & Treadmill & None \\
\hline Carlon & 2008 & Italy & 41 & NR & NR & 12 & 3 & Treadmill & None \\
\hline Cheetham & 2004 & UK & 30 & 65 & NR & 24 & 1 & $\begin{array}{l}\text { Circuit } \\
\text { training }\end{array}$ & None \\
\hline Ciuffeti & 1994 & Italy & 15 & 56 & $>99$ & 12 & 2 & $\begin{array}{l}\text { Mixed } \\
\text { exercises }\end{array}$ & None \\
\hline
\end{tabular}

\begin{tabular}{|c|c|c|c|c|c|c|c|c|c|}
\hline Collins & 2005 & USA & 27 & 70 & 98 & 24 & 3 & $\begin{array}{l}\text { Pole } \\
\text { striding }\end{array}$ & None \\
\hline Collins & 2012 & USA & 103 & 66 & 93 & 24 & 3 & $\begin{array}{l}\text { Treadmill } \\
+ \text { pole } \\
\text { striding }\end{array}$ & None \\
\hline Collins & 2011 & USA & 72 & 66 & 75 & 24 & 1 & Walking & None \\
\hline Cousin & 2011 & France & 31 & $56^{\mathrm{b}}$ & 97 & 4 & 5 & Treadmill & None \\
\hline Crowther & 2008 & USA & 11 & 71 & 50 & 52 & 3 & Treadmill & None \\
\hline Degischer & 2002 & Switzerland & 46 & 68 & NR & 12 & 1 & Treadmill & None \\
\hline Franz & 2010 & USA & 101 & 72 & 46 & 12 & 3 & Treadmill & None \\
\hline Gardner & 2005 & USA & 77 & NR & 88 & 24 & 3 & Treadmill & None \\
\hline Gardner & 2011 & USA & 40 & 66 & 45 & 12 & 3 & Treadmill & None \\
\hline Gardner & 2002 & USA & 31 & 68 & NR & 24 & 3 & Treadmill & None \\
\hline Gardner & 2012 & USA & 106 & 67 & 86 & 24 & 3 & Treadmill & None \\
\hline Gibelline & 2000 & Italy & 20 & 65 & 99 & 4 & 5 & Treadmill & None \\
\hline Greenhalgh & 2008 & UK & 127 & 65 & 63 & 24 & 1 & Treadmill & None \\
\hline Grizzo Cucato & 2011 & Brazil & 34 & 67 & 60 & 12 & 2 & $\begin{array}{l}\text { Circuit } \\
\text { training }\end{array}$ & None \\
\hline Hiatt & 1996 & USA & 29 & 61 & NR & 20 & 3 & Treadmill & None \\
\hline Hiatt & 1990 & USA & 25 & 67 & 100 & 12 & 3 & Treadmill & None \\
\hline Hiatt & 2011 & USA & 30 & 66 & 83 & 24 & 0,29 & Treadmill & None \\
\hline Hobbs & 2007 & UK & 9 & NR & 78 & 12 & 2 & $\begin{array}{l}\text { Circuit } \\
\text { training }\end{array}$ & None \\
\hline Hodges & 2008 & UK & 14 & 67 & NR & 12 & 2 & Treadmill & None \\
\hline Jones & 2012 & USA & 30 & 69 & 60 & 12 & 3 & Treadmill & None \\
\hline Kakkos & 2005 & UK & 12 & 61 & 92 & 6 & 3 & Treadmill & None \\
\hline Kiesewetter & 1987 & Germany & 15 & 64 & 70 & 6 & 5 & Treadmill & None \\
\hline Krause & 1978 & Germany & 63 & 66 & 77 & 6 & 5 & $\begin{array}{l}\text { Mixed } \\
\text { exercise }\end{array}$ & None \\
\hline
\end{tabular}




\begin{tabular}{|c|c|c|c|c|c|c|c|c|c|}
\hline Krause & 1976 & Germany & 55 & 65 & 74 & 6 & 5 & $\begin{array}{l}\text { Mixed } \\
\text { exercise }\end{array}$ & $\begin{array}{l}1 \text { myocardial } \\
\text { infarction }\end{array}$ \\
\hline Kruidenier & 2011 & Netherlands & 35 & 67 & 63 & 24 & 2,5 & Treadmill & None \\
\hline Lee & 2007 & UK & 33 & 68 & 67 & 12 & 3 & $\begin{array}{l}\text { Circuit } \\
\text { training }\end{array}$ & None \\
\hline Leicht & 2011 & Australia & 12 & 64 & 50 & 52 & 3 & Treadmill & None \\
\hline Lundgren & 1989 & Sweden & 25 & 61 & 79 & 24 & 2 & $\begin{array}{l}\text { Mixed } \\
\text { exercise }\end{array}$ & None \\
\hline Mannarino & 1991 & Italy & 10 & 63 & 67 & 24 & 2 & Treadmill & None \\
\hline Mannarino & 1989 & Italy & 8 & 69 & 75 & 24 & 2 & Treadmill & None \\
\hline Martinez & 2009 & Israel & 84 & 69 & 66 & 37 & 2 & Treadmill & None \\
\hline Mazari & 2012 & UK & 60 & 69 & 62 & 12 & 3 & $\begin{array}{l}\text { Circuit } \\
\text { training }\end{array}$ & None \\
\hline McDermott & 2009 & USA & 103 & NR & 52 & 24 & 3 & Treadmill & $\begin{array}{l}1 \text { cardiac } \\
\text { arrest, } \\
1 \text { chest pain }\end{array}$ \\
\hline McDermott & 2004 & USA & 24 & 70 & 50 & 12 & 3 & Treadmill & $\begin{array}{l}1 \text { heart } \\
\text { arrhythmias, } \\
1 \text { chest pain }\end{array}$ \\
\hline McGuigan ${ }^{70}$ & 2001 & Australia & 11 & 61 & 36 & 24 & 3 & $\begin{array}{l}\text { Circuit } \\
\text { training }\end{array}$ & None \\
\hline Mika & 2011 & Poland & 34 & 64 & 90 & 12 & 3 & Treadmill & None \\
\hline Mika & 2005 & Poland & 49 & 64 & 85 & 12 & 3 & Treadmill & None \\
\hline Murphy & 2012 & $\begin{array}{l}\text { USA + } \\
\text { Canada }\end{array}$ & 43 & 69 & 49 & 26 & 3 & Treadmill & None \\
\hline Nawaz & 2001 & UK & 52 & 69 & 83 & 6 & 2 & Treadmill & None \\
\hline $\mathrm{Ng}$ & 2005 & UK & 16 & NR & 63 & 8 & 3 & Walking & None \\
\hline Nicolaï & 2010 & Netherlands & 202 & 62 & 67 & 52 & 2,5 & Treadmill & None \\
\hline Parr & 2009 & South-Africa & 17 & 68 & 30 & 6 & 3 & $\begin{array}{l}\text { Strength } \\
\text { training }\end{array}$ & None \\
\hline Patterson & 1997 & USA & 27 & NR & 53 & 12 & 3 & $\begin{array}{l}\text { Mixed } \\
\text { exercise }\end{array}$ & None \\
\hline Perkins & 1996 & UK & 26 & 65 & NR & 24 & 2 & $\begin{array}{l}\text { Mixed } \\
\text { exercise }\end{array}$ & None \\
\hline Regensteiner & 1997 & USA & 10 & NR & NR & 12 & 3 & Treadmill & None \\
\hline
\end{tabular}

\begin{tabular}{|c|c|c|c|c|c|c|c|c|c|}
\hline Ritti Dias & 2010 & Brazil & 34 & 62 & 67 & 12 & 2 & $\begin{array}{l}\text { Strength } \\
\text { training }\end{array}$ & None \\
\hline Sanderson & 2006 & Australia & 28 & 66 & 39 & 6 & 3 & Treadmill & None \\
\hline Savage & 2001 & USA & 11 & 68 & 68 & 12 & 3 & Treadmill & None \\
\hline Saxton & 2011 & UK & 71 & 60 & 79 & 24 & 2 & Treadmill & None \\
\hline Scheffler & 1994 & Germany & 15 & 69 & 70 & 4 & 5 & $\begin{array}{l}\text { Treadmill } \\
\text { + walking }\end{array}$ & None \\
\hline Schlager & 2011 & Austria & 20 & 66 & 65 & 24 & 2 & Treadmill & None \\
\hline Slørdahl & 2005 & Norway & 18 & 66 & NR & 8 & 3 & Treadmill & None \\
\hline Spronk & 2009 & Netherlands & 75 & 68 & 52 & 24 & 2 & Treadmill & None \\
\hline Stewart & 2008 & UK & 30 & 62 & 67 & 12 & 2 & $\begin{array}{l}\text { Circuit } \\
\text { training }\end{array}$ & None \\
\hline Streminski & 1992 & Germany & 30 & 69 & 67 & 4 & 5 & Treadmill & $\begin{array}{l}1 \text { increased } \\
\text { heart rate }+ \\
\text { dyspnea; } \\
1 \text { worsening of } \\
\text { osteoarthritis; } \\
1 \text { ischialgia }\end{array}$ \\
\hline Tew & 2009 & UK & 27 & 69 & NR & 12 & 2 & $\begin{array}{l}\text { Arm } \\
\text { ergometry }\end{array}$ & None \\
\hline Tisi & 1997 & UK & 22 & 67 & 69 & 4 & 1 & $\begin{array}{l}\text { Mixed } \\
\text { exercise }\end{array}$ & None \\
\hline Treat-Jacobson & 2009 & USA & 37 & 76 & 33 & 12 & 3 & $\begin{array}{l}\text { Treadmill } \\
\text { or arm er- } \\
\text { gometry }\end{array}$ & None \\
\hline Tsai & 2002 & Taiwan & 27 & 68 & 81 & 12 & 3 & Treadmill & None \\
\hline Villemur & 2011 & France & 11 & 72 & NR & 2 & 5 & Treadmill & None \\
\hline Wang & 2007 & Australia & 22 & 54 & 100 & 12 & 3 & Treadmill & None \\
\hline Winterfeld & 1983 & Germany & 17 & 64 & NR & 12 & 2 & $\begin{array}{l}\text { Circuit } \\
\text { training }\end{array}$ & None \\
\hline Wood & 2006 & Australia & 7 & 65 & 72 & 6 & 3 & Treadmill & None \\
\hline
\end{tabular}

Notes: NR $=$ not reported, $N R=$ not reported,
$a=$ recalculated to frequency per week,
$b=$ median age 
Table 3 Overview of adverse events occurred during supervised exercise training (SET)

Event

\section{Heart arrhythmias}

Angina pectoris

Cardiac arrest ${ }^{2}$

Myocardial infarction ${ }^{\natural}$

ncreased heart rate and dyspnea

Worsening of osteoarthritise

Ischialgia

Notes: $a=$ successfully resuscitate

= fatal outcome

= no treatment needed

Table 4 Complication rates during SET

\begin{tabular}{l|cc} 
& Number of events & Complication rates $^{\mathbf{a}}$ \\
\hline All cause & 8 & $1: 10,340$ \\
Cardiac & 6 & $1: 13,788$ \\
Non-cardiac & 2 & $1: 41,363$ \\
\hline
\end{tabular}

Note: $\quad \mathrm{a}=$ expressed as 1 event per number of patient-training hours

\section{Discussion}

The aim of this review was to identify SET-related complications in patients with IC as a means to determine its safety. To our knowledge, this is the first study addressing the safety issue of SET. Eight complications were false-positive rate is observed in patients with chest pain, whereas this percentage is even higher in asymptomatic patients. ${ }^{\left({ }^{30}\right)} \mathrm{A}$ false-positive test result will incorrectly and unnecessary exclude IC patients from a firstchoice treatment. ${ }^{(1,7)}$ In addition, false-positive results may lead to unnecessary (invasive) interventions (eg, coronary angiography) with accompanied morbidity, mortality, and costs. The risk of a false-negative test result after CPET is also present, as illustrated by one study ${ }^{(31)} \mathrm{A}$ cardiac arrest was reported during exercise although no obstructive CAD was found during prior testing. Cardiac screening may therefore create a false sense of safety. Moreover, CPET itself also harbors a risk of cardiac complications. Approximately one to five complications per 10,000 tests were reported, ${ }^{(27,32)}$ a percentage that clearly exceeds any risk caused by SET. Some have suggested that CPET is useful in detecting silent ischemia. ${ }^{(33)}$ Because most patients with IC will experience myocardial ischemia as anginal pain during exertion, some $17 \%$ to $47 \%$ will be asymptomatic (ie, silent ischemia type I). ${ }^{(34)}$ Extensive research has been done in patients with diabetes mellitus, a condition associated with an even higher prevalence of silent ischemia. ${ }^{(35)} \mathrm{A}$ difference between silent and symptomatic CAD with respect to prognosis was never found. ${ }^{(34,36,37)}$ Patients with IC may potentially benefit from routine CAD screening through detection of silent ischemia; however, considering the high prevalence of silent ischemia and assuming that these patients were also present in our review, a larger number of incidents would have been expected. The value of CPET is therefore also questionable from this perspective. Lastly, CPET is potentially useful as a tool allowing for training optimization. A recent review attempted to identify the most important exercise components resulting in an optimal training protocol for patients with IC. The study concluded that intensity, duration, and program con- tent were not independently associated with improvement of maximal of pain-free walking distance. ${ }^{(25)}$ Therefore, selection of SET components based on CPET does not seem to be a useful strategy.

Our study has limitations associated with its retrospective methodology and the possibility of publication bias. Only 35 of 74 studies explicitly reported the possible occurrence of adverse events, whereas a detailed description was sometimes lacking. Therefore, it remains uncertain whether all reported events indeed occurred during SET. On the other hand, some complications may have been missed. However, these were most likely minor events pre- venting the patient from stopping any activity. By our strategy of using information on dropouts, the number of patient-hours was increased, as was the chance on some extra uncertainty. The included studies were very heterogenic in content of the SET program, and an exact description of intensity was often lacking. Therefore, identifying any potential as- sociation between intensity of SET and complication risk was not possible. Subgroup analyses were impossible due to the small number of adverse events. An additional disadvantage of the present study is that the most of the participants were men. Consequently, the safety of SET is not demonstrated in female IC patients, although gender differences regarding the response to SET were never reported. 
A major methodological concern is that some studies excluded patients with limited exercise capacity due to angina, heart failure, chronic obstructive pulmonary dis- ease, arthritis, poorly controlled hypertension, or recent myocardial infarction. Exclusion of these vulnerable cardiac patients might have resulted in an underestimation of the number of adverse events. Therefore, generalizing these results to IC patients with major comorbidities is hazardous. On the other hand, one must appreciate that exercise training also reduces the all-cause mortality in patients with congestive heart failure by $11 \% .{ }^{(38)}$ Others demonstrated in patients with stable CAD that a 12-month program of regular physical exercise resulted in superior event-free survival and exercise capacity compared with percutaneous coronary angioplasty (88\% vs. 70\%; P 1/4.023). ${ }^{(39)}$ As a consequence, patients with (cardiac) comorbidity should not routinely be excluded from SET in daily practice. However, each patient obviously requires careful monitoring.

\section{Conclusions}

The present review demonstrates that SET can safely be prescribed in IC patients because cardiovascular complication rates associated with this type of therapy are extremely low. However, caution should be taken when applying these results in patients with major comorbidity.

\section{References}

1. Norgren L, Hiatt WR, Dormandy JA, Nehler MR, Harris KA, Fowkes FG. InterSociety Consensus for the Management of Periph- eral Arterial Disease (TASC II) J Vasc Surg 2007;45(Suppl S):S5-67.

2. Spronk S, Bosch JL, Veen HF, den Hoed PT, Hunink MG. Inter- mittent claudication: functional capacity and quality of life after exercise training or percutaneous transluminal angioplastydsystematic review. Radiology 2005;235:833-42.

3. Regensteiner JG, Hiatt WR, Coll JR, Criqui MH, Treat-Jacobson D, McDermott MM, et al. The impact of peripheral arterial disease on health-related quality of life in the Peripheral Arterial Disease Awareness, Risk, and Treatment: New Resources for Survival (PART- NERS) Program. Vasc Med 2008;13:15-24.

4. Muluk SC, Muluk VS, Kelley ME, Whittle JC, Tierney JA, Webster MW, et al. Outcome events in patients with claudication: a 15-year study in 2777 patients. J Vasc Surg 2001;33:251-7; discussion: 257-8.

5. Diehm C, Allenberg JR, Pittrow D, Mahn M, Tepohl G, Haberl RL, et al. Mortality and vascular morbidity in older adults with asymp- tomatic versus symptomatic peripheral artery disease. Circulation 2009;120:2053-61.

6. Rehring TF, Sandhoff BG, Stolcpart RS, Merenich JA, Hollis HW Jr. Atherosclerotic risk factor control in patients with peripheral arterial disease. J Vasc Surg 2005;41:816-22.

7. Hirsch AT, HaskalZJ, Hertzer NR, Bakal CW, Creager MA, Halperin JL, et al. ACC/AHA 2005 guidelines for the management of patients with peripheral arterial disease (lower extremity, renal, mesenteric, and abdominal aortic): executive summary a collaborative report from the American Association for Vascular Surgery/Society for Vascular Surgery, Society for Cardiovascular Angiography and Interventions, Society for Vascular Medicine and Biology, Society of Interventional Radiology, and the ACC/AHA Task Force on Practice Guidelines (Writing Committee to Develop Guidelines for the Management of Patients With Peripheral Arterial Disease) endorsed by the American Association of Cardiovascular and Pulmonary Rehabilitation; National Heart, Lung and Blood Insti- tute; Society for Vascular Nursing; TransAtlantic Inter-Society Consensus; and Vascular Disease Foundation. J Am Coll Cardiol 2006;47:1239-312.

8. Tilloy E, Montaye M, Kee F, Bingham A, Arveiler D, Ruidavets JB, et al. Contribution of cardiovascular risk factors to coronary risk in patients with intermittent claudication in the PRIME Cohort Study of European men. Atherosclerosis 2009;206:563-8. 
9. Duran NE, Duran I, Gurel E, Gunduz S, Gol G, Biteker M, et al. Coronary artery disease in patients with peripheral artery disease. Heart Lung 2010;39:116-20.

10. Sukhija R, Yalamanchili K, Aronow WS. Prevalence of left main coro- nary artery disease, of three- or four-vessel coronary artery disease, and of obstructive coronary artery disease in patients with and without peripheral arterial disease undergoing coronary angiography for sus- pected coronary artery disease. Am J Cardiol 2003;92:304-5.

11. St-Pierre AC, Cantin B, Lamarche B, Auger D, Despres JP, Dagenais GR. Intermittent claudication: from its risk factors to its long-term prognosis in men. The Quebec Cardiovascular Study. Can J Cardiol 2010;26:17-21.

12. Watson L, Ellis B, Leng GC. Exercise for intermittent claudication. Cochrane Database Syst Rev 2008;(4):CD000990.

13. Leng GC, Fowler B, Ernst E. Exercise for intermittent claudication. Cochrane Database Syst Rev 2000;(2):CD000990.

14. Wind J, Koelemay MJ. Exercise therapy and the additional effect of supervision on exercise therapy in patients with intermittent claudica- tion. Systematic review of randomised controlled trials. Eur J Vasc Endovasc Surg 2007;34:1-9.

15. Bendermacher BL, Willigendael EM, Teijink JA, Prins MH. Supervised exercise therapy versus non-supervised exercise therapy for intermittent claudication. Cochrane Database Syst Rev 2006;(2):CD005263.

16. Gardner AW, Parker DE, Montgomery PS, Scott KJ, Blevins SM. Efficacy of quantified home-based exercise and supervised exercise in patients with intermittent claudication: a randomized controlled trial. Circulation 2011;123:491-8.

17. Fokkenrood HJ, Bendermacher BL, Lauret GJ, Willigendael EM, Prins MH, Teijink JA. Supervised exercise therapy versus non-supervised exercise therapy for intermittent claudication. Cochrane Database Syst Rev 2013;8:CD005263.

18. Sakamoto S, Yokoyama N, Tamori Y, Akutsu K, Hashimoto H, Takeshita S. Patients with peripheral artery disease who complete 12- week supervised exercise training program show reduced cardiovascu- lar mortality and morbidity. Circ J 2009;73:167-73.

19. Makris GC, Lattimer CR, Lavida A, Geroulakos G. Availability of su- pervised exercise programs and the role of structured home-based ex- ercise in peripheral arterial disease. Eur J Vasc Endovasc Surg 2012;44: 569-75; discussion: 576.

20. Lauret GJ, van Dalen HC, Hendriks HJ, van Sterkenburg SM, Koelemay MJ, Zeebregts CJ, et al. When is supervised exercise therapy considered useful in peripheral arterial occlusive disease? A nationwide survey among vascular surgeons. Eur J Vasc Endovasc Surg 2012;43: 308-12.
21. Shalhoub J, Hamish M, Davies AH. Supervised exercise for intermit- tent claudicationdan under-utilised tool. Ann R Coll Surg Engl 2009;91:473-6.

22. Jongert MW, Hendriks HJ, van Hoek J, Klaasboer-Kogelman K, Robeer GG, Simens B, et al. [KNGF-Guideline Intermittent Claudi- cation (author's translation)]. Ned Tijd Fysiother 2003;113:3-50.

23. Frans FA, Bipat S, Reekers JA, Legemate DA, Koelemay MJ. System- atic review of exercise training or percutaneous transluminal angioplasty for intermittent claudication. Br J Surg 2012;99:16-28.

24. Stewart KJ, Hiatt WR, Regensteiner JG, Hirsch AT. Exercise training for claudication. N Engl J Med 2002;347:1941-51.

25. Fakhry F, van de Luijtgaarden KM, Bax L, den Hoed PT, Hunink MG, Rouwet EV, et al. Supervised walking therapy in patients with inter- mittent claudication. J Vasc Surg 2012;56:1132-42

26. Pavy B, Iliou MC, Meurin P, Tabet JY, Corone S. Safety of exercise training for cardiac patients: results of the French registry of complica- tions during cardiac rehabilitation. Arch Intern Med 2006;166:2329-34.

27. Myers J, Arena R, Franklin B, Pina I, Kraus WE, McInnis K, et al. Recommendations for clinical exercise laboratories: a scientific statement from the American Heart Association. Circulation 2009;119:3144-61.

28. Skinner JS, Smeeth L, Kendall JM, Adams PC, Timmis A. NICE guidance. Chest pain of recent onset: assessment and diagnosis of recent onset chest pain or discomfort of suspected cardiac origin. Heart 2010;96:974-8.

29. Faisal AW, Abid AR, Azhar M. Exercise Tolerance Test: a comparison between true positive and false positive test results. J Ayub Med Coll Abbottabad 2007;19:71-4.

30. Megnien JL, Simon A. Exercise tolerance test for predicting coronary heart disease in asymptomatic individuals: a review. Atherosclerosis 2009;205:579-83.

31. McDermott MM, Ades P, Guralnik JM, Dyer A, Ferrucci L, Liu K, et al. Treadmill exercise and resistance training in patients with peripheral arterial disease with and without intermittent claudication: a randomized controlled trial. JAMA 2009;301:165-

32. Gibbons LW, Mitchell TL, Gonzalez V. The safety of exercise testing. Prim Care 1994;21:611-29.

33. Ahmed AH, Shankar K, Eftekhari H, Munir M, Robertson J, Brewer A, et al. Silent myocardial ischemia: Current perspectives and future di- rections. Exp Clin Cardiol 2007;12:189-96. 
34. Zellweger MJ. Prognostic significance of silent coronary artery disease in type 2 diabetes. Herz 2006;31:240-5.

35. Ditchburn CJ, Hall JA, de Belder M, Davies A, Kelly W, Bilous R. Silent myocardial ischaemia in patients with proved coronary artery disease: a comparison of diabetic and non-diabetic patients. Postgrad Med J 2001;77:395-8.

36. Moskowitz RM, Chatterjee K, Parmley WW. Silent myocardial ischemia: an update. Med Clin North Am 1988;72:1033-54.

37. Sayer JW, Timmis AD. Investigation of coronary artery disease in diabetes: is screening of asymptomatic patients necessary? Heart 1997;78:525-6.

38. O'Connor CM, Whellan DJ, Lee KL, Keteyian SJ, Cooper LS, Ellis SJ, et al. Efficacy and safety of exercise training in patients with chronic heart failure: HF-ACTION randomized controlled trial. JAMA 2009;301:1439-50.

39. Hambrecht R, Walther C, Mobius-Winkler S, Gielen S, Linke A, Conradi K, et al. Percutaneous coronary angioplasty compared with exercise training in patients with stable coronary artery disease: a ran- domized trial. Circulation 2004;109:1371-8.

Additional material for this article (Studies included in the review) may be found online at www.jvascsurg.org. 


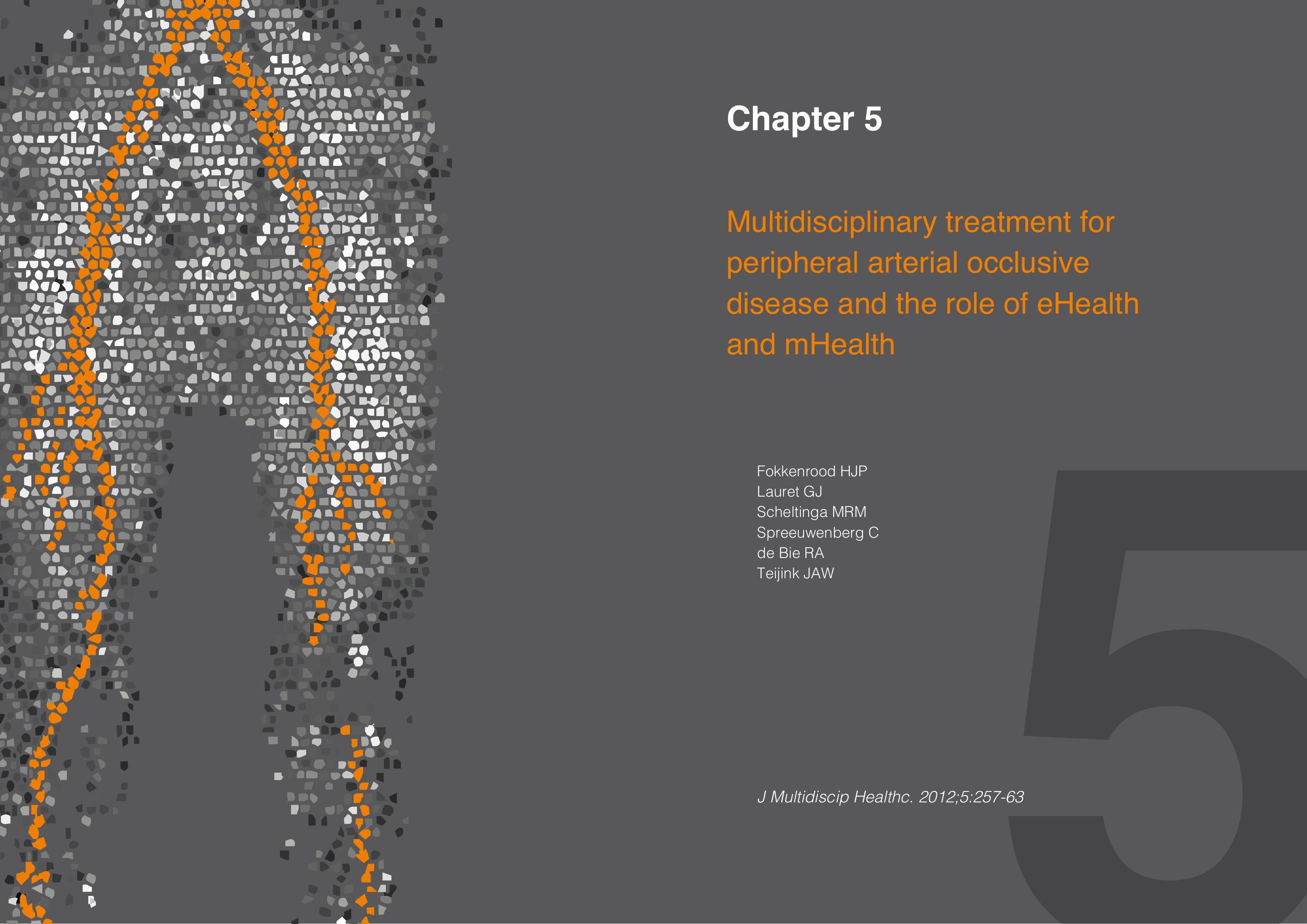




\section{Abstract}

Increasingly unaffordable health care costs force care providers to develop economically viable and efficient health care plans in the near future. Nowadays, only a minority of all newly diagnosed peripheral arterial occlusive disease (PAOD) patients receives an efficient and structured conservative treatment for their disease. The aim of the present article is to introduce an innovative effective treatment model termed ClaudicatioNet. This concept was launched in the Netherlands as a means to tackle these shortcomings and stimulate cohesion and collaboration between stakeholders

The overall goal of ClaudicatioNet is to stimulate quality and transparency of PAOD treatment by optimizing multidisciplinary healthcare chains on a national level. Improved quality is based on stimulating both a theoretical and practical base of knowledge, while eHealth and mHealth technologies are used to create clear insights of provided care to enhance quality control management. These technologies can be used to stimulate patient empowerment thereby increasing efficacy of PAOD treatment even more. This online community consists of a web portal with public and personal information supplemented with a mobile application. By connecting these tools, a social community is created where patients can meet and keep in touch with fellow patients whereas useful information for supervising healthcare professionals is provided.

The ClaudicatioNet concept will likely create a more efficient and cost effective PAOD treatment by simply improve the quality of supervised training (SET) programs, extending its possibilities and stimulating patient empowerment by using eHealth and mHealth solutions. A free market principle is introduced by creating transparency of provided care by using objective and subjective outcome parameters. Cost effectiveness is achieved as SET programs will possibly substitute or postpone expensive invasive vascular interventions.

\section{Introduction}

In the near future, the increasingly unaffordable health care costs in Europe (from 13\% of national income in 2012 to $31 \%$ in 2040 in the Netherlands, comparable for other European countries), necessitates a more economically viable and efficient healthcare. ${ }^{1}$ In a recently released document titled "Healthcare, how much is it worth?" the Dutch ministry of health, welfare and sport notes several reasons for this increase. ${ }^{(1)}$ The aging population explains $25 \%$ of this rise, while a larger amount is clarified by the growth in prosperity including the introduction of new technologies, change of expectations of healthcare in society and increasing life expectancies. Additionally the change in epidemiologic factors, causing an increase in patients with chronic diseases, will lead to a rise in demand for healthcare, again resulting in a rise of costs. These changes in society and its influence on healthcare are well reflected in peripheral arterial occlusive disease (PAOD). PAOD is a chronic systemic disease caused by the manifestation of atherosclerosis. The atherosclerotic process of narrowing and hardening of arteries can occur in each artery of the human body although it mainly affects coronary, cerebral and peripheral arteries (especially those in the lower extremities). ${ }^{(2)}$ PAOD has a high prevalence in the general population affecting up to $20 \%$ in persons over 70 years. ${ }^{3}$ These numbers indicate that PAOD affects over 27 million individuals in North America and Europe. ${ }^{2}$ The manifestation of PAOD varies from absence of symptoms to tissue loss that may eventually require amputation of an affected limb. PAOD patients commonly present with symptoms of typical intermittent claudication (IC, which means 'to limp') in $20-50 \%$ of the cases. ${ }^{(2)}$ IC is defined as muscle discomfort in the lower limb elicited by exercise and relieved by rest within 10 minutes. ${ }^{(2)}$ IC has a significant impact on quality of life. New insights to op timize PAOD (IC) treatment are based on non-invasive conservative as well as (minimal) invasive strategies. However, restructuring the provided healthcare system might support an efficient PAOD treatment even more. The aim of this article is to introduce an innovative treatment model based on the WHO chronic care framework in combination with an optimized multidisciplinary healthcare chain and the implementation of innovative eHealth \& mHealth technologies. 


\section{Efficient conservative treatment of PAOD}

Several international guidelines (the American College of Cardiology/ American Heart Association (ACC/AHA) and the Trans-Atlantic Inter-Society Consensus on Management of Peripheral Arterial Disease (TASC II) describe an overall strategy and basic treatment for patients with symptomatic PAOD. ${ }^{(2,4)}$ Treatment of PAOD should consist of a multi-component therapy of cardiovascular risk reduction by pharmacology interventions and lifestyle coaching (1) and symptomatic treatment (2). ${ }^{(5)}$

The first component aims to prevent cardiovascular events (myocardial infarction, stroke) and related morbidity and mortality. The prevalence of cerebrovascular disease in patients with PAOD is about $25-50 \%{ }^{(6)}$ In a subgroup of patients with severe and symptomatic PAOD a 15 -fold increase in mortality rate was found. ${ }^{(7)}$ For IC, a 5-year mortality rate of $19.2 \%$ is described, of which $70 \%$ is due to cardiovascular causes. Cardiovascular risk reduction is important to prevent cardiovascular events (myocardial infarction or stroke) and related morbidity and mortality. The most important modifiable risk factors for atherosclerosis are smoking, hypertension, diabetes mellitus, hyperlipidaemia and obesity ${ }^{(8)}$ According to international guidelines, all symptomatic patients with or without a history of cardiovascular disease are generally prescribed antiplatelet therapy in combination with a statin. ${ }^{(9)}$

The second component aims at relieving symptoms related to PAOD. An initial treatment modality is exercise therapy, first suggested by Erb in $1898 .^{(10)}$ This approach was supported more than a century later by a Cochrane review. In this review, an overall improvement in maximal walking time with a mean difference of 5.12 minutes (CI 4.51 - 5.72) was found in favor of exercise therapy compared with usual care or placebo. ${ }^{(11)}$ In daily practice, lack of adequate individual supervision appears to be an important barrier for the initiation and continuation of exercise therapy in patients with PAOD. A Cochrane review by Bendermacher et al. and a RCT by Nicolai et al. showed that supervised exercise therapy (SET) was superior to a non-supervised program. ${ }^{(12,13)}$ In a cohort study, community-based SET appeared to be as effective as hospital-based SET. ${ }^{(13)}$ Communitybased SET has the advantage of providing a larger capacity of care and is feasible in close proximity to the patient's home environment. With this body of evidence, it is clear that SET provided by a physical therapist (PT) in combination with cardiovascular risk management (CVRM) must be offered to all patients with IC.

\section{Current status and problem statement for the Dutch situation}

Unfortunately, only a minority of all newly diagnosed IC patients receives an efficient and structured treatment of their disease. We are convinced that the underlying contributing factors impeding full-scale implementation of SET \& CVRM programs are:

- Outdated national guidelines.

The guidelines of the Dutch Association of General Practitioners and the CBO guideline followed by Dutch vascular surgeons are at best ambiguous and do not mention the need of SET. ${ }^{(14,15)}$ In contrast, the contemporary international guidelines for PAOD explicitly state supervision as a necessary component in exercise therapy.

- Availability of a valid and established SET program

When medical specialists and General Practitioners (GP) have carried out the indication and initiated referral for SET correctly. Whom to refer to? Insights in PTs who provide qualitative SET programs were not available. Transparency and accessibility to quality SET programs are required.

The vast majority of the 23,000 Dutch PT's are not adequately trained according to the Royal Dutch Society for Physical Therapy guideline for IC. Those who are, do not always have sufficient experience to provide this form of therapy in a correct way. Moreover a SET program has a broader scope than physiotherapy alone. An essential feature of SET is that full attention is paid to existing comorbidities and modifiable lifestyle factors. If these aspects are not addressed appropriately, suboptimal results and loss of resources will occur. Adequately trained PT's should ideally be able to perform individual training, recognise symptoms, provide lifestyle counselling and monitor medication adherence.

- Reimbursement issues

A major problem is the fact that the Dutch healthcare system does not stimulate the use of conservative treatment modalities for patients with IC. Cardiovascular risk management and invasive vascular interventions are fully compensated by the Dutch basic healthcare insurance. However, for patients with IC, the first 20 treatment sessions of a SET program are not covered in this basic health care insurance (since January 1st, 2012) and have to be paid for by the patient (ei- 
ther directly or through additional insurance). From the 21st session onwards all additional treatment sessions given in one year are covered by the basic health care insurance. This peculiar reimbursement policy results in a financially driven motivation to be treated by a vascular surgeon with a minimal invasive vascular intervention (e.g. angioplasty) or even bypass surgery (both fully reimbursed). This in spite of the associated risk of morbidity $(<0,5-10 \%)$ and even mortality (2-3\% for bypass surgery). 9

- A knowledge gap

$\triangleright \quad$ In a recent nationwide survey among Dutch vascular surgeons, it appeared that around $70 \%$ of vascular surgeons believe that co-existing significant cardiopulmonary comorbidity and/or an aorta-iliac stenosis or occlusion are arguments not to refer for a SET program. Recent evidence shows that these arguments seem to be out-dated. ${ }^{(16)}$

$\triangleright \quad$ In severe or invalidating IC cases, as subjectively as these may be, invasive vascular interventions are performed without awaiting the possible positive effects of a SET program

\section{Introducing The ClaudicatioNet Concept}

To tackle the present shortcomings and optimize the cohesion and collaboration between all stakeholders (including the patient and insurance companies), the ClaudicatioNet concept was launched in the Netherlands in 2011. The goal of ClaudicatioNet is to improve the quality and transparency of PAOD treatment. Including an optimal working referral system by stimulating multidisciplinary healthcare supported with innovative eHealth solutions. The ClaudicatioNet concept aims at a nationwide enrolment. Regional networks, based on the 12 Dutch provinces and local hospital coverage are created.

The role of a GP or vascular surgeon in the ClaudicatioNet concept

Setting up a regional network is initiated by vascular surgeons introducing the concept to apprehensive healthcare professionals together with local, enthusiastic and motivated PTs. Subsequently all healthcare professionals need to be familiarized with the concept
Figure 1 Schematic overview of role models within the ClaudicatioNet (CNet) Concept.

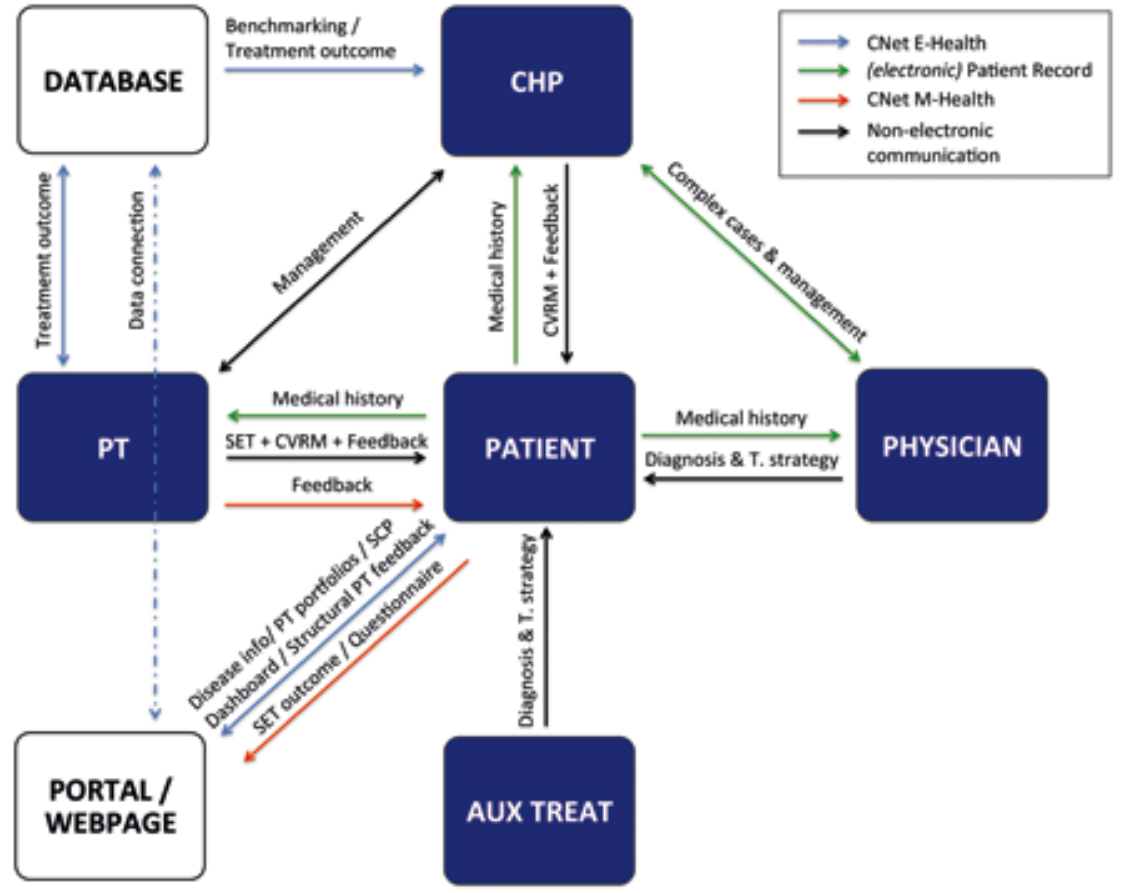

Notes: PT: Physical Therapist; CHP: Coordinating Healthcare Professional: AUX TREAT: auxiliary treatment professional: SET: Supervised Exercise Treatment; CVRM: Cardio vascular Risk Management: $T$ : treatment; SCP: Social Community Platform.

and their respective roles. The first step in the patient's pathway is determining the diagnosis of IC by a physician (GP or vascular surgeon). Subsequently, a GP or a vascula surgeon initiates a treatment strategy (conservative vs. invasive) and supports the coordinating healthcare professional (CHP) in complex cases. 
The role of a coordinating healthcare professional in the ClaudicatioNet concept

A CHP (e.g. GP's and vascular surgeons or their supporting staff), is pivotal within the ClaudicatioNet concept and the management of the multidisciplinary treatment of PAOD patients. As can be seen in Fig. 1 the collaboration between CHP, PT and patient is essential in the ClaudicatioNet model. The supporting staff member of a physician (vascular nurse, GP practice assistant) accepts/takes the role of CHP. The CHP functions as a care manager coordinating a patient's CVRM and SET and comprehends the availability of high quality care in the vicinity of the patient. Furthermore the CHP collaborates closely with the PT's in the regional network overseeing the quality of care provided. Ultimately these CHP need to embrace, participate and manage their regional network based on treatment results and opinions of treated patients. Auxiliary treatment by specialized healthcare professionals (CVRM prevention and/or diabetic treatment teams) could support the $\mathrm{CPH}$ by providing specialized care for the patient.

The role of a specialized PT in the ClaudicatioNet Concept.

PTs need to understand the 3 year specialisation program. At the forefront of the treatment program are specialized PT's providing SET and, if applicable, stimulate lifestyle changes and medication adherence. PTs are required to treat patients with contemporary SET programs. To guarantee this quality, ClaudicatioNet provides a professional development program for specialisation in the field of PAOD. This program is complementary to existing specialisations in chronic illness or cardiopulmonary rehabilitation (e.g. COPD, heart failure). Apart from acquiring a sound theoretical base of knowledge, PTs gain practical knowledge by increasing their experience by regularly treating patients with PAOD.

The role of the patient in the ClaudicatioNet concept

The patient fulfils an important role in the concept, by delivering objective as well as subjective feedback of provided care to all stakeholders (figure 1). SET outcomes like maximal walking distance, functional walking distance, quality of life and information on smoking cessation and medication compliance are useful in evaluating quality of provided care.

Creating an efficient referring system

A three months SET program that actually starts 2 weeks before a three months evalu- ation appointment precludes evaluation of a first line conservative treatment approach and is therefore not efficient. Delay in the initiation of a SET program occurs frequently, both due to patient as well as or PT factors (holiday's, waiting lists, postponing the first appointment by the patient etc.).This will be prevented by a web-based referring system (automated patient - PT allocation and software that locates and notifies the PT closest to the patient's home). The PT should contact the patient within a limited time frame (for example 2 working days) and initiate the SET program within 5 working days. In case a PT does not make contact with the patient within two working days, a nearby PT is notified automatically. The first responder is then awarded by the possibility to treat a patient and subsequent reimbursement.

\section{Quality of provided care}

All PTs can join a regional network, however they have to meet a set of criteria. Completion of a registered course 'Intermittent Claudication' is obligatory. As well as a wellequipped practice and a broad patient orientation, so that other limitations are recognized and reported. After these primary criteria are met, the PT enters a specialisation program and is entered into an online web-based 'care-finder' directory. This website is used by patients as well as CPHs to choose a PT based on aspects such as location (address or postal code) and personal portfolio data (figure 1). During this three-year specialisation program, PTs need to comply with a progressive set of criteria to ensure participation If these criteria are not met, visibility on the care-finder ends and so receiving referrals.

Participation criteria

1. The PT delivers care according to up to date evidence based guidelines in PAOD SET treatment.

2. The PT provides standardised feedback of results, motivation and medication adherence to the CHP

3. The PT keeps a correct patient administration, including outcome and process indicators of all patients.

4. The PT actively participates in a life long learning in the field of peripheral arterial disease and concomitant disease. Fifteen hours of CNet accredited courses annually and presence (every other year) at the yearly organised ClaudicatioNet congress are mandatory. 
5. The PT maintains an up to date web based personal portfolio (www.claudicationet.nl). In this profile all items of a PTs specialisation progress is visualized. Items like attendance at additional relevant courses, on site visitation reports, contact information, a photograph (recognition of caregiver) as well as space for some personal (ambition) statements are registered in this portfolio.

\section{Transparency of provided care}

ClaudicatioNet improves transparency of provided care by creating clear and extensive portfolios on the care-finder website. Portfolios will be updated with real-time outcome information as soon as a connection is made between the national ClaudicatioNet database and currently existing patient managing software. As of 2013, patients and CHP's will have access to this data through a user-friendly dashboard in order to visualize a clear overview of outcome results (figure 1). This will also allow patients to gain direct feedback onto their own results in a patient's personal web portal (www.etalagebenen.nl).

CHP's will be able to effectively monitor the progress of their patients and, more importantly, monitor outcome results of their own regional network by comparing these with a nationwide benchmark. The development of this innovative online feedback system enhances quality control management and strengthens the multidisciplinary health care chain. PTs with outstanding results can easily be identified and showcased. Others with suboptimal results will be stimulated to learn from these colleagues or, if needed, removed from the care-finder directory.

\section{Improving patient empowerment}

Stimulating self-management causes the patient to learn and become more engaged in their own health process. This is useful in PAOD treatment, because of the importance of lifestyle changes and a proactive attitude. Implementation of e-Health \& $\mathrm{m}$-Health technology is promising and has the potential of a significant reduction in healthcare costs.
e-Health solutions

Structural feedback from patients regarding the quality of provided SET in a simple short questionnaire, offers tremendous possibilities (figure 1). For example, patients will be asked about their opinions of involved caregivers (GP, VS, CPH and PT) and the provided SET program. This information is then compared and analysed with objective SET outcome results (maximal walking distance, functional walking distance, QoL surveys).

To improve the patient's own responsibility in the treatment of PAOD, a part of the numerous SET sessions can be utilized to introduce patients with the personal web-portal. Patients gain access to an online community specifically geared to PAOD patients. This portal brings together a wealth of information for patients through highly accessible online resources. The website will have two components, namely a public domain and a personal portfolio. The public section contains general disease information on PAOD and information regarding treatment modalities (figure 1). Together with a social community platform, where patients can view public profiles and engage with peers, as well as a notice board where patients can post messages for other network participants (figure 1). Patients can exchange experiences, knowledge or even get in touch with each other (by chat, forums or through a video call connection). The personal section allows access to a patient' own journal (with outcome results registered by their PT), their treatment plan and questionnaires in order to monitor, evaluate and benchmark the care provided. It also allows synchronous and asynchronous contact with healthcare providers through modalities as mail, chat and video call.

\section{m-Health solutions}

The omnipresence of mobile technology offers unique opportunities for the healthcare industry. It has the potential to make healthcare better, faster, cheaper and more accessible. M-Health can improve the quality of care in that it helps patients and clinicians gain a better understanding of the disease through the wealth of personalized information generated by remote health monitoring devices and apps. It increases the access and efficiency by allowing patients and physicians to monitor and analyse (real-time) health data and empowering patients to learn and become engaged in their health process. Lastly, it can significantly reduce healthcare costs by eliminating unnecessary treatment and facilitating patients to self-manage their condition through automated and highly personal tools. 
ClaudicatioNet is developing a mobile application to augment the patient personal digital portfolio. The 'Walk Mate' app is an innovative application that has several features to help reinforce self-management and patient empowerment through peer support, gamification and telecoaching. The app features an ambient location radar in order to search for fellow patients or volunteers within the WalkMate network, a pre-recorded audio coach for walking advices and stimulation, GPS tracking device to register walking distances and speed, live coaching by (schooled) peers and coach (PT) support through an audio/video call system (figure 1). The diversity and the ability to personalise the available functions, the presence of virtual and live coaching and the facilitation of social interaction and support makes this application a powerful tool in adjunction to SET. Ultimately, outcome parameters of the WalkMate app will be incorporated into the personal patient' portfolio on the personal domain of web portal website (www.etalagebenen.nl). This app will go live in 2013.

\section{Conclusion}

Physicians, CHP's, PTs and most of all patients will benefit from participation in a regional ClaudicatioNet network. By referring patients to ClaudicatioNet PTs, healthcare professionals are guaranteed of transparent and standardised high quality treatment. Through ClaudicatioNet all caregivers are collaboratively able to provide the best standards of practice. In time, other treatment goals such as lifestyle counselling and monitoring medication adherence will be taken up by all involved caregivers to extend the possibilities of SET.

Optimizing the concept will stimulate the effectiveness of a multidisciplinary healthcare chain that is nowadays required. An economic recession in combination with an aging population will cause associated increase of costs. The ClaudicatioNet concept is likely to create a more efficient and cost effective PAOD treatment. First of all by simply improve the quality of provided SET by offering PTs a controlled specialization program. Secondly by introducing a free market principle in healthcare by creating transparency of provided care through the usage of objective outcome parameters. Furthermore SET extended with a focus on cardiovascular risk reduction in a high risk population should be effective because of the reduction in morbidity and mortality caused by diseases with a cardiovascular origin. Cost effectiveness is achieved for the simple reason that a SET program will substitute or at least postpone expensive invasive vascular interventions. Encouraging patient empowerment by using innovative eHealth and mHealth solutions will create an online community, thereby informing and connecting fellow patients.

\section{Acknowledgements}

The authors are grateful for the assistance in writing of Nicole Verhofstad, $\mathrm{PhD}$ as well as Daniëlle van Dalen, MSc from our department of vascular surgery, Catharina Hospital, Eindhoven, The Netherlands. 


\section{References}

1. Rapport "De zorg: hoeveel extra is het ons waard? Dutch Ministry of Health Welfare and Sports. 12-06-2012.

2. Norgren L, Hiatt WR, Dormandy JA, Nehler MR, Harris KA, Fowkes FG. Inter-Society Consensus for the Management of Peripheral Arterial Disease (TASC II). J Vasc Surg. Jan 2007;45 Suppl S:S5-67.

3. Selvin E, Erlinger TP. Prevalence of and risk factors for peripheral arterial disease in the United States: results from the National Health and Nutrition Examination Survey, 19992000. Circulation. Aug 10 2004;110(6):738-743.

4. Hirsch AT, Haskal ZJ, Hertzer NR, et al. ACC/AHA 2005 Practice Guidelines for the management of patients with peripheral arterial disease (lower extremity, renal, mesenteric, and abdominal aortic): a collaborative report from the American Association for Vascular Surgery/Society for Vascular Surgery, Society for Cardiovascular Angiography and Interventions, Society for Vascular Medicine and Biology, Society of Interventional Radiology, and the ACC/AHA Task Force on Practice Guidelines (Writing Committee to Develop Guidelines for the Management of Patients With Peripheral Arterial Disease): endorsed by the American Association of Cardiovascular and Pulmonary Rehabilitation; National Heart, Lung, and Blood Institute; Society for Vascular Nursing; TransAtlantic Inter-Society Consensus; and Vascular Disease Foundation. Circulation. Mar 21 2006;113(11):e463-654.

5. Lauret GJ, van Dalen DC, Willigendael EM, et al. Supervised exercise therapy for intermittent claudication: current status and future perspectives. Vascular. Feb 2012;20(1):12-19.

6. Criqui MH. Systemic atherosclerosis risk and the mandate for intervention in atherosclerotic peripheral arterial disease. Am J Cardiol. Oct 11 2001;88(7B):43J-47J.

7. Criqui MH, Langer RD, Fronek A, et al. Mortality over a period of 10 years in patients with peripheral arterial disease. N Engl J Med. Feb 6 1992;326(6):381-386.

8. Dormandy J, Heeck L, Vig S. Predictors of early disease in the lower limbs. Semin Vasc Surg. Jun 1999;12(2):109-117.

9. MRC/BHF Heart Protection Study of cholesterol lowering with simvastatin in 20,536 highrisk individuals: a randomised placebo-controlled trial. Lancet. Jul 6 2002;360(9326):7-22.

10. Erb W. About intermittent walking and nerve disturbances due to vascular disease [Uber das "intermitterende Hinken" und adere nervose Storungen in Folge von Gefasserkrankungen] Deutsch Z Nervenheilk. 1898;13:1-76.
11. Watson L, Ellis B, Leng GC. Exercise for intermittent claudication. Cochrane Database Syst Rev. 2008(4):CD000990.

12. Bendermacher BL, Willigendael EM, Teijink JA, Prins MH. Supervised exercise therapy versus non-supervised exercise therapy for intermittent claudication. Cochrane Database Syst Rev. 2006(2):CD005263.

13. Nicolai SP, Teijink JA, Prins MH. Multicenter randomized clinical trial of supervised exercise therapy with or without feedback versus walking advice for intermittent claudication. J Vasc Surg. Aug 2010;52(2):348-355.

14. Bartelink M, Stoffers H, Boutens E, Hooij J, Kaiser V, Boomsma L. NHG-standaard Perifeer arterieel vaatlijden [Guideline peripheral arterial disease from the Dutch Genera Practioners Society]. Huisarts en Wetenschap 2003;46::848-858.

15. Vahl AC. Richtlijn diagnostiek en behandeling van arterieel vaatlijden van de onderste extremiteit 2005.

16. Lauret GJ, van Dalen HC, Hendriks HJ, et al. When is supervised exercise therapy considered useful in peripheral arterial occlusive disease? A nationwide survey among vascular surgeons. Eur J Vasc Endovasc Surg. Mar 2012;43(3):308-312. 


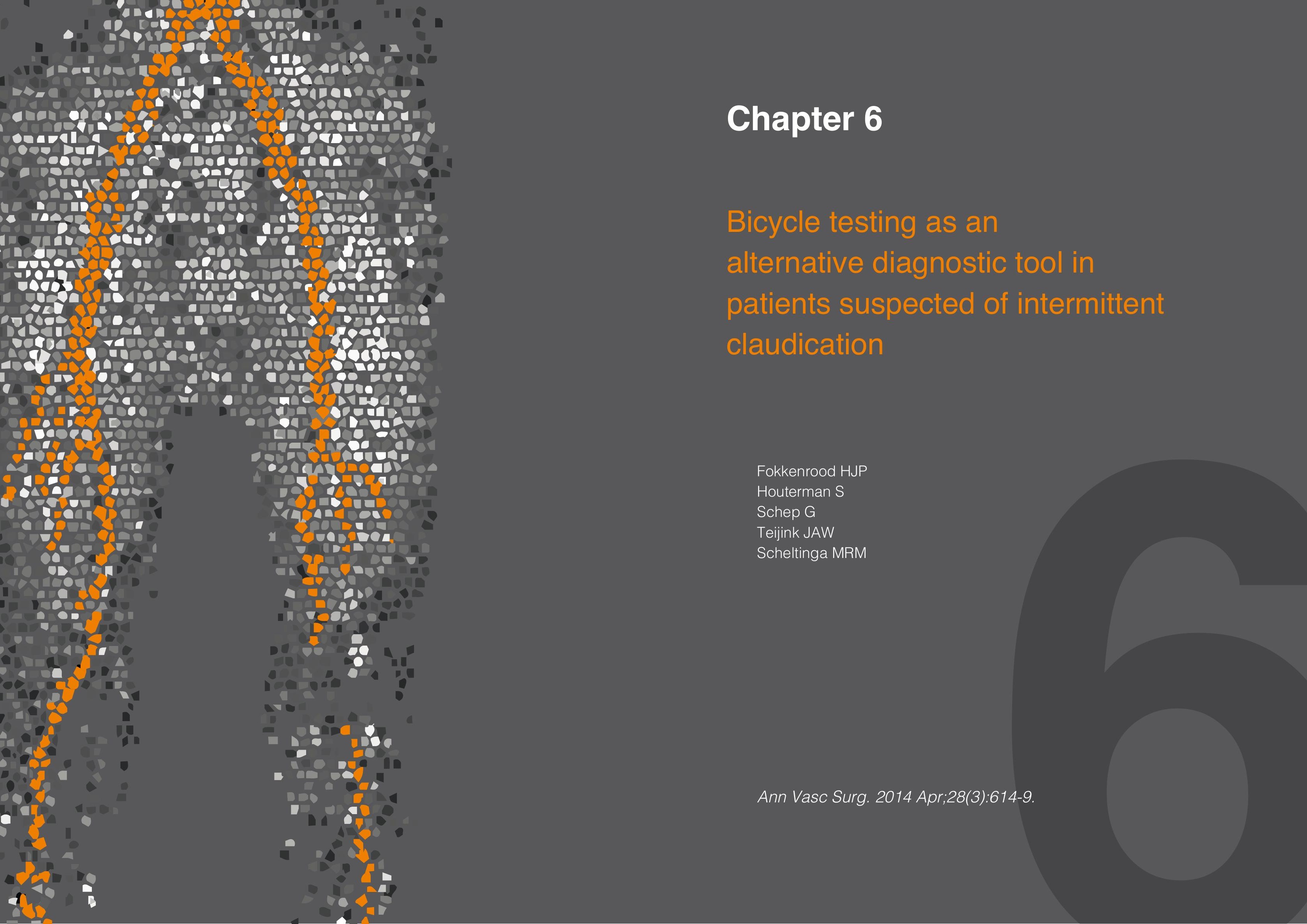




\section{Abstract}

Background

The Ankle-Brachial Index (ABI) obtained after a treadmill challenge is often used to confirm the diagnosis of intermittent claudication (IC). However, some patients fail treadmill testing due to (temporary) orthopedic or neurologic comorbidity or fear of falling. Aim of this study was to evaluate the role of bicycle testing as an alternative for treadmill testing. It was hypothesized that ABIs obtained after bicycle tests were not different compared to values after standard treadmill testing.

Methods:

In this validation study, newly diagnosed IC patients (Rutherford 1-3) underwent a standard treadmill test (TT, 'gold standard') and two bicycle protocols, one with a continuous resistance submaximal character (submaximal bicycle test, SBT) and a second with an incremental ramp form having a maximal character (maximal bicycle test, MBT). ABI of both legs were obtained prior to and twice after each of these three different exercise tests. Healthy individuals matched for age and gender served as controls.

Results:

The study population consisted of 32 patients (age $68 \pm 11,21$ male). ABIs of each leg $(\mathrm{n}=64)$ obtained after TT correlated significantly with values obtained after either bicycle test (TT vs SBT, $r=0.90, \mathrm{p}<0.001$; TT vs MBT, $\mathrm{r}=0.88, \mathrm{p}<0.001$ ). Drops in ABI after both types of exercise were significantly correlated (TT vs SBT: $r=0.66$, $\mathrm{p}<0.001$; TT vs MBT, $\mathrm{r}=0.32, \mathrm{p}<0.01)$. A $98 \%$ sensitivity and a $86 \%$ specificity for the diagnosis IC was observed after SBT. After MBT, these values were $98 \%$ and $43 \%$, respectively. Healthy controls $(n=13)$ always demonstrated ABI values $>0.9$ after cycling.

Conclusions:

Both a submaximal and a maximal bicycle test may serve as an alternative noninvasive tool for detecting intermittent claudication. Bicycle tests may potentially be used in patients unable to perform a treadmill test.

\section{Introduction}

The diagnosis intermittent claudication (IC) is usually suspected following a medical history and physical examination. Noninvasive diagnostic vascular examinations are often used as an adjunctive tool to confirm a clinical diagnosis IC or to screen patients who have associated risk factors. Calculation of the ankle-brachial index (ABI) is a relatively simple and inexpensive method to confirm the suspicion of peripheral arterial occlusive disease $^{(1)}$. ABI measurements can be obtained before and after a standard exercise to un mask occlusive disease that is not apparent from studies during resting states. Exercise augments the pressure gradient across stenotic lesions thereby optimizing test sensitivity in patients with a typical history of $\mathrm{IC}^{(2,3)}$

According to the Trans-Atlantic Inter-Society Consensus on Management of Peripheral Arterial Disease (TASC II) guidelines, treadmills are preferentially used for challenging patients suspected of $\mathrm{IC}^{(3)}$. Other forms of tests such as cycling are not frequently performed for this purpose. A simple explanation may be that an IC patient typically presents with impaired walking rather than impaired cycling. Therefore, a walking test may seem an obvious choice for eliciting symptoms of IC. Moreover, an unknown portion of referred patients are (temporarily) unable to walk on a treadmill due to a recent operation or fear. This group of mostly elderly individuals often requires more training and proper supervision before treadmill testing is sufficiently discriminative. Cycling tests may possibly serve as an alternative diagnostic challenge test for vascular obstructive disease in these patient groups ${ }^{(4)}$. Cycling is weight independent and possibly better tolerated by some of these patients.

An additional advantage of bicycle testing is the convenient incorporation of cardiopulmonary exercise monitoring equipment such as an electrocardiogram and blood pressure registration. These supporting tools may be advantageous given the high incidence of cardiovascular comorbidity in an IC population ${ }^{(5)}$. It is presently unknown if bicycling testing is as sensitive as treadmill testing in diagnosing IC. The goal of the present study was to determine the correlation between treadmill testing and bicycle testing in IC patients. We hypothesized that bicycle testing is a viable alternative for treadmill testing in confirming the diagnosis IC 


\section{Methods}

\section{Subjects}

The medical ethical board of the Máxima Medical Centre (MMC), Veldhoven, The Netherlands, approved this study. Patients with IC were selected in the outpatient vascular clinic between March 2011 and June 2011. Inclusion criteria were newly diagnosed patients with symptoms of IC $>3$ months and an $\mathrm{ABI}<0.9$ at rest or an $\mathrm{ABI}<0.9$ after exercise or a fall in ankle systolic pressure by more than 20 percent from its baseline value after exercise. Patients with rest pain, tissue loss or severe cardiopulmonary disease (>NYHA class II) or problems understanding the study protocol were excluded.

Studying healthy controls was deemed necessary in order to verify if bicycle testing altered $A B I$ values after exercise. Individuals matched for age and gender with recently corrected minor non-vascular surgical morbidity not reporting IC were asked to serve as controls. All participants were unaware of the study hypothesis and gave verbal and written informed consent.

\section{Sample size and statistical power}

A minimum of 26 patients was required to detect a minimal 0.15 difference in ABI index between measurements after a treadmill test and a bicycle test with $80 \%$ of power using a two-sided t-test and a 0.05 significancy level. To allow for a $25 \%$ dropout rate, a total of 32 patients was required. A sample size of 8 controls was calculated for attaining a significant difference compared to IC patients.

\section{Study Protocol}

A vascular surgeon performed history taking and physical examination and checked whether patients met inclusion criteria. They underwent treadmill and bicycle tests in random order. A Doppler probe (Nicolet Vasoguard, VIASYS Healthcare, USA) measured systolic pressures of right brachial artery, right posterior tibial artery (RPTa) and left posterior tibial artery (LPTa) in fixed order. If RPTa or LPTa were absent, measurements were obtained from the pedal dorsal artery (PDa). ABI measurement of just a single foot artery (and not both) was performed as a means to minimize the elapsed time between consecutive measurements. If signals over the PDa were also absent, the patient was excluded. ABI values were calculated as ratios to brachial systolic pressure. Control subjects only performed bicycle testing.
Treadmill test

Resting ABI values were measured prior to treadmill testing after participants rested in a supine position for 5 minutes. A treadmill test (TT) operated at a speed of $3.0 \mathrm{~km}$ per hour with an $8 \%$ slope for a 5 minute maximum. Duration until onset of IC (initial claudication duration, ICD, in seconds) and maximum duration (absolute claudication duration, ACD, in seconds) were noted after 5 minutes of walking (or after exhaustion). ABIs were obtained from both sides as fast as possible three times during a 6-minute time period after discontinuation of the test. Right and left legs were subsequently measured, whereas measurements were always started in the right leg. As timing of these latter measurements showed a too large variance, only the first two values were used for further analysis.

Submaximal and maximal bicycle tests

Prior to bicycle testing, participants were allowed a 5-minute rest in supine position. ABI values were obtained with a hand-held Doppler probe (Huntleigh Dopplex D900, Huntleigh, United Kingdom). An automatic pneumatic blood pressure monitor was used to obtain systolic blood pressures of the right brachial artery.

Cycling tests were performed using an electronically braked computer-controlled cycle ergometer bicycle (LODE ${ }^{\oplus}$ Excalibur Sport, Lode, The Netherlands). Seat and steer height of this bicycle were optimally adjusted to the subject's own posture. Individuals were instructed to perform a submaximal bicycle test (SBT) for a 5-minute maximum period with 65 rounds per min (rpm) and continuous resistance ('Step form'). The amount of resistance was computed to approach a similar workload $\left(\right.$ in $\mathrm{VO}_{2}$ ) as performed during the walking tests using the American College of Sports Medicine (ACSM) leg ergometry and walking equations ${ }^{(6)}$. Duration until onset of IC and maximum duration were noted after 5 minutes of this cycling exercise (or earlier if the subject stopped in case of exhaustion or IC). ABI values of both sides were subsequently obtained two times immediately after each other, again the right leg was measured first. After a 10 minute resting time (including the 6 minute measurement period), a maximal bicycling test (MBT) was star ted using an incremental approach ('ramp'). Aim of this heavier protocol was to expose patients to a maximal exercise test with continuously increasing resistance towards a peak after approximately 10 minutes. A questionnaire was used prior to this exercise test to allow for an estimation of this peak tolerance. If unbearable pain or exhaustion occurred, $\mathrm{ABI}$ values of both legs were again subsequently registered. 
Statistical analysis

Statistical analysis was performed using SPSS Statistics (MAC OS X version 20.0). Demographic data were analyzed using Pearson's chi-square, or Fisher's exact tests in case of cells with small numbers. It was assumed that both legs could be used as independent parameters in the analysis as each leg of a patient may respond differently to testing. ABI values were analyzed for skewness and kurtosis. A Wilcoxon Signed Rank test and Spearman's correlations were utilized to compare values in case of non-normal distribution whereas a paired Students T-test and Pearson's correlations analyzed normal distributed variables. Bland Altman plots (BA plots) were used to verify agreement between treadmill and bicycle tests. In this BA diagrams the differences between treadmill and bicycle testing (y-axis) were plotted against the averages of these two exercise types ( $\mathrm{x}$-axis). As a result the mean difference and its $95 \%$ confidence limits are shown. $\mathrm{P}$ values less than 0.05 were considered statistically significant.

\section{Results}

A total of 40 patients and 14 controls were eligible and consented to the study. Eight patients were excluded (ABI $>0.9$ after exercise $n=2$, incompressible arteries $n=3$, inability to perform TT because of psychological reasons or equilibrium discomfort $n=3$ ) as was 1 'healthy' control (rest ABI <0.9). Therefore, a total of 32 patients (64 legs) and 13 controls (26 legs) were used in the analyses. There were no differences in demographic data between the two groups (table 1). ABI values obtained from patients who performed a treadmill test (TT) first $(\mathrm{n}=17)$ were not different from data of subjects performing a bicycle test first $(n=15)$

Correlations in patient legs with an $A B \mid<0.9(n=64)$

56 of 64 patient legs demonstrated an $\mathrm{ABI}<0.9$ after TT. ABI values of all 64 legs obtained after both cycling tests correlated significantly with $\mathrm{ABIs}$ measured after treadmill testing (TT vs SBT, $\mathrm{r}=0.90, \mathrm{p}<0.001$; TT vs MBT, $\mathrm{r}=0.88, \mathrm{p}<0.001$; figure $1 \& 2$ ). The average discrepancy (bias) between the TT/SBT is $0.04 \pm 0.14$ (Bland-Altman plot, Figure 3). A substantial scatter is visible throughout the whole range of measurements. However, there was no converging or diverging trend visible in the scatterplot (figure 3 ).

Figure 4 depicts the correlation $(\mathrm{r}=0.66, \mathrm{p}<0.001)$ between the absolute fall of $\mathrm{ABI}$ after a treadmill exercise $(\triangle \mathrm{ABI}, \mathrm{TT})$ compared to the drop of ABI after a SBT $(\triangle \mathrm{ABI}$,
SBT). A weak correlation was also observed between these values after $\triangle \mathrm{ABI}$, TT and $\operatorname{MBT}(r=0.32, p=0.01$, graph not shown).

Correlations in patients legs with $A B I>0.9$ in rest $(n=22)$

22 of 64 patient legs demonstrated an $A B I>0.9$ in rest. $A B I$ values of these legs obtained after both cycling tests correlated significantly with ABIs measured after treadmill testing ( $\mathrm{n}=22$, TT vs SBT, $\mathrm{r}=0.77, \mathrm{p}<0.001$; TT vs MBT, $\mathrm{r}=0.51, \mathrm{p}<0.02)$.

\section{Sensitivity and specificity}

$A B I$ values of 64 patient legs were used in a sensitivity analysis whereas $A B I<0.9$ after TT was used as golden standard. The SBT revealed a $98 \%$ sensitivity for the diagnosis IC and a $86 \%$ specificity with an ABI cut off value of 0.89 (AUC: 0.98 ; figure 5). Positive predicted values (PPV) and negative predicted values (NPV) were $98 \%$ and $86 \%$, respectively. The MBT showed a $98 \%$ sensitivity and a $43 \%$ specificity with a $0.92 \mathrm{ABI}$ cut off value (AUC 0.95; graph not shown) and a PPV of $93 \%$ and NPV of $75 \%$ respectively.

ABIs of healthy controls were always $>0.9$ after both bicycle tests. $(n=26$; ABI prior to testing: $1.16 \pm 0.10,1^{\text {th }} \mathrm{ABI}$ measured directly after SBT: $1.09 \pm 0.10$, ABI measured directly after MBT: $1.02 \pm 0.12$

Figure 1 Pearson's correlation of ABI measured directly after treadmill testing (TT) and sub maximal bicycle testing (SBT).

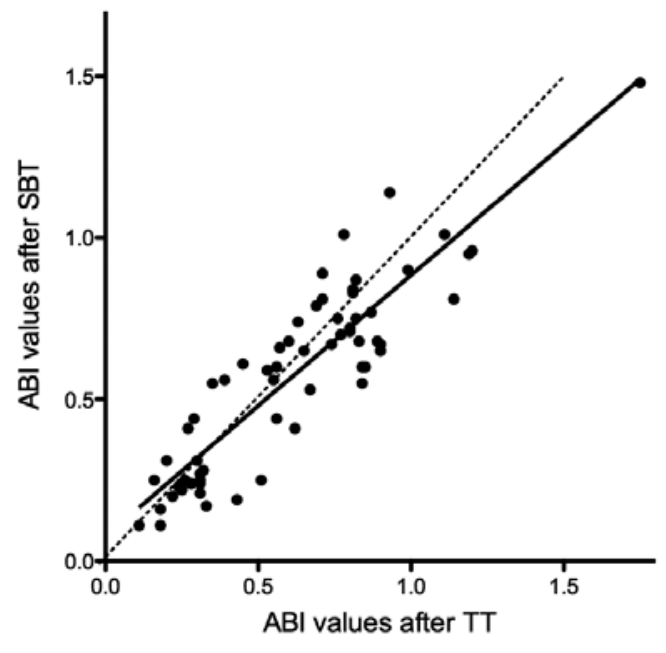

Note: Dotted line is line of identity. 

Figure 2 Pearson's correlation of ABI measured directly after treadmill testing (TT) and

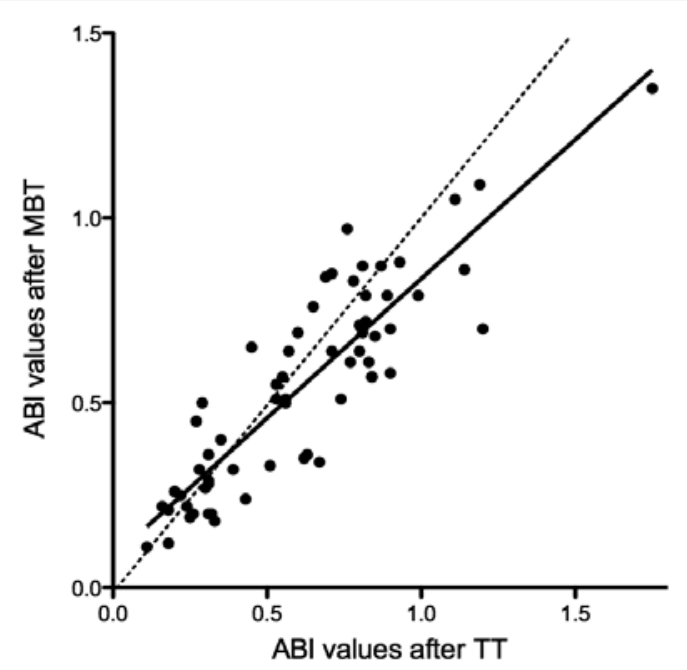

Note: Dotted line is line of identity.

Figure 3 BlandeAltman plot of ABI values of treadmill testing (TT) versus submaximal bicycle testing (SBT) directly after exercise ( $\mathrm{n} 1 / 464)$

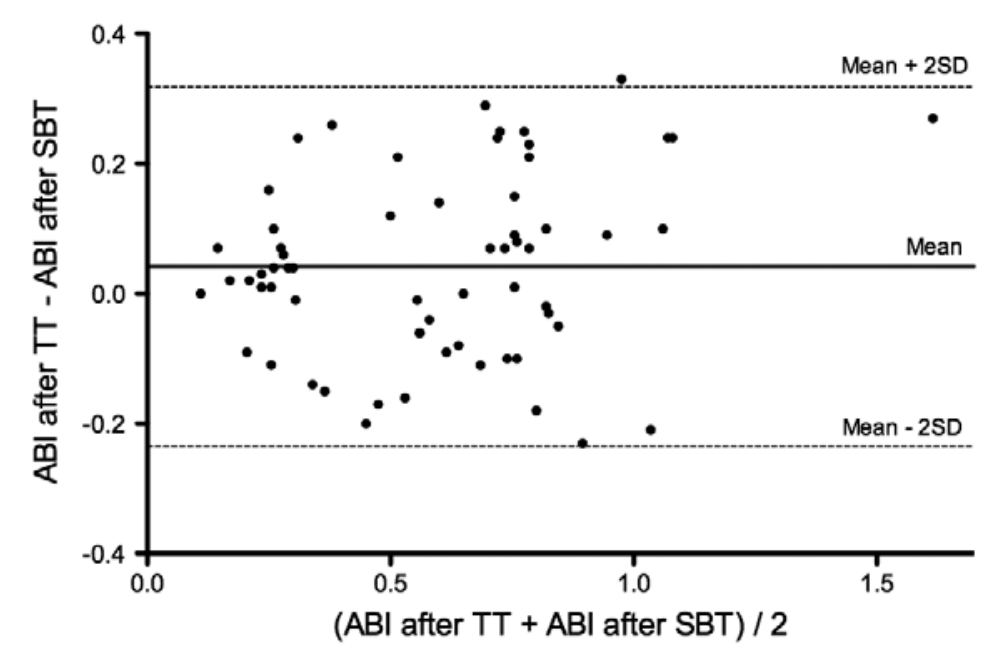

Note: Horizontal bold line depicts the mean difference (bias), whereas the dotted lines show the $95 \%$ limits of agreement, which are defined as the mean difference \pm 1.96 times the standard deviation of the differences.
Figure 4 Pearson's correlation of absolute fall of $\mathrm{ABI}$ between rest and post treadmill exercise $(\triangle A B I T T)$ and the fall of $A B I$ between rest and after submaximal cycling $(\triangle A B I S B T)$.

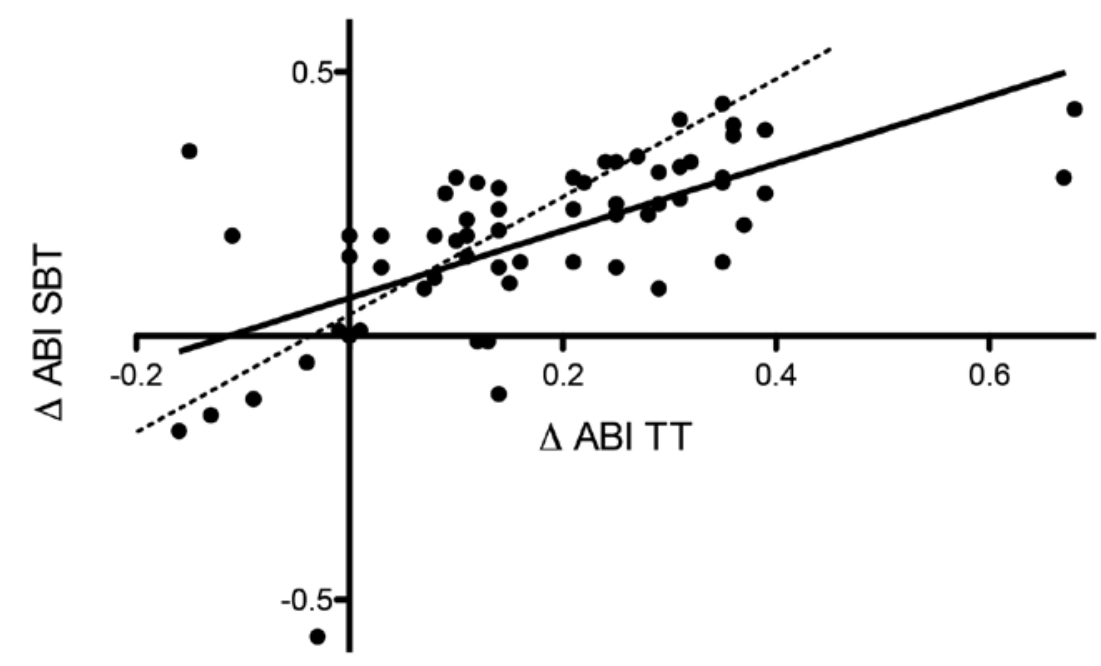

Note: Dotted line is line of identity.

Figure 5 ROC curve of submaximal bicycle test (SBT) and maximal bicycle test (MBT)

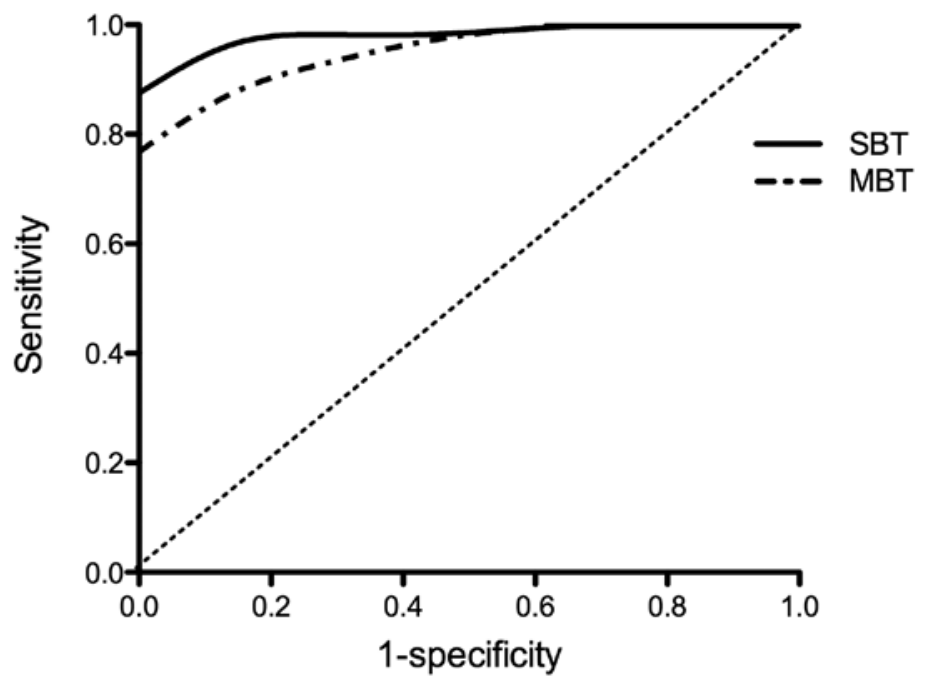

Note: Dotted line is line of identity. 


\section{Discussion and Conclusion}

Up to $50 \%-80 \%$ of patients with peripheral arterial occlusive disease (PAOD) are symptomatic, and half of these demonstrate complaints of $\mathrm{IC}^{(1)}$. A resting ABI measurement with additional exercise testing using a standard treadmill test is a simple, inexpensive and effective non-invasive diagnostic method for IC with a high sensitivity (79-95\%) and specificity $(95-100 \%)^{(7)}$. However, some patients are not able to adequately perform such testing, occasionally due to fear or (temporary) orthopedic or neurological causes. In the present trial, $7.5 \%$ of the patients were not able to safely/reliably complete a treadmill test. Other studies reported that $22-45 \%$ of the eligible patients were unable to undertake a treadmill test, mainly because of cardiac and pulmonary problems ${ }^{(8)}$. An alternative stress test may allow for a proper identification of IC in these patients. The present study was designed to validate two protocols of different intensity using a bicycle ergometer as an alternative diagnostic tool in patients suspected of IC. Findings of this study indicate that data obtained from bicycle testing are closely correlated with data after treadmill testing. Moreover high sensitivities for the diagnosis IC were obtained. Both a submaximal as well as a maximal bicycle test appeared valid methods and may serve as an alternative to treadmill testing in patients with IC.

Several theoretical advantages associated with a bicycle test may be identified. The method is 'non-weightbearing' allowing the testing of patients with orthopedic disease or with equilibrium problems. Bicycles can be used in patients who do not feel confident with treadmill testing. As in treadmill testing, diagnostic bicycle tests may also serve as a screening tool for determining cardiovascular risk ${ }^{(9,10)}$. For instance, a 10-year mortality rate due to cardiovascular disease of $62 \%$ for men with PAOD compared to $17 \%$ in the population of men without was found ${ }^{(5)}$. Others already demonstrated that bicycle testing is predictive of cardiovascular events and all-cause death. Furthermore, bicycling testing may have additional advantages in a subgroup of patients with severe cardiopulmonary disease or with very mild IC as the workload is more easily administered and monitored. These issues are particularly relevant in cyclists suffering from IC at high intensity exercise due to vascular flow limitation in the iliac arteries ${ }^{(11)}$. Furthermore, other characteristics of bicycle testing such as pedal forces are potentially useful in quantifying IC or PAOD. One could hypothesize that diminished blood flow in affected arteries will result in declining muscle strengths. As a consequence, pedal forces may also decline after pain symptoms are reported. Therefore, a bicycle may serve as a tool in several areas including the diagnostic, therapeutic and research arena

A fair correlation between $\mathrm{ABI}$ after walking tests and bicycling tests was earlier found in a small IC population $(\mathrm{r}=0.51-0.86)^{(12)}$. The present study confirmed in a twice as large group that ABI after walking and bicycling were strongly correlated $(r=0.88-0.90)$. Bland Altman plots, traditionally considered a robust reflection of agreement between different two tests, demonstrated minimal differences between both exercise methods. However, a substantial dispersion was observed indicating a considerable variability. This inconsistency may possibly be explained by an error in reproducibility. Earlier research suggested that an up to $19 \%$ difference between two consecutive $\mathrm{ABI}$ values may just be attributed to intra-observer errors ${ }^{(13)}$. A comparable magnitude of error was also observed in the present study as ABIs of $23 \%$ of the measured legs demonstrated an absolute ABI difference $>0.15$ prior to testing.

It is doubtful whether ABI drops after a cycling test reflect alterations obtained after a treadmill test. Although expected, one group of researchers did not find a significant correlation between absolute fall in ABI after both types of exercises ${ }^{(12)}$. It was hypothesized that this absent correlation was possibly due to a different haemodynamic response in the lower extremity after either cycling or walking. Motivation, experience and joint stiffness may also have added to the remaining variability in performance ability ${ }^{(14)}$. Cycling was deemed less useful as a diagnostic tool. In contrast the present study found a significant correlation (ICC $=0.66, \mathrm{p}<0.001$, figure 4 ) between $\mathrm{ABI}$ falls after either challenge. It may well be that systemic and local factors may play a less important role than previously suggested. Moreover, this finding also contributes to the confidence we have in the potential of a bicycle test as a useful diagnostic tool.

Which bicycle test may be preferred as an alternative diagnostic tool in future IC populations? The present study tested two different protocols. The first was a 'submaximal' regimen characterized by identical energy expenditure and mode of administration (direct and continuous submaximal exercise). By using such an exercise design, a possible confounding effect of workload or differences in energy expenditure was minimized. A second 'maximal test' was introduced to maximize these effects. As sensitivity of both bicycle tests were high (98\%) whereas the SBT demonstrated a higher specificity, it is 
advised to standardly use a submaximal regimen. Moreover, the risk on a cardiovascular event during submaximal testing may be reduced.

In conclusion, the present study indicates that bicycle exercise testing is a valid alternative tool in diagnosing patients with intermittent claudication (IC). Bicycle testing confers additional advantages including incorporation of a cardiovascular screening program. Patients suspected of having IC harbouring (temporary) contraindications for treadmill testing (neurological, orthopedic, fear) may safely be diagnosed using a bicycle. Submaximal testing is preferred to maximal testing because of optimal sensitivity and specificity whereas a risk on (cardiovascular) complications is lowest.

\section{References}

1. Hirsch AT, Haskal ZJ, Hertzer NR, Bakal CW, Creager MA, Halperin JL, et al. ACC/AHA 2005 Practice Guidelines for the management of patients with peripheral arterial disease (lower extremity, renal, mesenteric, and abdominal aortic): a collaborative report from the American Association for Vascular Surgery/Society for Vascular Surgery, Society for Cardiovascular Angiography and Interventions, Society for Vascular Medicine and Biology, Society of Interventional Radiology, and the ACC/AHA Task Force on Practice Guidelines (Writing Committee to Develop Guidelines for the Management of Patients With Peripheral Arterial Disease): endorsed by the American Association of Cardiovascular and Pulmonary Rehabilitation; National Heart, Lung, and Blood Institute; Society for Vascular Nursing; TransAtlantic Inter-Society Consensus; and Vascular Disease Foundation Circulation. 2006;113(11):e463-654.

2. Nicolaï SPA. The impact of supervised exercise therapy on intermittent claudication. 2010 .

3. Norgren L, Hiatt WR, Dormandy JA, Nehler MR, Harris KA, Fowkes FG. Inter-Society Consensus for the Management of Peripheral Arterial Disease (TASC II). J Vasc Surg. 2007;45 Suppl S:S5-67. Epub 2007/01/16.

4. Sanderson B, Askew C, Stewart I, Walker P, Gibbs H, Green S. Short-term effects of cycle and treadmill training on exercise tolerance in peripheral arterial disease. J Vasc Surg 2006;44(1):119-27. Epub 2006/07/11.

5. Criqui MH, Langer RD, Fronek A, Feigelson HS, Klauber MR, McCann TJ, et al. Mortality over a period of 10 years in patients with peripheral arterial disease. $N$ Engl J Med. 1992;326(6):381-6. Epub 1992/02/06.

6. American College of Sports Medicine: Guidelines for Exercise Testing and Prescription 8th ed. Thompson W, editor. Philadelphia: Lippincott Williams \& Wilkins; 2009.

7. Kruidenier LM, Nicolai SP, Hendriks EJ, Bollen EC, Prins MH, Teijink JA. Supervised exercise therapy for intermittent claudication in daily practice. J Vasc Surg. 2009;49(2):363-70

8. Yamamoto K, Miyata T, Onozuka A, Koyama H, Ohtsu H, Nagawa H. Plantar flexion as an alternative to treadmill exercise for evaluating patients with intermittent claudication. Eur J Vasc Endovasc Surg. 2007;33(3):325-9. Epub 2006/12/02.

9. Laukkanen JA, Lakka TA, Rauramaa R, Kuhanen R, Venalainen JM, Salonen R, et al. Cardiovascular fitness as a predictor of mortality in men. Arch Intern Med. 2001;161(6):82531. Epub 2001/03/27. 
10. Mora S, Redberg RF, Cui Y, Whiteman MK, Flaws JA, Sharrett AR, et al. Ability of exercise testing to predict cardiovascular and all-cause death in asymptomatic women: a 20-year follow-up of the lipid research clinics prevalence study. JAMA. 2003;290(12):1600-7. Epub 2003/09/25.

11. Schep G, Bender MH, Schmikli SL, Mosterd WL, Hammacher ER, Scheltinga M, et al. Recognising vascular causes of leg complaints in endurance athletes. Part 2: the value of patient history, physical examination, cycling exercise test and echo-Doppler examination. Int J Sports Med. 2002;23(5):322-8.

12. Askew CD, Green S, Hou XY, Walker PJ. Physiological and symptomatic responses to cycling and walking in intermittent claudication. Clin Physiol Funct Imaging. 2002;22(5):34855. Epub 2002/12/19.

13. Caruana MF, Bradbury AW, Adam DJ. The validity, reliability, reproducibility and extended utility of ankle to brachial pressure index in current vascular surgical practice. European journal of vascular and endovascular surgery: the official journal of the European Society for Vascular Surgery. 2005;29(5):443-51. Epub 2005/06/21.

14. Arfvidsson B, Wennmalm A, Gelin J, Dahllof AG, Hallgren B, Lundholm K. Co-variation between walking ability and circulatory alterations in patients with intermittent claudication. Eur J Vasc Surg. 1992;6(6):642-6. 


\title{
Chapter 7
}

\author{
Agreements and discrepancies \\ between the estimated walking \\ distance, non-graded and graded \\ treadmill testing and outside \\ walking in patients with \\ intermittent claudication
}

\author{
Fokkenrood HJP \\ van den Houten MML \\ Houterman S \\ Breek JC \\ Scheltinga MRM \\ Teijink JAW
}

Accepted in Ann Vasc Surg.

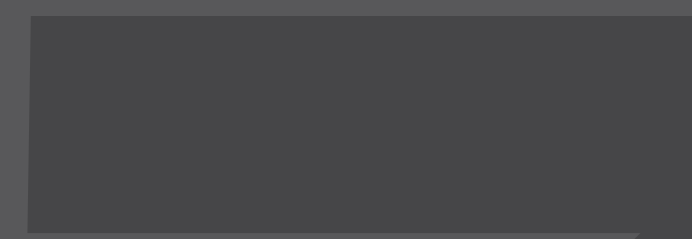




\section{Abstract \\ Objective \\ Disease severity in patients with intermittent claudication (IC) is often assessed using walking distances and treadmill tests. The aim of this study was to determine the agreement between walking distance as estimated by the patient, as measured during outside walking and as determined using a non- (NGTP) and an incremental graded (Gardner Skinner) treadmill protocol (GSP).}

Methods

In this prospective observational study, 30 patients with IC estimated their maximum walking distance (MWD) and completed a 'Walking Impairment Questionnaire' (WIQ). Outside walking was determined using a measuring wheel and a GPS controlled device. Primary outcomes were differences in MWD and variability (coefficient of variation, COV). Secondary outcomes were results of WIQ and differences in walking speed.

Results

Estimated walking distance was significantly higher than MWD as objectively measured during outside walking ( $400 \mathrm{~m}$ vs $309 \mathrm{~m}$, respectively $\mathrm{P}=.02$ ). A substantial variability $(\mathrm{COV}=55 \%)$ was found between both parameters. A small $35 \mathrm{~m}$ MWD difference between outside walking and GSP was found with a substantial scatter $(\mathrm{COV}=42 \%)$. In contrast, a much larger $122 \mathrm{~m}$ MWD difference was present between outside walking and NGTP (COV: 89\%). Patients walked significantly faster in the open air than on treadmills (median outside walking speed=3.8 km/h, GSP=3.2 $\mathrm{km} / \mathrm{h}, \mathrm{NGTP}=2.8 \mathrm{~km} / \mathrm{h} ; \mathrm{P}<.001)$.

\section{Conclusions}

An incremental graded (Gardner Skinner) treadmill protocol demonstrated the best agreement to outside walking. Discrepancies between treadmill tests and outside walking may be explained by a difference in walking speed. A single determination of a walking distance is a poor reflection of true walking capacity.

Key words: peripheral arterial disease, walking speed, variability, treadmill testing.

\section{Introduction}

Intermittent claudication (IC) is a classical symptom reflecting peripheral arterial disease (PAD). IC limits walking capacity and daily functioning ${ }^{(1)}$. Overall treatment strat egies are well described in international guidelines ${ }^{(2-4)}$. Limitations in walking distance play an important role in the assessment of disease severity. However, the value of various walking distance assessments is disputed. For instance, patients' estimations of walking distances do not properly reflect objectively measured daily life walking distances ${ }^{(5-7)}$. A disease specific questionnaire such as the Walking Impairment Questionnaire (WIQ) may quantify walking impairments in IC patients better but correlations with walking distances appeared weak ${ }^{(6)}$

Standardized treadmill tests are widely used for the objective assessment of walking distances ${ }^{(2-4)}$. However, there is a substantial variability in treadmill protocols ${ }^{(8)}$. In previous studies, fixed inclination was compared with flat off-treadmill walking (in- and outdoors $)^{(5,6,9,10)}$. Interestingly, none of these comparing studies used a graded incremental treadmill test, while such type of testing is recommended in the guidelines for physical therapy because of its high reliability ${ }^{(11,12)}$. Furthermore, previous studies used corridor walking as an imitation of daily life walking ${ }^{(5,6,10)}$. IC patients are mostly limited during outside walking with variations in speed, weather condition and surface. Compared to corridor walking, outside walking might be a more reliable reflection of daily life walking.

This study aims to compare the results in walking distances in a group of IC patients using four different tools that are frequently used by physical therapists in the assessment of IC severity. Results of a graded and a non-graded treadmill protocol, patient estimations and outside walking were compared in a single model. 


\section{Methods}

\section{Subjects}

This study was approved by the Medical Ethics Committee of the Catharina Hospital, Eindhoven, The Netherlands. Thirty consecutive patients with complaints of IC, confirmed by non-invasive testing $(<0.9$ Ankle-Brachial Index (ABI) at rest or a fall in systolic ankle pressure by more than $20 \%$ after exercise), were recruited from the vascular outpatient clinic. Patients with comorbidity possibly limiting walking apart from IC (i.e. neurological disorders, severe COPD, congestive heart failure, orthopedic impairments) or with insufficient knowledge of the English or Dutch language were excluded. All participants provided verbal and written informed consent.

\section{Study Protocol}

Baseline characteristics, comorbidity, medical history and cardiovascular risk factors were recorded. All patients performed an open air distance measuring test and completed two treadmill protocols on one day. The order of the three tests was randomized using 'Randomizer' (Kwixo Designs, lite version) for Android smartphones. Three physiotherapy students were trained to standardize patients' encouragement. Pairing of patient and physiotherapy student was also randomized. To minimize a difference in grade of encouragement, these tests were all performed under supervision of the same student. Patients rested for 20 minutes (supine or seated) between tests as ABI values are known to recover within this time interval ${ }^{(13)}$ Primary study outcomes were maximal walking distance (MWD) as determined by the patient's estimation, as obtained during outside walking and during the two treadmill tests. In addition, walking speed and the WIQ results were analyzed.

$$
\text { Self-reported MWD }
$$

Before testing, patients were asked to estimate their MWD, defined as 'the maximum distance (meters) you can walk before you are forced to stop by leg pain'

Outside walking

To approximate a real 'daily life' maximal walking distance, patients were asked to walk a standardized outside walking course on the parking lot of our training facility. They walked mostly in straight lines on the sidewalk and and were not interrupted by traffic, traffic lights, cyclists or otherwise. The course is a big square that is paved with regular stones and has a few curbs. One of the team of three researchers always walked some 3-5 meters behind the patient. The degree of encouragement during outside walking or during treadmill testing were similar. Each patient was instructed to continue until they were forced to stop by leg pain. MWD was recorded using both a measuring wheel (Stanley Black \& Decker Inc., New Britain USA) and a GPS controlled device (iPhone 4s; Apple, Silicon Valley, USA). Walking time was recorded using the iPhone.

\section{Treadmill tests}

Two different treadmill protocols were used. A graded incremental test (Gardner-Skinner Protocol, GSP) allows patients to walk at 3.2 kilometer per hour $(\mathrm{km} / \mathrm{h})$ with a $0 \%$ incline that increases by $2 \%$ every 2 minutes 14 . The maximum test duration is 20 minutes. The non-graded treadmill protocol (NGTP) has a fixed $0 \%$ incline and allows the patient to walk with a favorite walking speed which was set during the first 30 seconds of the treadmill testing. The use of handrails during treadmill walking was not permitted. Results are expressed as MWD.

Walking Impairment Questionnaire

Patients were asked to complete the WIQ evaluating several components of daily walking ability including an estimation of walking distance, speed and stair-climbing ability 15 . Patients were instructed to rank the degree of difficulty for each component using a 0 to 4 Likert scale. A validated Dutch version of the WIQ was used 16.

Walking Speed

Average walking speed of outside walking was calculated by dividing walking distance by time and was expressed in kilometer per hour $(\mathrm{km} / \mathrm{h})$.

\section{Statistical analysis}

It was assumed that outside walking reflected daily life walking most closely, and was therefore used as reference value. The distance in meters as obtained with the measuring wheel was used as reference value in all analyses. The Friedman two-way analysis of variance test determined differences between multiple assessments. A Wilcoxon Signed Rank test was used for comparison of two measurements. A Bonferroni method was used as post-hoc procedure for correction of multiple comparison testing. 
Various methods were used to assess study outcomes. Overall reliability was assessed by means of an Intraclass Correlation Coefficients (ICC) with 95\% confidence intervals (CI). Variability in measurements was assessed using coefficient of variation (COV). The $\mathrm{COV}$ was calculated as the standard deviation of the absolute difference between two assessments (outside walking vs. patient's estimation, outside walking vs. GSP, outside walking vs. NGTP) divided by the mean of the averages. Reproducibility was analyzed in Bland-Altman plots. These plots were used to visualize agreement between two measurements and were presented with $95 \%$ limits of agreement, calculated as the mean difference \pm 1.96 standard deviation (SD). The mean of both measurements was depicted on the horizontal axis whereas the difference was illustrated on the vertical axis. Linear regression analysis was performed and mean difference (bias) was calculated. Spearman rank correlations were estimated to compare WIQ scores with walking distances and speed. A correlation coefficient was considered strong if $\geq 0.7$, moderate if between 0.3 and 0.7 , and weak if $\leq 0.3$. P values less than 0.05 were considered statistically significant. Statistical analysis was performed using SPSS Statistics for Windows (version 20.0).

\section{Results}

Patients

Demographics and baseline characteristics of the 30 patients are presented in table 1.

Walking distances

Walking distances and walking speeds are listed in table 2.

Outside walking versus estimated walking distance

A moderate reliability was found between these outcomes (ICC $=0.62$ ). The median patients' estimated MWD was $400 \mathrm{~m}$, which is significantly higher than measured during outside walking (median $=309 \mathrm{~m}, \mathrm{P}=.02$ ) (table 2). The mean difference found in the Bland-Altman plot in MWD between both outcomes was $122 \mathrm{~m}$ (95\% limits of agreement: $-677.4 m-433.6 m$ ). A substantial and significant divergent scatter was reflected by the Bland-Altman plot (figure 1) indicating that the agreement between outside walking and estimated distances decreased when patients judged that their walking distance was longer than it actually was. This variability between outcomes was confirmed by a $55 \%$ COV value.
Outside walking versus Gardner Skinner Treadmill Protocol (GSP) Again a moderate reliability was found between these outcomes (ICC=0.67). No significant differences were found in median MWD as measured during outside walking (309m) and GSP (250m, P=.70, table 2). The mean difference in MWD as shown in the Bland Altman plot between outside walking and the GSP was 35m (95\% limits of agreement: $-328.5 \mathrm{~m}-399.0 \mathrm{~m}$ ) (figure 2). A $42 \%$ COV was found, dropping to $19 \%$ after removing two extremes (figure 2).

Outside walking versus Non Graded Treadmill Protocol (NGTP)

A moderate reliability was found between these outcomes (ICC $=0.46$ ). No significant differences in median MWD were found comparing outside walking (309m) with NGTP (317m, $\mathrm{P}=.20$, table 2). A - $122 \mathrm{~m}$ mean difference (95\% limits of agreement: -920.5 - 676.4) was calculated and depicted in the Bland Altman plot (figure 3). A significant negative scatter trend was seen (figure 3) indicating that the agreement between outside walking and the NGTP outcomes was lower in patients with larger walking distances. An 89\% COV variability was found, which dropped to $32 \%$ after removing two extreme outliers.

\section{WIQ scores and correlations}

The WIQ distance score correlated well with values of MWD as estimated by the patient or as measured during outside walking or following GSP or NGTP testing (table 3). In contrast, the WIQ total score correlated moderately with these distances (table 3).

Walking speed

Walking speed during outside walking was significantly faster than during the GSP and NGTP (medians: outside walking=3.8 km/h, GSP=3.2 km/h, NGTP=2.8 km/h; P<.001, table 2). Outside walking speed correlated moderately with the WIQ speed score $(\mathrm{r}=$ $0.62, \mathrm{p}<.001)$.

\section{Outside walking measuring methods}

Median MWD as measured with the iPhone $(309 \mathrm{~m})$ were not different compared to values obtained with a measuring wheel $(290 \mathrm{~m}, \mathrm{P}=.064)$. A strong correlation was observed between these values (ICC $=0.997$ ). 
Figure 1 Bland-Altman plot with linear regression analysis MWD OW - ED

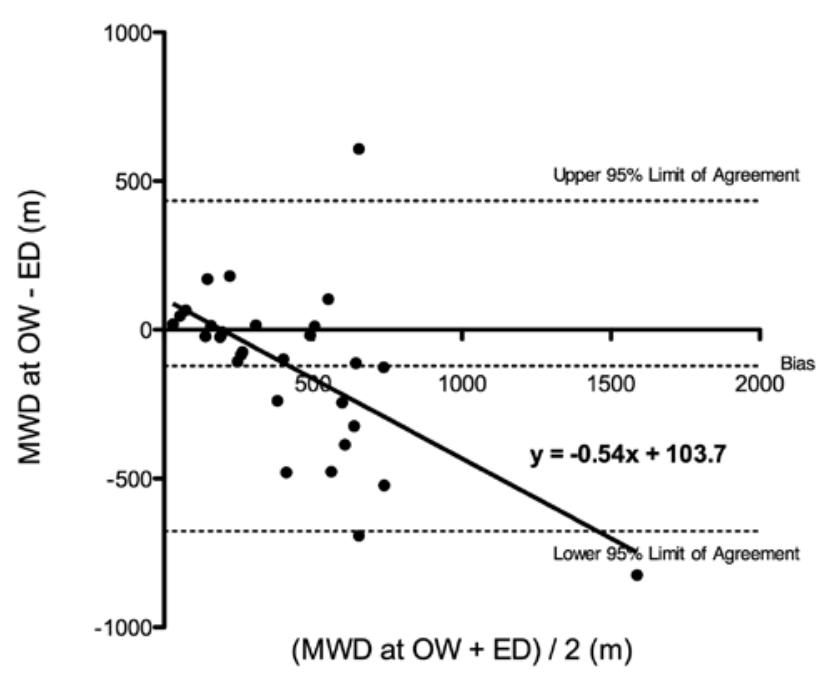

Note: ED, Estimated Distance; MWD, Maximum walking distance; OW, outside walking.

Figure 2 Bland-Altman plot with linear regression analysis MWD OW - GSP

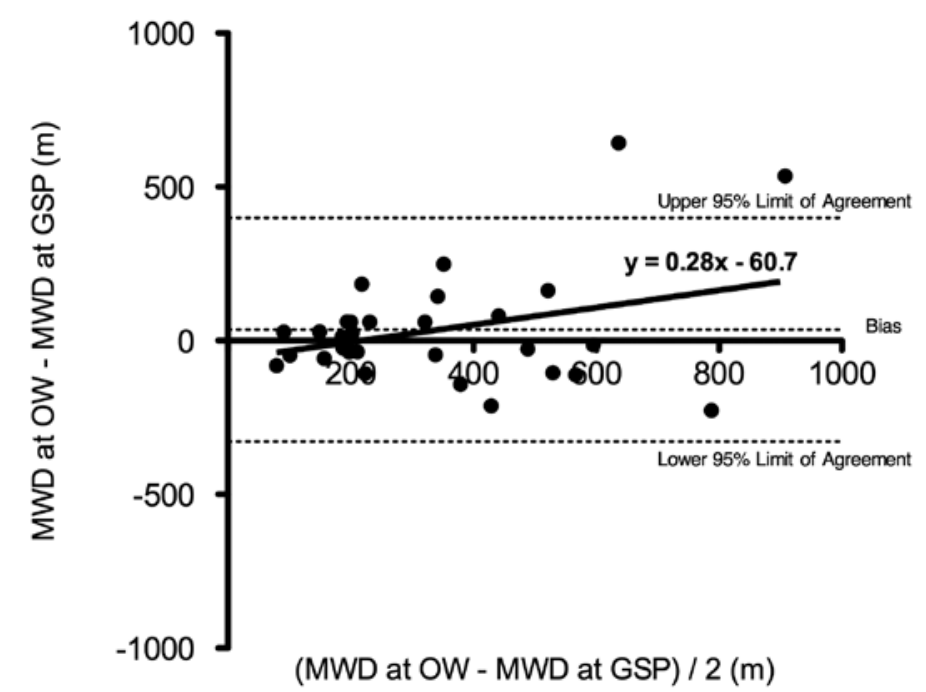

Note: GSP, Gardner-Skinner protocol; MWD, Maximum walking distance; OW, outside walking
Figure 3 Bland-Altman plot with linear regression analysis MWD OW - NGTP

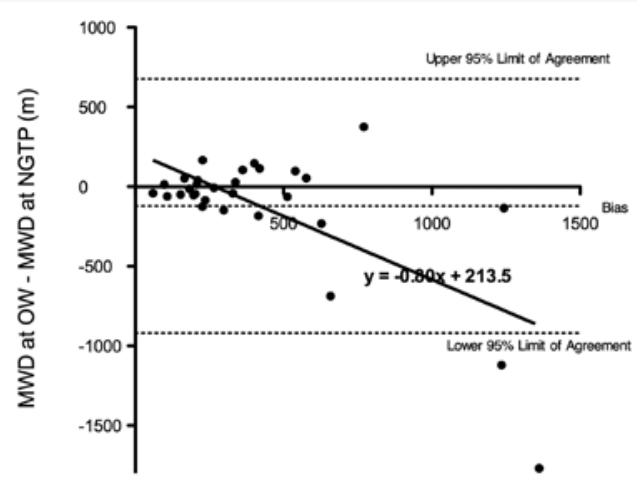

(MWD at OW + MWD at NGTP) / 2 (m)

Note: MWD, Maximum walking distance: NGTP, non-graded treadmill protocol: OW, outside walking

Table $1 \quad$ Baseline characteristics

\begin{tabular}{lc} 
Characteristics & Value (total population $\mathbf{n = 3 0}$ ) \\
\hline Patient characteristics, median (range) & $67(44-87)$ \\
Age, years & $27(18-37)$ \\
Body mass index, kg/m² & \\
Patient characteristics, No. (\%) & 63 \\
Male & 23 \\
Diabetes Mellitus & 17 \\
Hypercholesterolemia & 17 \\
Hypertension & \\
Smoking & 40 \\
Current & 47 \\
Former & 13 \\
Never & \\
Cardiovascular history & 20 \\
MI & 3 \\
CABG & 13 \\
Other & 63 \\
None & 17 \\
Chronic Obstructive Pulmonary Disease & 23 \\
Arthritis & \\
\hline
\end{tabular}

Note: CABG: Coronary artery bypass grafting; MI: Myocardial infarction; 
Table 2 Walking distances and walking speed

\begin{tabular}{|c|c|c|c|c|c|c|c|c|}
\hline \multirow[t]{2}{*}{ Outcomes } & \multirow[t]{2}{*}{$\begin{array}{c}\text { GSP, } \\
\text { Median } \\
\text { (IQR) }\end{array}$} & \multirow[t]{2}{*}{$\begin{array}{l}\text { NGTP, } \\
\text { Median } \\
\text { (IQR) }\end{array}$} & \multirow[t]{2}{*}{$\begin{array}{l}\text { OW, } \\
\text { Median } \\
\text { (IQR) }\end{array}$} & \multirow[t]{2}{*}{$\begin{array}{c}\text { ED } \\
\text { Median } \\
\text { (IQR) }\end{array}$} & \multirow[t]{2}{*}{$\begin{array}{c}\text { Overall } \\
\mathbf{P} \\
\text { Value }^{\mathrm{a}}\end{array}$} & \multicolumn{2}{|c|}{$\begin{array}{l}\text { Per Comparison } \\
\text { Difference } \\
\text { P Value }^{\mathrm{b}}\end{array}$} & \multirow{2}{*}{$\begin{array}{c}\begin{array}{c}\text { ICC }(95 \% \text { Cl), } \\
\text { P Value }\end{array} \\
\begin{array}{c}0.67(0.42-0.83), \\
P<.001\end{array}\end{array}$} \\
\hline & & & & & & $\begin{array}{l}\text { OW- } \\
\text { GSP: }\end{array}$ & .70 & \\
\hline \multirow[t]{3}{*}{ MWD, m } & $\begin{array}{c}250 \\
(178-463)\end{array}$ & $\begin{array}{c}317 \\
(190-546)\end{array}$ & $\begin{array}{c}309 \\
(178-478)\end{array}$ & $\begin{array}{c}400 \\
(188-740)\end{array}$ & .05 & $\begin{array}{l}\text { OW- } \\
\text { NGTP: }\end{array}$ & .20 & $\begin{array}{c}0.46(0.14-0.70) \\
P=.004\end{array}$ \\
\hline & & & & & & OW-ED: & .02 & $\begin{array}{c}0.62(0.34-0.80) \\
P<<.001\end{array}$ \\
\hline & & & & & & $\begin{array}{l}\text { OW- } \\
\text { GSP: }\end{array}$ & $<.001$ & $\begin{array}{c}0.08(-.12-0.34) \\
P=.226\end{array}$ \\
\hline \multirow{2}{*}{$\begin{array}{l}\text { Walking } \\
\text { Speed, } \\
\mathrm{km} / \mathrm{h}\end{array}$} & $\begin{array}{c}3.16 \\
(3.11-3.18)\end{array}$ & $\begin{array}{c}2.76 \\
(2.48-3.44)\end{array}$ & $\begin{array}{c}3.81 \\
(3.21-4.50)\end{array}$ & n.a. & $<.001$ & $\begin{array}{l}\text { OW- } \\
\text { NGTP: }\end{array}$ & $<.001$ & $\begin{array}{c}0.41(-.10-0.75) \\
P<.001\end{array}$ \\
\hline & & & & & & $\begin{array}{l}\text { GSP- } \\
\text { NGTP: }\end{array}$ & .08 & $\begin{array}{c}0.10(-.23-0.42), \\
P=.287\end{array}$ \\
\hline
\end{tabular}

otes: Cl, confidence interval; ED, estimated distance; GSP, Gardner-Skinner protocol; ICC, Intraclass correlali coefficient; IQR, Interquartile range; MWD, maximum walking distance; NGTP, non-graded treadmil

= Considering a Friedman two way analysis of

$b=$ Considering a Wilcoxon signed-rank test. A bonferroni-corrected significance level of $\mathrm{P}<0.02$ indicates statistically significant difference.

Table 3 WIQ and estimated: correlations

\begin{tabular}{l|ccc} 
& WIQ distance score & WIQ total score & ED \\
\hline ED & 0.81 & 0.69 & - \\
GSP MWD & 0.80 & 0.66 & 0.86 \\
NGTP MWD & 0.73 & 0.64 & 0.76 \\
OW MWD & 0.77 & 0.70 & 0.74 \\
\hline
\end{tabular}

ED, Estimated difference; GSP, Gardner-Skinner protocol; MWD, Maximum walking distance; NGTP, non-graded treadmill protocol; OW, outside walking; VAS, Visual Analogue Scale; WIQ, Walking

\section{Discussion}

The efficacy of treatment strategies for clinical decision-making and research purposes in patients with IC is often evaluated on the basis of changes in walking distances ${ }^{(2-4)}$. Such distances may be estimated by the patient or measured using a treadmill. The value of both assessments is debatable as these parameters merely provide insight into walking capacity, which not necessarily reflects the patient's perceived disability ${ }^{(6,11)}$. Self-reported walking capacity appeared a poor reflection of objectively measured $\mathrm{MWD}^{(5-7,10)}$. The present study confirms these findings.

Our results may indicate that treadmill testing provides a reliable reflection of the outside walking distance in IC patients. Differences between MWD after either a treadmill or outside walking were not significant. However, only moderate ICCs and substantial COVs were found regarding these parameters. Others found MWD variation in a single patient, when repeatedly measured, which probably contributes to these large COV values ${ }^{(17)}$. Some judged that differences in MWD following treadmill walking and off treadmill corridor were due to the inclination in treadmill protocols ${ }^{(6)}$. Although this explanation may seem adequate, the present study challenges this assumption as worse results regarding variability, reproducibility and reliability of a NGTP compared to a GSP with regard to outside walking were found. Another possible explanation for this discrepancy is the difference in walking speed. Walking at a faster pace might give a patient the impression of longer distance coverage, while a higher walking speed causes a higher metabolic demand leading to lower walking distances. In other words, the incremental inclination in the GSP may compensate for the increased outside walking speed. Surprisingly, patients did not walk faster during NGTP testing, possibly causing the poor results in variability, reproducibility and reliability values. Although precautions were made to ensure that patient encouragement did not differ during testing, the influence of a researcher (one of a team of three) who was escorting the patient during the outside walking test could not be excluded. In conclusion, a single MWD assessment is not a proper reflection of walking impairment in IC patients and may not necessarily correspond with daily life walking.

The findings of our study have implications for the evaluation of outcomes in clinical practice and future research. Researchers should realize that the frequently used MWD outcome shows substantial variability. Additionally, our study confirms results of other 
studies indicating that a functional impairment questionnaire such as the WIQ may be an adequate instrument for monitoring walking capacity in $\mathrm{IC}^{(6,18)}$. However, one should realize that the Spearman rank correlation coefficients to analyze WIQ data may have been overestimated when compared to our ICC values. Spearman's coefficients do not correct a systematic measurement error. Nevertheless, future research should focus more on patient-reported outcomes of health related quality of life, perceived disability and burden of disease. These parameters can be of more importance than the determination of a patients' walking capacity alone as is currently obtained by a WIQ. In addition, walking (exercise) behavior should be monitored over prolonged periods of time to provide a more reliable reflection of a patients' walking impairment (outside walking). A 6-minute walking test, a shuttle walking-test or GPS-based accelerometers (physical activity monitors) may be alternatives to treadmill testing. The present data also indicate that a dedicated application on a smartphone is a valid alternative for a measuring wheel. Future novel applications for measuring walking behavior in combination with an assessment of disease burden in daily life could contribute to a better understanding of the impact of walking limitations in IC patients.

\section{Study Limitations}

The present study harbors methodological shortcomings. Although the test order was randomized, a potential 'training effect' could have biased our results. Furthermore, walking distances and speed were assessed as a one-time measurement whereas a multiple assessment might have strengthened our conclusion. Patients were not blinded to distance and time while walking the treadmill tests. In addition, a relatively small population was studied although its size is similar or even larger compared to most previous studies $^{(7,10,14,19)}$.

\section{Conclusions}

An incremental graded treadmill protocol in IC patients reflects outside walking best compared to a patient's estimated walking distance or a non-graded protocol. A single MWD assessment is not a proper reflection of the walking impairment in IC patients, probably due to the wide intra-variability in walking distances. Treadmill walking may not necessarily correspond with daily life walking. Future research should focus on walking behaviour over prolonged periods of time and patient-reported outcomes of health related quality of life and burden of disease.

\section{Acknowledgements}

We would like to thank M.M.H.C Bijvelds, M.J.W. van Galen and A. Boekee, students at Fontys University of Applied Sciences, Department of Physiotherapy for support in patient measurements as well as F.A.M. Brooijmans, physical therapist, for using his equipment and practice. 


\section{References}

1. Breek JC, Hamming JF, De Vries J, Aquarius AE, van Berge Henegouwen DP. Quality of life in patients with intermittent claudication using the World Health Organisation (WHO) questionnaire. Eur J Vasc Endovasc Surg. Feb 2001;21(2):118-122.

2. Norgren L, Hiatt WR, Dormandy JA, Nehler MR, Harris KA, Fowkes FG. Inter-Society Consensus for the Management of Peripheral Arterial Disease (TASC II). J Vasc Surg. Jan 2007;45 Suppl S:S5-67.

3. Hirsch AT, Haskal ZJ, Hertzer NR, et al. ACC/AHA 2005 Practice Guidelines for the management of patients with peripheral arterial disease (lower extremity, renal, mesenteric, and abdominal aortic): a collaborative report from the American Association for Vascular Surgery/Society for Vascular Surgery, Society for Cardiovascular Angiography and Interventions, Society for Vascular Medicine and Biology, Society of Interventional Radiology, and the ACC/AHA Task Force on Practice Guidelines (Writing Committee to Develop Guidelines for the Management of Patients With Peripheral Arterial Disease): endorsed by the American Association of Cardiovascular and Pulmonary Rehabilitation; National Heart, Lung, and Blood Institute; Society for Vascular Nursing; TransAtlantic Inter-Society Consensus; and Vascular Disease Foundation. Circulation. Mar 21 2006;113(11):e463-654.

4. Layden J, Michaels J, Bermingham S, Higgins B, Guideline Development G. Diagnosis and management of lower limb peripheral arterial disease: summary of NICE guidance. Bmj. 2012;345:e4947.

5. Watson CJ, Phillips D, Hands L, Collin J. Claudication distance is poorly estimated and inappropriately measured. Br J Surg. Aug 1997;84(8):1107-1109.

6. Frans FA, Zagers MB, Jens S, Bipat S, Reekers JA, Koelemay MJ. The relationship of walking distances estimated by the patient, on the corridor and on a treadmill, and the Walking Impairment Questionnaire in intermittent claudication. J Vasc Surg. Mar 2013;57(3):720727 e721.

7. Tew G, Copeland R, Le Faucheur A, Gernigon M, Nawaz S, Abraham P. Feasibility and validity of self-reported walking capacity in patients with intermittent claudication. Journal of vascular surgery. May 2013;57(5):1227-1234.

8. Fokkenrood HJ, Bendermacher BL, Lauret GJ, Willigendael EM, Prins MH, Teijink JA. Supervised exercise therapy versus non-supervised exercise therapy for intermittent claudication. Cochrane Database Syst Rev. Aug 23 2013;8:CD005263.
9. Fahrig C, Heidrich H, Voigt B, Wnuk G, Hirche H, Roggenbuck U. [What is the value of determining walking distance in peripheral arterial occlusive disease on the treadmill and in daily life? Prospective correlation study]. Med Klin (Munich). Jun 15 1999;94(6):303305.

10. Le Faucheur A, Abraham P, Jaquinandi V, Bouye P, Saumet JL, Noury-Desvaux B. Measurement of walking distance and speed in patients with peripheral arterial disease: a novel method using a global positioning system. Circulation. Feb 19 2008;117(7):897-904.

11. Nicolai SP, Viechtbauer W, Kruidenier LM, Candel MJ, Prins MH, Teijink JA. Reliability of treadmill testing in peripheral arterial disease: a meta-regression analysis. J Vasc Surg. Aug 2009;50(2):322-329.

12. Jongert M, Hendriks H, van Hoek J, Kaasboer Kogelman K, Robeer G, Simens B. KNGF richtlijn claudicatio intermittens. Nederlands Tijdschrift voor Fysiotherapie. 2003(6):3-50.

13. Sakurai T, Matsushita M, Nishikimi N, Nimura Y. Effect of walking distance on the change in ankle-brachial pressure index in patients with intermittent claudication. Eur J Vasc Endovasc Surg. May 1997;13(5):486-490.

14. Gardner AW, Skinner JS, Cantwell BW, Smith LK. Progressive vs single-stage treadmill tests for evaluation of claudication. Med Sci Sports Exerc. Apr 1991;23(4):402-408.

15. Regensteiner JG, Steiner JF, Panzer RJ, Hiatt WR. Evaluation of walking impairment by questionnaire in patients with peripheral arterial disease. J Vasc Med Biol 1990;2:142-150.

16. Verspaget M, Nicolai SP, Kruidenier LM, Welten RJ, Prins MH, Teijink JA. Validation of the Dutch version of the Walking Impairment Questionnaire. Eur J Vasc Endovasc Surg. Jan 2009;37(1):56-61.

17. Le Faucheur A, Noury-Desvaux B, Mahe G, et al. Variability and short-term determinants of walking capacity in patients with intermittent claudication. J Vasc Surg. Apr 2010;51(4):886-892.

18. Sagar SP, Brown PM, Zelt DT, Pickett WL, Tranmer JE. Further clinical validation of the walking impairment questionnaire for classification of walking performance in patients with peripheral artery disease. International journal of vascular medicine. 2012;2012:190641.

19. Degischer S, Labs KH, Aschwanden M, Tschoepl M, Jaeger KA. Reproducibility of constant-load treadmill testing with various treadmill protocols and predictability of treadmill test results in patients with intermittent claudication. J Vasc Surg. Jul 2002;36(1):83-88. 


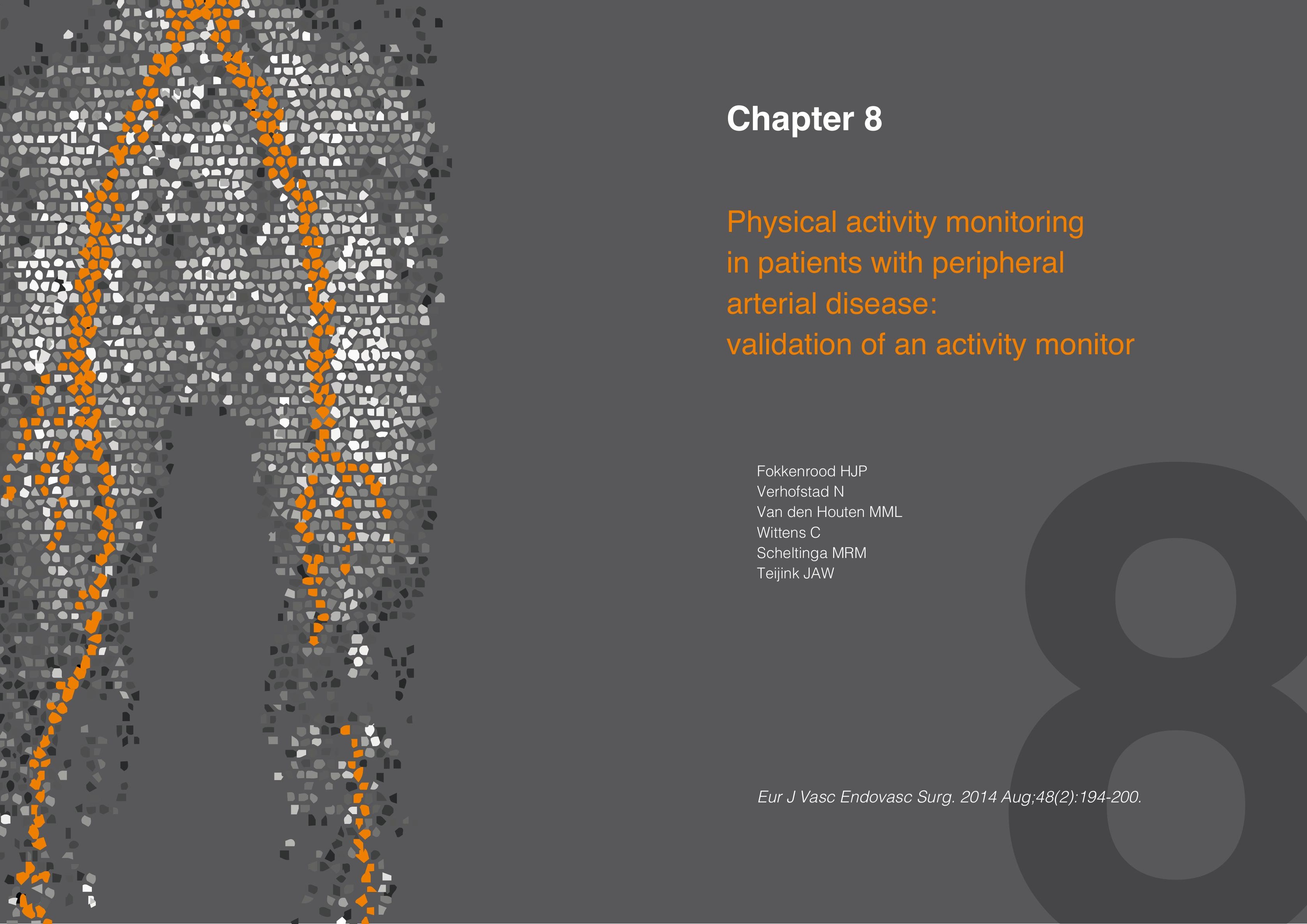




\section{Abstract}

Objectives

Daily life physical activity (PA) of patients with peripheral arterial disease (PAD) may be severely hampered by intermittent claudication (IC). From a therapeutic as well as research standpoint, it may be more relevant to determine improvement in PA as outcome measure in IC. Aim of this study was to validate daily activities using a novel type of tri-axial accelerometer (MoveMonitor) in IC patients.

Methods

IC patients were studied during a hospital visit. Standard activities (locomotion, lying, sitting, standing, shuffling, number of steps and "not worn" detection) were video recorded and compared with activities scored by the MoveMonitor. Inter-rater reliability (expressed in Intraclass Correlation Coefficients (ICC)), sensitivity, specificity and predictive values (PPV) were calculated for each activity.

\section{Results}

Twenty-eight hours of video observation were analysed $(n=21)$. Our video annotation method (gold standard) appeared accurate for most postures (ICC $>0.97$ ) except for shuffling (ICC $=0.38$ ). The MoveMonitor showed high sensitivities ( $>86 \%$ ), specificities (>91\%) and PPV (>88\%) for locomotion, lying, sitting and the "not worn" detection. Moderate accuracy was found for standing (46\%), while shuffling appeared not detectable (18\%). A strong correlation was found between video recordings and the MoveMonitor regarding the "number of steps" calculations (ICC=0.90).

\section{Conclusions}

The MoveMonitor provides accurate information on a diverse set of postures, daily activities and number of steps in IC patients. However, the detection of low amplitude movements such as shuffling and "sitting to standing" transfers is a matter of concern. This tool is useful to assess the role of physical activity as a novel clinically relevant outcome parameter in IC.

\section{Introduction}

In daily life, patients with symptomatic peripheral arterial disease (PAD) may be severely limited due to symptoms of intermittent claudication (IC). Disease severity and effect of treatment modalities are often assessed by outcome measures such as maximum and pain-free walking distance. However, a large discrepancy and variability has been reported between walking ability and claudication walking distances as measured on a treadmill, suggesting that treadmill assessments may not be representative of daily life walking ability ${ }^{(1-3)}$. Assessment of IC using patient reported outcome is subjective, insensitive and a poorly reproducible tool for determining severity of symptoms ${ }^{(4-6)}$. Objective clinical measurements such as Doppler ultrasonography and angiography provide only information on vessel patency and lesion severity. These imaging techniques are registered under standardized conditions and do not take the patients' coherent daily ambulatory limitations into account.

A clear call was made for alternative tests to determine walking capacity over a prolonged period of time ${ }^{(1,2)}$. Moreover, despite the fact that IC patients have an increased risk for cardiovascular or cerebrovascular events ${ }^{(7)}$, current PAD treatment is mainly focussed on the limitation in walking distance. However an increased walking capacity does not automatically imply a change in a patients' exercise behaviour. From a therapeutic as well as research standpoint, it may be more relevant to determine physical activity (PA) as outcome measure for treatment modalities of IC. Improved levels of PA might be indicative of an increased exercise behaviour resulting in cardiovascular event risk reduction and improvement of Quality of Life (QoL) on the long term ${ }^{(8,9)}$. Formerly, habitual PA was frequently ascertained using questionnaires or diaries, but patients are known to report inaccurately and results tend to be biased due to socially desirable answers ${ }^{(4-6)}$. Therefore, it seems necessary to obtain an objective measure of the patient's PA over a prolonged period of time.

Nowadays PA levels can be measured with activity monitors. Tri-axial accelerometers measure accelerations in three dimensions that can be converted to intensities and metabolic equivalents (METs) enabling a quantification of overall PA. The Dynaport MoveMonitor (DP) is such an activity monitor and is easily applicable in a daily life setting and is optimized for clinical research assessments. The DP was previously validated in an 
elderly population ${ }^{(10)}$, in Parkinsons disease ${ }^{(11,12)}$ and COPD patients ${ }^{(13-15)}$. To our knowledge, studies validating the DP in detecting daily activities in a PAD population were not previously reported. However, IC symptoms may significantly influence the DP outcomes due to altered walking patterns which may have impact on the detection of gait and postures ${ }^{(16-18)}$. Furthermore, all previous studies were performed in a laboratory setting with patients walking a specific trajectory ${ }^{(10-13)}$. Moreover, the number of observation hours was rather limited and obtained from small groups ${ }^{(10,11,13,15)}$. One study excluded patients with walking impairments ${ }^{(13)}$ and two other studies used out-dated accelerometer technology $y^{(14,15)}$. Overall, most studies suffered from substantial methodological shortcomings when using the DP for assessing daily life ambulatory activities in patients with walking impairments due to IC.

The aim of the present study is to validate the Dynaport MoveMonitor in symptomatic IC patients in a near real-life setting. If valid, the accelerometer can be used for the assessment of PA as a potential outcome measure in these populations.

\section{Methods}

Recruitment

Patients with IC (PAD stage 2-3 according to the Rutherford classification) and visiting the vascular outpatient clinic of our hospital between August and November 2012 were eligible for this study. This study was conducted with approval of the local medical ethics committee of the Catharina Hospital (Eindhoven, the Netherlands)

\section{Inclusion criteria}

Inclusion criteria were $>3$ months symptoms of IC, and an $<0.9 \mathrm{ABI}$ at rest or a fall in systolic ankle pressure by more than $20 \%$ after treadmill testing. A treadmill protocol with a fixed inclination of $8 \%$ at $3.2 \mathrm{~km} / \mathrm{h}$ for a maximum of $5 \mathrm{~min}$ was used.

\section{Exclusion criteria}

Patients with walking difficulties other than due to IC were excluded (e.g. prior amputation, severe arthritis, COPD GOLD 3-4, congestive heart failure (>NYHA class II) as was the use of walking aids. Patients with recent (less than 12 months) vascular surgical intervention prior to the study were also excluded as were patients unable to understand all specifics of the study protocol or having insufficient knowledge of the Dutch language.

\section{Video Observation and activity monitoring}

Specifics of patient's medical and surgical history were obtained followed by a physical examination and a check of inclusion and exclusion criteria. After signing an informed consent, a DP (DynaPort, McRoberts BV, The Hague, the Netherlands) attached to a neoprene belt was strapped around the patient's waist at the level of the midlower back (figure 1). The patient's hospital visit (e.g. waiting room, doctor's visit, vascular laboratory as sessments, treadmill testing, etc.) was then continuously video-recorded (GZ-HM335BE, JVC, Yokohama, Japan). Consequently, patients were asked to walk the hospitals car parking lot as abnormal walking due to IC would possibly occur during this effort. Subjects were instruct to act and move as they would normally do. Patients were filmed anonymously. Two observers were randomly assigned to perform all video recordings. Video recording of the activities was considered as 'gold standard'.

Figure 1 A patient wearing the dynaport movemonitor (DP)

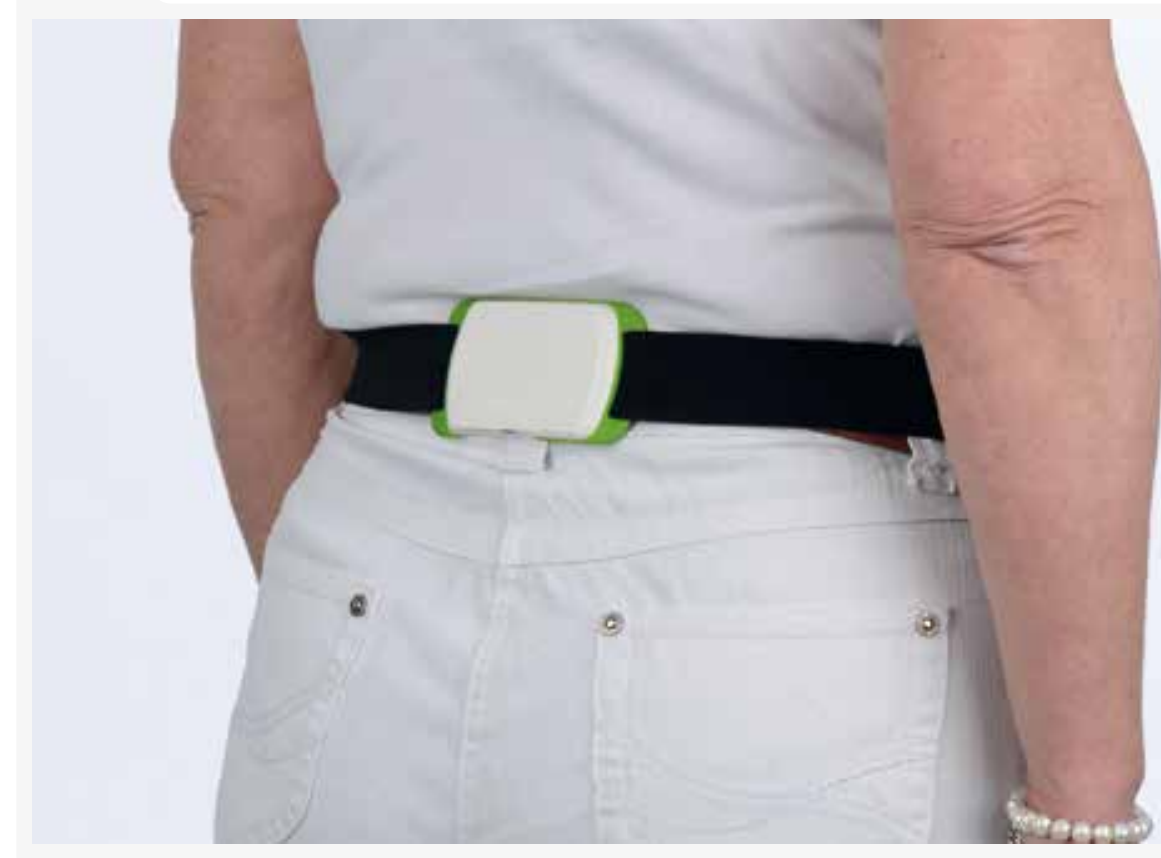


Categorizing movements by video

Table I depicts seven standard categories associated with daily activities including lying, sitting, standing, shuffling, locomotion, (device) 'not worn', and 'activity not recorded' (private actions such as visit to restroom). Specifics of each category and transitions between the seven categories were described in detail. A concise description of categorical and transitional activities formed the basis for a subsequent evaluation of all video recordings. All recorded activities were scored in time per activity (in seconds) using annotation software (ELAN 4.4.0, Max Planck Institute for Psycholinguistics, Nijmegen, the Netherlands) and exported as Microsoft Excel files. Additionally, the number of steps of all walking activities per patient were counted. All video recordings were scored in duplicate by two observers allowing inter-rater reliability (IRR) verification.

\section{DynaPort MoveMonitor (DP)}

We chose to use the tri-axial DP accelerometer $(84 \times 50 \times 8 \mathrm{~mm}, 70 \mathrm{~g})$ to monitor activities. Compared to other activity monitors, the DP showed high correlations between indirect calorimetry and generated MET output whereas walking speed was correctly measured in a population with chronic obstructive pulmonary disease ${ }^{(19)}$. The device consists of a tri-orthogonal orientated piezo-capacitive acceleration sensor, a rechargeable battery and removable SD card to store the acceleration data. A DP stores digital data for a maximum of seven days. The raw acceleration data lend itself to a pattern recognition approach using logical algorithms (MoveMonitor analysis software, version 2.6) for the classification of postures (lying, sitting and standing) and motions (locomotion and shuffling). The detection algorithm consists of 5 major parts as published previously ${ }^{(11,12)}$. The first step is gait period detection based on an intensity threshold. These potential gait periods are scanned using frequency analysis and a validated step detection method resulting in 3 categories: walking, active (but not walking), and static periods. Second, transition detection is performed to identify upward or downward transitions. The result is the identification of either up (standing) or down (lying or sitting). Subsequently, angle calculation based on sensor tilt is used to determine whether the down part of this vector can be identified as lying $\left(<30^{\circ}\right)$ or sitting. Next, shuffling separation divides the active (not walking) parts into 2 categories: shuffling and transitions. Shuffling is defined as all movement from A to B that is not walking. Thus, if the number of steps is less than 3 or the intensity and direction of the motion do not comply with the characteristics of walking, the movements are classified as shuffling. The results of the software analysis were returned in comma separated value (CSV) files. The reports listed six of the described activities per second (table 1), except for the "activity not recorded" category. Data obtained from the DP were synchronized with data generated by video recording (ELAN 4.4.0, Max Planck Institute for Psycholinguistics, Nijmegen, the Netherlands).

\begin{tabular}{|c|c|}
\hline Category & Interpretation \\
\hline Lying & $\begin{array}{l}\text { - Lying } \\
\text { - From standing to lying: starting from the sitting position } \\
\text { Sitting with straight legs }\end{array}$ \\
\hline Sitting & $\begin{array}{l}\text { Sitting } \\
\text { From standing to sitting: starting from flexion of the hip } \\
\text { From lying to standing when subject is sitting }>5 \text { s during the transition } \\
\text { - Drunk movements during sitting } \\
\text { Dressing and undressing during sitting }\end{array}$ \\
\hline Standing & $\begin{array}{l}\text { Standing } \\
\text { From sitting to standing: starting from extension of the hip } \\
\text { A pause during walking }>5 \mathrm{~s} \\
\text { Shuffling }<5 \mathrm{~s} \text { before a transition from standing to lying/sitting } \\
\text { Dressing and undressing during standing }\end{array}$ \\
\hline Locomotion & $\begin{array}{l}\text { - Walking } \\
\text { - Walking upstairs } \\
\text { A pause during walking }<5 \mathrm{~s} \\
\text { - Shuffling }<5 \mathrm{~s} \text { before } \mathrm{a} \text { atransition from walking to lying/sitting } \\
\text { Shufling }<5 \mathrm{~s} \text { before a transition from standing to walking }\end{array}$ \\
\hline Shuffling & $\begin{array}{l}\text { - Shuffling } \\
\text { Shuffling }>5 \mathrm{~s} \text { between two other activities } \\
\text { Shuffling }>5 \mathrm{~s} \text { before a transition from standing/walking to lying/sitting }\end{array}$ \\
\hline Device not worn & $\begin{array}{l}\text { - The time period in which the DP is picked up from a table and attached to the patient } \\
\text { The time period in which the patient is not wearing the DP during a video record } \\
\text { measurement }\end{array}$ \\
\hline Not recorded & $\begin{array}{l}\text { - The time period in which the DP already is measuring data, but video recording is } \\
\text { not yet started }\end{array}$ \\
\hline
\end{tabular}

Note: DP: DynaPort MoveMonitor

Data analysis

The first analysis of data was aimed at determining inter-rater reliability (IRR) of video recording itself, considered as the gold standard. The duration of activity (in 0.1 seconds) per category was summed for each patient. These values were analyzed for skewness and kurtosis to obtain an impression of the distribution. In case of normally distributed data, IRR of video recording were determined by comparing total duration per activity 
between both observations using intraclass correlation coefficients (ICC) with a two-way mixed model and absolute agreement.

Aim of the second analysis was to validate the DP by using two types of analyses. Transformation in an "activity per second" format was required for annotation files. For this purpose, a computer program was developed (MATLAB 7.14, MathWorks, Massachusetts). The software converted the annotated duration of activities into an "activity per second" format. Activities defined by the DP and by video recordings were than compared by matching each activity per second for the six overlapping categories (except for the "not recorded" category). The agreement between the DP and the gold standard was calculated per subject by adding up the duration that the activity codes matched and was expressed as a percentage of the total duration that an activity was observed on video. Non-agreement percentages per subject were defined as: (total duration that the video observation and the DP corresponded at the same moment for not 'activity category' ( total duration that not 'activity category' was observed on video) x $100 \%$. Sensitivity, specificity and predictive values were calculated by taking the mean of agreement or nonagreement values respectively for each activity category as suggested by Dijkstra et al. ${ }^{(11)}$. The second type of determining the validity of the DP was using ICCs for step count. Gait characteristics as observed on video were again considered as 'gold standard'. Steps performed on the treadmill (to obtain ankle brachial indexes) were analyzed separately from walking during a patients' hospital visit. "Not recorded" periods $>5$ seconds were excluded from analysis. Outliers of agreement were estimated per activity category and defined as four times the standard deviation (SD) of agreement. ICC were considered strong if $\geq 0.7$, moderate between 0.3 and 0.7 , and weak $\leq 0.3$. P-values $<0.05$ were considered statistically significant. Statistical analysis was performed using SPSS Statistics (MAC OS X version 20.0).

\section{Results}

A total of 27 patients were eligible and all consented to this study. However, data of 6 patients were excluded for reasons listed in figure 2. Patient characteristics of the remaining 21 participants are shown in table 2. Bilateral IC symptoms were observed in $71 \%$ of the population. More than half $(13 / 21,62 \%)$ had undergone peripheral vascular surgery but still reported IC symptoms. A total of 27.9 hours of video film was obtained and analysed. Mean video time was 83 minutes per patient (range: $48-110 \mathrm{~min}$ ).

\section{Figure 1 Flowchart of study population allowing validation of MoveMonitor}

\section{Eligible PAD patients ( $n=27)$}

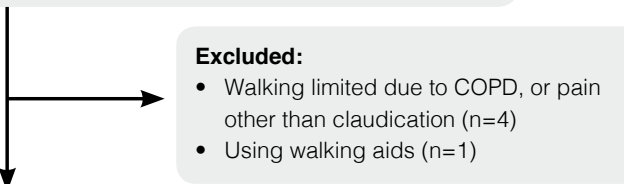

Patients meeting inclusion and exclusion criteria $(n=22)$

MoveMonitor data loss $(n=1)$

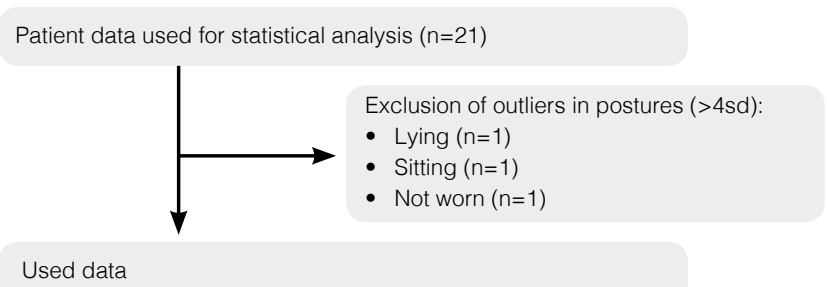

Used data

Notes: *PAD: Peripheral Arterial Disease, ABI: Ankle Brachial Index, IC: Intermittent Claudication, COPD: Chronic Obstructive Pulmonary Disease, sd: standard deviation

Inter-rate reliability (IRR) of video observations

IRR data were normally distributed. IRR between both video observers was excellent for most activity categories (ICC of 1.00 for lying, sitting and walking, 0.98 for standing, $\mathrm{p}<0.005)$. Moreover, the ICC for "device not worn" and "not recorded" detections were also excellent $(1.00$ and 0.99 , respectively $(\mathrm{p}<0.005))$. However, the ICC for shuffling was poor (0.38).

\section{Validity of the DynaPort MoveMonitor}

Mean duration $( \pm \mathrm{SD})$ of the postures standing, locomotion, lying and sitting per patient were $8.7( \pm 6.1), 15.8( \pm 5.9), 15.2( \pm 6.9)$ and $35.3( \pm 17.1)$ minutes, respectively. Total 
duration of these four postures ranged from 183 to 707 minutes (table 3). In contrast, shuffling was measured for a mere 5 minutes (mean $( \pm \mathrm{SD})$ per patient: $24 \pm 18 \mathrm{sec}$ ) and occurred in twelve patients only. The "device not worn" category was registered in just seven participants with a total measured time of 160 minutes (mean $( \pm S D)$ per patient: $22.9 \pm 9.8 \mathrm{~min})$. Just 22 seconds $(<0.1 \%$ of total time registered) were labelled as a "not recorded" event leading to removal from further analysis. In total, 5 of the 126 obtained activities (3.9\%) were defined as outliers ( $>4$ times SD of agreement) and were detected in the categories locomotion, sitting and "not worn" (table 5). These activities were also removed from analysis. Table 5 shows these outliers; activity as observed by video recording compared to the result of DP detection.

The agreement between video observation and DP data of observed activities is depicted in table 3. High levels of sensitivity were found for locomotion (86.1\%), lying (96.8\%), sitting (90.6\%) and 'device not worn' (88.7\%). High specificities and PPVs were also found regarding these four categories $(>88.3 \%$; table 4$)$.

In contrast, the DP showed a low $46.2 \%$ sensitivity value (table 3 ). In reality "sitting" was performed in $37.1 \%$ of this 'standing' time (table 3). This poor agreement is likely due to aberrant data obtained from 10 of the 21 patients. Eight of these 10 patients were actually sitting (instead of standing) in 49.9 to $74.9 \%$ of the videoed time. In the two other measurements, the patient was moving in $27.5 \%$ and $29.3 \%$ of the "standing" time respectively. Video observations and DP data did also show a low agreement regarding the category shuffling (17.5\%; table 3 ) although a high specificity (98.7\%) was found.

Data of walks during patient' hospital visit (mean number of steps: $1561 \pm 675$ steps) and treadmill walking (mean number of steps: $473 \pm 155$ steps) were normally distributed and used for step analysis. The ICC of calculated steps between video observation and DP data was 0.90 (95\% confidence interval (CI): $0.77-0.96, \mathrm{p}=.001$ ) and 0.84 for treadmill walking (95\% CI: 0.63 - 0.93). One patient performed 2199 steps while the DP detected just 908 steps. Analysis revealed that this patient wore the DP upside down. The data set of this patient was defined as outlier and excluded for the activity analysis ("locomotion activity", table 5) but not for the step analysis.
Table 2 Patient demographics

Analysed population $(n=21)$

\begin{tabular}{|c|c|c|}
\hline \multicolumn{2}{|c|}{ Gender (\% male) } & 62 \\
\hline \multicolumn{2}{|c|}{ Age (years $\pm s d)$} & $67 \pm 10$ \\
\hline \multicolumn{2}{|c|}{$\mathrm{BMI}\left(\mathrm{kg} / \mathrm{m}^{2} \pm \mathrm{sd}\right)$} & $26 \pm 4$ \\
\hline \multicolumn{3}{|c|}{ Affected side } \\
\hline \multicolumn{2}{|l|}{ Left } & $24 \%$ \\
\hline \multicolumn{2}{|l|}{ Right } & $5 \%$ \\
\hline \multicolumn{2}{|l|}{ Both } & $71 \%$ \\
\hline \multicolumn{3}{|l|}{$A B I$} \\
\hline \multicolumn{2}{|c|}{ Rest, worst lega (mean \pm sd) } & $0,70 \pm 0,21$ \\
\hline \multicolumn{2}{|c|}{ Rest, best leg ${ }^{\mathrm{b}}$ (mean $\pm \mathrm{sd}$ ) } & $0,92 \pm 0,17$ \\
\hline \multicolumn{2}{|c|}{ Post-exercise, worst lega $(\operatorname{mean} \pm$ sd) } & $0,49 \pm 0,28$ \\
\hline \multicolumn{2}{|c|}{ Post-exercise, best leg ${ }^{\mathrm{b}}$ (mean $\left.\pm \mathrm{sd}\right)$} & $0,79 \pm 0,28$ \\
\hline \multicolumn{3}{|c|}{ Cardiovascular medical history } \\
\hline \multicolumn{2}{|l|}{ PTA } & $35 \%$ \\
\hline \multicolumn{2}{|c|}{ Leg surgery } & $25 \%$ \\
\hline \multicolumn{2}{|c|}{ CABG / PCI } & $40 \%$ \\
\hline \multicolumn{2}{|l|}{ Other } & $25 \%$ \\
\hline \multicolumn{3}{|c|}{ Comorbidity } \\
\hline \multicolumn{2}{|c|}{ COPD } & $29 \%$ \\
\hline \multicolumn{2}{|c|}{ Arthritis } & $14 \%$ \\
\hline Notes: & $\begin{array}{l}\text { BMI: body mass index, CAE } \\
\text { COPD: chronic obstructive } \\
\text { Brachial Index, PCI: percuta } \\
\text { PTA: per cutaneous translun } \\
\text { endarterectomy }\end{array}$ & $\begin{array}{l}\text { artery bypass grafting, } \\
\text { ease, ABI: Ankle } \\
\text { ry intervention, } \\
\text { sty, TEA: thrombo- }\end{array}$ \\
\hline
\end{tabular}

Table 3 Agreement and non-agreement between video observation and DynaPort MoveMonitor (DP) data per activity

DynaPort data

\begin{tabular}{|c|c|c|c|c|c|c|c|c|}
\hline & & \multirow[b]{2}{*}{$\begin{array}{c}\text { Total video } \\
\text { observation } \\
\text { (min) }\end{array}$} & \\
\hline & & & \begin{tabular}{|l} 
Locomotion \\
(mean \% \pm sd)
\end{tabular} & $\begin{array}{c}\text { Lying } \\
\text { (mean \% } \pm \text { sd) }\end{array}$ & $\begin{array}{c}\text { Shuffling } \\
\text { (mean \% } \% \text { sd) }\end{array}$ & $\begin{array}{c}\text { Standing } \\
\text { (mean } \% \pm \text { sd) }\end{array}$ & $\begin{array}{c}\text { Sitting } \\
\text { (mean \% } \% \text { sd) }\end{array}$ & $\begin{array}{l}\text { Not worn" } \\
\text { (mon } \% \pm \text { sd }\end{array}$ \\
\hline \multirow{6}{*}{ 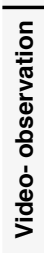 } & Locomotic & 315 & $86.1 \pm 11.8$ & $0.5 \pm 0.9$ & $2.3 \pm 1.6$ & $8.8 \pm 7.2$ & $2.8 \pm 4.6$ & 0.0 \\
\hline & Lying & 319 & $0.5 \pm 0.7$ & $96.8 \pm 3.9$ & $0.3 \pm 0.4$ & $0.4 \pm 0.9$ & $1.9 \pm 2.7$ & 0.0 \\
\hline & Shuffling & 5 & $6.6 \pm 7.0$ & 0.0 & $17.5 \pm 13.8$ & $49.2 \pm 24.5$ & $26.7 \pm 30.6$ & 0.0 \\
\hline & Standing & 183 & $5.3 \pm 8.2$ & $3.5 \pm 4.3$ & $5.9 \pm 3.9$ & $46.2 \pm 19.0$ & $37.1 \pm 22.2$ & $0.4 \pm 1.9$ \\
\hline & Sitting & 707 & $0.3 \pm 0.4$ & $0.5 \pm 0.8$ & $0.4 \pm 0.5$ & $7.4 \pm 11.8$ & $90.6 \pm 12.3$ & $0.9 \pm 3.9$ \\
\hline & Not worn & 160 & $0.0 \pm 0.1$ & $4.9 \pm 3.6$ & $0.2 \pm 0.2$ & $5.8 \pm 10.1$ & $0.2 \pm 0.2$ & $88.7 \pm 9.3$ \\
\hline
\end{tabular}


Table 4 Specificity and positive predictive values of the DynaPort Movemonitor

\begin{tabular}{lcc} 
Activity & Specificity (\%) & Positive Predictive Value (\%) \\
\hline Locomotion & 99.0 & 94.9 \\
Lying & 98.6 & 94.1 \\
Shuffling & 98.7 & 3.7 \\
Standing & 93.9 & 47.8 \\
Sitting & 91.4 & 88.3 \\
Not worn & 99.6 & 95.4 \\
\hline
\end{tabular}

Note: Video observation data is used as gold standard

Table 5 Data of removed outliers per activity

Activity as categorized by the DynaPort

\begin{tabular}{lc|ccccccc}
\multicolumn{7}{c}{ Activity as categorized by the DynaPort } \\
\hline $\begin{array}{l}\text { Observed } \\
\text { activity } \\
\text { (by video registration) }\end{array}$ & $\begin{array}{c}\text { Total } \\
\text { duration } \\
\text { (s) }\end{array}$ & $\begin{array}{c}\text { Locomotion } \\
\text { (\% of time) }\end{array}$ & $\begin{array}{c}\text { Lying } \\
\text { \% of time) }\end{array}$ & $\begin{array}{c}\text { Shuffling } \\
\text { (\% of time) }\end{array}$ & $\begin{array}{c}\text { Standing } \\
\text { (\% of time) }\end{array}$ & $\begin{array}{c}\text { Sitting } \\
\text { (\% of time) }\end{array}$ & $\begin{array}{c}\text { Not worn } \\
\text { (\% of time) }\end{array}$ \\
\hline Locomotion & 1346 & 38.9 & 0.2 & 5.4 & 35.7 & 19.4 & 0.0 \\
Sitting & 876 & 0.2 & 0.7 & 0.1 & 59.8 & 39.1 & 0.0 \\
Not worn & 1875 & 0.0 & 98.7 & 0.3 & 0.5 & 0.4 & 0.0 \\
Not worn & 162 & 0.0 & 0.0 & 0.0 & 100 & 0.0 & 0.0 \\
Not worn & 469 & 0.0 & 1.9 & 1.3 & 95.1 & 1.7 & 0.0
\end{tabular}

\section{Discussion}

Symptoms of intermittent claudication might influence daily life activities. Moreover, IC may have profound consequences for exercise ability, behavior and levels of physical activity (PA). Findings of this 'real life' design study indicate that activities detected by the DP showed high sensitivity and specificity values for most activity categories except for "standing" and "shuffling".

Measuring inter-rate reliability (IRR) characteristics is an important step in the evaluation of a 'gold standard' that is used to validate novel tools such as the DP. Strong correlations concerning the IRR were found in 6 out of 7 activity categories. In contrast, a poor IRR was found for shuffling (ICC of 0.38). High IRRs were previously found in a similar but smaller video study of 5 elderly patients (ICC of $0.95,0.78,0.99$ and 0.98 for walking, sitting, standing and lying, respectively $)^{(12)}$. The poor ICC for shuffling is probably due to ambiguities in our annotation protocol (table 1). Furthermore, transitions per se were difficult to score using a 'per second' time window analysis method, whereas the duration of a particular transition between activities is often a matter of seconds, a phenomenon that was also reported previously ${ }^{(11)}$.

A poor sensitivity of $46.2 \%$ of the DP was found for the activity "standing" (PPV: 47.8). These results are somewhat lower as compared to other studies with communitydwelling patients and Parkinsons disease patients (80.2\% and $81.4 \%$, respectively) (10). Additionally, we found a large standard deviation (19.0\%) for the "standing" activity, which can be explained by 10 aberrant measurements. It is thought that the DP missed several transitions between sitting and standing that may have considerably influenced outcomes, especially due to increased durations of activities. The low PPV of 'shuffling' (3.7\%) is particularly striking and induced by a low IRR and a difference between the an notation protocol and the algorithms that were used by the DP in allocating transitions to specific activities. According to our protocol, observers assessed transitions between activities as part of the previous activity, while in contrast the DP scored them as shuffling. Therefore conclusions regarding shuffling cannot be drawn from this study. However, it should be appreciated that shuffling activities were just observed during a relatively short period ( $1 \%$ of total time recorded). Therefore, the effect of shuffling on overall PA performance is very limited.

An overestimation of gait duration (10.7\%) and underestimation of number of steps (7.4\%) in Parkinsons disease patients was previously found ${ }^{(12)}$. However, these studies were performed in a laboratory setting with relatively short distances and just $236.8 \mathrm{mi}$ nutes of video observation per study. Despite that walking patterns are altered in IC patients ${ }^{(16-18)}$, the present study that was executed under daily life conditions using prolonged video observation periods demonstrated that the DP can accurately measure number of steps in a IC population.

Studying PA levels and ambulatory activities in daily life may yield important information regarding quality of life, health status or mortality in chronic diseases such as COPD and PAD/IC. There is an increasing interest in understanding associations between sedentary activities and their impact on quality of life ${ }^{(20-22)}$. As a consequence, 
research interest may shift from focussing on measurement of exercise capacity (maximal or pain-free walking distances) to determining daily activities over a prolonged period of time. Our study shows that the DP can correctly measure most types of ambulatory activities in daily life. Future research should aim to determine the value of PA as a novel outcome measurement in IC related topics such as in the comparison between IC treatment modalities.

\section{Study limitations}

Video-observers and the DP scored shuffling differently. In retrospect, positional change would have been marked as 'shuffling. Furthermore, reference values of physiological or walking intensity parameters were not obtained although the DP is capable of determining the intensity of periods of locomotion (movement intensity) ${ }^{(23)}$. Therefore, a validation of energy expenditure values could not be made. Although movement intensity may be of importance in IC patients, the present study focused on validation of periods of activities rather than intensity. The assessment and the effect of treatment strategies on physical activity and daily activities in PAD patients should be subject of future research.

\section{Conclusion}

A tri-axial MoveMonitor activity monitor provides accurate information on a diverse set of daily activities in IC patients when compared to a video technique. However, the detection of low amplitude movements such as shuffling and "sitting to standing" transfers is a matter of concern. This tool is useful to assess the role of physical activity as a novel clinically relevant outcome parameter in IC

\section{Acknowledgements}

We would like to thank I.A.R. Kuijlaars and S. van den Tillart, both students at Fontys University of Applied Sciences, Department of Physiotherapy for their support of video recording patients and helping out with video annotations. We also appreciate the assistance of H.C.W. van Dalen for patient recruitment and patient counselling. The support of personnel of our vascular laboratory is highly appreciated. The authors report no conflicts of interest in this work.

\section{References}

1. Frans FA, Zagers MB, Jens S, Bipat S, Reekers JA, Koelemay MJ. The relationship of walking distances estimated by the patient, on the corridor and on a treadmill, and the Walking Impairment Questionnaire in intermittent claudication. J Vasc Surg. 2013 Mar;57(3):7207 e1. PubMed PMID: 23313183.

2. Nicolai SP, Viechtbauer W, Kruidenier LM, Candel MJ, Prins MH, Teijink JA. Reliability of treadmill testing in peripheral arterial disease: a meta-regression analysis. J Vasc Surg. 2009 Aug;50(2):322-9. PubMed PMID: 19631868.

3. Watson CJ, Phillips D, Hands L, Collin J. Claudication distance is poorly estimated and inappropriately measured. Br J Surg. 1997 Aug;84(8):1107-9. PubMed PMID: 9278653.

4. Adams SA, Matthews CE, Ebbeling CB, Moore CG, Cunningham JE, Fulton J, et al. The effect of social desirability and social approval on self-reports of physical activity. American journal of epidemiology. 2005 Feb 15;161(4):389-98. PubMed PMID: 15692083. Pubmed Central PMCID: 2958515. Epub 2005/02/05. eng.

5. Neilson HK, Robson PJ, Friedenreich CM, Csizmadi I. Estimating activity energy expenditure: how valid are physical activity questionnaires? The American journal of clinical nutrition. 2008 Feb;87(2):279-91. PubMed PMID: 18258615. Epub 2008/02/09. eng.

6. Shephard RJ. Limits to the measurement of habitual physical activity by questionnaires. British journal of sports medicine. 2003 Jun;37(3):197-206; discussion PubMed PMID: 12782543. Pubmed Central PMCID: 1724653. Epub 2003/06/05. eng.

7. Norgren L, Hiatt WR, Dormandy JA, Nehler MR, Harris KA, Fowkes FG. Inter-Society Consensus for the Management of Peripheral Arterial Disease (TASC II). J Vasc Surg. 2007 Jan;45 Suppl S:S5-67. PubMed PMID: 17223489. Epub 2007/01/16. eng.

8. Kodama S, Saito K, Tanaka S, Maki M, Yachi Y, Asumi M, et al. Cardiorespiratory fitness as a quantitative predictor of all-cause mortality and cardiovascular events in healthy men and women: a meta-analysis. Jama. 2009 May 20;301(19):2024-35. PubMed PMID 19454641. Epub 2009/05/21. eng.

9. Yusuf S, Hawken S, Ounpuu S, Dans T, Avezum A, Lanas F, et al. Effect of potentially modifiable risk factors associated with myocardial infarction in 52 countries (the INTERHEART study): case-control study. Lancet. 2004 Sep 11-17;364(9438):937-52. PubMed PMID: 15364185. Epub 2004/09/15. eng.

10. Dijkstra B, Kamsma Y, Zijlstra W. Detection of gait and postures using a miniaturised triaxial accelerometer-based system: accuracy in community-dwelling older adults. Age and ageing. 2010 Mar;39(2):259-62. PubMed PMID: 20083616. Epub 2010/01/20. eng. 
11. Dijkstra B, Kamsma YP, Zijlstra W. Detection of gait and postures using a miniaturized triaxial accelerometer-based system: accuracy in patients with mild to moderate Parkinson's disease. Archives of physical medicine and rehabilitation. 2010 Aug;91(8):1272-7. PubMed PMID: 20684910. Epub 2010/08/06. eng.

12. Dijkstra B, Zijlstra W, Scherder E, Kamsma Y. Detection of walking periods and number of steps in older adults and patients with Parkinson's disease: accuracy of a pedometer and an accelerometry-based method. Age and ageing. 2008 Jul;37(4):436-41. PubMed PMID: 18487266. Epub 2008/05/20. eng.

13. Langer D, Gosselink R, Sena R, Burtin C, Decramer M, Troosters T. Validation of two activity monitors in patients with COPD. Thorax. 2009 Jul;64(7):641-2. PubMed PMID: 19561287. Epub 2009/06/30. eng.

14. Kanda M, Minakata Y, Matsunaga K, Sugiura H, Hirano T, Koarai A, et al. Validation of the triaxial accelerometer for the evaluation of physical activity in Japanese patients with COPD. Intern Med. 2012;51(4):369-75. PubMed PMID: 22333371. Epub 2012/02/16. eng.

15. Pitta F, Troosters T, Spruit MA, Decramer M, Gosselink R. Activity monitoring for assessment of physical activities in daily life in patients with chronic obstructive pulmonary disease. Archives of physical medicine and rehabilitation. 2005 Oct;86(10):1979-85. PubMed PMID: 16213242. Epub 2005/10/11. eng.

16. Gardner AW, Forrester L, Smith GV. Altered gait profile in subjects with peripheral arterial disease. Vasc Med. 2001;6(1):31-4. PubMed PMID: 11358158.

17. Crowther RG, Spinks WL, Leicht AS, Quigley F, Golledge J. Relationship between temporal-spatial gait parameters, gait kinematics, walking performance, exercise capacity, and physical activity level in peripheral arterial disease. J Vasc Surg. 2007 Jun;45(6):1172-8. PubMed PMID: 17543681. Epub 2007/06/05. eng.

18. Celis R, Pipinos, II, Scott-Pandorf MM, Myers SA, Stergiou N, Johanning JM. Peripheral arterial disease affects kinematics during walking. J Vasc Surg. 2009 Jan;49(1):127-32. PubMed PMID: 19028062. Epub 2008/11/26. eng.

19. Van Remoortel H, Raste Y, Louvaris Z, Giavedoni S, Burtin C, Langer D, et al. Validity of six activity monitors in chronic obstructive pulmonary disease: a comparison with indirect calorimetry. PloS one. 2012;7(6):e39198. PubMed PMID: 22745715. Pubmed Central PMCID: 3380044.

20. Hamilton MT, Healy GN, Dunstan DW, Zderic TW, Owen N. Too Little Exercise and Too Much Sitting: Inactivity Physiology and the Need for New Recommendations on Sedentary Behavior. Current cardiovascular risk reports. 2008 Jul;2(4):292-8. PubMed PMID: 22905272. Pubmed Central PMCID: 3419586
21. Katzmarzyk PT. Physical activity, sedentary behavior, and health: paradigm paralysis or paradigm shift? Diabetes. 2010 Nov;59(11):2717-25. PubMed PMID: 20980470. Pubmed Central PMCID: 2963526.

22. Katzmarzyk PT. Standing and Mortality in a Prospective Cohort of Canadian Adults. Med Sci Sports Exerc. 2013 Oct 22. PubMed PMID: 24152707.

23. Van Hees VT, Slootmaker SM, De Groot G, Van Mechelen W, Van Lummel RC. Reproducibility of a triaxial seismic accelerometer (DynaPort). Med Sci Sports Exerc. 2009 Apr;41(4):810-7. PubMed PMID: 19276852. 


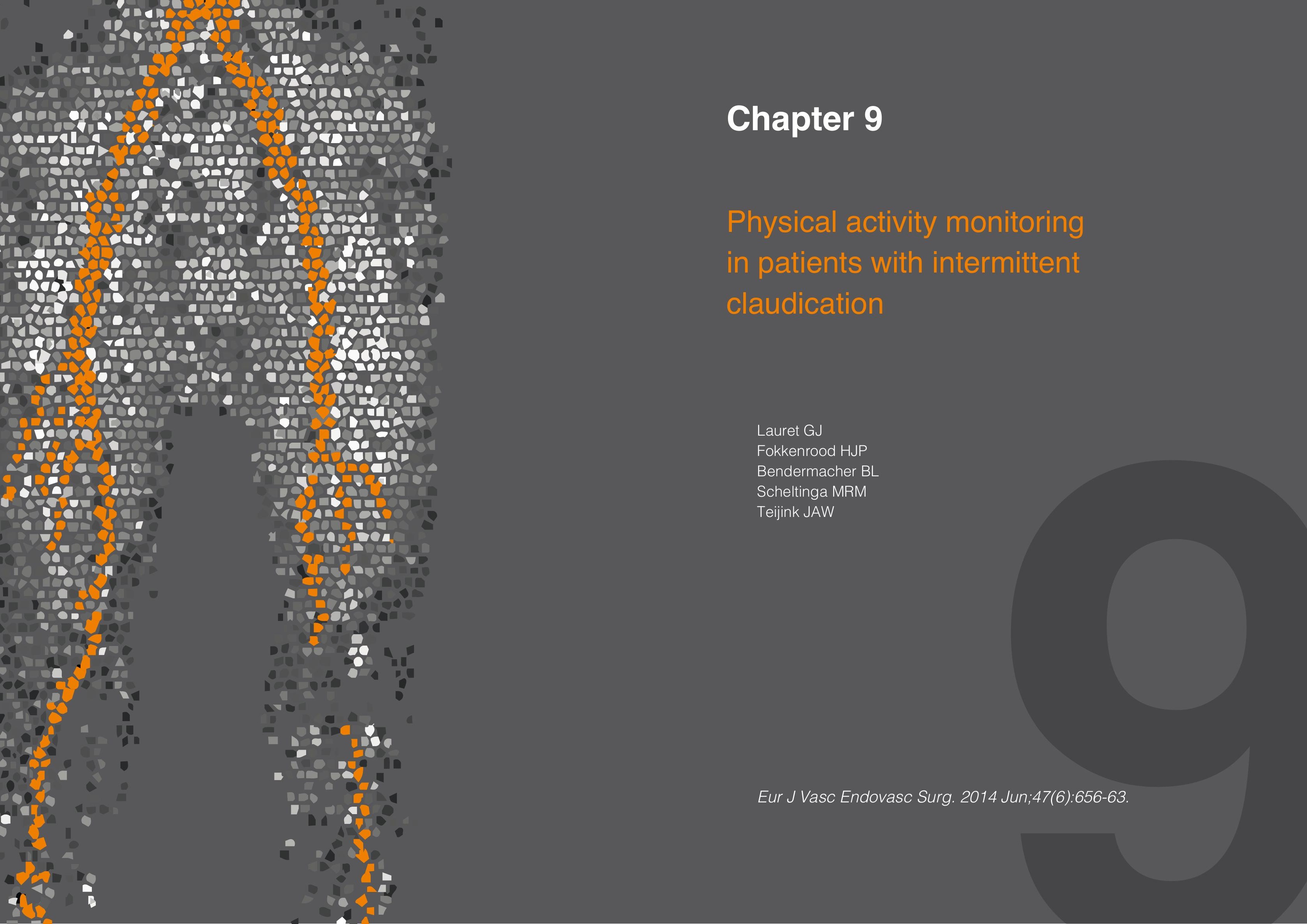




\section{Abstract}

Introduction

Reduced physical activity (PA) is associated with a higher mortality rate and more rapid functional decline in patients with intermittent claudication (IC). The newest generation of accelerometers can assess both direction and intensity of activities three-dimensionally and may also adequately calculate energy expenditure in daily life. The aim of this study was to quantify daily PA level and energy expenditure of newly diagnosed patients with IC and healthy controls. PA outcomes are compared with contemporary public health physical activity guidelines.

Materials \& methods

Before initiating treatment, 94 patients with newly diagnosed IC and 36 healthy controls were instructed to wear a tri-axial seismic accelerometer for 1 week. Daily PA levels (in metabolic equivalents, METs) were compared to the ACSM/AHA public health PA minimum recommendations ( $\geq 64 \mathrm{METs} \cdot \mathrm{min} \cdot$ day, in bouts of $\geq 10 \mathrm{~min}$ ). A subgroup analysis assessed the effect of functional impairment on daily PA levels.

\section{Results}

Data of 56 IC patients and 27 healthy controls were available for analysis. Patients with IC demonstrated significantly lower mean daily PA levels ( \pm S.D.) compared to controls (387 \pm 198 METs-min vs. $500 \pm 156$ METs-min, $\mathrm{p}=0.02)$. This difference was solely attributable to a subgroup of IC patients with the largest functional impairment (WIQ-score $<0.4$ ). Only $45 \%$ of IC patients met the public health physical activity guidelines compared to $74 \%$ of the healthy controls $(\mathrm{p}=0.01$ ).

Conclusion

More than half of patients with intermittent claudication (IC) do not meet recommended standards of physical activity (PA). Considering the serious health risks associated with low PA levels, these findings underscore the need for more awareness to improve physical exercise in patients with IC.

\section{Introduction}

Intermittent claudication (IC) is closely associated with cardiovascular and cerebrovascular disease. ${ }^{(1-3)}$ Compared to healthy adults, IC patients are burdened with a low health-related quality of life and functional impairment during daily activities. ${ }^{(4,5)} \mathrm{A}$ reduced exercise capacity and lower daily free-living physical activity (PA) level are both strong predictors of long-term mortality. In contrast, higher PA levels are associated with less functional decline. ${ }^{(6-9)}$

The ACSM/AHA have issued recommendations on types and amounts of PA needed for (older) adults to improve and maintain health. ${ }^{(10)}$ Specific recommendations are provided that apply to adults $>65$ years of age or to adults aged 50-64 years with chronic conditions or physical functional limitations. ${ }^{(1)}$ All adults are advised to engage in moderate-intensity aerobic exercise for a minimum of 30 minutes during five days a week, or vigorous-intensity aerobic PA for a minimum of 20 minutes at three days a week. Activi ties should be performed in bouts of at least 10 minutes. Combinations of moderate- and vigorous-intensity aerobic PA can also be performed to meet these recommendations.

Metabolic equivalents (METs) are used by the ACSM/AHA as a means to express the energy expenditure or energy costs of physical activities. The total amount of PA is a function of its intensity, duration and frequency. Accordingly, vigorous intensity activities (>6.0 METs) performed for a particular duration and frequency generate greater energy expenditure than moderate-intensity activities (3.0-6.0 METs) of the same duration and frequency. When combining the recommendations on moderate- and vigorous-inten sity physical activity, the daily minimum goal of PA should be in the range of 64-107 METs $\times \min . .^{(10,11)}$

In literature, $\mathrm{PA}$ is defined and determined in different ways. Frequently used definitions of PA are 'time spent in different activities (sedentary/ambulatory), number of steps, duration of walking events or the score on a specific exercise test or questionnaire'(8,12-15 PA objectively measured by energy expenditure is seldomly performed in patients with IC. ${ }^{(15-17)}$ Regularly described methods for PA measurement are PA questionnaires, pedometers or activity monitors. However, only the latter method is found capable of adequately assessing energy expenditure. ${ }^{(18,19)}$ 
The newest generation of activity monitors are based on tri-axial accelerometer techniques measuring accelerations in three dimensions that can be converted to intensities and METs. In contrast to unilateral accelerometers (or vertical accelerometers), tri-axial accelerometers also measure activities that do not include vertical movement. As such, PA is determined more precisely as demonstrated with high correlations between indirect calorimetry and generated MET output at different walking speeds. ${ }^{(18,20,21)}$ To our knowledge, no studies are available on the use of a tri-axial accelerometer in patients with IC compared to healthy adults.

The purpose of this prospective observational study was to objectively determine the PA using a tri-axial accelerometer in patients with IC and healthy adults. Furthermore, number and percentage of participants meeting the lower limit of the ACSM/AHA recommendations for PA and public health are determined. It was hypothesized that healthy adults had a higher PA level and complied more frequently to these minimum recommendations compared to IC patients.

\section{Materials \& Methods}

Participant selection

Patients with clinical manifestations of IC were recruited at the outpatient clinic of Vascular Surgery of the Catharina Hospital, Eindhoven and Maxima Medical Center, Veldhoven/Eindhoven, The Netherlands. Healthy individuals recruited from family or friends of healthcare workers served as controls. All subjects gave written informed consent and all procedures described in this study were approved by the Medical Ethical Committee, Catharina Hospital, Eindhoven.

\section{Eligibility assessment}

\section{IC group}

Patients without any previous history of peripheral arterial occlusive disease (PAOD) presenting with new onset clinical manifestations of IC underwent an ankle-brachial index (ABI) measurement using standard equipment. Patients with values below 0.90 at rest or a drop in value of more than 0.15 after a standard treadmill test were considered eligible.
Exclusion criteria included serious cardiopulmonary limitations (NYHA class 3-4), critical limb ischemia or previous lower-limb amputation, use of walking aids, psychiatric instability or other serious comorbidity which possibly limited the patient's walking ability

Control group

Healthy volunteers aged $>45$ years without a history of PAOD, cardiac or pulmonary disease were included if they were able to walk without any limitations or walking aids. Participants were excluded if an ABI measurement was below 0.90 at rest or decreased more than 0.15 after a standard treadmill test.

Functional impairment and health-related quality of life scores After consenting to the study specifics, a Dutch validated version of the Walking Impairment Questionnaire (WIQ), 12-item Short Form Physical Functioning Summery (SF-12 PCS) and 12-item Short Form Mental Functioning Summery (SF12 MCS) were assessed prior to treatment in the IC patients and in controls. ${ }^{(22,23)}$ Evidence based conservative treatment was subsequently started in the IC group. Each patient received cardiovascular risk management including antiplatelet therapy and a sta-

\section{Physical activity monitoring}

Dynaport tri-axial seismic accelerometer

Both groups of study participants were asked to wear a tri-axial seismic accelerometer (Dynaport MoveMonitor, McRoberts B.V., The Hague, The Netherlands) during a 1 week time period. The Dynaport MoveMonitor (size $84 \mathrm{~mm}$ X 50m X 8mm; weight $55 \mathrm{~g}$ ) contains three orthogonal piezo-capacitive acceleration sensors, each measuring at a sample rate of $100 \mathrm{~Hz}$. The accelerometer has a direct current response to the Earth's gravitational field, and used a seismic or a proof mass suspended by a spring structure in a case. The case has a micro USB connection and a rechargeable battery and stores the raw data on a Micro-SD card. The Dynaport MoveMonitor is placed in a belt that is strapped around the waist. It is positioned at the base of the lumbar column just cranial to the buttocks. The Dynaport technology is validated for counting steps, detecting time spent in different activities, activity-related energy expenditure and assessment of reproducibility. ${ }^{(18,21,24-28)}$ 
Monitoring protocol

All participants were instructed to correctly wear the Dynaport MoveMonitor for 7 consecutive days. As the device is not waterproof, participants were asked to take off the device when taking a shower or a bath. Furthermore, to achieve better compliance, participants were instructed not to wear the device during sleeping. They were instructed to perform their regular daily activities during this week. Supervised exercise therapy (SET) was initiated after this one week monitoring period in IC patients. SET was provided by a specialised physical therapist in a community-based setting. According to the quality standards and guidelines of the Dutch ClaudicatioNet Network and Royal Dutch Society for Physical Therapy, the physical therapist assessed the pain-free walking distance (PFWD) and maximum walking distance (MWD) at baseline according to a standardised graded treadmill protocol. ${ }^{(29,30)}$

\section{Outcomes}

Primary outcomes

- The daily PA level (measured in METs $\times$ min)

- The daily PA level performed in bouts of $>10$ minutes moderate- or vigorousintensity PA (measured in METs $\times$ min)

- The number and percentage of participants meeting the lower limit of the ACSM recommendation for PA and public health (67 METs $\times$ min a day)

Secondary outcomes

- The average daily time spent in different activities (Lying, Standing, Sitting, Walking, Shuffling) and the time spent not wearing the device

- The average daily number and highest number of steps walked in one period (top period of steps)

- The average daily time spent in light-, moderate- or vigorous-intensity activity. Sedentary activity is activity with an intensity of $<1.5$ METs, light activity is activity with an intensity of 1.5-3 METs, moderate activity is activity with an intensity of 3-6 METs and vigorous activity is activity with an intensity of 6-9 METs.

Data Analysis

Daily checks were made to assure proper use of the device. By definition, the device was worn correctly if it detected at least 20 steps and if it was 'worn' $\geq 10$ hours and 'not worn' for $\geq 5$ hours a day. Participants with less than 5 days of correctly wearing the device were arbitrarily excluded from analysis. Daily average outcomes were determined for each participant depending on the number of 'correctly worn days'.

Subgroup analysis

The IC group was divided into two subgroups according to the WIQ score $(<0.4$ or $\geq 0.4)$ in order to evaluate the hypothesis that IC patients with more functional impairmen have a lower daily PA level. The WIQ-score was used because it takes both the patient's effort to walk and his perceived impairment into account, while estimated or treadmil walking distances do not reflect walking distances in daily life. ${ }^{(31)}$ A lower WIQ-score reflects higher functional impairment. A cut-off value of 0.4 was arbitrarily chosen to establish even groups.

\section{Statistical analyses}

All analyses were performed using IBM SPSS Statistics Version 21 (SPSS Inc., Chicago, IL, USA). Categorical variables are presented as frequencies with percentages. Nominal variables are depicted as the mean \pm standard deviation in case of a normal distribution. Statistical differences between the groups were calculated with a Pearson Chi-Square test for categorical variables, an Independent sample T-test for continuous variables between two groups and a One-Way between-groups ANOVA for continuous variables between more than two groups. In case of significant differences between more than two groups, post-hoc Tukey tests were performed to assess a possible significant difference between groups. A p-value $<0.05$ was used for statistical significance.

Univariable and multivariable linear regression analysis were used to evaluate which pre-specified variables predicted daily level of physical activity. In the univariable regression analysis, each variable is included in a separate regression analysis. In the multivariable regression analysis, all statistically significant variables, identified by the univariable regression analysis, are included in one regression analysis, using the enter method. In cluded pre-specified variables were age, BMI, sex, resting ABI, IC symptoms of both legs, cardiac history, pulmonary history, WIQ score, SF-12 PCS score, SF-12 MCS score, and maximal walking distance measured at baseline. Multivariable linear regression analysis using the backward elimination method was used to identify the variables included in 
the final regression equation. The backward method starts with all the variables in the equation and in every step variables that do not have a statistically significant influence are excluded. The criterion for removal from the regression model was a p-value of more than 0.10 . The quality of the regression models was expressed with the $\mathrm{R}^{2}$ (explained variance) for linear regression analysis.

Table $1 \quad$ Baseline characteristics

\begin{tabular}{|c|c|c|c|c|c|c|c|c|c|c|}
\hline & \multicolumn{3}{|c|}{$\begin{array}{c}\text { IC subgroup } 1(n=30) \\
\text { WIQ }<0.4\end{array}$} & \multicolumn{3}{|c|}{$\begin{array}{c}\text { IC subgroup } 2(n=26) \\
\text { WIQ } \geq 0.4\end{array}$} & \multicolumn{3}{|c|}{ Control group $(n=27)$} & \multirow[t]{2}{*}{ P-value } \\
\hline & $N(\%)$ & Mean & S.D. & $N(\%)$ & Mean & S.D. & $N(\%)$ & Mean & S.D. & \\
\hline Male gender & $14(46.7)$ & - & - & $16(61.5)$ & - & - & $13(48.1)$ & - & - & $0.49^{\mathrm{a}}$ \\
\hline $\begin{array}{l}\text { Both legs } \\
\text { symptomatic }\end{array}$ & $18(60.0)$ & - & - & $12(46.2)$ & - & - & n.a. & - & & $0.30^{\mathrm{a}}$ \\
\hline $\begin{array}{l}\text { Pulmonary } \\
\text { history }\end{array}$ & $8(26.7)$ & - & - & $4(15.4)$ & - & - & n.a. & - & & $0.31^{a}$ \\
\hline Cardiac history & $11(36.7)$ & - & - & $11(42.3)$ & - & - & n.a. & - & - & $0.67^{\mathrm{a}}$ \\
\hline $\begin{array}{l}\text { Days correct } \\
\text { worn device }\end{array}$ & - & 5.80 & 0.61 & - & 5.80 & 0.76 & - & 6.37 & 0.74 & $0.001^{b}$ \\
\hline Age (years) & - & 69.6 & 8.8 & - & 69.4 & 8.3 & - & 62.9 & 9.9 & $0.002^{b}$ \\
\hline BMI & - & 28.0 & 4.4 & - & 26.2 & 3.1 & - & 26.7 & 4.2 & $0.23^{b}$ \\
\hline Resting ABI & - & 0.60 & 0.18 & - & 0.66 & 0.18 & - & 1.10 & 0.08 & $<0.001^{b}$ \\
\hline WIQ score & - & 0.19 & 0.12 & - & 0.62 & 0.15 & - & 0.93 & 0.16 & $<0.001^{10}$ \\
\hline $\begin{array}{l}\text { SF-12 PCS } \\
\text { score }\end{array}$ & - & 31.7 & 8.8 & - & 40.7 & 9.8 & - & 52.0 & 6.8 & $<0.001^{10}$ \\
\hline $\begin{array}{l}\text { SF-12 MCS } \\
\text { score }\end{array}$ & - & 52.6 & 9.6 & - & 52.1 & 7.9 & - & 52.4 & 10.1 & $0.98^{\mathrm{b}}$ \\
\hline PFWD (m) & - & 155 & 136 & - & 233 & 129 & - & n.a. & n.a. & $0.06^{\circ}$ \\
\hline MWD (m) & - & 296 & 225 & - & 486 & 274 & - & n.a. & n.a. & $0.008^{\circ}$ \\
\hline
\end{tabular}

Notes: $\quad A B I=$ ankle brachial index,$B M I=$ body mass index,$W I Q=$ Walking Impairment Questionnair SF-12 PCS score $=$ Short Form-12 Physical Component Summary score, SF-12 MCS = Short Form-12 Mental Component Summary score, PFWD = pain-free walking distance,

Pearson Chi-Square Test b One way between-groups ANOV

\section{Results}

Group baseline characteristics

A total of 130 participants were considered eligible (IC, $n=94$; controls, $n=36$ ). Analysis of the accelerometer data demonstrated that 56 IC patients and 27 controls met all criteria of a correctly worn device. A significant group difference regarding age, number of correctly worn days, resting ABI, WIQ-score, SF-12 PCS score and MWD was found between both groups. (Table 1)

Time spent in different activities or intensity-levels

IC patients spent almost 8.5 hours a day sitting ( $508 \pm 108$ minutes), more than 2.5 hours a day standing (165 \pm 60 minutes), more than 2 hours a day lying (132 \pm 101 minutes) 1 hour a day walking ( $65 \pm 33$ minutes) and $21 \pm 12$ minutes a day shuffling. (Table 2 ) Compared to the control group a significant difference was found in the time spent sitting and 'device not worn'. A significant group difference was also found regarding vigorousintensity activities (IC: $4 \pm 8$ vs. Controls: $11 \pm 10$ minutes a day, $\mathrm{p}=0.002$ ).

\section{Table 2 Average duration of different daily activities and intensity levels}

\begin{tabular}{l|cc|cc|c} 
& \multicolumn{2}{|c|}{ IC group $\mathbf{( n = 5 6 )}$} & \multicolumn{2}{|c|}{ Control group $\mathbf{( n = 2 7 )}$} & P-value a \\
& Mean & S.D. & Mean & S.D. & \\
\hline Lying (hours:min) & $2: 12$ & 101 & $2: 10$ & 62 & 0.92 \\
Sitting (hours:min) & $8: 28$ & 108 & $9: 20$ & 80 & 0.03 \\
Standing (hours:min) & $2: 45$ & 60 & $2: 33$ & 47 & 0.34 \\
Walking (hours:min) & $1: 05$ & 33 & $1: 16$ & 29 & 0.14 \\
Shuffling (hours:min) & $0: 21$ & 12 & $0: 26$ & 12 & 0.10 \\
Not Worn (hours:min) & $9: 13$ & 50 & $8: 16$ & 47 & $<0.001$ \\
Light activity (hours:min) & $1: 18$ & 33 & $1: 33$ & 55 & 0.13 \\
Moderate activity (hours:min) & $1: 23$ & 37 & $1: 35$ & 29 & 0.11 \\
Vigorous activity (hours:min) & $0: 04$ & 8 & $0: 11$ & 10 & 0.002 \\
\hline
\end{tabular}

Notes: a Independent Sample T-test, Light activity = activity with an intensity of 1.5-3 METs, Moderate activity = activity with an intensity of 3-6 METs, Vigorous activity = activity with an intensity of 6-9 METs)

Step analysis

Daily number of steps in the IC subgroups was significantly fewer compared to the control group (IC subgroup 1: $4663 \pm 3104$ vs. IC subgroup 2: $5761 \pm 2371$ vs. Controls: 6682 \pm 2701 , $\mathrm{p}=0.03$ ). The highest number of steps walked in one period (top period of steps) was also significantly lower in IC patients (IC subgroup 1: $1601 \pm 1414$ vs. IC subgroup 2: $2546 \pm 1894$ vs. Controls: $4584 \pm 4680, \mathrm{p}<0.001$ ). 
Daily physical activity level

A statistically significant difference $(\mathrm{p}=0.02)$ in both daily PA level and daily PA in bouts of $>10$ minutes of moderate- or vigorous intensity exercise, was found between the IC subgroups and the control group. (Figure 1,2) Post-hoc analyses showed that this difference was solely due to a significant difference between IC subgroup 1 (WIQ $<0.4$ ) and the control group ( $\mathrm{p}=0.018$ ). In contrast, no significant difference in daily PA level was found between IC subgroup 2 (WIQ $\geq 0.4$ ) and the control group ( $\mathrm{p}=0.28$ ).

Analysis of the number of participants achieving the lower (67 METs $\times$ min a day) and upper (107 METs $\times$ min a day) limit of the ACSM minimum recommendations showed a significant difference (lower limit: $\mathrm{p}=0.01$, higher limit: $\mathrm{p}=0.02$ ) between the IC subgroups and the control group in favour of the healthy controls. (Figure 3 )

Prediction model for daily physical activity level

Univariable regression analysis revealed that age, a previous history of pulmonary disease, MWD and the WIQ, SF-12 MCS and SF-12 PCS score, all independently influenced the daily PA level. (Table 3) Multivariable regression analysis including five variables (age, pulmonary history, SF-12 PFS, SF-12 MFS, MWD) explained 53\% ( $\mathrm{p}<0.001)$ of the variance in daily PA level:

Daily PA level of IC patients $($ METs $\times$ min $)=369.23-7.65 \times$ Age $+4.73 \times$ SF-12 PCS score $+6.53 \times$ SF-12 MCS score + 0.18 x MWD (- 138.65 if pulmonary history is present)
Table 3 Linear regression models for daily physical activity level (METs•min) of participants in the IC group

\begin{tabular}{|c|c|c|c|c|c|c|c|c|c|}
\hline & \multicolumn{4}{|c|}{ Univariable linear regression } & \multicolumn{2}{|c|}{$\begin{array}{l}\text { Multivariable } \\
\text { regression }{ }^{\circ}\end{array}$} & \multicolumn{2}{|c|}{$\begin{array}{l}\text { Final } \\
\text { regression }{ }^{d}\end{array}$} \\
\hline & & Constant ${ }^{\mathrm{a}}$ & $\mathrm{B}^{\mathrm{b}}$ & $\begin{array}{c}\mathrm{P}- \\
\text { value }\end{array}$ & $\begin{array}{c}\mathbf{R} \\
\text { square }\end{array}$ & B & $\begin{array}{c}\text { P- } \\
\text { value }\end{array}$ & B & $\begin{array}{c}P \text { - } \\
\text { value }\end{array}$ \\
\hline \multicolumn{2}{|l|}{ Age } & 1015.33 & -9.04 & $<0.05$ & 0.15 & -7.66 & 0.003 & -7.65 & 0.002 \\
\hline \multicolumn{2}{|c|}{ Gender (male) } & 403.83 & -29.09 & 0.59 & 0.01 & & & & \\
\hline \multicolumn{2}{|c|}{ Both legs symptomatic } & 425.05 & -70.58 & 0.19 & 0.03 & & & & \\
\hline \multicolumn{2}{|c|}{ Cardiac history } & 417.02 & -75.79 & 0.16 & 0.04 & & & & \\
\hline \multicolumn{2}{|c|}{ Pulmonary history } & 432.78 & -212.51 & $<0.05$ & 0.20 & -140.18 & 0.01 & -138.65 & 0.01 \\
\hline \multicolumn{2}{|l|}{ BMI } & 381.92 & 0.20 & 0.98 & 0.00 & & & & \\
\hline \multicolumn{2}{|c|}{ Resting ABI } & 333.86 & 85.05 & 0.57 & 0.01 & & & & \\
\hline \multicolumn{2}{|c|}{ WIQ score } & 300.1 & 223.83 & $<0.05$ & 0.08 & -63.96 & 0.55 & & \\
\hline \multicolumn{2}{|c|}{ SF-12 PCS score } & 111.22 & 7.69 & $<0.05$ & 0.16 & 5.51 & 0.04 & 4.73 & 0.04 \\
\hline \multicolumn{2}{|c|}{ SF-12 MCS score } & 18.19 & 7.04 & $<0.05$ & 0.10 & 6.57 & 0.01 & 6.53 & 0.01 \\
\hline \multicolumn{2}{|l|}{ MWD } & 282.57 & 0.27 & $<0.05$ & 0.13 & 0.20 & 0.03 & 0.18 & 0.04 \\
\hline
\end{tabular}

Figure 1 Daily physical activity level (mean \pm S.D.)

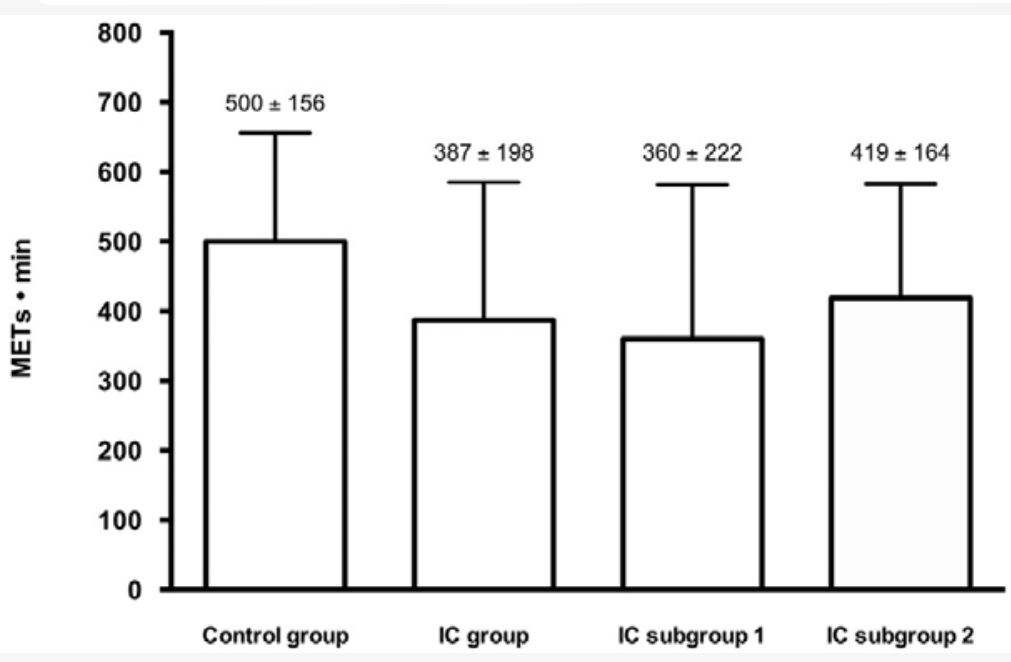


Figure 2 Daily physical activity level in bouts $>10$ min of moderate or vigorous activity (median, IQR)

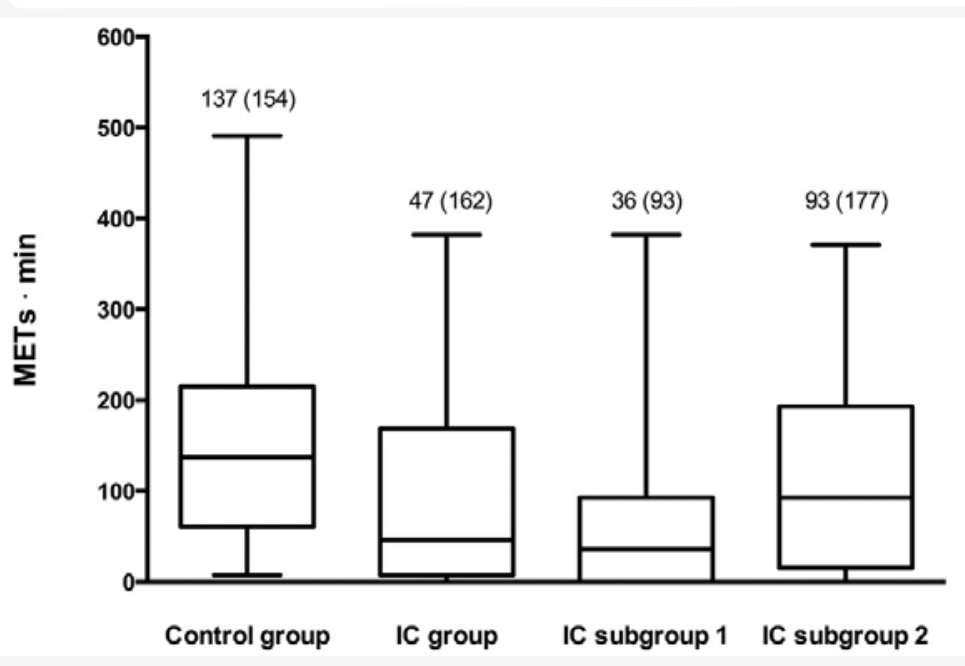

Figure 3

Adherence to ACSM recommendations for physical activity

Achieved lower limitof ACSM recommendations (67 METs•min a day)

- Achieved upper limit of ACSM recommendations (107 METs•min a day)

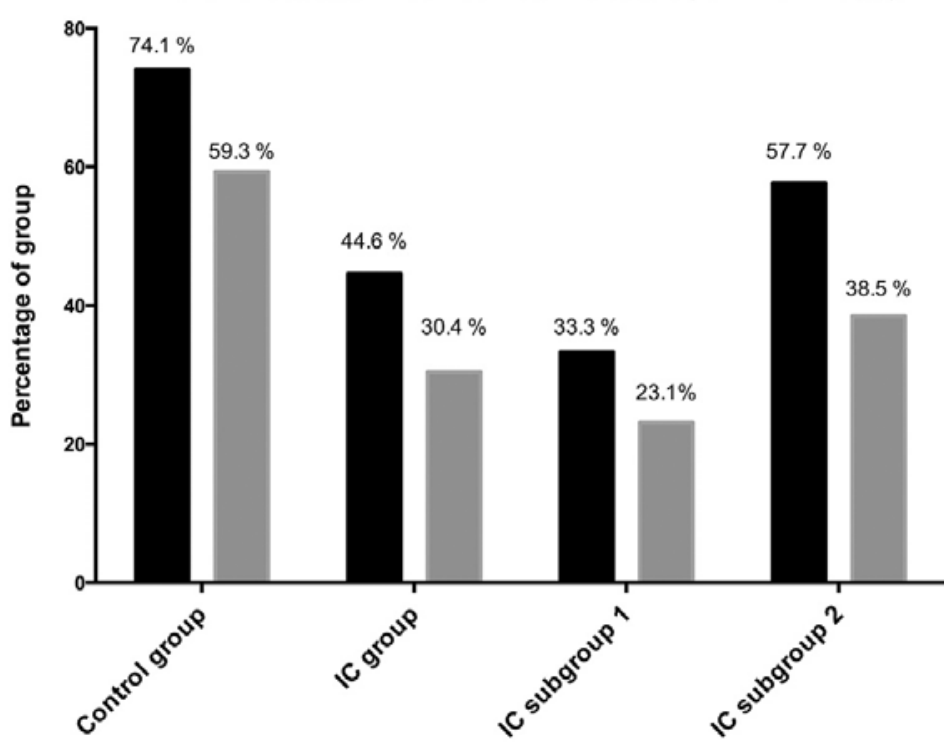

\section{Discussion}

This study hypothesized that IC patients would demonstrate a lower PA level and would comply less frequently to the lower limit of the ACSM/AHA recommendations for PA and public health compared to healthy adults. In a two-day assessment of PA using a vertical accelerometer and a pedometer, one other study found that daily PA level of IC patients was $42 \%-45 \%$ lower compared to healthy subjects of similar age. ${ }^{(17)}$ Also using a vertical accelerometer, a second study demonstrated that patients with peripheral arterial occlusive disease (PAOD) had markedly lower PA levels compared to non-PAOD participants $(803 \pm 364 \mathrm{kcal} / \mathrm{wk}$ vs. $1750 \pm 1296 \pm \mathrm{kcal} / \mathrm{wk}) .{ }^{15}$ Ever since the ACSM/AHA issued minimum recommendations on PA and public health were issued, studies describing to what extent IC patients meet these criteria in relation to healthy adults were not performed.

The present study using newest generation of tri-axial accelerometers found that fewer than half of IC patients meet the ACSM/AHA minimum recommendations while more than one-quarter of older healthy adults do not meet these criteria.

Moreover, the daily level of PA of IC patients (387 \pm 198 ) is much lower compared to healthy adults $(500 \pm 156)$. IC patients reporting substantial functional impairment (WIQ score $<0.4$ ) had the lowest mean daily PA level of all groups. Interestingly, the PA group difference was solely attributed to this subgroup. Only minor functional impairment in IC patients apparently does not result in lower daily PA level.

A tri-axial accelerometer allows for separately identifying various activities such as sitting, standing, lying or walking. The present study found significant group differences regarding time of sitting and 'not wearing the device.' Healthy adults appearly sit approximately one hour longer and might sleep less compared to IC patients. In contrast, walking time did not differ among groups, although the daily number of steps and highest number of steps were significantly lower in the IC group. This difference is possibly explained by a slower walk pace or cadence associated with IC. A previous study also suggested that patients with IC take fewer steps and have a lower daily average cadence compared to healthy adults. ${ }^{(32)}$

Variables influencing daily PA level in IC patients were hitherto not identified. The present study revealed that age, previous history of pulmonary disease, MWD and the 
WIQ, SF-12 MCS and SF-12 PCS score all independently influence these levels. Pulmonary history appeared the strongest factor. However, patient with serious pulmonary conditions (affecting the patient's walking ability) were excluded from this study. Therefore, the effect of pulmonary history on the daily PA level in an IC patient is probably underestimated. Patients with COPD are markedly inactive in daily life compared to healthy adults. ${ }^{(33)}$ Therefore, physicians need to realize that patients with IC and COPD are much less active compared to IC patients without pulmonary history or healthy adults.

A low daily PA level is generally considered a strong predictor of mortality and functional decline in patients with IC. ${ }^{(6-9)}$ More than light-intensity weekly PA improves 5-year survival rate significantly compared to light-intensity or no physical activity. ${ }^{(7)}$

For this reason, one could argue that the PA level is a valid outcome parameter in evaluating treatment effects of any intervention for IC. Current outcome parameters including maximum- or pain-free walking distances only describe the patient's exercise capacity while it does not reflect to what extent this capacity is used. In contrast, daily PA levels, provide objective information on the frequency, duration and intensity of exercise. Combined with a functional impairment score such as the WIQ-score, physicians may objectively monitor the patient's treatment progress.

Future studies should focus on the effects of different treatment strategies on PA. A rehabilitation program such as supervised exercise therapy (SET) improves walking performance and functional impairment. Most programmes promote, besides supervised sessions, daily home-based exercise in order to increase the patient's daily PA. No studies have substantiated the effect of SET on the daily level of PA yet. Therefore, accelerometer studies before and after different treatment strategies may shed light on these issues.

\section{Study limitations}

The present study is limited by the number of excluded participants. In total, 38 participants in the IC group (40.4\%) and 9 controls $(25.0 \%)$ were excluded because the device was not correctly worn for $\geq 5$ days. By definition, a correctly worn day was considered a day that the device was worn for $\geq 10$ hours, not worn for $\geq 5$ hours and with at least 20 steps. These strict criteria were a priori determined to prevent bias. For instance, if a participant wore the device for only 5 hours one day, unrepresentative data on the overall person's PA would have been collected. The high dropout rate may have potentially biased the PA results, most likely an overestimation of the current PA level in IC patients. Lack of motivation or misunderstanding the monitoring protocol could have led to incorrect use. A substantial number of participants said they had forgotten the end date of the monitoring period. In a few instances, participants fell asleep with the device still strapped to their waist. In our monitoring protocol, participants were asked to remove the device before sleeping to improve compliance. If the device was worn during night, that day was considered by definition 'not correctly worn'. We are not sure if compliance could have been higher if participants wore the device constantly. In future studies, regular check-ups by phone calls could be relevant as a means to increase compliance and un derstanding of the monitoring protocol. For clinical practice one could consider a shorter amount of the monitoring period, considering results are summarized in an average daily PA level. However, accuracy of PA results of a shorter monitoring period should first be validated since these could vary.

We experienced only a few measurement failures with the tri-axial accelerometer. The Dynaport MoveMonitor can fail if the battery is not fully charged or if the device is worn backwards. The device indicates if it is fully charged, minimizing the change of human errors. However, in a handful of cases the device did not measure for 7 days because the investigators replaced the original SD-cards with new ones. The new SD-cards appeared to consume more battery energy than the original ones. Therefore the device could only measure for 5 or 6 days. Besides this error, we did not experience device malfunction The investigators explicitly explained how to wear the device to minimize the change that participants wore the device backwards. This could be explained quite easy since the device is worn correct if one could read the word 'McRoberts' on the outside of the device. Therefore this error did not occur during any of the worn days.

Another study limitation is the lack of an age-matched control group. Although groups were initially matched for age and sex, a significant difference in age was present between the IC and control group once the IC group drop out rate appeared high. However, a sensitivity analysis including healthy adults aged $\leq 60$ years $(n=14)$ revealed no significant difference in daily PA level in comparison to 13 other healthy adults aged > 60 years $(526 \pm 160$ METs $\times$ min vs. $471 \pm 151$ METs $\times$ min, $p=0.37)$ although these group may have been underpowered. 


\section{Conclusions}

More than half of patients with intermittent claudication (IC) do not meet the minimum recommendations for physical activity (PA) and public health. Compared to healthy adults, they have a significantly lower daily PA level. PA differences are due to a IC subgroup with severe functional impairments. Because a low PA level is considered a strong predictor of mortality and functional decline, all health care workers should actively stimulate physical activities in IC. Future studies should assess the effects of treatment strategies including supervised exercise therapy on daily PA levels.

\section{Acknowledgements}

We would like to thank Rob van Lummel, Menno Zuidema and Erik Ainsworth of McRoberts B.V. (The Hague, The Netherlands) for their technical support regarding the Dynaport MoveMonitor.

\section{References}

1. Norgren L, Hiatt WR, Dormandy JA, Nehler MR, Harris KA, Fowkes FG. Inter-Society Consensus for the Management of Peripheral Arterial Disease (TASC II). J Vasc Surg. 2007;45 Suppl S:S5-67.

2. Criqui MH. Systemic atherosclerosis risk and the mandate for intervention in atherosclerotic peripheral arterial disease. Am J Cardiol. 2001;88(7B):43J-7J.

3. Criqui MHL, R. D.; Fronek, A. Mortality over a period of 10 years in patients with peripheral arterial disease. $N$ Engl J Med. 1992;326:7.

4. Regensteiner JG, Hiatt WR, Coll JR, Criqui MH, Treat-Jacobson D, McDermott MM, et al. The impact of peripheral arterial disease on health-related quality of life in the Peripheral Arterial Disease Awareness, Risk, and Treatment: New Resources for Survival (PARTNERS) Program. Vasc Med. 2008;13(1):15-24.

5. Dumville JC, Lee AJ, Smith FB, Fowkes FG. The health-related quality of life of people with peripheral arterial disease in the community: the Edinburgh Artery Study. Br J Gen Pract. 2004;54(508):826-31.

6. Leeper NJ, Myers J, Zhou M, Nead KT, Syed A, Kojima Y, et al. Exercise capacity is the strongest predictor of mortality in patients with peripheral arterial disease. J Vasc Surg. 2013;57(3):728-33.

7. Gardner AW, Montgomery PS, Parker DE. Physical activity is a predictor of all-cause mortality in patients with intermittent claudication. J Vasc Surg. 2008;47(1):117-22.

8. Garg PK, Liu K, Tian L, Guralnik JM, Ferrucci L, Criqui MH, et al. Physical activity during daily life and functional decline in peripheral arterial disease. Circulation. 2009;119(2):251-

9. McDermott MM, Liu K, Ferrucci L, Criqui MH, Greenland P, Guralnik JM, et al. Physical performance in peripheral arterial disease: a slower rate of decline in patients who walk more. Ann Intern Med. 2006;144(1):10-20.

10. Haskell WL, Lee IM, Pate RR, Powell KE, Blair SN, Franklin BA, et al. Physical activity and public health: updated recommendation for adults from the American College of Sports Medicine and the American Heart Association. Circulation. 2007;116(9):1081-93.

11. Nelson ME, Rejeski WJ, Blair SN, Duncan PW, Judge JO, King AC, et al. Physical activity and public health in older adults: recommendation from the American College of Sports Medicine and the American Heart Association. Circulation. 2007;116(9):1094-105. 
12. Clarke CL, Holdsworth RJ, Ryan CG, Granat MH. Free-living physical activity as a novel outcome measure in patients with intermittent claudication. Eur J Vasc Endovasc Surg. 2013;45(2):162-7.

13. Gardner AW, Montgomery PS, Scott KJ, Blevins SM, Afaq A, Nael R. Association between daily ambulatory activity patterns and exercise performance in patients with intermittent claudication. J Vasc Surg. 2008;48(5):1238-44.

14. McDermott MM, Liu K, Ferrucci L, Tian L, Guralnik JM, Liao Y, et al. Greater sedentary hours and slower walking speed outside the home predict faster declines in functioning and adverse calf muscle changes in peripheral arterial disease. J Am Coll Cardiol. 2011;57(23):2356-64.

15. McDermott MM, Liu K, O’Brien E, Guralnik JM, Criqui MH, Martin GJ, et al. Measuring physical activity in peripheral arterial disease: a comparison of two physical activity questionnaires with an accelerometer. Angiology. 2000;51(2):91-100.

16. Sieminski DJ, Cowell LL, Montgomery PS, Pillai SB, Gardner AW. Physical activity monitoring in patients with peripheral arterial occlusive disease. J Cardiopulm Rehabil. 1997;17(1):43-7.

17. Sieminski DJ, Gardner AW. The relationship between free-living daily physical activity and the severity of peripheral arterial occlusive disease. Vasc Med. 1997;2(4):286-91.

18. van Hees VT, van Lummel RC, Westerterp KR. Estimating activity-related energy expenditure under sedentary conditions using a tri-axial seismic accelerometer. Obesity (Silver Spring). 2009;17(6):1287-92.

19. Gardner AW, Poehlman ET. Assessment of free-living daily physical activity in older claudicants: validation against the doubly labeled water technique. J Gerontol A Biol Sci Med Sci. 1998;53(4):M275-80

20. Van Remoortel H, Giavedoni S, Raste Y, Burtin C, Louvaris Z, Gimeno-Santos E, et al. Validity of activity monitors in health and chronic disease: a systematic review. Int J Behav Nutr Phys Act. 2012;9:84.

21. Van Hees VT, Slootmaker SM, De Groot G, Van Mechelen W, Van Lummel RC. Reproducibility of a triaxial seismic accelerometer (DynaPort). Med Sci Sports Exerc. 2009; 41(4):810-7.

22. Verspaget M, Nicolai SP, Kruidenier LM, Welten RJ, Prins MH, Teijink JA. Validation of the Dutch version of the Walking Impairment Questionnaire. Eur J Vasc Endovasc Surg. 2009;37(1):56-61.
23. Gandek B, Ware JE, Aaronson NK, Apolone G, Bjorner JB, Brazier JE, et al. Cross-validation of item selection and scoring for the SF-12 Health Survey in nine countries: results from the IQOLA Project. International Quality of Life Assessment. J Clin Epidemiol. 1998;51(11):1171-8.

24. Langer D, Gosselink R, Sena R, Burtin C, Decramer M, Troosters T. Validation of two activity monitors in patients with COPD. Thorax. 2009;64(7):641-2.

25. Houdijk H, Appelman FM, Van Velzen JM, Van der Woude LH, Van Bennekom CA. Validity of DynaPort GaitMonitor for assessment of spatiotemporal parameters in amputee gait. J Rehabil Res Dev. 2008;45(9):1335-42.

26. Dijkstra B, Kamsma Y, Zijlstra W. Detection of gait and postures using a miniaturised triaxial accelerometer-based system: accuracy in community-dwelling older adults. Age Ageing. 2010;39(2):259-62.

27. Dijkstra B, Zijlstra W, Scherder E, Kamsma Y. Detection of walking periods and number of steps in older adults and patients with Parkinson's disease: accuracy of a pedometer and an accelerometry-based method. Age Ageing. 2008;37(4):436-41.

28. Van Remoortel H, Raste Y, Louvaris Z, Giavedoni S, Burtin C, Langer D, et al. Validity of six activity monitors in chronic obstructive pulmonary disease: a comparison with indirect calorimetry. PLoS One. 2012;7(6):e39198.

29. Gardner AW, Skinner JS, Cantwell BW, Smith LK. Progressive vs single-stage treadmil tests for evaluation of claudication. Med Sci Sports Exerc. 1991;23(4):402-8.

30. Jongert MWH, H.J.; van Hoek, J. [Guideline intermittent claudication from the Royal Dutch Society of Physical Therapy]. Ned Tijdschr Fysioth. 2003;6:50.

31. Frans FA, Zagers MB, Jens S, Bipat S, Reekers JA, Koelemay MJ. The relationship of walking distances estimated by the patient, on the corridor and on a treadmill, and the Walking Impairment Questionnaire in intermittent claudication. J Vasc Surg. 2013;57(3):720-7 e1.

32. Gardner AW, Montgomery PS, Scott KJ, Afaq A, Blevins SM. Patterns of ambulatory activity in subjects with and without intermittent claudication. J Vasc Surg. 2007;46(6) 1208-14.

33. Pitta F, Troosters T, Spruit MA, Probst VS, Decramer M, Gosselink R. Characteristics of physical activities in daily life in chronic obstructive pulmonary disease. Am J Respir Crit Care Med. 2005;171(9):972-7. 


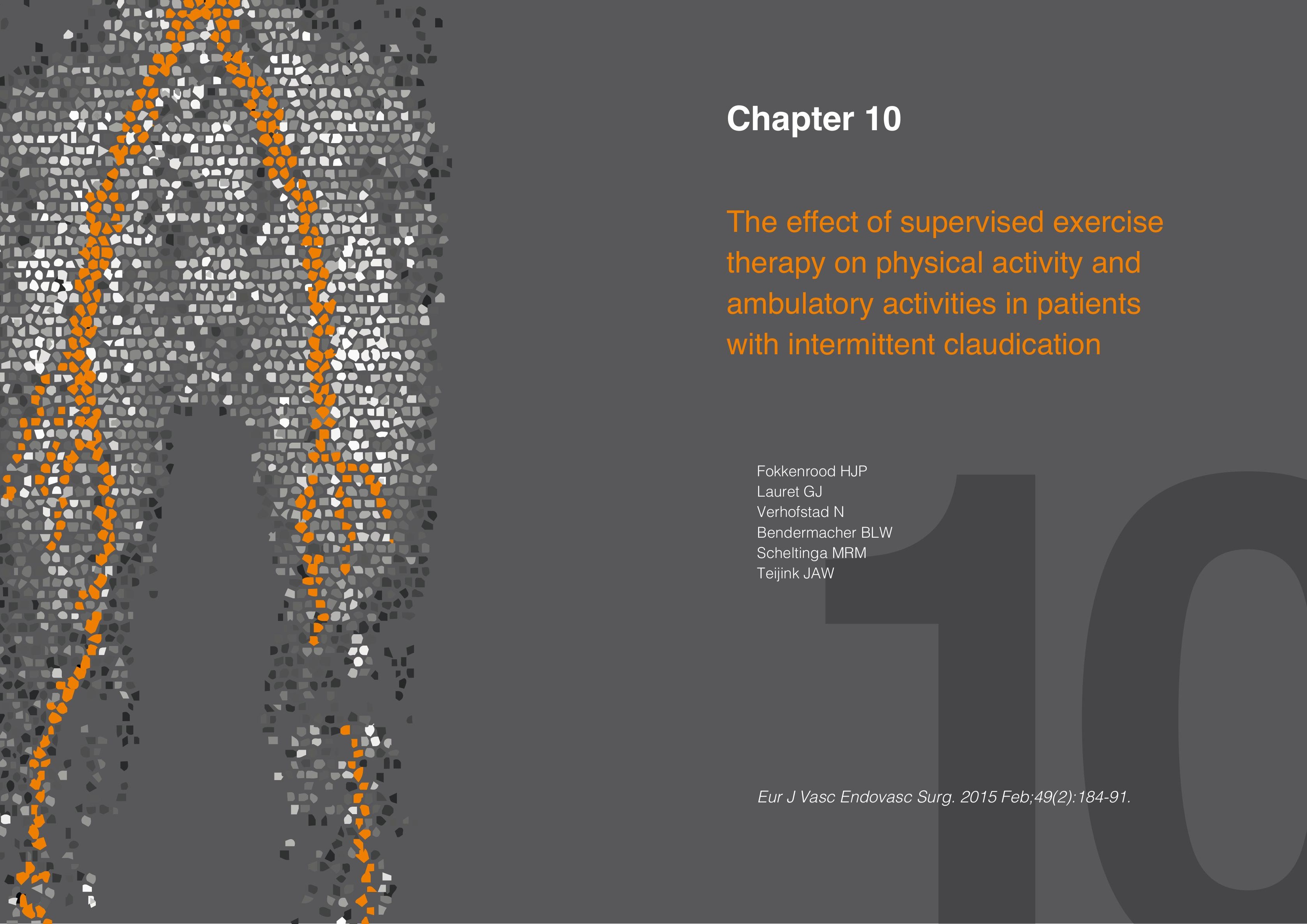




\section{Abstract \\ Objectives}

Intermittent claudication (IC) is associated with a reduction in physical activity (PA) and a more rapid functional decline leading to a higher mortality rate compared to healthy individuals. Supervised exercise therapy (SET) is known to increase the walking capacity of IC patients. However, it is unclear whether SET increases PA. The aim of this study was to investigate the effect of SET on PA levels and ambulatory activities in patients with IC.

Design \& Methods

Newly diagnosed IC patients were requested to wear an activity monitor one week prior to and one week immediately following 3 months of SET. Primary outcome was the percentage of patients meeting the minimum recommendations of PA (ACSM/ AHA public health, $\geq 67 \mathrm{METs} \cdot \mathrm{min} \cdot$ day, in bouts of $\geq 10 \mathrm{~min}$ ) at baseline and after 3 months of SET. Additionally, daily PA level (metabolic equivalents, METs-min), duration of ambulatory activities, daily number of steps, pain free walking distance (PFWD), maximal walking distance (MWD) and SF-36 health surveys were compared before and after SET.

$$
\text { Results }
$$

Data of 41 participants were available for analysis. A higher number of participants met the ACSM minimum recommendation for PA at the 3 months follow up (baseline: 43\%; 3 months: 63\%, p= .003). Despite significant increases in PFWD (baseline: 210m; 3 months: 390m, p=.001), MWD (baseline: 373m; 3 months: 555m, $\mathrm{p}=.002$ ) and physical functioning score (SF-36) following SET, no increase in mean daily PA level was found ( $395 \pm 220$ vs. $411 \pm 228$ METs-min, $\mathrm{p}=.43$ ). Furthermore, total number of steps and time spent in ambulatory activities did not change following SET.

\section{Conclusions}

Three months of SET for intermittent claudication leads to more patients meeting the ACSM/AHA public health minimum recommendations of PA. Assessment of PA may be incorporated as outcome parameter in future research comparing different treatment modalities for peripheral arterial disease.

\section{Introduction}

Most patients with intermittent claudication (IC) demonstrate a limited exercise performance and have increased risks on cardio- and cerebrovascular events, reduced quality of life (QoL) and higher mortality rates. ${ }^{(1)}$ Primary treatment of IC includes supervised exercise therapy (SET) as suggested by several international guidelines. ${ }^{(1-3)}$ SET significantly improves the maximal and pain-free walking distances and is cost-effective. ${ }^{(4-8)}$ However, the question arises whether effectiveness of PAD treatment modalities should be evaluated on the basis of changes in walking capacity only.

Individuals who are regularly physically active report better overall health, lower health care expenditures and fewer mobility limitations than their sedentary counterparts. ${ }^{(9,10)}$ The American Heart Association (AHA) and the American College of Sports Medicine (ACSM) provide specific recommendations of various types of activity to stimulate the elderly. Tailored recommendations are provided that apply to adults with clinically-significant chronic conditions or functional limitations that affect mobility and activity. ${ }^{(11)}$ Guidelines suggest to engage in moderate-intensity aerobic exercise for a minimum of 30 minutes during five days a week, or a minimum of 20 minutes of vigorousintensity activity on three days each week, or some combination of the two. ${ }^{(11)}$ Activities should be performed in bouts of at least 10 minutes. Intensity of effort is assessed in absolute terms by estimating the actual metabolic cost of a given activity and assigning intensity accordingly. ${ }^{(12)}$ A metabolic equivalent (MET) is an estimate of oxygen consumption at rest. A three-MET activity would be an activity that utilizes roughly three times the amount of resting energy expenditure. Accordingly, vigorous intensity activities (>6.0 METs) performed for a particular duration and frequency generate greater energy expenditure than moderate-intensity activities (3.0-6.0 METs) of the same duration and frequency. When combining the recommendations on moderate- and vigorous-intensity physical activity (PA), the daily minimum goal of physical activity (PA) should be in the range of 64-107 METs $\times$ min. ${ }^{(11)}$

Recent studies demonstrated that free-living daily PA levels in IC patients are lower compared to healthy controls ${ }^{(13-16)}$. However, PA is scantly used as an outcome paramete in trials concerning IC treatment ${ }^{(15,17-21)}$. It may be relevant to study the potential beneficial effects of SET on PA level and exercise behaviour in IC patients. If PA levels improve 
following SET, cardiovascular risk reduction and improved QoL may follow on the long term $^{(22,23)}$. Although SET has proven effective in improving walking distances ${ }^{(8,19)}$, one can question whether an increased walking capacity is of benefit during the patient's daily life activities. In other words, when an IC patient is able to walk further, this finding does not necessarily implicate that PA levels and/or exercise behavior are positively influenced. A potential goal of future PAD treatment should perhaps be aimed at increasing physical activity.

The aim of this study is to assess the effect of a SET program on PA and walking behavior in an IC population. In addition, we hypothesize that a SET induced increased walking distance would improve PA levels in IC patients.

\section{Methods}

The present study was executed between January 2013 and September 2013. The study was conducted following a previous study that was executed to quantify daily PA levels and energy expenditure in newly diagnosed IC patients. ${ }^{(16)}$

Patients were recruited from a population presenting with new onset manifestations of IC at outpatient departments of Vascular Surgery of the Catharina Hospital, Eindhoven and Maxima Medical Centre, Veldhoven/Eindhoven, The Netherlands. Following history taking and a physical examination, patients suspected of IC underwent an anklebrachial index (ABI) measurement using standard equipment. Patients with values below 0.90 at rest or a drop in value of more than 0.15 after a standardised treadmill test (at 3.2 $\mathrm{km} / \mathrm{hrs}$. and a $10 \%$ incline) were considered eligible.

Exclusion criteria were serious cardiopulmonary limitations (NYHA class 3-4), critical limb ischemia or previous lower-limb amputation, use of walking aids, psychiatric instability or other serious comorbidity which possibly limited the patient's walking ability. Patients who were treated with invasive revascularizations during follow up were excluded as well. Subjects that were willing to participate provided a written informed consent. All procedures described in this study were approved by the Medical Ethical Committee, Catharina Hospital, Eindhoven.

\section{Study protocol}

All participants received a detailed instruction on all specifics regarding proper handling and wearing of the DynaPort MoveMonitor (McRoberts BV, The Hague, the Netherlands) and were asked to wear the device correctly for 7 consecutive days. As the device is not waterproof, participants were instructed to remove the device when taking a shower or a bath. Participants were also asked to perform their normal daily activities during this week and not to wear the device during sleeping.

A 3 months period of SET was commenced immediately after the first week monitoring period. Patients were referred to a local physical therapist, who was trained in providing SET according to the Royal Dutch Society for Physical Therapy guidelines and the Dutch ClaudicatioNet network quality standards ${ }^{(24)}$. The educational program ensured that all patients received SET according to the guidelines of the Royal Dutch Society for Physical Therapy. ${ }^{(25)}$ The physical therapist assessed a baseline and a 3 months pain-free walking distance (PFWD) and maximum walking distance (MWD) using a standardised graded treadmill protocol (walking at 3.2 kilometer per hour $(\mathrm{km} / \mathrm{h}$ ) with a $0 \%$ incline that increases by $2 \%$ every 2 minutes till a maximum of $10 \%)^{(26,27)}$ Patients were tested for a maximum of 30 minutes $(1600 \mathrm{~m})$. Evidence-based cardiovascular risk management including antiplatelet and statin therapy was standardly initiated, in case patients were not taking this medication already. After 3 months, SET outcome was discussed with the patient followed by a second 7-day period of wearing the DynaPort MoveMonitor.

\section{Monitoring of physical activity and walking impairment}

The DynaPort MoveMonitor, a tri-axial seismic accelerometer, was used to measure PA. The DynaPort MoveMonitor was placed in a belt that was strapped around the waist. It was positioned at the base of the lumbar column just cranial to the buttocks. This accelerometer was chosen because of an optimal correlation between indirect calorimetry and generated MET output whereas walking speed was correctly measured in a population with chronic obstructive pulmonary disease ${ }^{(28)}$. Moreover, this activity monitor was recently validated in an IC population ${ }^{(29)}$. The device consists of a tri-orthogonal orientated piezo-capacitive acceleration sensor, a rechargeable battery and removable SD card to store the acceleration data. The raw acceleration data lend itself to a pattern recognition approach using logical algorithms (MoveMonitor analysis software, version 2.6) for the classification of postures (lying, sitting and standing) and motions (locomotion and shuf fling). General and specifics of the software were provided in several previously published $\operatorname{articles}^{(16,30-32)}$ 
A Dutch validated version of the Walking Impairment Questionnaire (WIQ) and a 36-item Short Form Health Survey version 2 (SF-36) were assessed at baseline and after the 3 months of SET treatment. ${ }^{(33-35)}$

\section{Primary outcomes}

- Percentage of participants meeting the ACSM lower limit recommendation for PA and public health (67 METs.min a day)

- Percentage of participants meeting the ACSM higher limit recommendation for PA and public health (107 METs.min a day)

\section{Secondary outcomes}

- Daily PA level (measured in METs.min)

- Daily PA level performed in bouts of $>10$ minutes of moderate or vigorous intensity (measured in METs.min)

- Mean time spent per day during different activities (in minutes; lying, standing, sitting, walking, shuffling, locomotion, not wearing the device)

- Mean number of steps walked in one period and maximal number per day (top period of steps)

- Activity per day (in minutes; sedentary activity: intensity <1.5 METs; light: 1.5-3 METs; moderate: 3-6 METs; vigorous: 6-9 METs)

- Change in SF-36 values

\section{Data Analysis}

Data checks per patient for each study day were deemed necessary to assure proper use of the device. By definition, the device was 'worn correctly' during a day if it detected a minimum of 20 steps and if it was 'worn' $\geq 9$ hours and if it was 'not worn' for $\geq 5$ hours a day. Moreover, patients were arbitrarily excluded from analysis if the device was worn during less than 5 days, to filter out incorrect or unrepresentative data. Mean time that was spent per day was determined for each participant depending on the number of 'correctly worn days'. Analysis was performed on patients with both a correct baseline and follow-up measurement.

Statistical analyses

All analyses were performed using IBM SPSS Statistics Version 21 (SPSS Inc., Chicago,
IL, USA). Categorical variables are presented as frequencies with percentages. A Pearson Chi-Square test was used to identify differences for categorical variables. To obtain an impression of the distribution, values were analyzed for skewness and kurtosis. Nominal normally distributed variables are depicted as the mean \pm standard deviation (SD), while non-normally distributed values are reported as median \pm interquartile range (IQR). Statistical differences between the included and excluded study populations were analysed with an independent Students T-test, while differences between time periods were calculated with a paired sample T-test or with Pearson correlation coefficients for continuous normal distributed variables. A Wilcoxon signed-rank test or Spearman's rho were utilized for non-normal distributed continuous variables. A p-value $<0.05$ was used for statistical significance.

\section{Results}

Baseline characteristics

A total of 126 IC patients wore the device correctly at baseline and were considered eligible for this study (figure 1). Analysis of the accelerometer data demonstrated that 17 subjects did not wore the device correctly for $\geq 5$ days at follow up. In six cases the internal memory card malfunctioned and data were not stored, another eight participants refused a follow up measurement and another 38 subjects were lost to follow up (36.5\%). As a consequence, data of 57 participants could be used for analysis (45.2\%), of which 10 patients received a vascular intervention during the study period and 6 did not receive SET due to inadequate health care insurance. The present study reflects the results obtained from 41 patients (35.3\% of the total study population). Baseline characteristics regarding both the included and excluded study population are depicted in table 1 .

\section{ACSM recommendations in IC patients}

A total of 18 participants achieved the lower limit of the ACSM recommendations (67 METs $\times$ min a day) and 12 of them even met the ACSM upper limit (107 METs $\times$ min a day) as well at baseline line. The number of participants meeting the lower limit of the ACSM recommendations was significantly lower at baseline $(n=18,43 \%)$ compared to the numbers at 3 months of follow up ( $n=26,63 \%, p=.003$, figure 2$)$. Of the initial 18 participants that achieved the lower limit of the ACSM recommendations at baseline, 16 achieved the 
lower limit at follow up (figure 2) again, while the remaining other two did not. From the 12 participants who achieved the higher limit of the ACSM recommendations at baseline (29\%), eight achieved the higher limit again after 3 months (figure 2). In total 14 subjects met the ACSM higher limit (34\%).

Daily level of physical activity in IC patients

Mean daily PA level (in METs $\times$ min) was normally distributed. No significant difference in mean daily PA level was found after 3 months of SET (baseline: $395 \pm 220$ METs $\times$ min vs. 3 months: $411 \pm 228$ METs $\times$ min, $\mathrm{p}=.43$; figure 3 ). Moreover, daily PA levels performed in bouts of $>10$ minutes were also not significantly different after 3 months ( $\mathrm{p}=.13$; figure 3). No significant correlation coefficients were found between the change in mean daily PA (METs $\times$ min) or mean daily PA in bouts and the increase in MWD ( $\triangle$ mean daily PA vs. $\triangle \mathrm{MWD}$ : $\mathrm{r}=.21, \mathrm{p}=.19 ; \Delta$ mean daily PA in bouts vs. $\triangle \mathrm{MWD}$ : $\mathrm{r}=.30, \mathrm{p}=.06$ ).

Time consumption and intensity of various activities

Table 2 depicts the time consumption and intensity of the various daily activities of IC patient. Data was non-normally distributed. No significant changes were found after 3 months of SET. Analysis of the intensity levels did also not show any significant differences between baseline and 3-months values (table 2). However, the mean maximal number of consecutive steps (top period of steps), which was normally distributed, was significantly higher after 3 months of SET (1914 \pm 1473 vs. $2390 \pm 1904$, p<.05).

Walking distances and quality of life

PFWD, MWD and total WIQ score significantly improved following SET (table 3). Moreover, quality of life as reflected by SF-36 scores showed a significant increase in the physical functioning (PF) and the bodily pain (BP) role (table 3). No significant correlation was found between the increase in both QoL roles and an improvement in maximal walking distance ( $\triangle \mathrm{PF}$ vs. $\triangle \mathrm{MWD}$ : $\mathrm{r}=-.07, \mathrm{p}=.75 ; \Delta \mathrm{BP}$ vs. $\Delta \mathrm{MWD}: \mathrm{r}=.08, \mathrm{p}=.73$ ).

\begin{tabular}{|c|c|c|c|}
\hline \multicolumn{4}{|c|}{ Table 1 Baseline characteristics } \\
\hline & \multicolumn{2}{|c|}{ Total Study population ( $n=126)$} & \multirow[b]{2}{*}{$P$ - value } \\
\hline & $\begin{array}{l}\text { Included patients } \\
(n=41)\end{array}$ & $\begin{array}{l}\text { Excluded patients } \\
(n=85)\end{array}$ & \\
\hline Male ( $\mathrm{N}-\%)$ & $20(48.8 \%)$ & $49(57.6 \%)$ & .45 \\
\hline Both legs symptomatic ( $\mathrm{N}$ - \%) & $19(46.3 \%)$ & $38(44.7 \%)$ & .29 \\
\hline Age (years) $($ mean $\pm S D)$ & $69 \pm 11$ & $68 \pm 10$ & .42 \\
\hline $\operatorname{BMI}\left(\mathrm{kg} / \mathrm{m}^{2}\right)($ mean $\pm \mathrm{SD})$ & $27.4 \pm 4.1 \mathrm{w}$ & $26.7 \pm 4.0$ & .37 \\
\hline Worst $\mathrm{ABl}$ in rest (mean $\pm \mathrm{SD}$ ) & $0.61 \pm 0.20^{a}$ & $0.63 \pm 0.19^{d}$ & .50 \\
\hline Worst $\mathrm{ABl}$ after effort (mean $\pm \mathrm{SD})$ & $0.43 \pm 0.21^{\mathrm{b}}$ & $0.44 \pm 0.22^{\circ}$ & .85 \\
\hline \multicolumn{4}{|l|}{ Duplex right leg ${ }^{\circ}$} \\
\hline No lesions & $6(14.6 \% w)$ & $\mathrm{n} / \mathrm{a}$ & \\
\hline Aortoiliac & $6(14.6 \%)$ & $n / a$ & \\
\hline Femoropopliteal & $12(29.3 \%)$ & $\mathrm{n} / \mathrm{a}$ & \\
\hline Combination & $5(12.2 \%)$ & $\mathrm{n} / \mathrm{a}$ & \\
\hline \multicolumn{4}{|l|}{ Duplex left leg ${ }^{\circ}$} \\
\hline No lesions & $10(24.4 \%)$ & $\mathrm{n} / \mathrm{a}$ & \\
\hline Aortoiliac & $4(9.8 \%)$ & $n / a$ & \\
\hline Femoropopliteal & $12(29.3 \%)$ & $\mathrm{n} / \mathrm{a}$ & \\
\hline Combination & $5(12.2 \%)$ & $\mathrm{n} / \mathrm{a}$ & \\
\hline Pulmonary history (N - \%) & $9(22.0 \%)$ & $16(18.8 \%)$ & .81 \\
\hline Cardiac history (N - \%) & $10(24.4 \%)$ & $29(34.1 \%)$ & .33 \\
\hline
\end{tabular}

Notes: a values based on 38 patients. ${ }^{b}$ values based on 30 patients. ' values based on 29 patients. ${ }^{a}$ values based on 82 patients. ${ }^{e}$ values based on 73 patients $n / a=$ (not available) 
Table 2 Mean daily activities and duration in different intensity levels at baseline and at hree months follow up

\begin{tabular}{l|c|c|c} 
& $\begin{array}{c}\text { Baseline (n=41) } \\
\text { Median (IQR) }\end{array}$ & $\begin{array}{c}\mathbf{3} \text { months (n=41) } \\
\text { Median (IQR) }\end{array}$ & P-value \\
\hline Device worn correctly (days) & $7(6-7)$ & $7(6-7)$ & \\
Time worn (min) & $910(880-1006)$ & $932(899-1043)$ & $.06^{\mathrm{a}}$ \\
\hline Lying (min) & $139(72-270)$ & $182(99-270)$ & $.27^{\mathrm{a}}$ \\
Sitting (min) & $462(390-580)$ & $512(397-607)$ & $.24^{\mathrm{a}}$ \\
Standing (min) & $151(108-221)$ & $168(123-209)$ & $.40^{\mathrm{a}}$ \\
Walking (min) & $64(40-87)$ & $61(42-88)$ & $.87^{\mathrm{a}}$ \\
Shuffling (min) & $20(13-25)$ & $17(13-32)$ & $.70^{\mathrm{a}}$ \\
Locomotion (min) & $89(61-116)$ & $82(60-125)$ & $.84^{\mathrm{a}}$ \\
Not Worn (min) & $529(434-559)$ & $509(397-541)$ & $.11^{\mathrm{a}}$ \\
\hline Steps (mean \pm SD) & $5732(3187)$ & $5805(3336)$ & $.43^{\mathrm{b}}$ \\
Top period consecutive steps & $1914(1473)$ & $2390(1904)$ & $.03^{\mathrm{b}}$ \\
(mean \pm SD) & $66(50-91)$ & $64(51-91)$ & $.29^{\mathrm{a}}$ \\
\hline Light activity (min) & $83(59-107)$ & $81(58-106)$ & $.81^{\mathrm{a}}$ \\
Moderate activity (min) & $1.3(0.4-6.2)$ & $0.9(0.4-7.9)$ & $.97^{\mathrm{a}}$ \\
Vigorous activity (min) &
\end{tabular}
Notes: a Wilcoxon signed rank test, ${ }^{b}$ paired T-test. Light activity = activity with an intensity of $1.5-3 \mathrm{METs}$,
Moderate activity $=$ activity with an intensity of $3-6 \mathrm{METs}$, Vigorous activity = activity with an intensity G 6 -9 METs.

Table 3 Quality of Life and walking distances at baseline and at three months follow up

\begin{tabular}{|c|c|c|c|}
\hline & $\begin{array}{c}\text { Baseline } \\
\text { Median (IQR) }\end{array}$ & $\begin{array}{l}3 \text { months } \\
\text { Median (IQR) }\end{array}$ & P-value \\
\hline PFWD (m) ${ }^{b}$ & $210(113-300)$ & $390(230-580)$ & $.001^{\mathrm{a}}$ \\
\hline $\operatorname{MWD}(m)^{\circ}$ & $373(254-631)$ & $637(403-1045)$ & $<.001^{\mathrm{a}}$ \\
\hline WIQ total score ${ }^{d}$ & $0.33(0.16-0.58)$ & $0.54(0.41-0.78)$ & $<.001^{\mathrm{a}}$ \\
\hline \multicolumn{4}{|l|}{$S F-36^{d}$} \\
\hline physical functioning & $36.0(25.5-43.9)$ & $38.1(33.9-46.5)$ & $.002^{\mathrm{a}}$ \\
\hline physical role & $42.2(30.5-48.9)$ & $39.8(32.8-52.0)$ & $.12^{\mathrm{a}}$ \\
\hline bodily pain & $41.4(37.2-49.3)$ & $46.1(37.2-50.3)$ & $.04^{\mathrm{a}}$ \\
\hline general health & $41.7(36.8-49.3)$ & $44.8(38.2-51.8)$ & $.06^{\mathrm{a}}$ \\
\hline vitality & $49.0(43.5-61.5)$ & $52.1(45.8-60.7)$ & $.35^{\mathrm{a}}$ \\
\hline social role & $45.9(35.0-56.8)$ & $51.4(40.5-56.8)$ & $.11^{\mathrm{a}}$ \\
\hline emotional role & $48.1(40.3-55.9)$ & $44.2(36.0-55.9)$ & $.34^{\mathrm{a}}$ \\
\hline mental health & $52.8(44.0-61.3)$ & $55.6(42.3-58.5)$ & $.85^{\mathrm{a}}$ \\
\hline
\end{tabular}

Notes: aWilcoxon signed rank test. bvalues based on 34 patients. cvalues based on 40 patients.

dvalues based on 39 patients.
Figure 1 Flowchart of study population

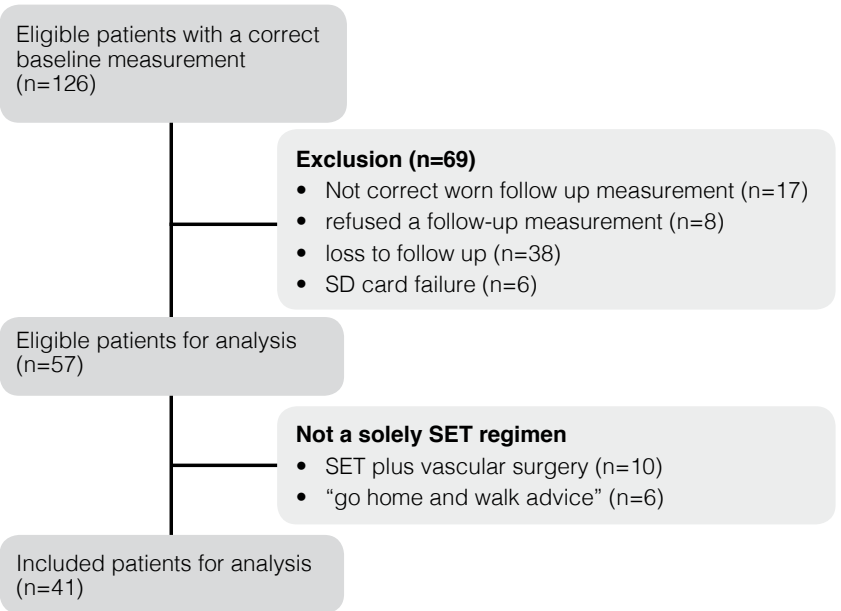

(Corn: "the device was 'worn correctly' during a day if it detected a minimum of 20 steps and If it was 'worn' $\geq 9$ hours and if it was 'not worn' for $\geq 5$ hours a day."

Figure 2 Adherence to ASCM minimum recommendation for physical activity and public health (67 METs-min a day) at baseline and at 3 months follow up

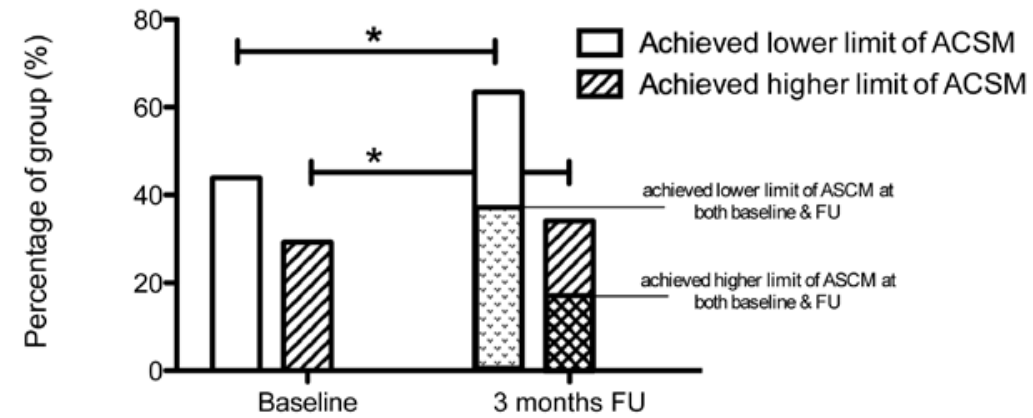

Note: 'indicates level of significance $<0.05$ 
Figure 3 Mean daily physical activity level at baseline and at 3 months follow up

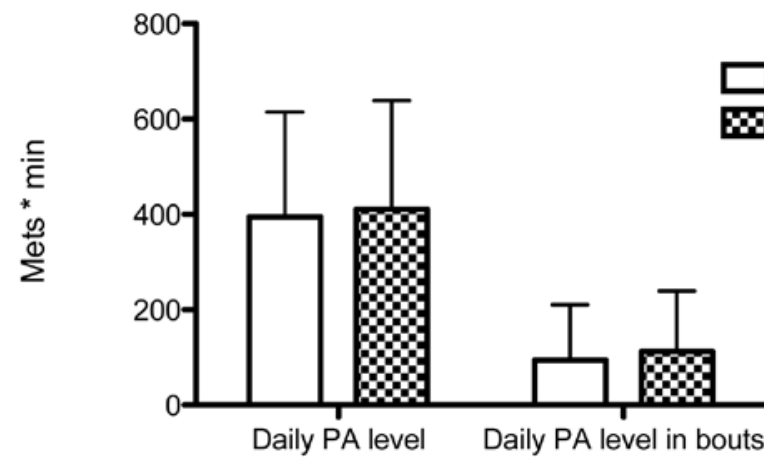

Note:

Data was normally distributed and analysed with a paired T-test.

\section{Discussion}

In line with the upcoming interest in studying potential associations between daily PA and their impact on cardiovascular risk reduction and mortality ${ }^{(36-42)}$, this study assesses the effect of SET on proportions of IC patients meeting the ACSM lower and higher limit recommendation for PA and public health. Several studies registered activity levels in IC patients. ${ }^{(15,17-21)}$ However, this parameter was never considered as a primary outcome value. McDermott et al. showed in a 7-day measurement model that IC patients significantly improved their PA levels (in activity units) after 6 months of home-based exercise.

(21) These findings might in part be confirmed by the present results. Although our study was based on a shorter follow up period and based on supervised therapy, SET increased the percentage of IC patients achieving the lower and higher limit of daily PA level as recommended in the international ACSM guideline ${ }^{(11)}$. However, firm conclusions cannot be drawn, since some patients did show a decline in PA level and mean values for ambulatory activities (e.g. walking time, total number of steps) were not influenced after a period of SET. Probably large variations in activities per patient (duration as well as intensity) and between patients in combination with our relatively small study population could have caused this contradiction. Therefore further research is necessary to optimize the determination of PA levels in patients suffering from IC. However from our results it may be argued that a 3-month SET program may have beneficial effects on increasing daily PA in an IC population.
It was hypothesized that an increased walking capacity would result in an improved PA level of IC patients. Although both the percentage of patients meeting the ACSM limits and walking capacity significantly improved after 3 months of SET, no significant correlation between the change in PA levels and the increase in walking distance was found. Therefore one may argue that components of a SET program other than an increased walking capacity influence daily PA. Our findings might suggest that solely focusing on improvement of walking capacity has a limited value in optimizing SET treatment efficacy. It appears that patients who are able to walk further (because of a decrease in IC symptoms), will not use this capacity to walk more often, longer or with probably more intensity in daily life.

The effect of SET on QoL is still subject to debate ${ }^{(8)} \mathrm{A}$ recently published meta-analysis found a positive trend in improved QoL after three months of SET, although only the SF-36 "general health" role appeared significantly increased. ${ }^{(8)}$ In addition, McDermott et al. found no group differences in changes in the SF-12 PCS or MCS subscales. ${ }^{(21)}$ In contrast, we found a significant increase in both the physical functioning and the bodily pain role after three months of SET. Although patients showed an increased walking capacity, no significant correlation in the change of SF-36 values was found. This finding was recently confirmed by others reporting that the improvement in self-efficacy, satisfaction with functioning, pain acceptance and social functioning after six months of home-based walking exercise compared to a non-exercising control group was independent of walking performance. ${ }^{(43)}$ In combination with our finding that walking capacity might be of diminished value, a shift in SET treatment paradigm seems necessary. Future research should therefore focus on the optimization of SET programs other than increasing walking capacity alone (intrinsic motivation, life-style, patient satisfaction and expectations, social functioning, etc.).

Unfortunately a large number of participants were lost to follow up which may have potentially resulted in a selection bias. However, this is probably not the case as any differences regarding baseline characteristics between the study group and excluded patients were found. Furthermore both study groups were a representative reflection of the general PAD population encountered in a vascular outdoor clinic. An important reason for this substantial loss to follow up is the fact that 56 of the 126 included patients were recruited from a previous performed study. ${ }^{(16)}$ Only 23 of these 56 patients were eligible 
for inclusion, because in the other patients the 3 months follow up period was already expired. Furthermore, introducing the Dynaport MoveMonitor from a research setting to daily practice in our patient outdoor clinic may boost wear compliance, as was observed in comparable research concerning COPD patients. ${ }^{44}$ Unfortunately, a reliable sub-analysis between revascularization and SET treatment could not be performed as only 16 participants did receive such a treatment. Future research is needed to identify the effect of different IC treatment modalities on daily PA levels and ambulatory activities.

\section{Conclusion}

A 3-month SET program increases the number of patients achieving the ACSM/AHA public health minimum recommendations for physical activity (PA). The general focus of increasing solely walking capacity seems ancillary to other elements of supervision. Further research is needed to determine the optimal content of a SET program. In concert with the interest in factors such as sedentary activities and cardiovascular event risks, exercise behavior and PA might be included as outcome parameter in future PAD research and eventually clinical practice.

\section{Acknowledgements}

We would like to thank Rob van Lummel, Menno Zuidema and Erik Ainsworth of McRoberts B.V. (The Hague, The Netherlands) for their technical support with the DynaPort MoveMonitor.

\section{References}

1. Norgren L, Hiatt WR, Dormandy JA, Nehler MR, Harris KA, Fowkes FG. Inter-Society Consensus for the Management of Peripheral Arterial Disease (TASC II). J Vasc Surg 2007;45 Suppl S:S5-67.

2. Hirsch AT, Haskal ZJ, Hertzer NR, et al. ACC/AHA 2005 guidelines for the management of patients with peripheral arterial disease (lower extremity, renal, mesenteric, and abdominal aortic): executive summary a collaborative report from the American Association for Vascular Surgery/Society for Vascular Surgery, Society for Cardiovascular Angiography and Interventions, Society for Vascular Medicine and Biology, Society of Interventiona Radiology, and the ACC/AHA Task Force on Practice Guidelines (Writing Committee to Develop Guidelines for the Management of Patients With Peripheral Arterial Disease) endorsed by the American Association of Cardiovascular and Pulmonary Rehabilitation National Heart, Lung, and Blood Institute; Society for Vascular Nursing; TransAtlantic Inter-Society Consensus; and Vascular Disease Foundation. J Am Coll Cardiol 2006;47:1239312.

3. Layden J, Michaels J, Bermingham S, Higgins B, Guideline Development G. Diagnosis and management of lower limb peripheral arterial disease: summary of NICE guidance. Bmj 2012;345:e4947.

4. Bermingham SL, Sparrow K, Mullis R, et al. The Cost-effectiveness of Supervised Exercise for the Treatment of Intermittent Claudication. Eur J Vasc Endovasc Surg 2013;46:707-14.

5. Mazari FA, Khan JA, Carradice D, et al. Economic analysis of a randomized trial of percutaneous angioplasty, supervised exercise or combined treatment for intermittent claudication due to femoropopliteal arterial disease. Br J Surg 2013;100:1172-9.

6. Spronk S, Bosch JL, den Hoed PT, Veen HF, Pattynama PM, Hunink MG. Cost-effectiveness of endovascular revascularization compared to supervised hospital-based exercise training in patients with intermittent claudication: a randomized controlled trial. J Vasc Surg 2008;48:1472-80

7. Fakhry F, van de Luijtgaarden KM, Bax L, et al. Supervised walking therapy in patients with intermittent claudication. J Vasc Surg 2012;56:1132-42.

8. Fokkenrood HJ, Bendermacher BL, Lauret GJ, Willigendael EM, Prins MH, Teijink JA. Supervised exercise therapy versus non-supervised exercise therapy for intermittent claudication. Cochrane Database Syst Rev 2013;8:CD005263. 
9. Brach JS, FitzGerald S, Newman AB, et al. Physical activity and functional status in community-dwelling older women: a 14-year prospective study. Arch Intern Med 2003;163:2565-71.

10. Nguyen HQ, Ackermann RT, Maciejewski M, et al. Managed-Medicare health club benefit and reduced health care costs among older adults. Preventing chronic disease 2008;5:A14.

11. Nelson ME, Rejeski WJ, Blair SN, et al. Physical activity and public health in older adults: recommendation from the American College of Sports Medicine and the American Heart Association. Circulation 2007;116:1094-105.

12. Ainsworth BE, Haskell WL, Herrmann SD, et al. 2011 Compendium of Physical Activities: a second update of codes and MET values. Med Sci Sports Exerc 2011;43:1575-81.

13. Gardner AW, Womack CJ, Sieminski DJ, Montgomery PS, Killewich LA, Fonong T. Relationship between free-living daily physical activity and ambulatory measures in older claudicants. Angiology 1998;49:327-37.

14. Sieminski DJ, Gardner AW. The relationship between free-living daily physical activity and the severity of peripheral arterial occlusive disease. Vasc Med 1997;2:286-91.

15. Crowther RG, Spinks WL, Leicht AS, Sangla K, Quigley F, Golledge J. Effects of a longterm exercise program on lower limb mobility, physiological responses, walking performance, and physical activity levels in patients with peripheral arterial disease. J Vasc Surg 2008; $47: 303-9$

16. Lauret GJ, Fokkenrood HJ, Bendermacher BL, Scheltinga MR, Teijink JA. Physical activity monitoring in patients with intermittent claudication. Eur J Vasc Endovasc Surg 2014;47:656-63.

17. Gardner AW, Montgomery PS, Parker DE. Optimal exercise program length for patients with claudication. J Vasc Surg 2012;55:1346-54.

18. Gardner AW, Parker DE, Montgomery PS, Scott KJ, Blevins SM. Efficacy of quantified home-based exercise and supervised exercise in patients with intermittent claudication: a randomized controlled trial. Circulation 2011;123:491-8.

19. Nicolai SP, Teijink JA, Prins MH. Multicenter randomized clinical trial of supervised exercise therapy with or without feedback versus walking advice for intermittent claudication. I Vasc Surg 2010;52:348-55

20. Hiatt WR, Creager MA, Amato A, Brass EP. Effect of propionyl-L-carnitine on a background of monitored exercise in patients with claudication secondary to peripheral artery disease. Journal of cardiopulmonary rehabilitation and prevention 2011;31:125-32.

21. McDermott MM, Liu K, Guralnik JM, et al. Home-based walking exercise intervention in peripheral artery disease: a randomized clinical trial. Jama 2013;310:57-65.
22. Kodama S, Saito K, Tanaka S, et al. Cardiorespiratory fitness as a quantitative predictor of all-cause mortality and cardiovascular events in healthy men and women: a meta-analysis. Jama 2009;301:2024-35.

23. Yusuf S, Hawken S, Ounpuu S, et al. Effect of potentially modifiable risk factors associated with myocardial infarction in 52 countries (the INTERHEART study): case-control study. Lancet 2004;364:937-52.

24. Lauret GJ, Gijsbers HJ, Hendriks EJ, Bartelink ML, de Bie RA, Teijink JA. The ClaudicatioNet concept: design of a national integrated care network providing active and healthy aging for patients with intermittent claudication. Vasc Health Risk Manag 2012;8:495-503.

25. Jongert M, Hendriks H, van Hoek J, Kaasboer Kogelman K, Robeer G, Simens B. KNGF richtlijn claudicatio intermittens. Nederlands Tijdschrift voor Fysiotherapie 2003:3-50.

26. Gardner AW, Skinner JS, Cantwell BW, Smith LK. Progressive vs single-stage treadmill tests for evaluation of claudication. Medicine and science in sports and exercise 1991;23:402-8.

27. Jongert MWH, H.J.; van Hoek, J. [Guideline intermittent claudication from the Royal Dutch Society of Physical Therapy]. Ned Tijdschr Fysioth 2003;6:50

28. Van Remoortel H, Raste Y, Louvaris Z, et al. Validity of six activity monitors in chronic obstructive pulmonary disease: a comparison with indirect calorimetry. PloS one 2012;7:e39198.

29. Fokkenrood HJ, Verhofstad N, van den Houten MM, et al. Physical activity monitoring in patients with peripheral arterial disease: validation of an activity monitor. Eur J Vasc Endovasc Surg 2014;48:194-200.

30. Dijkstra B, Kamsma Y, Zijlstra W. Detection of gait and postures using a miniaturised triaxial accelerometer-based system: accuracy in community-dwelling older adults. Age and ageing 2010;39:259-62.

31. Dijkstra B, Kamsma YP, Zijlstra W. Detection of gait and postures using a miniaturized triaxial accelerometer-based system: accuracy in patients with mild to moderate Parkinson's disease. Archives of physical medicine and rehabilitation 2010;91:1272-7.

32. Fokkenrood HJ, Verhofstad N, van den Houten MM, et al. Physical Activity Monitoring in Patients with Peripheral Arterial Disease: Validation of an Activity Monitor. Eur J Vasc Endovasc Surg 2014

33. Verspaget M, Nicolai SP, Kruidenier LM, Welten RJ, Prins MH, Teijink JA. Validation of the Dutch version of the Walking Impairment Questionnaire. Eur J Vasc Endovasc Surg 2009;37:56-61.

34. Ware JE, Jr. SF-36 health survey update. Spine 2000;25:3130-9. 
35. Ware JE, Jr., Gandek B. Overview of the SF-36 Health Survey and the International Quality of Life Assessment (IQOLA) Project. Journal of clinical epidemiology 1998;51:903-12.

36. Grontved A, Hu FB. Television viewing and risk of type 2 diabetes, cardiovascular disease, and all-cause mortality: a meta-analysis. Jama 2011;305:2448-55.

37. Katzmarzyk PT. Physical activity, sedentary behavior, and health: paradigm paralysis or paradigm shift? Diabetes 2010;59:2717-25.

38. Katzmarzyk PT. Standing and Mortality in a Prospective Cohort of Canadian Adults. Med Sci Sports Exerc 2013.

39. Maher C, Olds T, Mire E, Katzmarzyk PT. Reconsidering the sedentary behaviour paradigm. PloS one 2014;9:e86403.

40. Thorp AA, Owen N, Neuhaus M, Dunstan DW. Sedentary behaviors and subsequent health outcomes in adults a systematic review of longitudinal studies, 1996-2011. American journal of preventive medicine 2011;41:207-15.

41. van der Ploeg HP, Chey T, Korda RJ, Banks E, Bauman A. Sitting time and all-cause mortality risk in 222497 Australian adults. Arch Intern Med 2012;172:494-500.

42. Wilmot EG, Edwardson CL, Achana FA, et al. Sedentary time in adults and the association with diabetes, cardiovascular disease and death: systematic review and meta-analysis. Diabetologia 2012;55:2895-905.

43. Rejeski WJ, Spring B, Domanchuk K, et al. A group-mediated, home-based physical activity intervention for patients with peripheral artery disease: effects on social and psychological function. Journal of translational medicine 2014;12:29.

44. Niessen M, Pijnappels M, van Dieën J, Van Lummel RC. Detecting not-wearing periods during activity monitoring in older adults. 2013. 


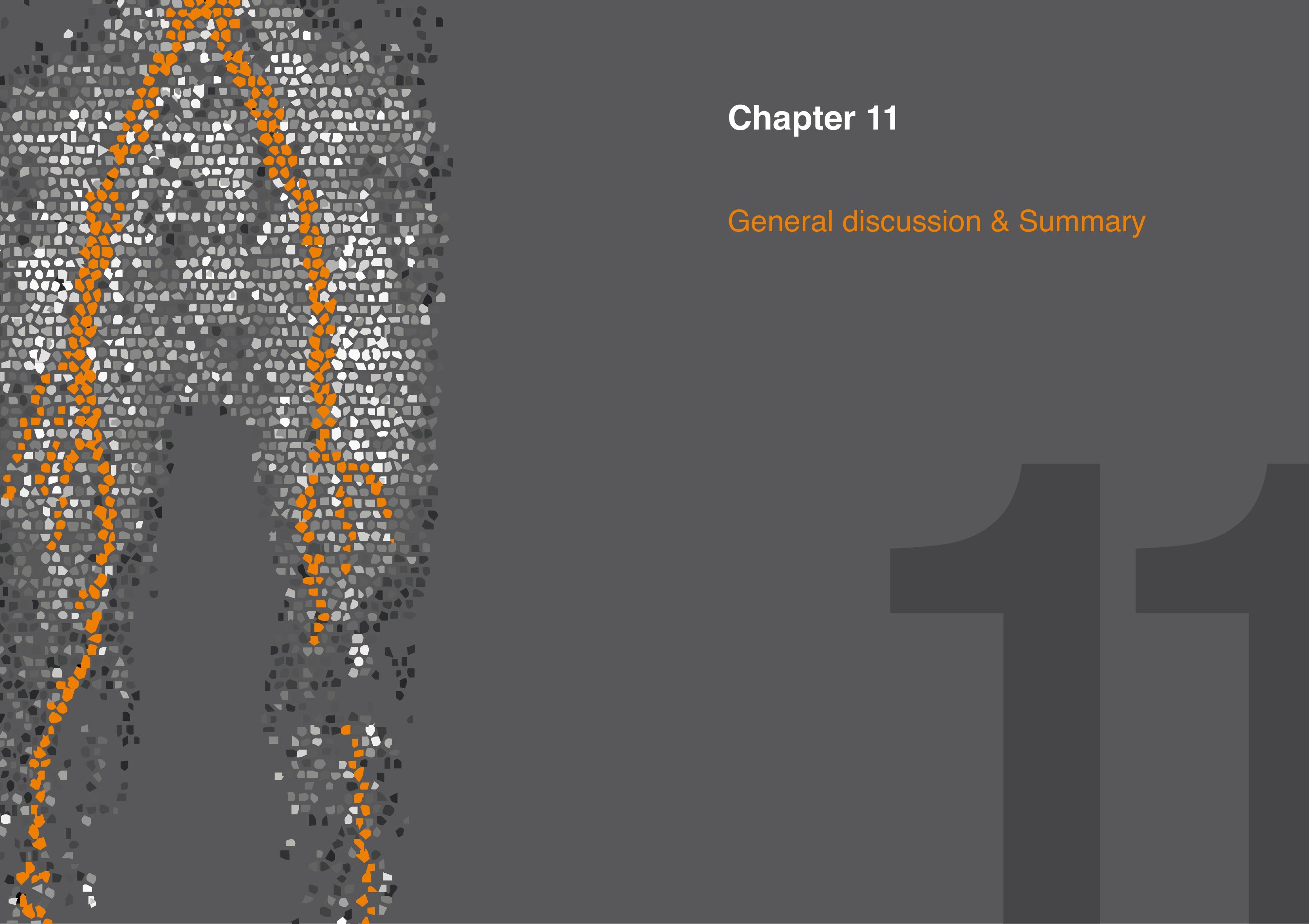




\section{General discussion \& Summary}

Peripheral arterial disease (PAD) is an expression of systemic atherosclerosis. Plaque formation causes progressive narrowing and hardening of the arteries. The manifestation of PAD is diverse. The vast majority of individuals are asymptomatic whereas only a small portion of patients develops tissue loss that necessitates amputation of the affected limb.

Globally, 202 million people are affected by PAD. The disease is found in 19\% of the Dutch population $>55$ years. ${ }^{(1,2)}$ Between 2000 and 2010, the number of patients with PAD has increased by nearly a quarter in first, second and third world countries1. In view of the association of PAD with loss of mobility, functional decline and cardiovascular events, this dramatic increase represents a major public health challenge. Recently, a call for governments, nongovernmental organizations and the private sector was made to address the social and economic consequences of PAD and to assess the best strategies for optimum treatment and prevention of this disease. . $^{(1)}$

Most PAD patients suffer from intermittent claudication (IC). ${ }^{(3)} \mathrm{IC}$ is defined as muscle discomfort in the lower limb reproducibly evoked by exercise and relieved by $<10 \mathrm{mi}-$ nutes rest. ${ }^{(3)}$ Most patients with IC are physically impaired. Therefore, treatment goals are to relieve symptoms and to improve exercise performance and daily functional abilities.
PART I - Towards a stepped care approach in intermittent claudication

Contemporary guidelines

A number of international guidelines provide recommendations for diagnosis and management of patients with PAD. ${ }^{(3-5)}$ IC patients are at risk for cardiovascular events and thus require intensive risk factor modification. Levels of blood pressure, glucose and cholesterol should be optimized. Attention should be paid to smoking cessation as nicotine use is the most important modifiable vascular risk factor. Antiplatelet therapy and statins are indicated for all IC patients as a means to reduce the risk of cardiovascular events. ${ }^{(6)}$

To relieve PAD related symptoms, a supervised exercise therapy regimen (SET) is advised as an initial treatment modality in these international guidelines. ${ }^{(3-5)}$ Several studies have demonstrated that some level of supervision is necessary to optimize results. Conversely, general and unstructured exercise recommendations that are haphazardly provided by a physician do not result in any clinical benefit..$^{(7-10)}$

\section{An update}

SET is effective as a treatment for IC. ${ }^{(7-10)}$ In chapter 2 a systematic meta-analysis was performed confirming that SET improves maximum treadmill walking distance compared to non-supervised exercise therapy regimens. Compared to the 2006 edition, ${ }^{(7)}$ which revealed a significant overall effect size of 0.58 , an increase to 0.69 was found, corresponding with an approximately 180 meters increase in walking distance favoring the supervised group. SET was also beneficial when maximum and pain-free walking distances at 12 months were considered. However, a significant effect on quality of life parameters as evaluated using a SF-36 questionnaire was not found.

A stepped care approach

Supported by this body of evidence, by international guidelines and by the Hippocratic oath adagium 'primum non nocere', SET should be offered to all IC patients as a firstchoice treatment option. ${ }^{(3-5)}$ Invasive means of limb revascularization, either minimal ly invasive (percutaneous transluminal angioplasty, PTA) or by means of conventional 'open' vascular surgery, should only be considered if a patient fails to respond to this conservative approach. This so-called stepped care model (SCM) is illustrated in figure 1. 
Figure 1 Schematic overview of the Stepped Care Model

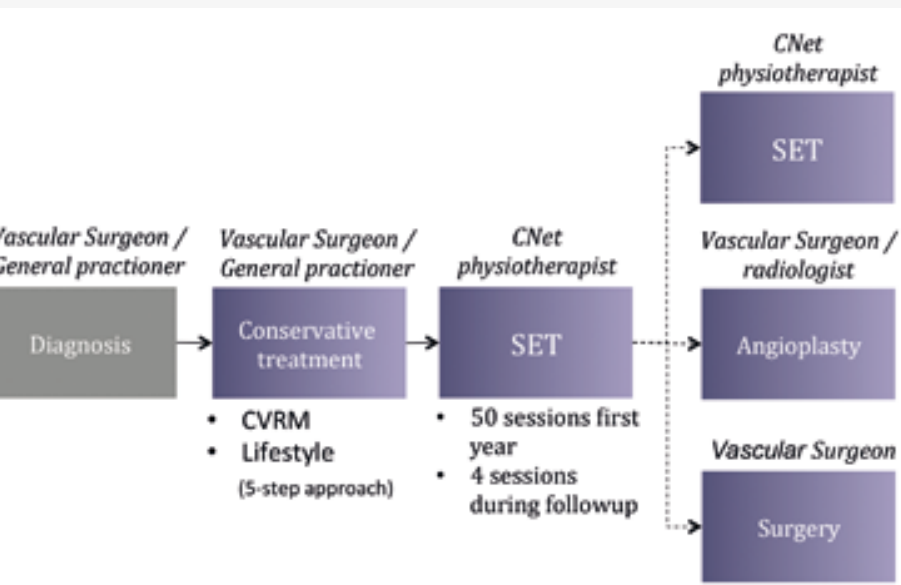

Notes: SET: Supervised exercise therapy

$$
\text { CVRM: Cardiovascular Risk Management }
$$$$
\text { CNet: ClaudicatioNet }
$$

In chapter 3 it is reported that in 2009 only $14 \%$ of the patients were treated with a SCM, while $28 \%$ of the patients primarily received a revascularization, of which $51 \%$ concerned aortoiliac lesions. More than half (58\%) were assumed to have received a proven inferior non-supervised walking advice (chapter 2). Ambiguities in the TASC II guideline may be responsible for a too liberal use of invasive procedures in patients with IC due to aortoiliac lesions. ${ }^{(3)}$ The role of invasive interventions as primary treatment for this type of lesion is unfortunately still subject of debate in current daily practice. The CLEVER trial demonstrated that SET resulted in a superior treadmill walking distance after 6 months compared to PTA with stent revascularization in aortoiliac disease, but a non-significant greater improvement of disease-specific quality of life in favor of PTA. ${ }^{(11)}$ The question that may be asked is: Why do most patients do not receive SET at all? Causes are multifactorial and depend on the physician who should prescribe SET as a first line treatment, on the patient who should be willing to comply with SET as a first line treatment, and on the health insurer who should reimburse SET.

\section{Reimbursement issues versus costs}

Unfortunately, there is no adequate reimbursement policy for IC worldwide. ${ }^{(12,13)}$ Nationwide implementation of SET programs was thought to require a substantial investment in most countries. ${ }^{(14)}$ Although several cost-effectiveness analyses were performed supporting a SET first treatment strategy ${ }^{(14-19)}$, no study investigated the overall economic consequences of a nationwide SCM implementation.

In chapter 3 a cost-analysis is performed 'as if a SCM (figure 1) was implemented' in the Dutch healthcare system. Costs of IC treatment were calculated and compared to estimated costs associated with a theoretical increase of nationwide SCM implementation Invoice data of all patients with IC in 2009 were obtained from a Dutch health insurance company (3.4 million members). Patients were divided into three groups based on initial treatment as followed after diagnosis $\left(\mathrm{t}_{0}\right)$. The (first) SET group received SET initiated at any time between 12 months before and up to 3 months after $t_{0}$, which was considered as Stepped Care. The (second) intervention group (INT) underwent endovascular or open revascularization between $t_{0}$ and $t_{+3 \text { months }}$. The third group (REST) received neither SET nor an intervention. All peripheral arterial disease related invoices were recorded during 2 years, and average costs per patient were calculated. Savings following use of a SCM were calculated for 3 scenarios. These scenarios were based on two critical success factor (the surgeons' compliance (willingness) to refer each IC patient to SET and the patient's motivation to participate in a SET program).

Despite the fact that, according to contemporary international guidelines, all patients with IC initially should be referred for SET ${ }^{(3-5)}$, this ratio was hypothetically set to $80 \%$ (best), 50\% (moderate) and 30\% (worst) based on reimbursement issues, appreciation of SET by vascular surgeons and preference (although evidence to do so is lacking) for a revascularization in certain cases. The patient's motivation to participate in a SET program, which largely depends on level of reimbursement as well as a thorough understanding of the benefits of a SET program in comparison to an invasive intervention, was set to $80 \%$ or $25 \%$. In total, three potential scenarios were considered: best (80\%-80\%), moderate (50\%-80\%) and worst case (30\%-25\%)

The percentage of patients who received a SCM in 2009 was $14.1 \%$, while $27.5 \%$ and $58.3 \%$ were treated with invasive revascularization, or neither of both, respectively. Within two years from $\mathrm{t}_{0}$, invasive revascularization in the SET group was performed in 45 patients (6.4\%). Additional interventions (primary at other location and/or re-interventions) were performed in 480 INT patients (35.2\%). Some 431 REST patients received additional SET $(n=299,10.3 \%)$ or an intervention $(n=132,4.5 \%)$. Mean total IC related 
costs per patient were $€ 2191, € 9851$ and $€ 824$ for SET, INT and REST, respectively. Based on a hypothetical worst, moderate, and best case scenario, some $3.8,20.6$ or 33.0 million euros would have been saved per year if SCM was implemented in the Dutch health care system.

A worldwide extrapolation: Savings up to 1 billion $€$ 's?

Despite limitations inherent to its retrospective character, this cost-analysis study added an important finding to the already existing body of solid evidence supporting SET as first line treatment for patients with IC. Extrapolation of these results (based on reported costs for SET and invasive interventions in the rest of Europe and the USA, having a low penetration of (community-based) supervised exercise programs and thus a low threshold for invasive vascular interventions) suggests that savings of around 1 billion euro's may be achieved.

Are costs really the problem?

Despite the finding that implementation of a SCM is beneficial concerning costs for healthcare insurers (a potential increase of quality of care at lower costs), it may seem that patients as well as their physicians are reluctant to embrace a SCM strategy. A significant number of claudicants is after a 'quick fix' of their problem. Therefore, they are not willing to adhere to a lengthy exercise program. They rather prefer a 'magic polypill' or a swift intervention. By doing so, the burden that is placed on their personal life is minimal. With a SCM, patients are obliged to make a concerted lifetime effort, to change their life-style and to increase their ambulatory activities. ${ }^{(20)}$ This is generally not what they expected when consulting their physician. Moreover, it's hard to comply with, as they were typically sedentary for much or all of their lives. ${ }^{(21)}$

Another possible explanation of the unpopularity of SET is put forward by the hypothesis that some physicians do not prefer SET. ${ }^{(22,23)}$ Vascular surgeons and interventional radiologists are remunerated for the execution of interventions. They opt for these invasive treatments because they are convinced that they optimally serve their patients, they like to perform these interventions whereas their skills have to be trained or improved. (22) The more complex and 'avant garde' an intervention is, the better the clinician's kudos within the hospital and at conferences. ${ }^{(22)}$ These sentiments are obviously augmented by the medical industry exerting aggressive promotion of new invasive techniques. In contrast, SET lacks promotion ${ }^{(16,22)}$.
Beneficial side effects of a mandatory three-month trial period of SET

Above-mentioned statements possibly contributed to our low 14\% SCM implementation ratio (chapter 3). However, apart from decreasing costs, the SET component of a SCM may reduce cardiovascular mortality and morbidity as collateral beneficial side effects. ${ }^{(24)}$ Moreover, starting with SET may provide awareness of important functional restrictions in daily life other than caused by IC (e.g. COPD, congestive heart failure, osteoarthritis, spinal stenosis, equilibrium disorders). As a benefit, SET as a systemic treatment modality treats both legs. So by following a SCM strategy, potentially futile vascular interventions in polymorbid patients who are limited by more than IC alone may be prevented. Implementing a SCM approach, more or less stimulating patients and physicians to try 'SET first', preserving 'invasive treatment next' for those not responding to SET, suits well in a world with rapidly rising health care system $\operatorname{costs}^{(25)}$.

\section{Is SET safe?}

A frequently used argument not to refer patients for SET is the matter of safety. ${ }^{(23)}$ Some fear the onset of cardiovascular events that may possibly occur during exercise in a population with known cerebral and coronary artery disease. ${ }^{(26,27)}$ In a nationwide survey among Dutch vascular surgeons, approximately $70 \%$ were convinced that coexisting cardiopulmonary comorbidity and/or aorta-iliac stenosis or occlusion were relative contraindications for SET participation. ${ }^{(23)}$ In chapter 4, SET related complications in patients with IC were systematically studied in a meta-analysis. A total of 74 articles representing 82,725 hours of training in 2,876 IC patients met inclusion criteria. Eight adverse events were reported, six of cardiac and two of non-cardiac origin, resulting in an all-cause complication rate of 1 per 10,340 patient-hours. It was concluded that SET could safely be prescribed to all patients with IC as an exceedingly low all-cause complication rate is found during SET. Furthermore, routine cardiac screening prior to commencing SET is not advised.

How to increase a Stepped Care approach nationwide?

It may seem that physicians, healthcare insurers as well as patients do not like SET ${ }^{(22)}$. As a consequence, SET is seriously underused as a therapeutic tool for IC in current clinical practice. ${ }^{(12,13)}$ Some also hypothesized a supposed shortage of supervised settings to which patients can be referred to, or the necessity for patients to travel to a SET facility as potential causes for this underutilization. ${ }^{(12,13)}$ To overcome these potential blockades, 
a community-based SET program was instigated ${ }^{(28)}$ that appeared effective after 3 and 6 months. ${ }^{(29)}$ Based on these results, a nationwide community based SET network was initiated providing a $100 \%$ SET availability in the Netherlands. ${ }^{(12,30)}$ In chapter 5 , this network, based on the World Health Organization chronic care framework, is presented in combination with the introduction of innovative technologies to simulate SCM implementation. This concept termed ClaudicatioNet was launched in 2011 in the Netherlands as a means to tackle some of earlier described shortcomings in IC treatment and to stimulate cohesion and collaboration between stakeholders. ${ }^{(30)}$ The overall goal of ClaudicatioNet is to stimulate quality and transparency of IC treatment by optimizing multidisciplinary healthcare chains on a national level. In this model, all patients suffering from IC are initially subjected to an extensive community-based SET program performed by a qualified and trained physiotherapist for at least 2-3 months before an invasive procedure is proposed $(\mathrm{SCM})^{(30)}$. SET is improved by stimulating both a theoretical and practical knowledge base. eHealth and mHealth technologies are used to create insights of provided care, to enhance quality control management, to facilitate patient empowerment and to stimulate life-style change. It is likely and subject of continuous research that the ClaudicatioNet concept will create a more efficient and cost effective management of IC.

\section{Conclusions}

The incidence of intermittent claudication (IC) is increasing worldwide whereas health care costs are progressively unaffordable (from 13\% of national income in 2012 to a calculated 31\% in 2040 in The Netherlands) ${ }^{(25)}$. Therefore, potential novel strategies for IC prevention and optimum treatment are required.

Current guidelines advocate the use of SET for $\mathrm{IC}^{(3-5)}$, as this tool is superior compared to a non-supervised exercise regimen (chapter 2). Moreover, SET is safe (chapter 4), possibly even more effective, durable and less harmful than a revascularization ${ }^{(11,17,31-38)}$, and certainly less expensive (chapter 3 ). At present, there is a nationwide availability in the Netherlands (chapter 5). However, a contradictory situation concerning the initial treatment of IC patients in the Netherlands is at hand. Despite the high availability of SET programs, a low referral rate of $14 \%$ was found (chapter 3 ). Although further research would be helpful (and is certainly required), the main blockage of adopting SET is apparently not a lack of evidence (other areas of vascular surgery practice have enthusiastically embraced other treatment modalities despite a much lower level of scientific justification). ${ }^{(22)}$ The patient's and doctor's unwillingness and misconceptions to partici- pate in combination with the anxiety among healthcare insurers all seem to contribute SET underutilization and unnecessary health expenditure. The introduction of a Stepped Care Model with a mandatory three-months trial period of SET according to the ClaudicatioNet quality standards might reduce this mismatch and could be beneficial for all stakeholders. It must be appreciated that politicians, health care insurers, physicians as well as patients should all head in the same direction in order to optimize the implementation of this approach. Quality of care is thus increased whereas financial profit is gained. The overall consequence of this approach on the Dutch as well as European and USA society should be subject of future research.

\section{PART II - Towards new outcome measures in intermittent claudication}

Diagnosing IC, are there any alternatives around?

Noninvasive diagnostic vascular examinations are often used as adjunctive tools to confirm the clinical diagnosis IC or to screen patients who have risk factors for PAD. Calculation of the ankle-brachial index (ABI) is a relatively simple and inexpensive method to confirm a suspicion of peripheral arterial disease. ${ }^{(26)} \mathrm{A}$ resting ABI measurement with additional exercise testing using a standard treadmill test is a simple, inexpensive and effective noninvasive diagnostic method for IC with a high sensitivity (79-95\%) and specificity (95-100\%). ${ }^{(39)} \mathrm{A}$ walking test may seem an obvious choice for eliciting symptoms of IC, because an IC patient typically presents with impaired walking rather than for example impaired cycling. However, some patients are not able to adequately perform treadmill testing, occasionally due to fear (of falling) or due to orthopedic or neurological causes precluding walking on a treadmill. Moreover, orthopedic/neurological diseases may mimic a clear IC diagnosis as a similar pattern of symptoms may present with these disorders during walking.

Cycling is a non-weight bearing form of exercise, relatively non-moving and possibly better tolerated and more discriminating in some of these IC patients. In chapter 6 , the correlation in $\mathrm{ABI}$ values obtained after treadmill testing and bicycle testing in IC patients was determined. In a validation study, newly diagnosed IC patients (Rutherford 1-3) un derwent a standard treadmill test and two bicycle protocols, one with a continuous re- 
sistance submaximal character and a second with an incremental ramp form, having a maximal character. ABI of both legs were obtained prior to and twice after each of these three different exercise tests.

It was concluded that bicycle exercise testing is a valid alternative tool in diagnosing patients with IC. Bicycle testing confers additional advantages. The tool is a non-weight bearing and non-moving exercise object whereas a cardiovascular screening program can also be incorporated. Patients suspected of IC who have contraindications for treadmill testing can be accurately diagnosed using a bicycle-test. Submaximal testing is preferred to maximal testing because of optimal sensitivity and specificity characteristics whereas the risk on (cardiovascular) complications is lowest.

\section{Contemporary determination of IC treatment effectiveness}

Current IC treatment strategies, described in international guidelines ${ }^{(3-5)}$, are mainly based on trials using the limitation in walking distance as primary outcome value. However, the value of various walking distance assessments is disputed. For instance, a patient's estimation of walking distance does not properly reflect objectively measured daily life walking distances. ${ }^{(40-43)} \mathrm{A}$ disease specific questionnaire such as the Walking Impairment Questionnaire (WIQ) may quantify walking impairments in IC patients better although correlations with walking distances appeared weak. ${ }^{(41)}$ Standardized treadmill tests are widely used as an objective assessment of walking distances. ${ }^{(3-5)}$ However, there is a substantial variability in treadmill protocols (chapter 2) whereas a relatively artificial measure of walking capacity is tested. ${ }^{(44)}$ In chapter 7 , results of walking distances in a group of IC patients using four different tools (a graded and a non-graded treadmill protocol, patient estimations and outside walking) that are frequently used by physical therapists in the assessment of IC severity are compared in a single model.

In chapter 7 it is illustrated that walking speed is of importance in the determination of walking capacity in an IC population. But above all an important piece of evidence is added to the discussion whether treadmill testing should be used as primary outcome measurement to determine treatment effects in future PAD trials. Researchers should realize that the frequently used MWD as primary outcome measurement demonstrates a substantial variability. A single MWD assessment may not be a proper reflection of walking impairment in IC patients and may certainly not correspond with (daily life) outside walking. Furthermore, self-reported walking capacity appeared a poor reflection of objectively measured MWD. ${ }^{(40-42,45)}$ Moreover, the value of both assessments is debatable as these parameters merely provide insight into walking capacity, a parameter that not necessarily corresponds with patient-perceived disability. ${ }^{(41,46)}$ Future research should therefore focus on patient-reported outcomes of perceived disability and burden of disease, as both can be of more importance than a determination of walking capacity. If walking (exercise) capacity is monitored, it should be measured over prolonged periods of time to provide a more reliable reflection of a patients' walking impairment. A 6-minute walking test, a shuttle walking-test or GPS-based accelerometers (physical activity monitors) may be better alternatives to treadmill testing.

\section{Physical activity as an alternative outcome measure in IC}

The fact that treadmill test results and ambulatory functions do show inconsistencies implies that an increased walking capacity does not automatically change a patients' exercise behaviour. ${ }^{(41,44)}$ Others have previously suggested that changes in treadmill test results do not properly reflect symptom relief after revascularization interventions for claudication. ${ }^{(47)} \mathrm{A}$ call was made for future studies to focus on quality of life parameters or other disease-specific functional outcomes to determine the effect of IC treatment modalities (chapter 2\&7). ${ }^{(20,43)}$ Moreover, in line with the upcoming interest in studying potential associations between daily physical activity (PA) and impact on cardiovascular risk reduction and mortality ${ }^{(48-54)}$, it may be more relevant to include PA as outcome measure in future IC research. IC is closely associated with cardiovascular and cerebrovascular disease, ${ }^{(3,55,56)}$ and improved levels of PA might result in cardiovascular event risk reduction on the long term. ${ }^{(57,58)}$

Nowadays, PA levels can be obtained with activity monitors. Tri-axial accelerometers measure accelerations in three dimensions that can be converted into intensities and metabolic equivalents (METs) enabling a quantification of overall PA. A MET is an estimate of oxygen consumption at rest. A three-MET activity would be an activity that utilizes roughly three times the amount of resting energy expenditure. When combining the recommendations on moderate- and vigorous-intensity physical activity, the daily minimum goal of PA should be in the range of 64-107 METs $\cdot \min .{ }^{(59)}$

The Dynaport MoveMonitor is an activity monitor that measures PA in METs, is easily applicable in a daily life setting and is optimized for clinical research assessments. The MoveMonitor was previously validated in an elderly population60 as well as for Par kinsons disease ${ }^{(61,62)}$ and $\mathrm{COPD}^{(63-65)}$. In chapter 8, the MoveMonitor is validated in an IC 
population in a near real-life setting. It was concluded that the MoveMonitor provides accurate information on a diverse set of postures, daily activities and number of steps in IC patients. This tool is useful to assess the role of physical activity as a novel clinically relevant outcome parameter in IC.

Physical activity levels of claudicants versus healthy individuals Compared to healthy adults, IC patients are burdened with a low health-related quality of life and functional impairment during daily activities. ${ }^{(66,67)}$ Individuals who are regularly physically active report better overall health, lower health care expenditures and fewer mobility limitations than their sedentary counterparts. ${ }^{(68,69)}$ The American Heart Association (AHA) and the American College of Sports Medicine (ACSM) provide specific recommendations of various types of activity to stimulate the elderly. Tailored recommendations are suggested that apply to adults with clinically-significant chronic conditions or functional limitations that affect mobility and activity. ${ }^{(59)}$ In chapter 9 , we quantified daily PA level and energy expenditure of newly diagnosed patients with IC and healthy controls. In conclusion, more than half of the patients with IC do not meet recommended standards of PA. Considering the serious health risks associated with low PA levels, these findings underscore the need for more awareness to improve physical exercise in patients with IC.

The impact of SET on physical activity level in IC patients. Since SET is the first choice option in the treatment of $\mathrm{IC}^{(3-5)}$ and as it is the cornerstone of a SCM, it may be relevant to study the potential beneficial effects of SET on PA level and exercise behaviour in IC patients. Moreover, SET offers patients at least 25 full hours of counseling with a specialized physiotherapist trained in motivation interviewing and life-style change. We do know that SET significantly improves the maximal and pain-free walking distance in IC (chapter 2), SET possibly leads to significant savings in our healthcare system (chapter 3 ) and that SET is proven to be cost-effective based on the change in walking distance. ${ }^{(14-19)}$ However, the question arises whether effectiveness of IC treatment modalities should be evaluated on the basis of changes in walking capacity only (chapter 2\&7\&8). In chapter 9 it was demonstrated that free-living daily PA levels in IC patients are lower compared to healthy controls. ${ }^{(70-73)}$ Despite these findings, PA is scantly used as an outcome parameter in trials concerning IC treatment, a fact that was previously reported by other researchers in this field. ${ }^{(9,72,74-77)}$ If PA levels improve following SET, cardiovascular risk reduction and improved Health related Quality of Life (HrQoL) may follow on the long term. ${ }^{(57,58)}$ Therefore, the effect of a SET program on PA, HrQoL and walking behavior in an IC population was assessed in chapter 10. We hypothesized that a SET induced increased walking distance would also improve PA levels in IC patients. A total of 41 newly diagnosed IC patients were requested to wear an activity monitor one week prior to and one week immediately following 3 months of SET.

A 3-month SET program was found to increase the number of patients achieving the ACSM/AHA public health minimum recommendations for physical activity (baseline: 43\%; 3 months: $63 \%, \mathrm{p}=.003$ ). However, firm conclusions could not be drawn, since some patients did show a decline in PA level or mean values for ambulatory activities after a period of SET. Probably large variations in activities per patient (duration as well as intensity) as well as between patients could have caused this contradiction. Moreover, a relatively small population was studied. Further research with larger populations is necessary to study PA levels in patients suffering from IC.

\section{Future perspectives}

It seems that solely focusing on exercise capacity such as maximal walking distance or time in the determination of effectiveness of IC treatment strategies seems insufficient. In chapter $8 \& 9$ it was demonstrated that PA is correctly measured with an activity monitor whereas IC patients show less activity levels as advised in the international guidelines compared to healthy adults. Increasing PA levels in an IC population may have beneficial effects. SET seems promising in achieving to do so (chapter 10). Surprisingly, no significant correlation between the change in PA levels and the increase in walking distance was found (chapter 10). Therefore one may argue that components of a SET program other than an increased walking capacity do influence daily PA. It appears that patients who are able to walk further (because of a decrease in IC symptoms), will not use this capacity to walk more often, longer or with probably more intensity in daily life. In ad dition, no significant correlation between the increase in walking capacity and the change of SF-36 values was found (chapter 10). This finding was recently confirmed by others. ${ }^{78}$ They reported that the improvement in self-efficacy, satisfaction with functioning, pain acceptance and social functioning after six months of home-based walking exercise compared to a non-exercising control group was independent of walking performance. In combination with our finding that walking capacity might be of diminished value, a shift in both SET treatment and primary research outcomes seems necessary. Nordanstig et al. 
were one of the first to use HrQoL as primary outcome in the recently published IRONIC (Invasive Revascularization or Not in IntermittentClaudication) trial. ${ }^{(79)}$ Apparently the call for and use of patient-centered outcomes is beginning to proliferate in medicine. ${ }^{\left({ }^{(0)}\right)} \mathrm{A}$ patient's assessment of how quality of life is affected by both the disease and its treatment is very important. Future research should therefore primarily focus on the change in $\mathrm{Hr}$ Qol and the reliable assessment of (disease-specific) HrQoL.

What other directions should future research take? SET programs require optimization. Factors such as intrinsic motivation, life-style change, patient satisfaction and expectations and social functioning should be subject of research other than the optimization of increasing walking capacity alone. We should concentrate on changing a patients' exercise behavior in daily life (life-style change) by tailoring SET to a patients needs (shared-decision making). Expectations of an IC patient should be leading in treatment. Moreover, a SET physiotherapist should address the change of a patients' walking pattern and combine different modes of exercise. ${ }^{(81)}$ One may also consider the effect of initiating exercise programs in a home-based environment, thereby diminishing the amount of labour-intensive supervision. ${ }^{(82,83)}$ Two recent published trials and a meta-analysis revealed promising results regarding the effect of such an approach. ${ }^{(75,77,78,84)}$ Future research should also be aimed at the optimal mixture of supervised and home-based programs in combination with evolving eHealth and mHealth technologies (activity monitors, smartphones, apps; chapter 5). This endeavor is likely to result in an optimal treatment strategy, both from a patient's perspective as well as from a cost-effectiveness perspective.

\section{References}

1. Fowkes FG, Rudan D, Rudan I, et al. Comparison of global estimates of prevalence and risk factors for peripheral artery disease in 2000 and 2010: a systematic review and analysis. Lancet 2013.

2. Meijer WT, Hoes AW, Rutgers D, Bots ML, Hofman A, Grobbee DE. Peripheral arterial disease in the elderly: The Rotterdam Study. Arterioscler Thromb Vasc Biol 1998;18:185-92.

3. Norgren L, Hiatt WR, Dormandy JA, Nehler MR, Harris KA, Fowkes FG. Inter-Society Consensus for the Management of Peripheral Arterial Disease (TASC II). J Vasc Surg 2007;45 Suppl S:S5-67.

4. Anderson JL, Halperin JL, Albert NM, et al. Management of patients with peripheral artery disease (compilation of 2005 and 2011 ACCF/AHA guideline recommendations): a report of the American College of Cardiology Foundation/American Heart Association Task Force on Practice Guidelines. Circulation 2013;127:1425-43.

5. Layden J, Michaels J, Bermingham S, Higgins B, Guideline Development G. Diagnosis and management of lower limb peripheral arterial disease: summary of NICE guidance. Bmj 2012;345:e4947.

6. Antithrombotic Trialists C. Collaborative meta-analysis of randomised trials of antiplatelet therapy for prevention of death, myocardial infarction, and stroke in high risk patients. Bmj 2002;324:71-86.

7. Bendermacher BL, Willigendael EM, Teijink JA, Prins MH. Supervised exercise therapy versus non-supervised exercise therapy for intermittent claudication. Cochrane Database Syst Rev 2006:CD005263.

8. Fakhry F, van de Luiitgaarden KM, Bax L, et al. Supervised walking therapy in patients with intermittent claudication. J Vasc Surg 2012;56:1132-42.

9. Nicolai SP, Teijink JA, Prins MH. Multicenter randomized clinical trial of supervised exercise therapy with or without feedback versus walking advice for intermittent claudication I Vasc Surg 2010;52:348-55.

10. Wind J, Koelemay MJ. Exercise therapy and the additional effect of supervision on exercise therapy in patients with intermittent claudication. Systematic review of randomised con trolled trials. Eur J Vasc Endovasc Surg 2007;34:1-9.

11. Murphy TP, Cutlip DE, Regensteiner JG, et al. Supervised exercise versus primary stenting for claudication resulting from aortoiliac peripheral artery disease: six-month outcomes from the claudication: exercise versus endoluminal revascularization (CLEVER) study. Circulation 2012;125:130-9. 
12. Makris GC, Lattimer CR, Lavida A, Geroulakos G. Availability of supervised exercise programs and the role of structured home-based exercise in peripheral arterial disease. Eur J Vasc Endovasc Surg 2012;44:569-75; discussion 76.

13. Shalhoub J, Hamish M, Davies AH. Supervised exercise for intermittent claudication - an under-utilised tool. Annals of the Royal College of Surgeons of England 2009;91:473-6.

14. Bermingham SL, Sparrow K, Mullis R, et al. The Cost-effectiveness of Supervised Exercise for the Treatment of Intermittent Claudication. Eur J Vasc Endovasc Surg 2013;46:707-14.

15. Mazari FA, Khan JA, Carradice D, et al. Economic analysis of a randomized trial of percutaneous angioplasty, supervised exercise or combined treatment for intermittent claudication due to femoropopliteal arterial disease. Br J Surg 2013;100:1172-9.

16. O’Brien-Irr MS, Harris LM, Dosluoglu HH, Dryjski ML. Endovascular intervention for treatment of claudication: is it cost-effective? Annals of vascular surgery 2010;24:833-40.

17. Spronk S, Bosch JL, den Hoed PT, Veen HF, Pattynama PM, Hunink MG. Cost-effectiveness of endovascular revascularization compared to supervised hospital-based exercise training in patients with intermittent claudication: a randomized controlled trial. J Vasc Surg 2008;48:1472-80.

18. Treesak C, Kasemsup V, Treat-Jacobson D, Nyman JA, Hirsch AT. Cost-effectiveness of exercise training to improve claudication symptoms in patients with peripheral arterial disease. Vasc Med 2004;9:279-85.

19. van Asselt AD, Nicolai SP, Joore MA, Prins MH, Teijink JA. Cost-effectiveness of exercise therapy in patients with intermittent claudication: supervised exercise therapy versus a 'go home and walk' advice. Eur J Vasc Endovasc Surg 2011;41:97-103.

20. Mays RJ, Regensteiner JG. Therapy for peripheral artery disease: gaps in treating patients with claudication. Circulation 2014;130:929-31

21. Galea MN, Weinman JA, White C, Bearne LM. Do behaviour-change techniques contribute to the effectiveness of exercise therapy in patients with intermittent claudication? A systematic review. Eur J Vasc Endovasc Surg 2013;46:132-41.

22. Popplewell MA, Bradbury AW. Why Do Health Systems Not Fund Supervised Exercise Programmes for Intermittent Claudication? Eur J Vasc Endovasc Surg 2014.

23. Lauret GJ, van Dalen HC, Hendriks HJ, et al. When is supervised exercise therapy considered useful in peripheral arterial occlusive disease? A nationwide survey among vascular surgeons. Eur J Vasc Endovasc Surg 2012;43:308-12.

24. Heran BS, Chen JM, Ebrahim S, et al. Exercise-based cardiac rehabilitation for coronary heart disease. Cochrane Database Syst Rev 2011:CD001800.
25. Rapport "De zorg: hoeveel extra is het ons waard? Dutch Ministry of Health Welfare and Sports.

26. Hirsch AT, Haskal ZJ, Hertzer NR, et al. ACC/AHA 2005 Practice Guidelines for the management of patients with peripheral arterial disease (lower extremity, renal, mesenteric, and abdominal aortic): a collaborative report from the American Association for Vascular Surgery/Society for Vascular Surgery, Society for Cardiovascular Angiography and Interventions, Society for Vascular Medicine and Biology, Society of Interventional Radiology, and the ACC/AHA Task Force on Practice Guidelines (Writing Committee to Develop Guidelines for the Management of Patients With Peripheral Arterial Disease): endorsed by the American Association of Cardiovascular and Pulmonary Rehabilitation; National Heart, Lung, and Blood Institute; Society for Vascular Nursing; TransAtlantic Inter-Society Consensus; and Vascular Disease Foundation. Circulation 2006;113:e463-654.

27. Tilloy E, Montaye M, Kee F, et al. Contribution of cardiovascular risk factors to coronary risk in patients with intermittent claudication in the PRIME Cohort Study of European men. Atherosclerosis 2009;206:563-8.

28. Willigendael EM, Bendermacher BL, van der Berg C, et al. The development and implementation of a regional network of physiotherapists for exercise therapy in patients with peripheral arterial disease, a preliminary report. BMC Health Serv Res 2005;5:49.

29. Bendermacher BL, Willigendael EM, Nicolai SP, et al. Supervised exercise therapy for intermittent claudication in a community-based setting is as effective as clinic-based. J Vasc Surg 2007;45:1192-6.

30. Lauret GJ, Gijsbers HJ, Hendriks EJ, Bartelink ML, de Bie RA, Teijink JA. The ClaudicatioNet concept: design of a national integrated care network providing active and healthy aging for patients with intermittent claudication. Vasc Health Risk Manag 2012;8:495-503,

31. Creasy TS, McMillan PJ, Fletcher EW, Collin J, Morris PJ. Is percutaneous transluminal angioplasty better than exercise for claudication? Preliminary results from a prospective randomised trial. European journal of vascular surgery 1990;4:135-40.

32. Spronk S, Bosch JL, den Hoed PT, Veen HF, Pattynama PM, Hunink MG. Intermittent claudication: clinical effectiveness of endovascular revascularization versus supervised hospital-based exercise training--randomized controlled trial. Radiology 2009;250:586-95.

33. Ahimastos AA, Pappas EP, Buttner PG, Walker PJ, Kingwell BA, Golledge J. A meta-analy sis of the outcome of endovascular and noninvasive therapies in the treatment of intermittent claudication. J Vasc Surg 2011;54:1511-21. 
34. Fakhry F, Rouwet EV, den Hoed PT, Hunink MG, Spronk S. Long-term clinical effectiveness of supervised exercise therapy versus endovascular revascularization for intermittent claudication from a randomized clinical trial. Br J Surg 2013;100:1164-71

35. Geraghty PJ, Mewissen MW, Jaff MR, Ansel GM, Investigators V. Three-year results of the VIBRANT trial of VIABAHN endoprosthesis vs bare nitinol stent implantation for complex superficial femoral artery occlusive disease. J Vasc Surg 2013.

36. Jongkind V, Akkersdijk GJ, Yeung KK, Wisselink W. A systematic review of endovascular treatment of extensive aortoiliac occlusive disease. J Vasc Surg 2010;52:1376-83.

37. Lensvelt MM, Reijnen MM, Wallis De Vries BM, Zeebregts CJ. Treatment strategies for extensive chronic SFA occlusions: indications and results. The Journal of cardiovascular surgery 2012;53:161-70.

38. Stewart KJ, Hiatt WR, Regensteiner JG, Hirsch AT. Exercise training for claudication. N Engl J Med 2002;347:1941-51.

39. Kruidenier LM, Nicolai SP, Hendriks EJ, Bollen EC, Prins MH, Teijink JA. Supervised exercise therapy for intermittent claudication in daily practice. J Vasc Surg 2009;49:363-70.

40. Watson CJ, Phillips D, Hands L, Collin J. Claudication distance is poorly estimated and inappropriately measured. Br J Surg 1997;84:1107-9.

41. Frans FA, Zagers MB, Jens S, Bipat S, Reekers JA, Koelemay MJ. The relationship of walking distances estimated by the patient, on the corridor and on a treadmill, and the Walking Impairment Questionnaire in intermittent claudication. J Vasc Surg 2013;57:720-7 e1.

42. Tew G, Copeland R, Le Faucheur A, Gernigon M, Nawaz S, Abraham P. Feasibility and validity of self-reported walking capacity in patients with intermittent claudication. Journal of vascular surgery 2013;57:1227-34.

43. Nordanstig J, Broeren M, Hensater M, Perlander A, Osterberg K, Jivegard L. Six-minute walk test closely correlates to "real-life" outdoor walking capacity and quality of life in patients with intermittent claudication. J Vasc Surg 2014;60:404-9.

44. McDermott MM, Ades PA, Dyer A, Guralnik JM, Kibbe M, Criqui MH. Corridor-based functional performance measures correlate better with physical activity during daily life than treadmill measures in persons with peripheral arterial disease. J Vasc Surg 2008;48:1231-7, 7 e1.

45. Le Faucheur A, Abraham P, Jaquinandi V, Bouye P, Saumet JL, Noury-Desvaux B. Measurement of walking distance and speed in patients with peripheral arterial disease: a novel method using a global positioning system. Circulation 2008;117:897-904.
46. Nicolai SP, Viechtbauer W, Kruidenier LM, Candel MJ, Prins MH, Teijink JA. Reliability of treadmill testing in peripheral arterial disease: a meta-regression analysis. J Vasc Surg 2009;50:322-9.

47. Murphy TP, Reynolds MR, Cohen DJ, et al. Correlation of patient-reported symptom outcomes and treadmill test outcomes after treatment for aortoiliac claudication. $J$ Vasc Interv Radiol 2013;24:1427-35; quiz 36.

48. Grontved A, Hu FB. Television viewing and risk of type 2 diabetes, cardiovascular disease, and all-cause mortality: a meta-analysis. Jama 2011;305:2448-55

49. Katzmarzyk PT. Physical activity, sedentary behavior, and health: paradigm paralysis or paradigm shift? Diabetes 2010;59:2717-25

50. Katzmarzyk PT. Standing and Mortality in a Prospective Cohort of Canadian Adults. Med Sci Sports Exerc 2013.

51. Maher C, Olds T, Mire E, Katzmarzyk PT. Reconsidering the sedentary behaviour paradigm. PloS one 2014;9:e86403.

52. Thorp AA, Owen N, Neuhaus M, Dunstan DW. Sedentary behaviors and subsequent health outcomes in adults a systematic review of longitudinal studies, 1996-2011. American journal of preventive medicine 2011;41:207-15.

53. van der Ploeg HP, Chey T, Korda RJ, Banks E, Bauman A. Sitting time and all-cause mortality risk in 222497 Australian adults. Arch Intern Med 2012;172:494-500.

54. Wilmot EG, Edwardson CL, Achana FA, et al. Sedentary time in adults and the association with diabetes, cardiovascular disease and death: systematic review and meta-analysis. Diabetologia 2012;55:2895-905.

55. Criqui MH. Systemic atherosclerosis risk and the mandate for intervention in atherosclerotic peripheral arterial disease. The American journal of cardiology 2001;88:43J-7J.

56. Criqui MHL, R. D.; Fronek, A. Mortality over a period of 10 years in patients with peripheral arterial disease. N Engl J Med 1992;326:7.

57. Kodama S, Saito K, Tanaka S, et al. Cardiorespiratory fitness as a quantitative predictor of all-cause mortality and cardiovascular events in healthy men and women: a meta-analysis. Jama 2009;301:2024-35.

58. Yusuf S, Hawken S, Ounpuu S, et al. Effect of potentially modifiable risk factors associated with myocardial infarction in 52 countries (the INTERHEART study): case-control study. Lancet 2004;364:937-52.

59. Nelson ME, Rejeski WJ, Blair SN, et al. Physical activity and public health in older adults: recommendation from the American College of Sports Medicine and the American Heart Association. Circulation 2007;116:1094-105. 
60. Dijkstra B, Kamsma Y, Zijlstra W. Detection of gait and postures using a miniaturised triaxial accelerometer-based system: accuracy in community-dwelling older adults. Age and ageing 2010;39:259-62.

61. Dijkstra B, Kamsma YP, Zijlstra W. Detection of gait and postures using a miniaturized triaxial accelerometer-based system: accuracy in patients with mild to moderate Parkinson's disease. Archives of physical medicine and rehabilitation 2010;91:1272-7.

62. Dijkstra B, Zijlstra W, Scherder E, Kamsma Y. Detection of walking periods and number of steps in older adults and patients with Parkinson's disease: accuracy of a pedometer and an accelerometry-based method. Age and ageing 2008;37:436-41.

63. Langer D, Gosselink R, Sena R, Burtin C, Decramer M, Troosters T. Validation of two activity monitors in patients with COPD. Thorax 2009;64:641-2.

64. Kanda M, Minakata Y, Matsunaga K, et al. Validation of the triaxial accelerometer for the evaluation of physical activity in Japanese patients with COPD. Intern Med 2012;51:36975.

65. Pitta F, Troosters T, Spruit MA, Decramer M, Gosselink R. Activity monitoring for assessment of physical activities in daily life in patients with chronic obstructive pulmonary disease. Archives of physical medicine and rehabilitation 2005;86:1979-85.

66. Regensteiner JG, Hiatt WR, Coll JR, et al. The impact of peripheral arterial disease on health-related quality of life in the Peripheral Arterial Disease Awareness, Risk, and Treatment: New Resources for Survival (PARTNERS) Program. Vasc Med 2008;13:15-24.

67. Dumville JC, Lee AJ, Smith FB, Fowkes FG. The health-related quality of life of people with peripheral arterial disease in the community: the Edinburgh Artery Study. The British journal of general practice : the journal of the Royal College of General Practitioners 2004;54:826-31.

68. Brach JS, FitzGerald S, Newman AB, et al. Physical activity and functional status in community-dwelling older women: a 14-year prospective study. Arch Intern Med 2003;163:2565-71.

69. Nguyen HQ, Ackermann RT, Maciejewski M, et al. Managed-Medicare health club benefit and reduced health care costs among older adults. Preventing chronic disease 2008;5:A14

70. Gardner AW, Womack CJ, Sieminski DJ, Montgomery PS, Killewich LA, Fonong T. Relationship between free-living daily physical activity and ambulatory measures in older claudicants. Angiology 1998;49:327-37.

71. Sieminski DJ, Gardner AW. The relationship between free-living daily physical activity and the severity of peripheral arterial occlusive disease. Vasc Med 1997;2:286-91.
72. Crowther RG, Spinks WL, Leicht AS, Sangla K, Quigley F, Golledge J. Effects of a longterm exercise program on lower limb mobility, physiological responses, walking performance, and physical activity levels in patients with peripheral arterial disease. J Vasc Surg 2008;47:303-9.

73. Lauret GJ, Fokkenrood HJ, Bendermacher BL, Scheltinga MR, Teijink JA. Physical activity monitoring in patients with intermittent claudication. Eur J Vasc Endovasc Surg 2014;47:656-63.

74. Gardner AW, Montgomery PS, Parker DE. Optimal exercise program length for patients with claudication. J Vasc Surg 2012;55:1346-54.

75. Gardner AW, Parker DE, Montgomery PS, Scott KJ, Blevins SM. Efficacy of quantified home-based exercise and supervised exercise in patients with intermittent claudication: a randomized controlled trial. Circulation 2011;123:491-8.

76. Hiatt WR, Creager MA, Amato A, Brass EP. Effect of propionyl-L-carnitine on a background of monitored exercise in patients with claudication secondary to peripheral artery disease. Journal of cardiopulmonary rehabilitation and prevention 2011;31:125-32.

77. McDermott MM, Liu K, Guralnik JM, et al. Home-based walking exercise intervention in peripheral artery disease: a randomized clinical trial. Jama 2013;310:57-65.

78. Rejeski WJ, Spring B, Domanchuk K, et al. A group-mediated, home-based physical activity intervention for patients with peripheral artery disease: effects on social and psychological function. Journal of translational medicine 2014;12:29.

79. Nordanstig J, Taft C, Hensater M, Perlander A, Osterberg K, Jivegard L. Improved quality of life after 1 year with an invasive versus a noninvasive treatment strategy in claudicants: one-year results of the Invasive Revascularization or Not in Intermittent Claudication (IRONIC) Trial. Circulation 2014;130:939-47.

80. Kinlay S. Outcomes for clinical studies assessing drug and revascularization therapies for claudication and critical limb ischemia in peripheral artery disease. Circulation 2013;127:1241-50.

81. Lauret GJ, Fakhry F, Fokkenrood HJ, Hunink MG, Teijink JA, Spronk S. Modes of exercise training for intermittent claudication. Cochrane Database Syst Rev 2014;7:CD009638.

82. Collins TC, Lunos S, Carlson T, et al. Effects of a home-based walking intervention on mobility and quality of life in people with diabetes and peripheral arterial disease: a randomized controlled trial. Diabetes care 2011;34:2174-9.

83. Regensteiner JG, Meyer TJ, Krupski WC, Cranford LS, Hiatt WR. Hospital vs home-based exercise rehabilitation for patients with peripheral arterial occlusive disease. Angiology 1997;48:291-300 
84. Gommans LN, Saarloos R, Scheltinga MR, et al. Editor's Choice - The Effect of Supervision on Walking Distance in Patients with Intermittent Claudication: A Meta-analysis. Eur J Vasc Endovasc Surg 2014;48:169-84. 


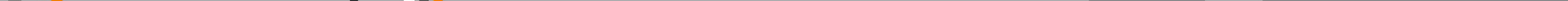




\section{Introductie}

Perifeer arterieel vaatlijden (PAV) wordt veroorzaakt door atherosclerose (slagaderverkalking). Het symptomenspectrum van PAV is sterk heterogeen en varieert van ziekte zonder klachten tot weefselversterf (gangreen). Claudicatio intermittens is een veel voorkomend symptoom van PAV en betekent letterlijk 'intermitterend hinken'. Claudicatio treedt op bij het stadium van PAV waarin patiënten pijn hebben bij het lopen die noodzaakt tot stoppen. Waar in rust de zuurstofvoorziening van de beenspieren nog volstaat, kan bij lopen aan de toegenomen zuurstofbehoefte onvoldoende worden voldaan. $\mathrm{Na}$ een stuk lopen moeten 'claudicanten' stoppen omdat zij pijn ervaren. Omdat claudicatio niet alleen de actieradius beperkt, maar ook de mens in zijn totale functioneren belemmert, gaan patiënten deze klachten maskeren, bijvoorbeeld door tijdens het gedwongen stilstaan net te doen of een etalage wordt bekeken. In de volksmond wordt bij claudicatio intermittens gesproken van 'etalagebenen'. De veroorzakende atherosclerose komt uiteindelijk bij alle mensen voor maar meer naarmate men ouder wordt. Een aantal factoren versnelt dit proces; roken en een ongezonde leefstijl zijn de grootste boosdoeners.

In Nederlands populatieonderzoek onder 55-plussers, werd de prevalentie van PAV geschat op 19,1\%.(1) Voor de Nederlandse situatie wordt uitgegaan van 800.000 tot een miljoen mensen met PAV. Per jaar komen er 25.000 nieuwe CI patiënten bij. ${ }^{(2)} \mathrm{Bij}$ patiënten met PAV is de levensverwachting ongeveer tien jaar verkort. Dit wordt met name veroorzaakt door sterfte aan andere hart- en vaatziekten dan perifeer arterieel vaatlijden, allen veroorzaakt door atherosclerose. ${ }^{(3-5)}$

De behandeling van CI rust op twee pijlers. De eerste pijler is cardiovasculair risicomanagement, waarmee alle acties worden bedoeld die het genoemde verhoogde risico op vroegtijdig overlijden of ernstige invaliditeit verkleinen. Dat wil zeggen, leefstijl aanpassingen als stoppen met roken, gezonde(re) voeding, meer bewegen. Maar ook medicamenteuze behandeling zoals met een plaatjesremmer, een cholesterolverlager, bloeddrukverlager(s) en adequate regulatie van eventueel aanwezige diabetes mellitus.

De tweede pijler is een symptomatische behandeling gericht op vermindering van de voornaamste klacht, het slechte lopen. Hierbij kan gekozen worden voor een conservatieve of een invasieve behandeling, of voor een combinatie van beiden. Onder conservatieve behandeling (looptherapie) verstaan we alle acties gericht op het toe laten nemen van de loopafstand, de ervaren mobiliteit, de mate van onafhankelijkheid en de aanwezige beinvloedbare slechte leefstijlfactoren. Onder looptherapie worden verschillende vormen verstaan. ${ }^{(6)}$ Bij 'niet-gesuperviseerde' looptherapie wordt de patiënt (passief) gewezen op het feit dat hij meer moet bewegen, soms wordt een folder meegeven. Bij 'gesuperviseerde' looptherapie (GLT) wordt de patiënt meerdere malen per week (actief) begeleid door een getrainde vaatverpleegkundige of fysiotherapeut. Daarnaast bestaat een zo genoemde 'home-based'-variant, waarbij de patiënt zonder direct contact wordt begeleid. Te denken valt dan aan logboeken, telefonisch contact of het gebruik van web-based applicaties (apps of (video)-chats). Invasieve behandelingen zijn onder te verdelen in minimaal invasieve, ook wel endovasculaire procedures (PTA, percutane transluminale angioplasty, 'dotteren' in de volksmond) en conventionele 'open' vaatchirurgische ingrepen.

\section{PART I - Op weg naar stepped care in de behandeling van claudicatio intermittens}

Wat is nu de optimale behandelingsstrategie voor een patiënt met $\mathrm{Cl}$ ?

In hoofdstuk 2 wordt in een update van een Cochrane meta-analyse uit 2006 de effecten van gesuperviseerde versus niet-gesuperviseerde looptherapie op de loopafstand en kwaliteit van leven geëvalueerd bij patiënten met PAV. In de meta-analyse werden 14 studies geïncludeerd met in totaal ruim 1000 patiënten. De follow-up van de studies varieerde van 6 weken tot 12 maanden. GLT toonde significante en klinische relevante verschillen tot 180 meter in verbetering van de maximale loopafstand vergeleken met niet-gesuperviseerde looptherapie. Verschillen in kwaliteit van leven konden niet worden aangetoond tussen beide therapieën, wellicht omdat een beperkt aantal studies (50\%) kwaliteit van leven hadden geregistreerd. Onze analyse laat zien dat het effect van GLT groter is dan werd aangenomen in de review uit 2006. Bovendien kan geconcludeerd worden dat meer onderzoek nodig is om de effecten van een toegenomen loopafstand op de kwaliteit van leven aan te tonen. Hierbij valt ook te denken aan de introductie van nieuwe, meer ziektegespecifieerde uitkomstmaten. 


\section{Een "stepped care" behandeling}

In hoofdstuk 3 wordt een innovatieve landelijke strategie geïntroduceerd om de behandeling van claudicatio intermittens te optimaliseren. ${ }^{(2,8)}$ In dit zogenoemde "stepped care" of wel "getrapte behandeling"- model ontvangen patiënten een behandeling, die niet zwaarder (risicodragend) is dan noodzakelijk. Het model is gebaseerd op vigerende richtlijnen ${ }^{(9-11)}$, de meest recente literatuur en het eeuwenoude adagium 'primum non nocere' ('first do no harm'). Samenvattend houdt het een 'verplichte' start in met tenminste 3 maanden GLT (figuur 1, hoofdstuk 11). Tijdens dit traject wordt veel aandacht besteed aan het beïnvloeden van aanwezige risicofactoren voor hart- en vaatziekten. Pas bij falen van dit traject, in de zin van een discrepantie tussen gewenste en bereikte loopafstand, wordt nadere diagnostiek gedaan en gekeken of een endovasculaire behandeling kan worden aangeboden.

Uit declaratiedata uit het jaar 2009 van een grote Nederlands zorgverzekeraar bleek dat slechts $14 \%$ van de PAV patiënten in Nederland werd behandeld volgens het stepped care model (hoofdstuk 3 ). De overige $28 \%$ werd direct een interventie aangeboden en $58 \%$ kreeg een niet nader gespecificeerd loopadvies (hoofdstuk 2). In de internationale literatuur wordt het niet beschikbaar zijn van GLT programma's vaak als argument gebruikt om patiënten dan maar te behandelen met een PTA dan wel een loopadvies. Ondanks dat in Nederland een landelijk dekkend netwerk voor GLT beschikbaar is, werd in 2009 ook in Nederland niet volgens deze internationale richtlijnen gewerkt. ${ }^{(9-1)}$ De oorzaak hiervan is multifactorieel; sommige vaatchirurgen behandelen (al dan niet specifieke categorieën patiënten) primair met een PTA. ${ }^{(12)}$ Daarnaast blijkt GLT vaak niet (volledig) vergoed te worden. Dit in tegenstelling tot een invasieve behandeling, die wel tot de basiszorg wordt gerekend. Onder druk van steeds nieuwe en dokters- aansprekende invasieve behandelmogelijkheden en de ongefundeerde aanname van patiënten en soms zelfs behandelaars dat CI eenvoudig en doeltreffend primair invasief behandeld kan worden, wordt de drempel tot primaire invasieve behandeling van CI verlaagd.

\section{Vergoeding versus kosten}

In de budget-impact-analyse van hoofdstuk 3 wordt het "stepped care model" toegepast. Drie hypothetische scenario's werden doorlopen. Deze 30-50-80 procent scenario's werden gebaseerd op verwijsgedrag en vergoeding (compliance). Het best-case scenario bestond zo uit de situatie waarin $80 \%$ van de patiënten met CI werd verwezen, gevolgd door $80 \%$ compliance (vergoeding en continuering van een traject GLT). Patiënten werden op basis van hun initiële behandeling (2009) na tijdstip van diagnose $\left(\mathrm{t}_{0}\right)$ ingedeeld in drie groepen. De GLT groep kreeg gesuperviseerde looptraining in de 12 maanden voor $t_{0}$ of 3 maanden na $t_{0}$. De interventie groep (INT) kreeg een endovasculaire of open revascularisatie tussen $t_{0}$ en $t_{3 m n d}$. De derde groep (REST) kreeg noch GLT noch een interventie in de eerste drie maanden. Alle PAV gerelateerde facturen werden geanalyseerd gedurende 2 jaar na $t_{0}$. Daaruit werden de gemiddelde kosten per patiënt per groep berekend. Implementatie van het stepped care model werd berekend voor drie scenario's (worst-, moderate, best-case).

Er werden 4954 patiënten geïncludeerd. Initiële behandeling was GLT ( $\mathrm{n}=701,14.1 \%)$, INT ( $n=1363,27.5 \%)$ of REST ( $n=2890,58.3 \%)$. Een invasieve behandeling werd bij 45 patiënten ( $n=6.4 \%)$ in de GLT groep in tweede instantie alsnog aangeboden en bij 480 patiënten in de INT groep (35.1\%). Van de REST groep kregen 431 patiënten alsnog een aanvullende behandeling (GLT: $n=299,10.3 \%)$ en/of een revascularisatie ( $n=132,4.5 \%)$. De gemiddelde kosten voor de groepen waren €2191, €9851 en €824 voor respectievelijk de GLT, INT en REST groep. Afhankelijk van het gekozen scenario (worst-moderatebest) werd bij implementatie van een stepped care model in de Nederlandse situatie een jaarlijks besparing potentieel van 3.8, 20.6, of 33.0 miljoen euro berekend.

De resultaten van deze studie bevestigen eerder gepubliceerde directe kosteneffectiviteit vergelijkingen tussen GLT en invasieve interventies. ${ }^{(13-16)}$ Implementatie van een stepped care model bij de behandeling van patiënten met claudicatio intermittens leidt tot significante kostenbesparingen. Een reductie van interventie geassocieerde mortaliteit en morbiditeit in deze patiëntenpopulatie is te verwachten. Het aantal interventies en het aantal daarmee geassocieerde complicaties kent immers een lineair verband. Alhoewel dit laatste niet onderzocht is in dit proefschrift, tonen anderen deze effecten wel aan. ${ }^{(17)}$

Ongekende voordelen van een stepped care aanpak

Naast een verschil in kosten, brengt een stepped care aanpak ten opzichte van een direct invasief alternatief meer voordelen met zich mee. Zo wordt bij stepped care niet alleen het aangedane been getraind, maar ook het op dat moment (mogelijk) geen klachten gevende, andere been. Dat geldt ook voor het tegelijk (mee) trainen van hart en longen (de cardiopulmonale conditie), hetgeen weer een positief effect heeft op de overleving 
en het verlagen van het risico op cardiovasculaire events. ${ }^{(17)}$ Effecten die weliswaar niet werden aangetoond in dit proefschrift, maar kunnen worden afgeleid uit onderzoek naar interventies gedaan door anderen. ${ }^{(18-20)}$

Een tot op heden nauwelijks onderkend en daardoor onbenut voordeel is dat een gesuperviseerd traject met ongeveer 20-25 'contacturen' gepaard gaat. In deze tijd kan een daartoe speciaal opgeleide en getrainde claudicatio-therapeut patiënten begeleiden bij leefstijlaanpassingen als stoppen met roken, het belang van medicatie compliance, een gezond dieet en meer bewegen naast de looptraining. ${ }^{(19)}$ Samen trainen en lotgenotencontact kunnen ook worden gestimuleerd door deze getrainde behandelaar. Supervisie wordt daarmee supervisie 'plus', of ook wel een "ClaudicatioNet traject" genoemd (hoofdstuk 5). Daar waar bij een 'PTA-eerst' behandeling weliswaar een sneller effect kan worden bereikt betreffende de loopcapaciteit, wordt een patiënt de kans ontnomen om deze minstens zo belangrijke voordelen te benutten.

GLT kent nog een voordeel. Wanneer wordt overgegaan tot een primair invasieve behandeling is dit gebaseerd op de klacht van de patiënt (de anamnese), het verrichte lichamelijk onderzoek en aanvullende, beeldvormende diagnostiek. De klachten van de patiënt worden in dit diagnostisch proces gerelateerd aan de bevindingen bij beeldvormende diagnostiek. In een dergelijk, decennia bestaand deductief proces was tot recent geen ruimte voor het proefondervindelijk signaleren van limiterende klachten die niet veroorzaakt worden door PAV. De zo bij een PAV patiënt eveneens aanwezige en misschien wel oorzakelijk limiterende klachten, bijvoorbeeld van het bewegingsapparaat, van cardiopulmonale of van neurogene oorzaak, blijven zo onontdekt. Dit is belangrijke informatie die idealiter moet worden onderzocht voordat de optie van een invasieve behandeling wordt overwogen. Een fysiotherapeut komt hier in de eerste GLT behandelingen proefondervindelijk achter, om zo zijn therapie aan te passen.

\section{Is GLT veilig?}

In hoofdstuk 4 van dit proefschrift concluderen wij dat GLT veilig is en kan worden voorgeschreven aan alle patiënten met CI. In een systematische review van 74 artikelen worden op een totaal van 82.725 trainingsuren van 2.876 patiënten, 8 adverse events gerapporteerd. Hiervan bleken 6 cardiovasculair gerelateerd.. Uiteindelijk wordt zo een complicatie-ratio van 1 op de 10.340 GLT trainingsuren gevonden. Dit lage getal moet worden afgezet tegen het risico op een myocardinfarct of een significante beroerte na een endovasculaire (infra-inguinale) behandeling (respectievelijk een totaal van $0.7 \%) .^{(21,22)}$ Ondanks dat dit relatief lage complicatie percentages zijn, moeten deze wel gerelateerd worden in het licht van de grote hoeveelheden interventies wereldwijd. Zo laten wij in hoofdstuk 3 zien dat er ongeveer 25.000 nieuwe claudicanten per jaar bij komen.

De landelijke implementatie van het stepped care model De vraag voor de komende jaren luidt dan ook; 'hoe krijgen wij alle neuzen dezelfde kant op?'. Hoe kunnen wij de behandeling van patiënten met claudicatio intermittens via het stepped care model verhogen? Een belangrijke aanzet daartoe werd gedaan in 2011 met de oprichting van ClaudicatioNet. ${ }^{(23)}$ De stichting ClaudicatioNet beoogd het creeren van een zorgmodel waarin evidence-based zorg geleverd wordt aan een geïnformeerde en actief participerende centraal staande PAV patiënt. ClaudicatioNet faciliteer daarmee in feite een geïntegreerd zorgnetwerk dat patiënten en behandelaars (bijv. vaatchirurgen, huisartsen, fysiotherapeuten) met elkaar in contact brengt. De stepped care aanpak wordt hiermee geïmplementeerd in het Nederlandse zorgsysteem. Transparante, kwalitatief hoogwaardige, wetenschappelijk bewezen en doelmatige zorg voor alle patiënten met PAV creëren, is het doel. De stichting beschikt over een landelijk dekkend netwerk van geschoolde fysio- en oefentherapeuten die een driejarig specialisatietraject doorlopen. ${ }^{(23)}$ Met eHealth- (en in de nabije toekomst ook mHealth) wordt inzicht verkregen in de kwaliteit van geleverde zorg. Niet alleen de patiënt krijgt op deze wijze feedback over zijn of haar vorderingen, maar ook de therapeut en verwijzer kunnen worden 'gebenchmarkt' met hun 'peers'. In hoofdstuk 5 worden enkele van deze processen en diensten beschreven

\section{Conclusie}

De incidentie van het aantal patiënten met PAV zal de komende jaren stijgen. ${ }^{(24)}$ De combinatie van frequenter voorkomen, een hoge kans op een fatale of invaliderende vasculaire gebeurtenis (hart- en/of herseninfarct), en een steeds duurder wordende behandeling, maakt dat PAV ondertussen een belangrijk gezondheidszorg probleem is geworden Zeker in het licht van de verwachting dat de nationale zorgkosten exponentieel zullen stijgen (13\% van 2012 bruto nationaal product naar 30\% in 2040). ${ }^{(25)}$ Huidige richtlijnen adviseren GLT boven niet-GLT of een interventie als primaire behandeling voor claudicatio (hoofdstuk 2). ${ }^{(9-11)}$ Bovendien is GLT veilig (hoofdstuk 4) duurzamer, goedkoper, gaat het gepaard met minder complicaties en is zeer waarschijnlijk effectiever vergeleken 
met een invasieve ingreep (hoofdstuk 3). ${ }^{(15,26-34)}$ Alhoewel meer onderzoek naar de effectiviteit van gesuperviseerde looptraining binnen het stepped care model noodzakelijk is, is landelijk gereguleerde implementatie van het concept niet te berusten op een gebrek aan literatuur. Zeker als men een vergelijking maakt naar de toepassing van andere behandelingen in de vaatchirurgie, die al snel omarmt worden bij een lager level of evidence. De ongefundeerde aanname van patiënten en verwijzers en daarmee ook de verzekeraar dat CI eenvoudig en doeltreffend primair invasief behandeld kan worden, lijkt de oorzaak te zijn voor het lage aantal verwijzingen naar GLT. De introductie van het stepped care model met een verplichte 3 maandelijkse periode GLT volgens het ClaudicatioNet principe zal er dan ook voor zorgen dat de huidige richtlijnen in praktijk worden gebracht. Betrokken partijen zullen de handen ineen moeten slaan om de zorg voor de patiënt met etalagebenen in de komende jaren te optimaliseren. Deze thesis kan dienen als opmaat hiervoor en is een duidelijke handreiking naar betrokken stakeholders.

\section{PART II - op weg naar nieuwe uitkomstparameters bij claudicatio intermittens}

Diagnosticeren van claudicatio, kan het ook anders?

Verlaagde enkel-arm index (EAI) waarden in rust $(<0.9$, normaal $>1.0)$ of na inspanning op een loopband $(\Delta>0.15)$ worden gehanteerd om PAV aan te tonen. Echter, sommige patiënten die verwezen worden voor een diagnostische loopbandtest kunnen deze niet ondergaan door ernstige co-morbiditeit of angst voor lopen op de loopband. Vaak kunnen deze patiënten wel fietsen. In hoofdstuk 6 werd een fietstest gevalideerd om claudicatio intermittens te diagnosticeren. In een prospectieve validatiestudie ondergingen 32 patiënten met bewezen PAV een standaard conventionele looptest en twee verschillende fietsprotocollen, een submaximale fietstest en een maximale fietstest. EAI waarden werd geregistreerd in rust en tweemaal na iedere inspanningstest. Controledata werd verkregen bij 13 individuen zonder PAV. Er werd geconcludeerd dat zowel een submaximale als een maximale fietstest bruikbare methoden zijn om PAV aan te tonen en kunnen worden gebruikt bij personen die een conventionele looptest niet kunnen ondergaan. Een submaximale fietstest lijkt superieur aan een maximale fietstest. Bovendien lijkt een fietstest voordelen te bieden ten opzichte van een conventionele looptest. Fietsen op een ergometer is gewichts-onafhankelijk (geen belasting voor de gewrichten) en is een "non-moving" oefening (dus goed bruikbaar voor patiënten met evenwichtsproblemen). Tevens bestaat de mogelijkheid de fietstest te combineren met een screening op cardiovasculaire pathologie.

Effectiviteitsmeting bij de behandeling van

claudicatio intermittens

Belangrijk onderdeel in de evaluatie van wetenschappelijk onderzoek, maar ook in het toepassen van de fysiotherapeutische behandeling bij claudicatio, is het toepassen van betrouwbare en valide meetinstrumenten. De meest gebruikte uitkomstmaat in onderzoek naar PAV is op dit moment de maximale of pijnvrije loopafstand of -tijd. De waarde van deze uitkomstmaat staat echter ter discussie. Het uitvragen van de loopafstand blijkt geen objectieve maat te zijn voor de daadwerkelijk gelopen afstand in het dagelijks leven. ${ }^{(35-38)}$ Specifieke vragenlijsten, zoals de Walking Impairment Questionnaire (WIQ) lijken beter te functioneren, maar ook hier blijven de correlaties met de daadwerkelijk gelopen afstand zwak. ${ }^{(36)}$ Loopbanden worden daarom veelal gebruikt om de afstand objectief te bepalen. ${ }^{(9-11)}$ Echter, er blijkt een grote verscheidenheid aan loopbandprotocollen te bestaan (hoofdstuk 2). Daarnaast wordt de meting niet verricht in het dagelijks leven maar in een voor de patiënt onnatuurlijke omgeving. ${ }^{(39)}$ In hoofdstuk 7 wordt de overeenkomst bepaald tussen de daadwerkelijk buiten gelopen loopafstand, de bij twee loopbandprotocollen gemeten loopafstand en de door de patiënt geschatte loopafstand. Er werd geconcludeerd dat patiënten met claudicatio intermittens hun maximale loopafstand overschatten, en dat deze verschillen mogelijk verklaard kunnen worden door een verschil in loopsnelheid. Echter, het belangrijkste is dat bevestigd wordt dat een resultaat van een loopbandtest mogelijk geen betrouwbare uitkomstmaat geeft. Zeker niet in onderzoek wat gericht is op het vaststellen van behandelingseffecten voor PAV. Bovendien geeft de loopafstand alleen inzicht in de mate van fysieke capaciteit. Het verhogen van deze capaciteit impliceert niet vanzelfsprekend dat de patiënt ook meer gaat bewegen (= activiteit). Daarbij is de toename in kwaliteit van leven niet per definitie gecorreleerd aan de toename van de loopcapaciteit (hoofdstuk 7). Al deze methodologische beperkingen leiden tot een lagere validiteit van deze uitkomstmaat dan gewenst. Een alternatieve maat, waarbij over langdurige tijd de activiteit van een claudicant gemeten kan worden, zou uitkomst kunnen bieden. 
Fysieke activiteit als alternatieve uitkomstmaat in $\mathrm{Cl}$

We zien dus verschillen tussen loopbandresultaten en het dagelijkse beweeggedrag van patiënten. Een toegenomen loopcapaciteit betekent niet automatisch dat een patiënt ook meer gaat bewegen. ${ }^{(36,39)}$ Anderen lieten eerder zien dat ook het effect van een revascularisatie op claudicatio-symptomen niet terug te zien is op loopbandresultaten. ${ }^{(40)}$ Onderzoekers laten daarom regelmatig doorschemeren dat de nadruk in toekomstig onderzoek meer moet liggen op "kwaliteit van leven"- parameters en ziekte-specifieke vragenlijsten om zodoende het effect van CI behandelingen beter te kunnen vergelijken (hoofdstuk 2\&7). ${ }^{(38,41)}$ Bovendien is maatschappelijk gezien ook meer interesse in dagelijkse fysieke activiteit en het gevolg daarvan op het verlagen van de cardiovasculaire morbiditeit en mortaliteit. ${ }^{(2-48)}$ Een logisch vervolg is dan ook om fysieke activiteit als uitkomstwaarde te bestuderen in PAV onderzoek. Men weet dat CI nauw gerelateerd is aan hart en vaatziekten $^{(11,49,50)}$, een verhoging van de mate van fysieke activiteit kan daarom resulteren in een verlaging op het krijgen van een van deze ziekten of een hieraan gerelateerde aandoening. ${ }^{(51,52)}$

Tegenwoordig kan fysieke activiteit vastgelegd worden met behulp van activiteitmonitors. Tri-axiale accelerometers meten acceleratie in drie dimensies en het resultaat daarvan kan geconverteerd worden in intensiteiten en metabolische equivalenten (METs). Hierdoor kan men fysieke activiteiten kwantificeren. De MET-waarde ofwel het metabool equivalent is een meeteenheid binnen de fysiologie voor de hoeveelheid energie die een bepaalde fysieke inspanning kost ten opzichte van de hoeveelheid benodigde energie in rust. Eén MET komt overeen met de ruststofwisseling ofwel basaalstofwisseling, de hoeveelheid energie die verbruikt wordt tijdens stilzitten. Volgens de huidige richtlijnen wordt een minimum van dagelijks 64-107 METs·min geadviseerd. ${ }^{(53)}$

De Dynaport MoveMonitor is een activiteitenmonitor die fysieke activiteit uitdrukt in METs, makkelijk is in het dagelijks gebruik en geoptimaliseerd is voor klinisch onderzoek. Hoewel de MoveMonitor reeds is gevalideerd in diverse patiëntengroepen ${ }^{(54-59)}$, ontbrak een validatiestudie in een studiepopulatie met claudicanten in een niet-klinische onderzoek setting. In hoofdstuk 8 wordt geconcludeerd dat de MoveMonitor accurate informatie verschaft over diverse houdingen, dagelijkse activiteiten en het aantal stappen. Het apparaat wordt als bruikbaar beschouwd bij het bepalen van fysieke activiteit en levert innovatieve klinisch relevante uitkomstgegevens voor onderzoek naar dit ziektebeeld.
Fysieke activiteit van claudicanten ten opzichte van gezonde proefpersonen

Ten opzichte van gezonde volwassenen, hebben patienten met CI een lagere kwaliteit van leven en functioneren zij bij dagelijkse activiteiten slechter. ${ }^{(60,61)}$ Verder weten we dat personen die regelmatig fysiek actief zijn, vaak een betere gezondheid hebben met lagere zorgkosten en dat zij minder invaliditeit vertonen ten opzichte van personen die voornamelijk een zittend leven leiden. ${ }^{(62,63)}$ De Amerikaanse Hartstichting (AHA) en het Amerikaanse College van Sportgeneeskunde (ACSM) hebben richtlijnen opgesteld waar aan ouderen minimaal zouden moeten voldoen. Deze aanbevelingen zijn aangepast voor patienten met chronische aandoeningen. ${ }^{(53)}$ In hoofdstuk 9 wordt de dagelijkse fysieke activiteit van patiënten met CI vergeleken met gezonden proefpersonen. Tevens worden de resultaten vergeleken met de hierboven genoemde aanbevelingen. Het bleek dat meer dan de helft van de CI patiënten niet voldoen aan de eisen zoals gesteld door de AHA. Deze resultaten in acht nemend, met daarbij de verhoogde risico's op hart- en vaatziekten in deze populatie, doen ons concluderen dat het belangrijk is om fysieke activiteit te stimuleren. Deze bevindingen moeten leiden tot meer awareness voor deze uitkomstparameter in zowel onderzoek als bij verwijzer en behandelaar. Het is essentieel om de fysieke activiteit in het dagelijks leven van patiënten met CI te verhogen.

De impact van GLT op fysieke activiteit

GLT is de belangrijkste pijler binnen het stepped care model (hoofdstuk 3). ${ }^{(9-11)}$ De 20-25 'contacturen' van een speciaal opgeleide en getrainde therapeut die beschikbaar komen bij GLT, kunnen uitstekend ingezet worden om patiënten te begeleiden. Leefstijlaanpassingen als stoppen met roken, het belang van medicatie compliance, een gezond dieet en meer bewegen naast de looptraining zijn belangrijke speerpunten. PAV patiënten blijken een forse reductie in dagelijkse fysieke activiteit te hebben (hoofdstuk 9), wat geassocieerd is met een verhoogde mortaliteit. ${ }^{(51,52)}$ Ondanks dat GLT de loopcapaciteit verhoogt, is het effect van deze therapie op de fysieke activiteit bij personen met PAV onbekend. In hoofdstuk 10 wordt onderzocht of GLT een positief effect heeft op zowel fysieke activiteit als dagelijkse activiteiten (gedrag) en kwaliteit van leven bij patiënten met PAV.

Nieuw gediagnosticeerde CI patiënten werden gevraagd om een activiteitenmonitor (Dynaport MoveMonitor) te dragen gedurende één week voor de start van de GLT, en na een periode van 3 maanden GLT. De primaire uitkomstmaat was de toename in patiënten 
die voldeden aan de minimum eis voor fysieke activiteit zoals voorgesteld door ACSM ( $\geq 67$ METs.min·dag, in perioden van $\geq 10 \mathrm{~min}$ ). Data van 41 patiënten waren bruikbaar voor analyse. Na 3 maanden GLT bleek een significant hoger percentage patiënten te voldoen aan de genoemde ACSM minimum eisen (baseline: 43\%; 3 maanden: 63\%, $\mathrm{p}=.003$ ). Echter, harde conclusies konden niet getrokken worden, omdat sommige patiënten juist een afname lieten zien in zowel fysieke activiteit (in METs.min.dag) als in hun gemiddelde waarden met betrekking tot dagelijkse activiteiten. Waarschijnlijk heeft zowel een grote variatie in activiteiten van een patiënt (zowel duur als intensiteit) als een grote variatie tussen patiënten deze tegenstelling veroorzaakt. Bovendien is slechts een relatieve kleine studiepopulatie gebruikt. Vervolgonderzoek met een grotere studiepopulatie is noodzakelijk om de effecten van diverse behandelingsopties op de fysieke activiteit van patiënten met $\mathrm{CI}$ te bestuderen.

\section{Toekomstperspectieven}

Het lijkt er op dat het puur en alleen focussen op de loopcapaciteit, zoals maximale loopafstand of -tijd, inefficiënt is bij het bepalen van de effectiviteit van CI behandelingen. In hoofdstuk $\mathbf{8}$ werd aangetoond dat fysieke activiteit correct gemeten werd met een activiteitenmonitor. Daarnaast lieten wij zien dat CI patiënten minder actief waren dan geadviseerd wordt in de internationale richtlijnen en ook ten opzichte van gezonde proefpersonen (hoofdstuk 9).

Het verhogen van de fysieke activiteit in patiënten met CI heeft een gunstig effect op de verlaging van hart- en vaatziekten. ${ }^{(51,52)}$ GLT lijkt veelbelovend om dit te bewerkstelligen (hoofdstuk 10). Verrassend genoeg werd geen significante correlatie gevonden tussen de verandering in fysieke activiteit en de toename in loopafstand (hoofdstuk 10). Men zou op basis hiervan kunnen beargumenteren dat andere componenten van looptraining, anders dan de toename van de loopafstand, van invloed is op de fysieke activiteit. Het lijkt of patiënten die in staat zijn verder te wandelen (door een afname in CI symptomen) deze capaciteit niet gebruiken in hun dagelijks leven om ook daadwerkelijk vaker, langer of meer intensief te lopen. Bovendien werd geen significante correlatie gevonden tussen de toename in loopcapaciteit en de verandering van kwaliteit van leven (hoofdstuk 10). Deze bevinding werd recentelijk ook bevestigd door anderen. ${ }^{\left({ }^{64)}\right.} \mathrm{Zij}$ beschreven dat de vooruitgang in zelfredzaamheid, tevredenheid in het functioneren, pijntolerantie en sociaal functioneren na zes maanden home-based looptraining los staat van de loopcapaciteit. In combinatie met onze bevindingen dat de loopcapaciteit niet correleert met fysieke activiteit leidt tot het inzicht dat een verschuiving dient plaats te vinden in het doel van het fysiotherapeutisch behandelen. Maar ook in het stellen van de primaire uitkomstmaten in medisch wetenschappelijk onderzoek. Gelukkig zien we dit laatste steeds vaker gebeuren, zo waren Nordanstig et al. een van de eersten die gezondheid gerelateerde kwaliteit van leven als primaire uitkomstmaat gebruikten in hun recentelijk gepubliceerde IRONIC (Invasive Revascularization or Not in IntermittentClaudication) trial. ${ }^{(65)}$ Toekomstig CI onderzoek zal zich daarom primair moeten richten op de veran dering van kwaliteit van leven en de betrouwbare beoordeling hiervan.

En verder? GLT programma's van de toekomst vereisen verdere optimalisatie. Niet alleen zou de focus van onderzoek moeten liggen op de toename van loopcapaciteit, maa ook factoren zoals intrinsieke motivatie, life-style veranderingen, de verwachtingen en de tevredenheid van de patiënt en zijn sociaal functioneren. Wij zouden ons moeten richten op het veranderen van het beweeggedrag van de patiënt in zijn dagelijkse leven door het GLT programma toe te spitsen op de specifieke patiëntbehoefte. De verwachtingen van de CI patiënt zou leidend moeten zijn tijdens de behandeling. Daarnaast dient de fysiotherapeut zich te concentreren op het looppatroon en het combineren van verschillende manieren van training. ${ }^{(67)}$ Een optimale mix van supervisie met home-based training, waarbij eHealth en mHealth technologieën worden ingezet, zouden hier tot een verdere optimalisatieslag kunnen leiden (hoofdstuk 5). Het betrouwbaar kunnen vaststellen van het effect van diverse therapieën en behandelingsstrategieën in de behandeling van PAV (zoals de stepped care aanpak), zullen er uiteindelijk voor zorgen dat de PAV patiënt hiervan zal profiteren. 


\section{Referenties}

1. Meijer WT, Hoes AW, Rutgers D, Bots ML, Hofman A, Grobbee DE. Peripheral arterial disease in the elderly: The Rotterdam Study. Arteriosclerosis, thrombosis, and vascular biology 1998;18:185-92.

2. Fokkenrood HJ, Scheltinga MR, Koelemay MJ, et al. Significant savings with a stepped care model for treatment of patients with intermittent claudication. Eur J Vasc Endovasc Surg 2014;48:423-9.

3. Criqui MH, Langer RD, Fronek A, et al. Mortality over a period of 10 years in patients with peripheral arterial disease. $N$ Engl J Med 1992;326:381-6.

4. Dormandy J, Heeck L, Vig S. Predictors of early disease in the lower limbs. Semin Vasc Surg 1999;12:109-17.

5. Leng GC, Lee AJ, Fowkes FG, et al. Incidence, natural history and cardiovascular events in symptomatic and asymptomatic peripheral arterial disease in the general population. Int J Epidemiol 1996;25:1172-81.

6. Gommans LN, Saarloos R, Scheltinga MR, et al. Editor's Choice - The Effect of Supervision on Walking Distance in Patients with Intermittent Claudication: A Meta-analysis. Eur J Vasc Endovasc Surg 2014;48:169-84

7. Bendermacher BL, Willigendael EM, Teijink JA, Prins MH. Supervised exercise therapy versus non-supervised exercise therapy for intermittent claudication. Cochrane Database Syst Rev 2006:CD005263

8. Fokkenrood HJ, Lauret GJ, Scheltinga MR, Spreeuwenberg C, de Bie RA, Teijink JA. Multidisciplinary treatment for peripheral arterial occlusive disease and the role of eHealth and mHealth. Journal of multidisciplinary healthcare 2012;5:257-63.

9. Anderson JL, Halperin JL, Albert NM, et al. Management of patients with peripheral artery disease (compilation of 2005 and 2011 ACCF/AHA guideline recommendations): a report of the American College of Cardiology Foundation/American Heart Association Task Force on Practice Guidelines. Circulation 2013;127:1425-43.

10. Layden J, Michaels J, Bermingham S, Higgins B, Guideline Development G. Diagnosis and management of lower limb peripheral arterial disease: summary of NICE guidance. Bmj 2012;345:e4947.

11. Norgren L, Hiatt WR, Dormandy JA, Nehler MR, Harris KA, Fowkes FG. Inter-Society Consensus for the Management of Peripheral Arterial Disease (TASC II). J Vasc Surg 2007;45 Suppl S:S5-67.
12. Lauret GJ, van Dalen HC, Hendriks HJ, et al. When is supervised exercise therapy considered useful in peripheral arterial occlusive disease? A nationwide survey among vascular surgeons. Eur J Vasc Endovasc Surg 2012;43:308-12.

13. Bermingham SL, Sparrow K, Mullis R, et al. The Cost-effectiveness of Supervised Exercise for the Treatment of Intermittent Claudication. Eur J Vasc Endovasc Surg 2013;46:707-14.

14. O’Brien-Irr MS, Harris LM, Dosluoglu HH, Dryjski ML. Endovascular intervention for treatment of claudication: is it cost-effective? Annals of vascular surgery 2010;24:833-40.

15. Spronk S, Bosch JL, den Hoed PT, Veen HF, Pattynama PM, Hunink MG. Cost-effectiveness of endovascular revascularization compared to supervised hospital-based exercise training in patients with intermittent claudication: a randomized controlled trial. J Vasc Surg 2008;48:1472-80

16. van Asselt AD, Nicolai SP, Joore MA, Prins MH, Teijink JA. Cost-effectiveness of exercise therapy in patients with intermittent claudication: supervised exercise therapy versus a 'go home and walk' advice. Eur J Vasc Endovasc Surg 2011;41:97-103.

17. Sakamoto S, Yokoyama N, Tamori Y, Akutsu K, Hashimoto H, Takeshita S. Patients with peripheral artery disease who complete 12-week supervised exercise training program show reduced cardiovascular mortality and morbidity. Circulation journal : official journal of the Japanese Circulation Society 2009;73:167-73.

18. Janssen V, De Gucht V, Dusseldorp E, Maes S. Lifestyle modification programmes for patients with coronary heart disease: a systematic review and meta-analysis of randomized controlled trials. European journal of preventive cardiology 2013;20:620-40.

19. Cunningham MA, Swanson V, Holdsworth RJ, O'Carroll RE. Late effects of a brief psychological intervention in patients with intermittent claudication in a randomized clinical trial. Br J Surg 2013;100:756-60.

20. Cunningham MA, Swanson V, O'Carroll RE, Holdsworth RJ. Randomized clinical trial of a brief psychological intervention to increase walking in patients with intermittent claudication. Br J Surg 2012;99:49-56.

21. Nordanstig J, Smidfelt K, Langenskiold M, Kragsterman B. Nationwide experience of cardio- and cerebrovascular complications during infrainguinal endovascular intervention for peripheral arterial disease and acute limb ischaemia. Eur J Vasc Endovasc Surg 2013;45:270-4.

22. Sachs T, Pomposelli F, Hamdan A, Wyers M, Schermerhorn M. Trends in the national outcomes and costs for claudication and limb threatening ischemia: angioplasty vs bypass graft. J Vasc Surg 2011;54:1021-31 e1 
23. Lauret GJ, Gijsbers HJ, Hendriks EJ, Bartelink ML, de Bie RA, Teijink JA. The ClaudicatioNet concept: design of a national integrated care network providing active and healthy aging for patients with intermittent claudication. Vasc Health Risk Manag 2012;8:495-503.

24. Fowkes FG, Rudan D, Rudan I, et al. Comparison of global estimates of prevalence and risk factors for peripheral artery disease in 2000 and 2010: a systematic review and analysis. Lancet 2013.

25. Rapport "De zorg: hoeveel extra is het ons waard? Dutch Ministry of Health Welfare and Sports.

26. Murphy TP, Cutlip DE, Regensteiner JG, et al. Supervised exercise versus primary stenting for claudication resulting from aortoiliac peripheral artery disease: six-month outcomes from the claudication: exercise versus endoluminal revascularization (CLEVER) study. Circulation 2012;125:130-9.

27. Creasy TS, McMillan PJ, Fletcher EW, Collin J, Morris PJ. Is percutaneous transluminal angioplasty better than exercise for claudication? Preliminary results from a prospective randomised trial. European journal of vascular surgery 1990;4:135-40.

28. Spronk S, Bosch JL, den Hoed PT, Veen HF, Pattynama PM, Hunink MG. Intermittent claudication: clinical effectiveness of endovascular revascularization versus supervised hospital-based exercise training--randomized controlled trial. Radiology 2009;250:586-95.

29. Ahimastos AA, Pappas EP, Buttner PG, Walker PJ, Kingwell BA, Golledge J. A meta-analysis of the outcome of endovascular and noninvasive therapies in the treatment of intermittent claudication. J Vasc Surg 2011;54:1511-21.

30. Fakhry F, Rouwet EV, den Hoed PT, Hunink MG, Spronk S. Long-term clinical effectiveness of supervised exercise therapy versus endovascular revascularization for intermittent claudication from a randomized clinical trial. Br J Surg 2013;100:1164-71.

31. Geraghty PJ, Mewissen MW, Jaff MR, Ansel GM, Investigators V. Three-year results of the VIBRANT trial of VIABAHN endoprosthesis vs bare nitinol stent implantation for complex superficial femoral artery occlusive disease. J Vasc Surg 2013.

32. Jongkind V, Akkersdijk GJ, Yeung KK, Wisselink W. A systematic review of endovascular treatment of extensive aortoiliac occlusive disease. J Vasc Surg 2010;52:1376-83.

33. Lensvelt MM, Reijnen MM, Wallis De Vries BM, Zeebregts CJ. Treatment strategies for extensive chronic SFA occlusions: indications and results. The Journal of cardiovascular surgery 2012;53:161-70.

34. Stewart KJ, Hiatt WR, Regensteiner JG, Hirsch AT. Exercise training for claudication. N Engl J Med 2002;347:1941-51.
35. Watson CJ, Phillips D, Hands L, Collin J. Claudication distance is poorly estimated and inappropriately measured. Br J Surg 1997;84:1107-9.

36. Frans FA, Zagers MB, Jens S, Bipat S, Reekers JA, Koelemay MJ. The relationship of walking distances estimated by the patient, on the corridor and on a treadmill, and the Walking Impairment Questionnaire in intermittent claudication. J Vasc Surg 2013;57:720-7 e1.

37. Tew G, Copeland R, Le Faucheur A, Gernigon M, Nawaz S, Abraham P. Feasibility and validity of self-reported walking capacity in patients with intermittent claudication. Journal of vascular surgery 2013;57:1227-34.

38. Nordanstig J, Broeren M, Hensater M, Perlander A, Osterberg K, Jivegard L. Six-minute walk test closely correlates to "real-life" outdoor walking capacity and quality of life in patients with intermittent claudication. J Vasc Surg 2014;60:404-9.

39. McDermott MM, Ades PA, Dyer A, Guralnik JM, Kibbe M, Criqui MH. Corridor-based functional performance measures correlate better with physical activity during daily life than treadmill measures in persons with peripheral arterial disease. J Vasc Surg 2008;48:1231-7, 7 e1.

40. Murphy TP, Reynolds MR, Cohen DJ, et al. Correlation of patient-reported symptom outcomes and treadmill test outcomes after treatment for aortoiliac claudication. $J$ Vasc Interv Radiol 2013;24:1427-35; quiz 36.

41. Mays RJ, Regensteiner JG. Therapy for peripheral artery disease: gaps in treating patients with claudication. Circulation 2014;130:929-31.

42. Grontved A, Hu FB. Television viewing and risk of type 2 diabetes, cardiovascular disease, and all-cause mortality: a meta-analysis. Jama 2011;305:2448-55.

43. Katzmarzyk PT. Physical activity, sedentary behavior, and health: paradigm paralysis or paradigm shift? Diabetes 2010;59:2717-25.

44. Katzmarzyk PT. Standing and Mortality in a Prospective Cohort of Canadian Adults. Med Sci Sports Exerc 2013.

45. Maher C, Olds T, Mire E, Katzmarzyk PT. Reconsidering the sedentary behaviour paradigm. PloS one 2014;9:e86403.

46. Thorp AA, Owen N, Neuhaus M, Dunstan DW. Sedentary behaviors and subsequent health outcomes in adults a systematic review of longitudinal studies, 1996-2011. American journal of preventive medicine 2011;41:207-15.

47. van der Ploeg HP, Chey T, Korda RJ, Banks E, Bauman A. Sitting time and all-cause mortality risk in 222497 Australian adults. Arch Intern Med 2012;172:494-500. 
48. Wilmot EG, Edwardson CL, Achana FA, et al. Sedentary time in adults and the association with diabetes, cardiovascular disease and death: systematic review and meta-analysis. Diabetologia 2012;55:2895-905.

49. Criqui MH. Systemic atherosclerosis risk and the mandate for intervention in atherosclerotic peripheral arterial disease. The American journal of cardiology 2001;88:43J-7J.

50. Criqui MHL, R. D.; Fronek, A. Mortality over a period of 10 years in patients with peripheral arterial disease. N Engl J Med 1992;326:7.

51. Kodama S, Saito K, Tanaka S, et al. Cardiorespiratory fitness as a quantitative predictor of all-cause mortality and cardiovascular events in healthy men and women: a meta-analysis. Jama 2009;301:2024-35.

52. Yusuf S, Hawken S, Ounpuu S, et al. Effect of potentially modifiable risk factors associated with myocardial infarction in 52 countries (the INTERHEART study): case-control study. Lancet 2004;364:937-52.

53. Nelson ME, Rejeski WJ, Blair SN, et al. Physical activity and public health in older adults: recommendation from the American College of Sports Medicine and the American Heart Association. Circulation 2007;116:1094-105.

54. Dijkstra B, Kamsma Y, Zijlstra W. Detection of gait and postures using a miniaturised triaxial accelerometer-based system: accuracy in community-dwelling older adults. Age and ageing 2010;39:259-62.

55. Dijkstra B, Kamsma YP, Zijlstra W. Detection of gait and postures using a miniaturized triaxial accelerometer-based system: accuracy in patients with mild to moderate Parkinson's disease. Archives of physical medicine and rehabilitation 2010;91:1272-7.

56. Dijkstra B, Zijlstra W, Scherder E, Kamsma Y. Detection of walking periods and number of steps in older adults and patients with Parkinson's disease: accuracy of a pedometer and an accelerometry-based method. Age and ageing 2008;37:436-41.

57. Langer D, Gosselink R, Sena R, Burtin C, Decramer M, Troosters T. Validation of two activity monitors in patients with COPD. Thorax 2009;64:641-2.

58. Kanda M, Minakata Y, Matsunaga K, et al. Validation of the triaxial accelerometer for the evaluation of physical activity in Japanese patients with COPD. Intern Med 2012;51:369-

59. Pitta F, Troosters T, Spruit MA, Decramer M, Gosselink R. Activity monitoring for assessment of physical activities in daily life in patients with chronic obstructive pulmonary disease. Archives of physical medicine and rehabilitation 2005;86:1979-85.
60. Regensteiner JG, Hiatt WR, Coll JR, et al. The impact of peripheral arterial disease on health-related quality of life in the Peripheral Arterial Disease Awareness, Risk, and Treatment: New Resources for Survival (PARTNERS) Program. Vasc Med 2008;13:15-24.

61. Dumville JC, Lee AJ, Smith FB, Fowkes FG. The health-related quality of life of people with peripheral arterial disease in the community: the Edinburgh Artery Study. The British journal of general practice : the journal of the Royal College of General Practitioners 2004;54:826-31.

62. Brach JS, FitzGerald S, Newman AB, et al. Physical activity and functional status in community-dwelling older women: a 14-year prospective study. Arch Intern Med 2003;163:2565-71.

63. Nguyen HQ, Ackermann RT, Maciejewski M, et al. Managed-Medicare health club benefit and reduced health care costs among older adults. Preventing chronic disease 2008;5:A14

64. Rejeski WJ, Spring B, Domanchuk K, et al. A group-mediated, home-based physical activity intervention for patients with peripheral artery disease: effects on social and psychological function. Journal of translational medicine 2014;12:29.

65. Nordanstig J, Taft C, Hensater M, Perlander A, Osterberg K, Jivegard L. Improved quality of life after 1 year with an invasive versus a noninvasive treatment strategy in claudicants: one-year results of the Invasive Revascularization or Not in Intermittent Claudication (IRONIC) Trial. Circulation 2014;130:939-47.

66. Kinlay S. Outcomes for clinical studies assessing drug and revascularization therapies for claudication and critical limb ischemia in peripheral artery disease. Circulation 2013;127:1241-50

67. Lauret GJ, Fakhry F, Fokkenrood HJ, Hunink MG, Teijink JA, Spronk S. Modes of exercise training for intermittent claudication. Cochrane Database Syst Rev 2014;7:CD009638. 


\section{Introductie}

Perifeer arterieel vaatlijden (PAV) is de verzamelnaam voor slagaderlijke vaatziekten in het lichaam, de hart- en hersenvaten uitgezonderd. PAV is een uitingsvorm van atherosclerose, in de volksmond abusievelijk aderverkalking genoemd, terwijl slagaderverkalking wordt bedoeld. Claudicatio intermittens is een veel voorkomend symptoom bij PAV en betekent letterlijk 'intermitterend hinken'. Claudicatio treedt op bij het stadium van PAV waarin patiënten pijn hebben bij het lopen, hetgeen noodzaakt tot stoppen. Waar in rust de zuurstofvoorziening van de beenspieren volstaat, wordt bij lopen aan de toegenomen zuurstofbehoefte onvoldoende voldaan. $\mathrm{Na}$ een bepaalde afstand lopen moeten 'claudicanten' stoppen omdat zij pijn ervaren. Omdat dit noodgedwongen pauzeren niet alleen de actieradius beperkt, maar ook als mens ongemakkelijk wordt ervaren, gaan patiënten deze klachten maskeren, bijvoorbeeld door net te doen of een etalage wordt bekeken tijdens het gedwongen stilstaan. In de volksmond wordt bij claudicatio intermittens daarom gesproken van 'etalagebenen'.

PAV komt wereldwijd voor bij ruim 200 miljoen mensen. ${ }^{(1)}$ De afgelopen 10 jaar is het aantal patiënten met PAV wereldwijd met bijna een kwart gestegen, zowel in hoge- als ook in lage inkomenslanden. ${ }^{(1)}$ De combinatie van frequenter voorkomen, de hogere kans op een geassocieerde fatale of invaliderende vasculaire gebeurtenis (hart- en/of herseninfarct) en de aanzienlijke kostenstijging die gepaard gaat met de behandeling, maakt dat PAV ondertussen een belangrijk gezondheidszorg probleem is geworden. Zeker in het licht van de verwachting dat de nationale zorgkosten exponentieel zullen stijgen (13\% van 2012 bruto nationaal product naar 30\% in 2040)(2) en de behandeling van PAV hier fors aan zal bijdragen. Onlangs werd een oproep gedaan aan overheden, relevante organisaties en de private sector om met een oplossing te komen voor de maatschappelijke en economische consequenties van PAV. ${ }^{(1)}$

\section{Stepped care}

In het eerste deel van dit proefschrift wordt een innovatieve strategie geïntroduceerd om de behandeling van claudicatio intermittens te optimaliseren. ${ }^{(3,4)}$ Deze "stepped care approach" of wel "getrapte behandeling" levert naast economische ook maatschappelijke voordelen op in de vorm van minder sterfte en morbiditeit, meer aandacht voor cardiovasculair risico management en daarmee een betere kwaliteit van zorg voor deze groep patiënten en mogelijk langere overleving. In dit model ontvangen patiënten een behan- deling die niet zwaarder (risicodragend) is dan noodzakelijk. Het model is gebaseerd op de vigerende richtlijnen ${ }^{(5-7)}$, meest recente literatuur en het eeuwenoude adagium 'primum non nocere' ('first do no harm'). Samenvattend houdt het een 'verplichte' start met minimaal 3 maanden Gesuperviseerde Looptherapie (GLT) in. Tijdens dit traject word veel aandacht besteed aan het beïnvloeden van aanwezige risicofactoren voor hart- en vaatziekten. Pas bij falen van dit traject, in de zin van een discrepantie tussen gewenste en bereikte loopafstand wordt nadere diagnostiek verricht en beoordeeld of een endovasculaire behandeling kan worden aangeboden.

\section{3 miljoen besparing}

In dit proefschrift worden, in een budget impact analyse (BIA) op basis van tweede lijn declaratie gegevens bij een grote Nederlandse zorgverzekeraar, de kosten van deze anpak vergeleken met een initiële endovasculaire procedure en niet-gesuperviseerde looptherapie. ${ }^{(4)}$ De in twee jaar gegenereerde gemiddelde kosten van een interventietraject bleken vijf maal hoger dan bij de "stepped care approach". Om het effect van volledige landelijke implementatie van dit model te concretiseren is gewerkt met drie scenario's. Deze zijn gebaseerd op twee essentiële factoren die momenteel als belemmerend worden ervaren om het stepped care model in praktijk te brengen. In het $80-80 \%$ scenario, wordt verondersteld dat in 2018 80\% van alle patiënten primair naar een traject GLT wordt verwezen en in $80 \%$ van deze gevallen de patiënt voldoende verzekerd is om deze behandeling daadwerkelijk te ondergaan. De verwijzingen komen vanuit de tweede lijn tot stand als andere belemmerende factoren worden weggenomen. Een onvoldoende verzekerde patiënt die zelf een aanvullende bijdrage niet wil of kan dragen zal kiezen voor een veel duurdere maar voor hemzelf 'gratis' interventie. Op basis van dit scenario zou in Nederland een jaarlijkse besparing van $€ 33$ miljoen euro gerealiseerd kunnen worden. Een besparing die hand in hand gaat met betere, veiligere zorg!

Duurzaam, kwalitatief beter en goedkoper, kan dat?

Ja, althans zo blijkt uit onze analyse. Waarin belangrijke aanvullende voordelen van GLT niet werden meegerekend. Voordelen die bij een initiële behandeling met een revascularisatie niet optreden. Zo wordt bij GLT (en daarmee stepped care) niet alleen het aangedane been getraind, maar ook het op dat moment (mogelijk nog) geen klachten gevende, andere been. Dat geldt ook voor het gelijktijdig mee trainen van hart en longen (de cardiopulmonale conditie), hetgeen weer een positief effect kan hebben op de overleving 
en het verlagen van het risico op cardiovasculaire events. ${ }^{(8)}$ Effecten die weliswaar niet werden onderzocht, laat staan aangetoond in dit proefschrift, maar die kunnen worden afgeleid uit onderzoek naar psychologische interventies zoals verricht door anderen. ${ }^{(9-11)}$ Een interventie bestaande uit motiverende gespreksvoering van slechts twee sessies laat het loopgedrag verbeteren, een effect dat zelfs voor minimaal twee jaar stand houdt. ${ }^{(12)}$

Een tot op heden nauwelijks onderkend en daardoor niet benut voordeel is dat bij een gesuperviseerd traject ongeveer 20-25 'contacturen' beschikbaar komen. In deze tijd kan een daartoe speciaal opgeleide en getrainde claudicatio-therapeut patiënten begeleiden bij leefstijlaanpassingen als stoppen met roken, het belang van medicatie compliance, een gezond dieet en meer bewegen naast de looptraining. ${ }^{(10)}$ Samen trainen en lotgenotencontact kunnen ook worden gestimuleerd door deze getrainde behandelaar. Supervisie wordt daarmee supervisie 'plus', of ook wel "ClaudicatioNet traject" genoemd. Daar waar bij een 'PTA ('Dotter')-eerst' behandeling weliswaar mogelijk een sneller effect kan worden bereikt betreffende de loopcapaciteit, wordt een patiënt de kans ontnomen om deze minstens zo belangrijke voordelen te benutten.

GLT kent nog een voordeel, een ander aspect wat invasief ingestelde behandelaars zich mogelijk onvoldoende realiseren. Bij een primair invasieve behandeling wordt de klacht van de patiënt op basis van de anamnese gerelateerd aan de vasculaire afwijking. De patiënt wordt zo de kans ontnomen op het proefondervindelijk signaleren van limiterende klachten die niet veroorzaakt worden door PAV. De eveneens aanwezige limiterende klachten, bijvoorbeeld van het bewegingsapparaat of van neurogene oorzaak, kunnen zo onontdekt blijven bij een PAV patiënt. Maar ook het feit dat een patiënt mogelijk door kortademigheid wordt beperkt en niet door de aanwezige pijn in het been. Dit is belangrijke informatie die idealiter moet worden onderzocht voordat de optie van een invasieve behandeling wordt overwogen. Een binnen ClaudicatioNet werkzame fysiotherapeut komt hier in de eerste behandelingen proefondervindelijk achter. In voorkomende gevallen kan hier specifieke training op worden geïnitieerd (er bestaan gevalideerde programma's voor COPD, hartfalen, artrose, etc.). De algehele conditie, COPD, pijn op de borst, neurogene klachten, een versleten heup of knie worden echt niet beter van een vasculaire interventie! ${ }^{(12)}$

Toch wordt in de dagelijkse praktijk als eerste behandelingsoptie nog (te) vaak voor een invasieve behandeling gekozen. In dit proefschrift wordt aangetoond dat van de bijna
5000 keer dat in 2009 de 'DBC claudicatio intermittens' door een chirurg werd geopend, in een derde van de gevallen primair werd gekozen voor een invasieve interventie. ${ }^{(4)}$ Slechts bij 14\% werd eerst gekozen voor GLT en daarmee 'stepped care'. Opvallend is vervolgens dat in deze laatste groep in $6.4 \%$ van de gevallen, tijdens de twee jaar follow-up periode, alsnog werd gekozen voor een vasculaire interventie. Terwijl dat percentage in de "PTA eerst" groep 35,2\% betrof. ${ }^{(4)}$ Dit hoge percentage kan enerzijds worden verklaard door het bekende feit dat gedotterde trajecten opnieuw dichtslibben en anderzijds door het feit dat klachten van het andere been opnieuw voor een PTA in aanmerking zullen komen. De uitdaging is dan ook om in de komende jaren het percentage stepped care te verhogen tot idealiter $100 \%$. Het is aan zorgverzekeraars, het zorginstituut Nederland, huisartsen en vaatchirurgen om dit te realiseren.

\section{Hoe?}

Maar hoe kan dit percentage verhoogd worden? Het aantonen van de effectiviteit van GLT als primaire behandeling, de meerwaarde van een volledig ClaudicatioNet traject en de aangetoonde besparingen met de effectuering van het stepped care model bieden immers geen garantie dat invoering van deze behandeling vanzelf zal volgen. Een aantal obstakels moet overwonnen worden. Ten eerste dient zowel bij patiënt, huisarts, vaatchirurg en andere betrokken zorgverleners waar nodig het beeld van gesuperviseerde looptherapie als inferieure behandeling bijgesteld te worden. Dit is noodzakelijk om te komen tot de gewenste en noodzakelijke actieve participatie van de patiënt en past bij het leggen van verantwoordelijkheid bij die patiënt. De houding van de verwijzende arts zal daarin moeten veranderen. ${ }^{(13)}$

Marketingstrategieën van de medische industrie proberen artsen juist te overtuigen dat de nieuwste medische technologie effectiever en duurzamer is dan de vorige generatie dotter ballonnen en stents. Deze bedrijven hebben, in tegenstelling tot de 'sponsor' van GLT, een gigantisch budget en sluiten met hun marketing aan bij de intrinsieke wens tot handelen van vaatchirurgen en interventie-radiologen. Het is dan ook noodzakelijk om in de komende jaren meer aandacht te geven aan de behandeling van claudicatio in de eerste lijn. Substitutie van deze zorg naar deze eerste lijn zal vanzelf leiden tot implementatie van stepped care, eenvoudigweg omdat invasieve interventies geen optie zijn binnen de huisartsenpraktijk. 
De vraag voor de komende jaren luidt dan ook; 'hoe krijgen wij alle neuzen dezelfde kant op?? Een belangrijke aanzet daartoe werd gedaan in 2011 met de oprichting van ClaudicatioNet. ${ }^{(14)}$ De stichting ClaudicatioNet beoogd het creëren van een zorgmodel waarin evidence-based zorg geleverd wordt aan een goed geïnformeerde en actief participerende, centraal-staande PAV patiënt. ClaudicatioNet faciliteert daarmee in feite een geïntegreerd zorgnetwerk dat patiënten en behandelaars (bijv. vaatchirurgen, huisartsen, fysiotherapeuten) met elkaar in contact brengt. De stepped care approach wordt hierdoor geïmplementeerd in het Nederlandse zorgsysteem. Transparantie en hoogwaardige conservatieve zorg voor alle patiënten met PAV is het doel. De stichting beschikt over een landelijk dekkend netwerk van geschoolde fysio- en oefentherapeuten die een driejarig specialisatietraject doorlopen. ${ }^{(3,14)}$ Met eHealth- (en in de nabije toekomst ook mHealth) wordt inzicht verkregen in de kwaliteit van geleverde zorg. Niet alleen de patiënt krijgt op deze wijze feedback over zijn of haar vorderingen, maar ook de therapeut en verwijzer kunnen worden 'gebenchmarkt' met hun 'peers'. In dit proefschrift worden enkele van deze processen en diensten uitgebreid beschreven. ${ }^{(3)}$

Op weg naar nieuwe uitkomstmaten

Belangrijk onderdeel is het toepassen van betrouwbare en valide meetinstrumenten voor instelling en evaluatie van de geboden fysiotherapeutische behandeling. In het tweede deel van deze thesis ("towards new outcome measures") wordt een wetenschappelijke basis gelegd voor een mogelijke nieuwe uitkomstmaat van claudicatio-behandeling. ${ }^{(15-18)} \mathrm{De}$ meeste gebruikte uitkomstmaat in onderzoek naar PAV is op dit moment de 'maximale of pijnvrije loopafstand of -tijd. Deze parameters geven echter alleen inzicht in de mate van fysieke capaciteit. Het verhogen van deze capaciteit betekend niet vanzelfsprekend dat de patiënt ook meer gaat bewegen (= activiteit). Of sterker nog dat de kwaliteit van leven wordt beïnvloedt. ${ }^{(16)}$ Bovendien vertoont de loopcapaciteit een grote variabiliteit in de tijd. Deze beperkingen leiden tot een mindere betrouwbaarheid en validiteit van deze uitkomstmaat dan gewenst. Een alternatieve maat waarbij over langdurige tijd de activiteit van een claudicant gemeten kan worden zou uitkomst kunnen bieden. Zeker als deze wordt gecombineerd met de door de claudicatio-therapeut vastgelegde kwaliteit van leven en door de patiënt aangeleverde Patient Related Outcome Measures (PROMS).
Op welke manier krijgt dit valorisatietraject vorm?

Het percentage 'stepped care' bij claudicanten zal in de komende jaren verder moeten toenemen. Succesfactoren voor deze toename zijn terug te voeren op een toename van kosten in de eerste lijn, welke direct zullen leiden tot aanzienlijke besparingen in de tweede lijn. En daarmee komt meteen het probleem voor een groot deel aan het licht. De besparingen in de tweede lijn lijken welhaast als triviaal te worden ervaren, terwijl de eerste lijn niet weet waar ze de investeringen vandaan moet halen. Zorgverzekeraars, Zorginstituut-Nederland en uiteindelijk het Ministerie van Volksgezondheid spelen een belangrijke rol om deze impasse te doorbreken. Een verstandige eerste stap moet bestaan uit het opnemen van GLT in de basiszorg.

Ook zal in de toekomst nog meer wetenschappelijk onderzoek nodig zijn. Allereerst moet een gedegen kosteneffectiviteitsstudie naar het ClaudicatioNet-concept worden verricht, aangezien nu alleen een kostenanalyse is verricht. Tevens kan men het effect van optimalisatie van inhoud van de trainingsprogramma's bestuderen. ${ }^{(19)}$ Bij het beschikbaar komen van data uit de landelijke ClaudicatioNet database (per medio 2015) ontstaat de mogelijkheid om deze verschillende behandelingsstrategieën gerandomiseerd en met grote studiepopulaties te vergelijken.

Betrokken partijen zullen de handen ineen moeten slaan om de zorg voor de patiën met etalagebenen in de komende jaren te optimaliseren. Deze thesis kan dienen als opmaat hiervoor en is een duidelijke handreiking naar betrokken stakeholders. 


\section{Referenties}

1. Fowkes FG, Rudan D, Rudan I, et al. Comparison of global estimates of prevalence and risk factors for peripheral artery disease in 2000 and 2010: a systematic review and analysis. Lancet 2013.

2. Rapport "De zorg: hoeveel extra is het ons waard? Dutch Ministry of Health Welfare and Sports.

3. Fokkenrood HJ, Lauret GJ, Scheltinga MR, Spreeuwenberg C, de Bie RA, Teijink JA. Multidisciplinary treatment for peripheral arterial occlusive disease and the role of eHealth and mHealth. Journal of multidisciplinary healthcare 2012;5:257-63.

4. Fokkenrood HJ, Scheltinga MR, Koelemay MJ, et al. Significant savings with a stepped care model for treatment of patients with intermittent claudication. Eur J Vasc Endovasc Surg 2014;48:423-9.

5. Hirsch AT, Haskal ZJ, Hertzer NR, et al. ACC/AHA 2005 Practice Guidelines for the management of patients with peripheral arterial disease (lower extremity, renal, mesenteric, and abdominal aortic): a collaborative report from the American Association for Vascular Surgery/Society for Vascular Surgery, Society for Cardiovascular Angiography and Interventions, Society for Vascular Medicine and Biology, Society of Interventional Radiology, and the ACC/AHA Task Force on Practice Guidelines (Writing Committee to Develop Guidelines for the Management of Patients With Peripheral Arterial Disease): endorsed by the American Association of Cardiovascular and Pulmonary Rehabilitation; National Heart, Lung, and Blood Institute; Society for Vascular Nursing; TransAtlantic Inter-Society Consensus; and Vascular Disease Foundation. Circulation 2006;113:e463-654.

6. Layden J, Michaels J, Bermingham S, Higgins B, Guideline Development G. Diagnosis and management of lower limb peripheral arterial disease: summary of NICE guidance. Bmj 2012;345:e4947.

7. Norgren L, Hiatt WR, Dormandy JA, Nehler MR, Harris KA, Fowkes FG. Inter-Society Consensus for the Management of Peripheral Arterial Disease (TASC II). J Vasc Surg 2007;45 Suppl S:S5-67.

8. Sakamoto S, Yokoyama N, Tamori Y, Akutsu K, Hashimoto H, Takeshita S. Patients with peripheral artery disease who complete 12-week supervised exercise training program show reduced cardiovascular mortality and morbidity. Circulation journal : official journal of the Japanese Circulation Society 2009;73:167-73.
9. Janssen V, De Gucht V, Dusseldorp E, Maes S. Lifestyle modification programmes for patients with coronary heart disease: a systematic review and meta-analysis of randomized controlled trials. European journal of preventive cardiology 2013;20:620-40.

10. Cunningham MA, Swanson V, Holdsworth RJ, O'Carroll RE. Late effects of a brief psychological intervention in patients with intermittent claudication in a randomized clinical trial. Br J Surg 2013;100:756-60

11. Cunningham MA, Swanson V, O'Carroll RE, Holdsworth RJ. Randomized clinical trial of a brief psychological intervention to increase walking in patients with intermittent claudication. Br J Surg 2012;99:49-56.

12. Cunningham MA, Swanson V, Pappas E, O'Carroll RE, Holdsworth RJ. Illness beliefs and walking behavior after revascularization for intermittent claudication: a qualitative study. Journal of cardiopulmonary rehabilitation and prevention 2014;34:195-201.

13. Lauret GJ, van Dalen HC, Hendriks HJ, et al. When is supervised exercise therapy considered useful in peripheral arterial occlusive disease? A nationwide survey among vascular surgeons. Eur J Vasc Endovasc Surg 2012;43:308-12.

14. Lauret GJ, Gijsbers HJ, Hendriks EJ, Bartelink ML, de Bie RA, Teijink JA. The ClaudicatioNet concept: design of a national integrated care network providing active and healthy aging for patients with intermittent claudication. Vasc Health Risk Manag 2012;8:495-503.

15. Fokkenrood HJ, Houterman S, Schep G, Teijink JA, Scheltinga MR. Bicycle testing as an alternative diagnostic tool in patients suspected of intermittent claudication. Annals of vascular surgery 2014;28:614-9

16. Fokkenrood HJ, Lauret GJ, Verhofstad N, Bendermacher BL, Scheltinga MR, Teijink JA The effect of supervised exercise therapy on physical activity and ambulatory activities in patients with intermittent claudication. Eur J Vasc Endovasc Surg 2015;49:184-91.

17. Fokkenrood HJ, Verhofstad N, van den Houten MM, et al. Physical activity monitoring in patients with peripheral arterial disease: validation of an activity monitor Eur J Vasc Endovasc Surg 2014;48:194-200.

18. Lauret GJ, Fokkenrood HJ, Bendermacher BL, Scheltinga MR, Teijink JA. Physical activity monitoring in patients with intermittent claudication. Eur J Vasc Endovasc Surg 2014;47:656-63.

19. Gommans LN, Saarloos R, Scheltinga MR, et al. Editor's Choice - The Effect of Supervision on Walking Distance in Patients with Intermittent Claudication: A Meta-analysis. Eur J Vasc Endovasc Surg 2014;48:169-84. 


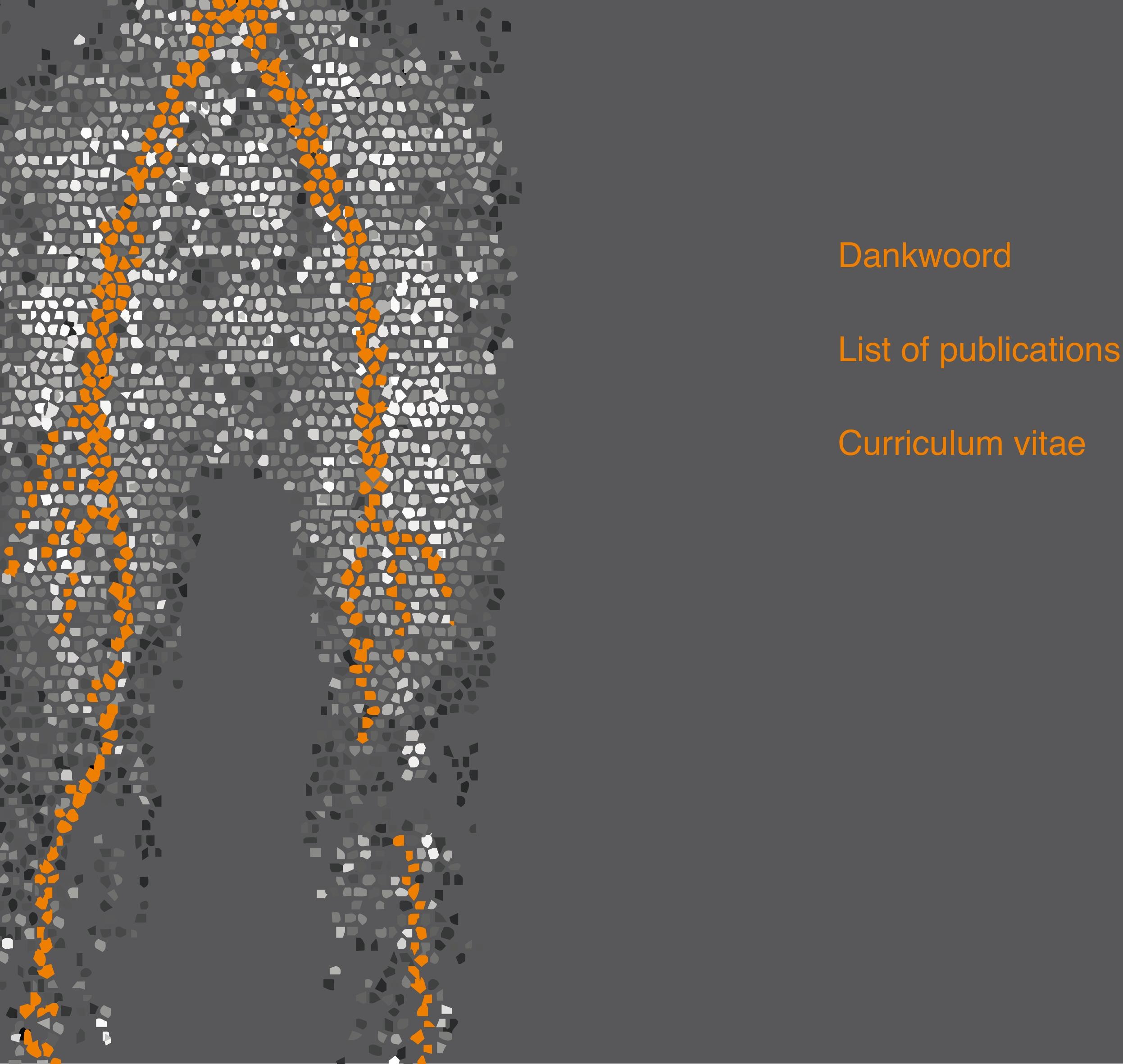




\section{Dankwoord}

Een keihard cliché, maar promoveren doe je niet alleen! Veel mensen hebben een steentje bijgedragen aan mijn promotie en ik wil dan ook iedereen hartelijk danken. Een aantal personen wil ik graag in het bijzonder noemen:

Hooggeleerde promotor prof. dr. J.A.W. Teijink, beste Joep. Waar moet ik beginnen? Jouw onuitputtelijke energie en doorzettingsvermogen zijn ongekend. Ik ken maar weinig mensen die zoveel balletjes tegelijkertijd in de lucht kunnen houden, maar toch weet je altijd tijd vrij te maken voor je promovendi. Het enthousiasme waarmee ideeën direct worden omarmd samen met jouw positiviteit werken aanstekelijk. Door jou ben ik het medisch wetenschappelijk onderzoek gaan waarderen. De steun om mijn carrière niet te vervolgen in de vaatchirurgie, maar in de orthopedie, is veelzeggend en waardeer ik zeer. Zonder jou geen manuscript. Joep enorm bedankt!

Weledelzeergeleerde copromotor dr. M.R.M. Scheltinga, beste Marc, "wie schrijft die blijft!". Een quote die jij zeer regelmatig ten gehore brengt en mij heeft aangezet om te starten met dit avontuur. Jouw enthousiasme voor onderzoek is ongekend. Welke perifeer werkzame vaatchirurg is nu tweemaal copromotor op één dag? Zonder jouw daadkracht had menig artikel nog als word-document op mijn computer gestaan. De snelheid waarmee jij teksten reviseert is ongelofelijk. Uit het feit dat mijn teksten in de loop van de tijd minder rood gekleurd terugkwamen, blijkt dat ik veel van je geleerd heb. Fantastisch dan ook dat ik nu mijn klinische ervaring in het MMC mag opdoen. Marc onwijs bedankt!

Alle medeauteurs, dank voor jullie kritische blik op mijn werk. Van zowel de positieve als negatieve feedback heb ik veel opgestoken. In het bijzonder wil ik Saskia Houterman danken. De discussies over het weergeven van onze resultaten, het meedenken in studiedesigns en de hulp met statistische analyses, zijn van grote waarde geweest voor mijn artikelen.

Leden van de manuscriptcommissie, hartelijk dank voor de beoordeling van mijn proefschrift. 
Dank ook aan alle patiënten, die direct of indirect hebben bijgedragen aan dit proefschrift. Uiteindelijk gaat het allemaal om het optimaliseren van de behandeling voor jullie.

Mijn medepromovendi Gert-Jan, Rutger, Pieter, Thijs, Lindy, Yannick en de nieuwste aanwinst David. Zonder jullie waren de uurtjes in "ons hok" waarschijnlijk een lange zit geworden. De eeuwige strijd tussen de aorta-boys, de strijd voor WiFi en goede koffie leidde tot een inspirerende werkomgeving. Creativiteit staat bij deze club hoog in het vaandel. CHAPSTICK!

Mijn ClaudicatioNet collega’s Danielle, Loes, Nicole, Regine en Yvonne. Bij fysiotherapeutisch Nederland staan deze namen inmiddels in het geheugen gegrift. Ons eigen jaarcongres, onze beursstand, de gadgets, de presentaties, de huisstijl, de humor, de talloze ritten naar informatiebijeenkomsten, etc etc. Bedankt voor alles.

De Vaatclub. Marc, Philippe, Edith, Bianca, Jan, Marijn, Sjaak en de reeds hierboven genoemde personen. Bedankt voor het meedenken met menige studie, het meehelpen met presentaties, revisies en natuurlijk de jaarlijkse uitjes.

De maatschap chirurgie en de assistenten van zowel het Catharina Ziekenhuis als het Maxima Medisch Centrum. Ik wil jullie graag hartelijk danken voor het opnemen van mij als arts-onderzoeker binnen jullie gelederen.

De dames van de polikliniek van beide ziekenhuizen. Bedankt voor jullie tomeloze inzet en enthousiasme bij de inclusie van patiënten voor mijn studies.

De leden van de Oud-leden Vereniging Bonobo. Niet zozeer voor de wetenschappelijke bijdrage, maar vooral voor de veelvuldige momenten van afleiding. Mannen, het gaat soms zeker om het feestje!

De Nijmeegse Fiets Combinatie. Ook al ben ik het anker, de vele uurtjes op het zadel gaven steeds weer de energie om de finish (dit proefschrift) te halen. Thnx!
Mijn ceremoniemeesters. Michiel Heevel en Sander Klieverik voor een dag die we niet snel zullen vergeten.

Mijn paranimfen. Dr. T. van Assen! Fantastisch dat wij op één dag de spreekwoordelijke "s" zullen kwijt raken. Samen promoveren is een bekroning op onze vriendschap. We maken er een fantastisch feest van!

Steven, broer(tje). Ongelofelijk hoe jij altijd voor mij klaar staat. Het is eigenlijk met geen pen te beschrijven. Ik kan niet trotser zijn om jou als broer te hebben, oprecht bedankt.

Mijn schoonfamilie, Joop, Annelies, Thea, Susan, Maxime. Altijd weer geïnteresseerd in mijn medische verhalen. Bedankt voor jullie interesse.

Mijn familie. Frans en Adri, Josine en natuurlijk oma Joke. Zonder jullie onvoorwaardelijke steun en vertrouwen had ik nooit zo ver kunnen komen.

Mijn geliefde, Kelly. Ik kan zonder moeite een hele pagina volschrijven waarom ik dit manuscript aan jou zou moeten opdragen. We hebben zowel pieken als dalen gekend tijdens dit project, maar jij bent degene die altijd voor mij klaar staat. Onbeschrijfelijk hoe wij elkaar aanvullen. Jij bent voor mij een lot uit de loterij. Wij, als team, kunnen de wereld aan! Hunt, op naar de volgende uitdaging! 


\section{List of publications}

1. Fokkenrood HJP, Lauret GJ, Scheltinga MRM, Spreeuwenberg C, de Bie RA, Teijink JAW. Multidisciplinary treatment for peripheral arterial occlusive disease and the role of eHealth and mHealth. J Multidiscip Healthc. 2012;5:257-63.

2. Fokkenrood HJP, Bendermacher BLW, Lauret GJ, Willigendael EM, Teijink JAW, Prins MH. Supervised exercise therapy vs. non-supervised exercise therapy for intermittent claudication. Cochrane Database Syst Rev. 2013 Aug 23;8.

3. Fokkenrood HJP, Schep G, Houterman S, Teijink JAW, Scheltinga MRM. Bicycle testing as an alternative diagnostic tool in patients suspected of intermittent claudication. Ann Vasc Surg. 2014 Apr;28(3):614-9.

4. Lauret GJ, Fokkenrood HJP, Wittens C, Scheltinga MRM, Teijink JAW. Physical activity monitoring in patients with peripheral arterial disease. Eur J Vasc Endovasc Surg. 2014 Jun;47(6):656-63.

5. Fokkenrood HJP, Scheltinga MRM, Koelemay MJW, Breek JC, Hasaart F, Vahl AC, Teijink JAW. Significant savings with a stepped care approach for intermittent claudication. Eur J Vasc Endovasc Surg. 2014 Oct;48(4):423-9.

6. Lauret GJ, Fakhry F, Fokkenrood HJP, Hunink MG, Teijink JAW, Spronk S. Modes of exercise training for intermittent claudication. Cochrane Database Syst Rev. 2014 Jul 4;7

7. Gommans LNM, Saarloos R, Houterman S, Scheltinga MRM, Fokkenrood HJP, Teijink JAW. The effect of supervision on walking distances in patients suffering from intermittent claudication; a meta-analysis. Eur J Vasc Endovasc Surg. 2014 Aug;48(2):169-184.

8. Fokkenrood HJP, Verhofstad N, van den Houten MML, Wittens C, Scheltinga MRM, Teijink JAW. Physical activity monitoring in patients with peripheral arterial disease: a validation study. Eur J Vasc Endovasc Surg. 2014 Aug;48(2):194-200.

9. Gommans LNM, Fokkenrood HJP, van Dalen HCW, de Bie RA, Peters RJG, Teijink JAW. The safety of supervised exercise therapy: a systematic review. J Vasc Surg. 2015 Feb;61(2):512-518

10. Fokkenrood HJP, Lauret GJ, de Bie RA, Scheltinga MRM, Teijink JAW. The effect of supervised exercise therapy on physical activity and ambulatory activities in patients with intermittent claudication. Eur J Vasc Endovasc Surg. 2015 Feb;49(2):184-91.

11. Fokkenrood HJP, van den Houten MML, Houterman S, Breek JC, Scheltinga MRM, Teijink JAW. Agreement between a patient's estimation of walking distance, non-graded and graded treadmill testing and outside walking in intermittent claudication. (Accepted in Ann Vasc Surg.). 


\section{Curriculum vitae auctoris}

Hugo Johannes Paulus Fokkenrood was born on the 19th of March, 1986 in Rhenen, the Netherlands, as the youngest of two. After attending primary school, he graduated in 2004 from high school (Athenaeum, Christelijk Lyceum Veenendaal). Since an early age, Hugo demonstrated a strong preference towards technology, gadgets, the human body and kinetics. This typical combination of interests urged him to initiate a study 'Technical Medicine' (University of Twente, Enschede). After earning his bachelor in 2007, he became progressively convinced that the medical side of it all did matter the most. He was elected to earn a master degree in 'Medicine and Clinical Research' (A-KO, Maastricht University). During his clinical internships he noticed that surgery in general, but orthopaedic surgery in particular fitted his interests best. He performed research during his last year of medical school at the Departments of Vascular Surgery and Sport Medicine at Maxima Medical Centre (Veldhoven, dr. M.R.M. Scheltinga, dr. G. Schep). After graduating medical school in September 2011, he was offered a position as $\mathrm{PhD}$ student/Medica Coordinator in the ClaudicatioNet organisation (prof. dr. J.A.W. Teijink, Catharina Hospital, Eindhoven). His research focused on the conservative management of intermittent claudication, especially the nationwide introduction of an innovative treatment strategy and on improving disease outcome measurements by the implementation of technologic novelties. Despite his fascination for vascular oriented research, he followed his heart and was granted a resident Orthopaedics position in January 2015 in the Maastricht area. $\mathrm{He}$ currently lives with his girlfriend Kelly Huntjens in Eindhoven. 
